\title{
Reinventing Journalism
}

Supporting processes of invention and change in media worlds

Joakim Karlsen

Thesis submitted for the degree of Philosophiae Doctor (Ph.D)

Department of Informatics

Faculty of Mathematics and Natural Sciences

University of Oslo

May 2018 
(C) Joakim Karlsen, 2018

Series of dissertations submitted to the

Faculty of Mathematics and Natural Sciences, University of Oslo No. 2007

ISSN 1501-7710

All rights reserved. No part of this publication may be reproduced or transmitted, in any form or by any means, without permission.

Cover: Hanne Baadsgaard Utigard.

Print production: Reprosentralen, University of Oslo. 


\section{Acknowledgements}

This thesis would never have been completed without the help, support and cooperation from colleagues, friends and family. The people at my faculty who gave me the opportunity to do this have been helpful and supportive from start to finish. Without the active facilitation by Jan Høiberg in 2012, this work could not have commenced. In the five years since then, Christian Heide, Monica Kristiansen and Harald Holone have provided me with the invaluable time needed for me to proceed.

My master's thesis supervisor, Gisle Hannemyr, was helpful in introducing me to my main supervisor, Jo Herstad at the Department of Informatics at the University of Oslo. I have appreciated Jo's openness, creativity and sound advice. Anders Fagerjord, my co-supervisor at the Department of Media and Communication at the University of Oslo, has been wonderful in answering my calls for support.

I would probably have given up had it not been for Susanne Koch Stigberg, and the many enjoyable conversations we have had about our shared research interests. Eirik Stavelin has been the perfect collaborator, being both explorative and analytical, creative and critical. It has been both enjoyable and enriching working with Anders Sundnes Løvlie.

This work would not have been possible without the collaboration with Ånund Austenå, who embarked on making transmedia documentaries with me. The projects we undertook together were against the odds, but Ånund is the kind of guy you want to break new trails with. Further, the thesis could not have been completed without the friendly people who let me interview them, of which there are too many to name here. I am grateful for the support I got from Kjetil Haugbro and Arena Magica in the early phases of the project.

There are several people who have provided feedback and support for this work: Sundeep Sahay, Jens Kaasbøl and Egil Øvrelid.

Without the love and support of my wife and children, I would never have managed this involved and laborious task. I dedicate my thesis to the four people I could not live without: Kristine, Emil, Jenny and Helma.

Joakim Karlsen

Halden, May 2018 


\section{Abstract}

Reinventing journalism by using the capabilities of the computer as the medium is called for to increasingly reach audiences both online and in mobile contexts. The main challenge faced by the journalism practitioners meeting this call has been taking the risks inherent in challenging existing conventions in their media worlds.

Processes of reinvention in journalism relying on explorations of the computer as the medium have so far mostly been investigated by researchers in media studies, and to a lesser degree, by researchers in the technology design fields. It is possible to identify how the understanding of these processes can be strengthened by contributions from the technology design fields, when it comes to understanding how information technologies shape and are shaped by them.

The key concepts defined and developed in this thesis are form-giving with the computer as the medium, cooperative activities, conventions, infrastructures and media worlds. To understand the basic activities initiating processes of reinvention in media worlds, I develop a theoretical framework that articulates form-giving with the computer as the medium. Further, I develop a framework that articulates how the infrastructure of media worlds matters when mobilizing cooperative activities for form-giving work that challenges earlier conventions regarding both what to make and how to make it.

The methodology chosen in this thesis is interpretative, relying on interviews, observations and research through design. These methods have been chosen to give a deeper understanding of the conditions for successfully mobilizing cooperative activities and networks for reinvention in media worlds.

The thesis contributes both to media studies and to technology design fields, computer supported cooperative work (CSCW) and information systems (IS) by: 1) giving an early account of technically-advanced journalism in newsrooms; 2) undertaking a rare comparison of how processes of invention and change are undertaken in the media worlds of news and documentary film-making; 3 ) giving a description of a relatively new domain for the technology design fields; 4) developing a model of form-giving with the computer as the medium that relates computation, interactivity and collaboration; 5) operationalizing the concepts of infrastructure and infrastructuring for researchers willing to engage with processes of reinvention in media worlds; and 6) developing a transmedia documentary project in cooperation with a small Norwegian film studio. 


\section{List of publications}

1. Karlsen, Joakim, and Eirik Stavelin. 2014. "Computational Journalism in Norwegian Newsrooms". Journalism Practice 8 (1): 34-48.

2. Karlsen, Joakim. 2014. "Transmediavendingen i Ny Norsk Uavhengig Dokumentarfilm”. I Hvor Går Dokumentaren? Nye Tendenser i Film, Fjernsyn Og På Nett, edited by Henrik Grue Bastiansen and Pål Aam, 195-220. Bergen: Fagbokforlaget.

3. Karlsen, Joakim, Susanne Koch Stigberg, and Jo Herstad. 2016. "Probing Privacy in Practice: Privacy Regulation and Instant Sharing of Video in Social Media When Running”. In Proceedings of the Ninth International Conference on Advances in ComputerHuman Interactions, 29-36. ACHI 2016. Venezia, Italy, Thinkmind.

4. Karlsen, Joakim 2016. "Aligning Participation with Authorship: Independent Transmedia Documentary Production in Norway". VIEW Journal of European Television History and Culture 5 (10): 40-51.

5. Karlsen, Joakim, and Anders Sundnes Løvlie. 2017. "'You Can Dance Your Prototype If You like': Independent Filmmakers Adapting the Hackathon”. Digital Creativity 28 (3): 224-39. 


\section{Table of contents}

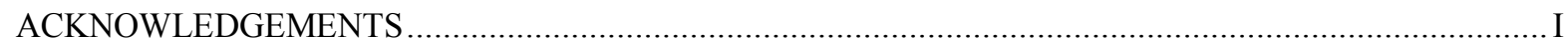

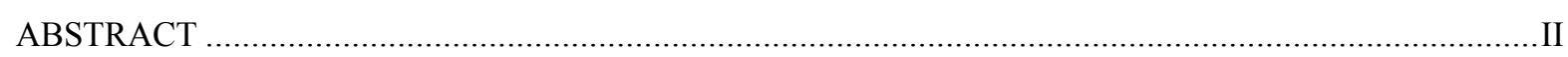

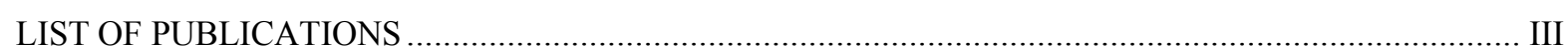

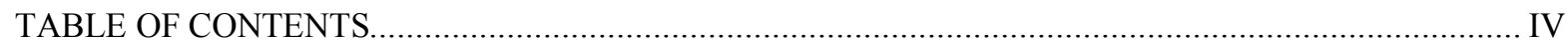

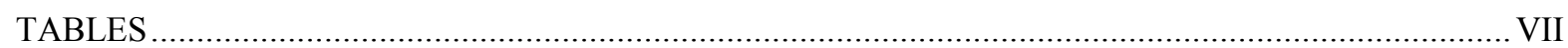

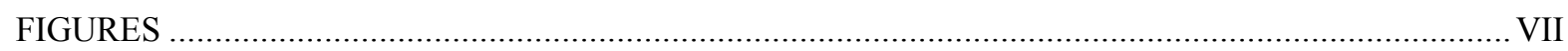

PART I: SUMMARY OF THE RESEARCH CONTRIBUTION

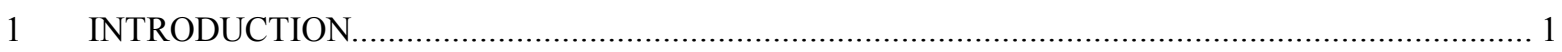

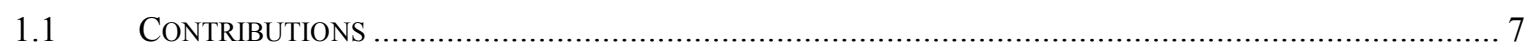

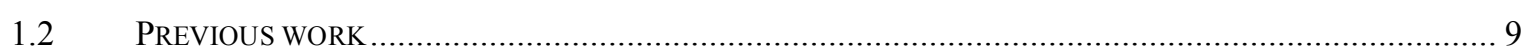

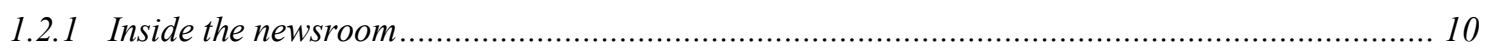

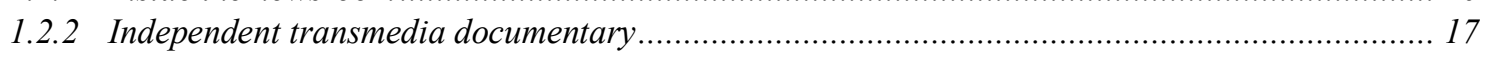

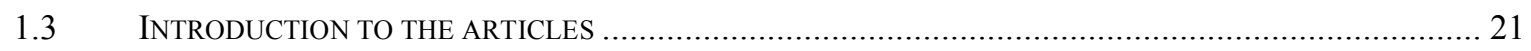

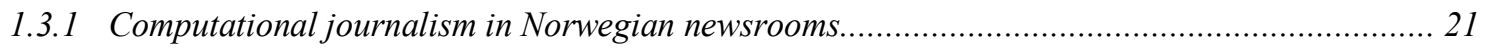

1.3.2 The transmedia turn in Norwegian independent documentary film production .......................... 22

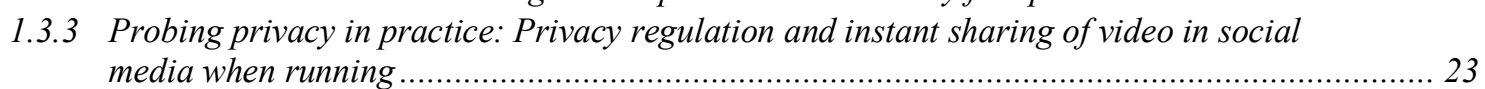

1.3.4 Aligning participation with authorship: Independent transmedia documentary production

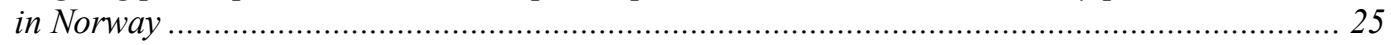

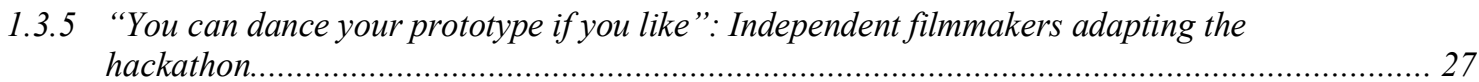

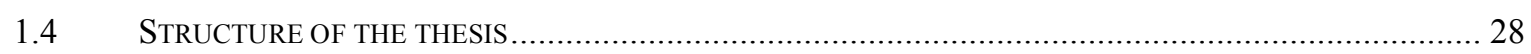

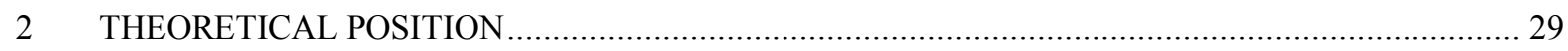

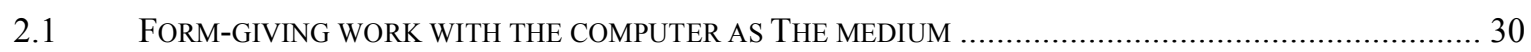

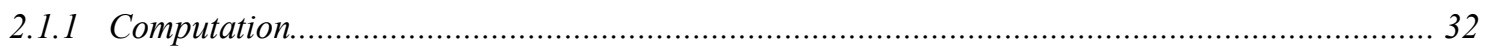

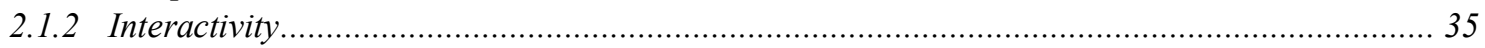

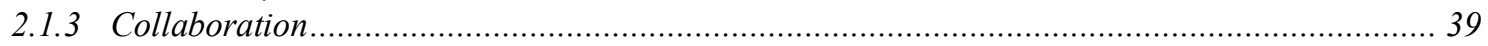

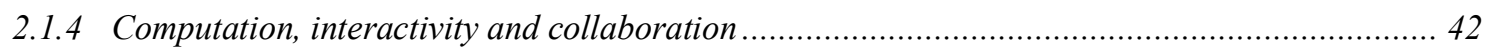

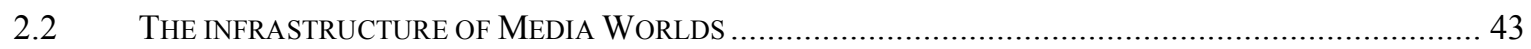

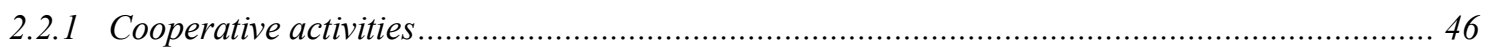

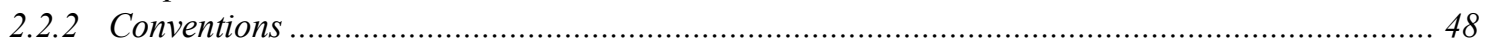

2.2.3 Change

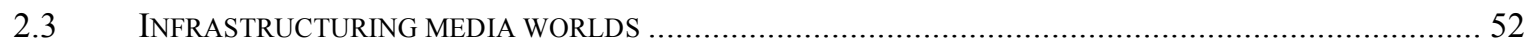

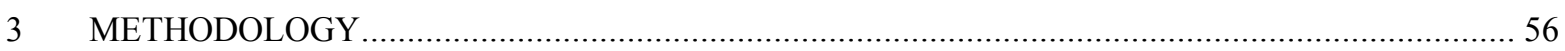

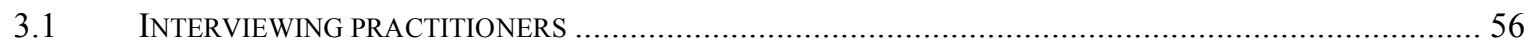

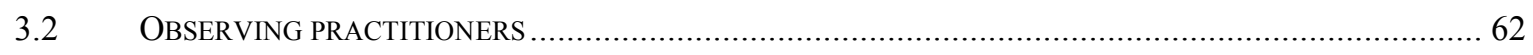

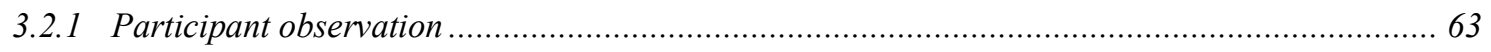

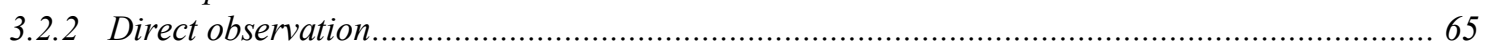

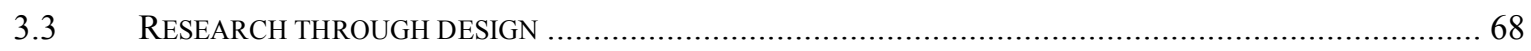

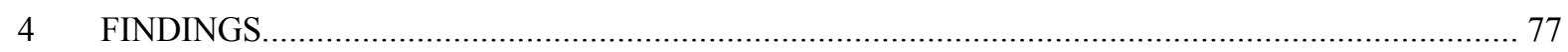

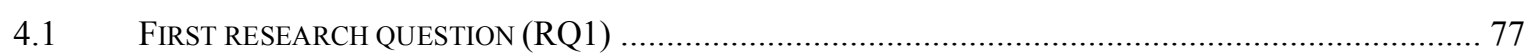

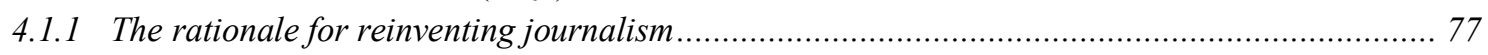

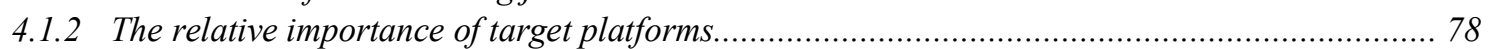

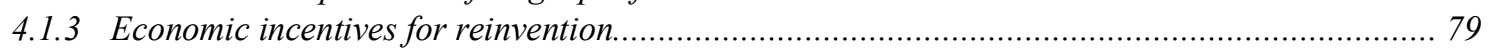

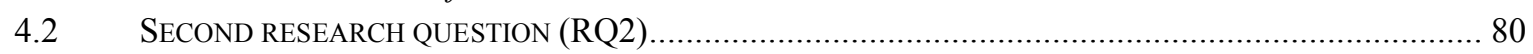

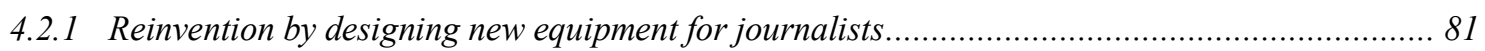

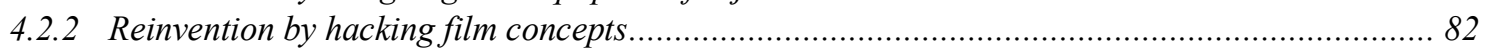

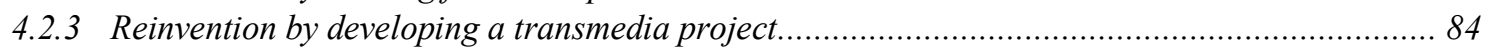


$5.1 \quad$ PROCESSES OF INVENTION AND CHANGE IN THE NEWSROOM ...................................................8.

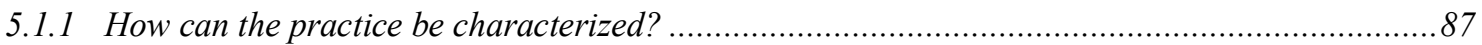

5.1 .2 Do they need a specialized information system? ............................................................89

5.1.3 Subordinating technical work to the rationale given by journalism ........................................91

5.2 MOBILIZING RESOURCES FOR TRANSMEDIA DOCUMENTARY ......................................................93

5.2.1 Taking the transactional approach when recruiting technically-skilled form-givers ...................94

5.2.2 Finding a rationale for transmedia documentary ...............................................................95

5.2.3 Breaking the conventions of independent documentary film production ...................................96

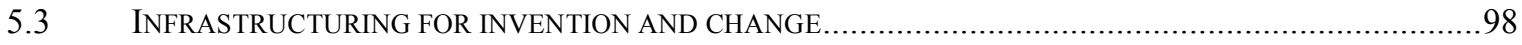

6 CONCLUSION

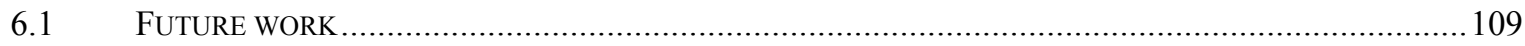

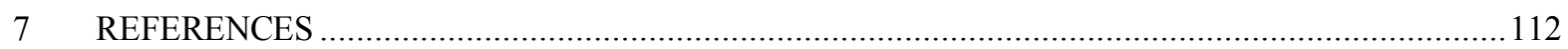

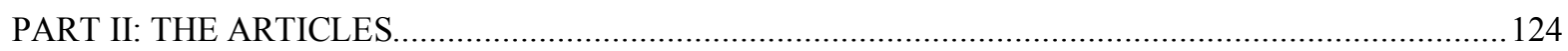

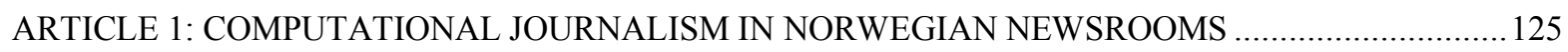

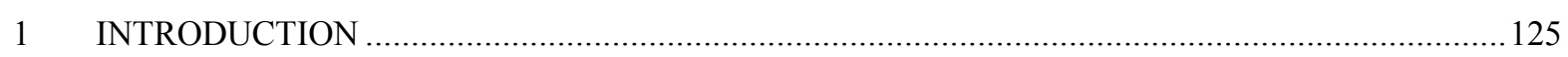

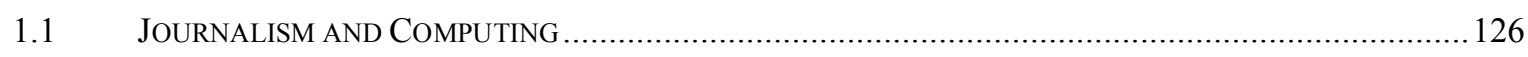

1.2 COMPUTATIONAL JOURNALISM AS A RHETORICAL CRAFT ..................................................... 128

2 RESEARCH DESIGN - FINDING, SELECTING AND INTERVIEWING THE JOURNALISTS ...... 130

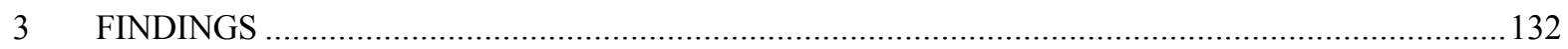

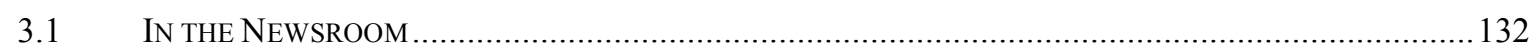

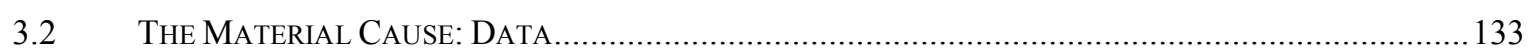

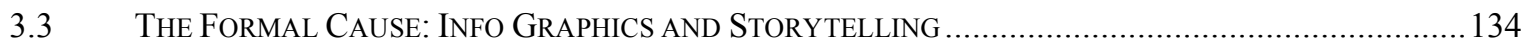

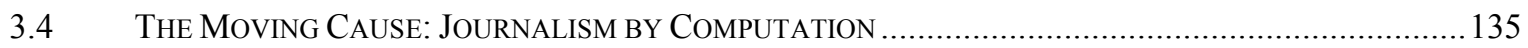

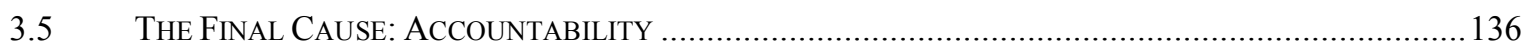

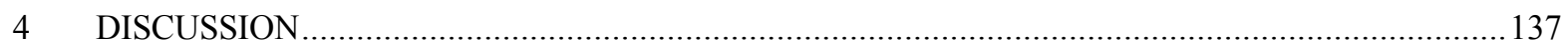

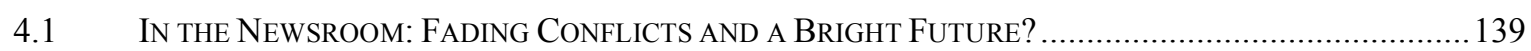

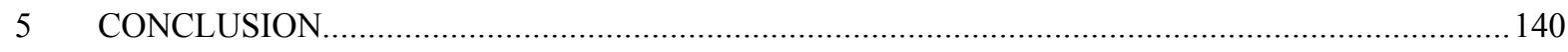

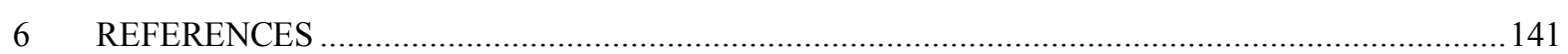

ARTICLE 2: TRANSMEDIAVENDINGEN I NY NORSK UAVHENGIG DOKUMENTARFILM ........... 144

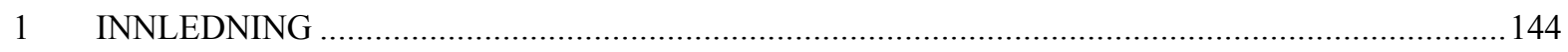

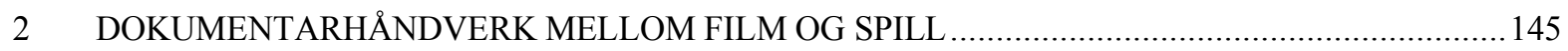

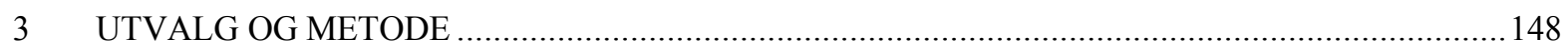

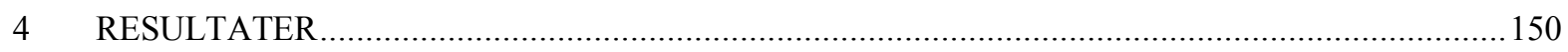

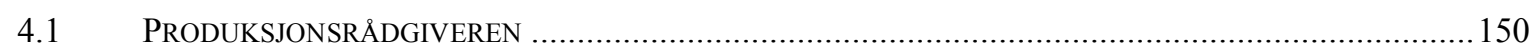

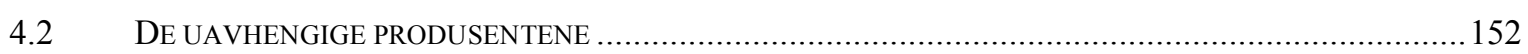

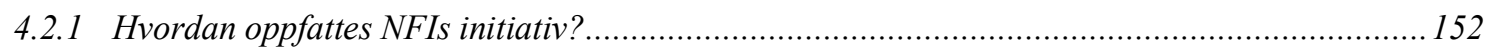

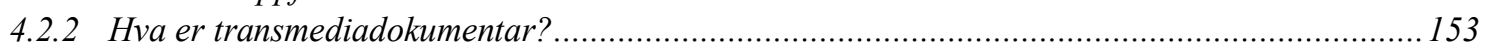

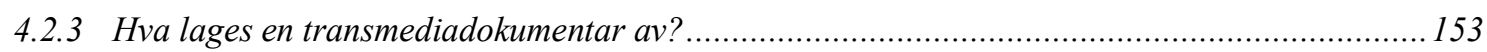

4.2.4 Hvilket formål har en transmediadokumentar? ................................................................. 155

4.2.5 Hvilken form har en transmediadokumentar?.................................................................. 156

4.2.6 Hvordan skal en transmediadokumentar lages? ............................................................ 157

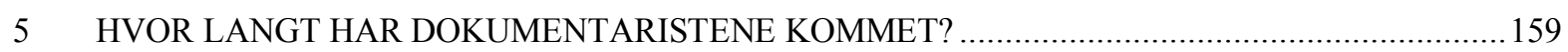

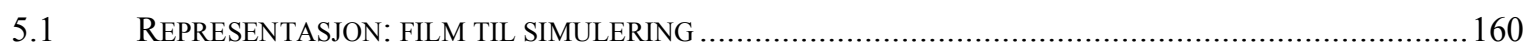

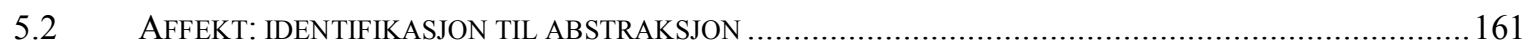

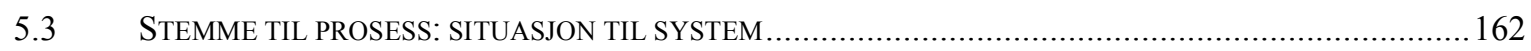

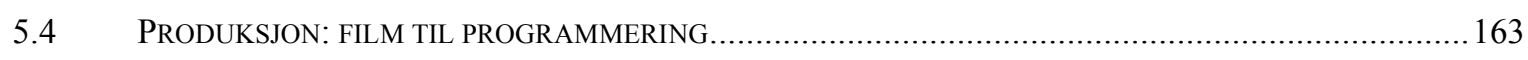

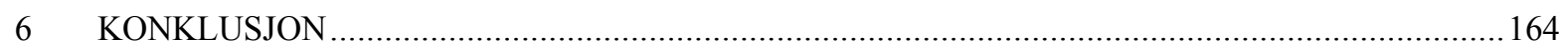


7 REFERANSER

ARTICLE 3: PROBING PRIVACY IN PRACTICE: PRIVACY REGULATION AND INSTANT

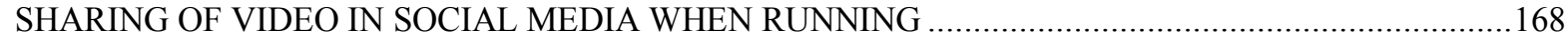

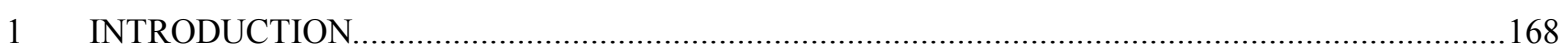

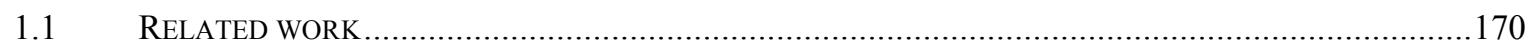

2 PRIVACY

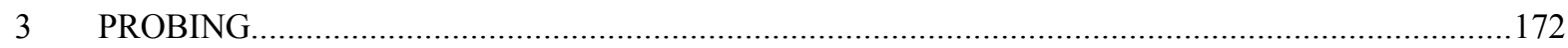

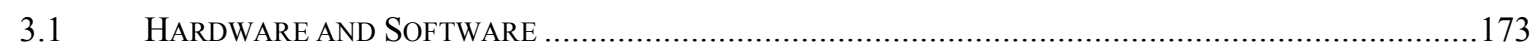

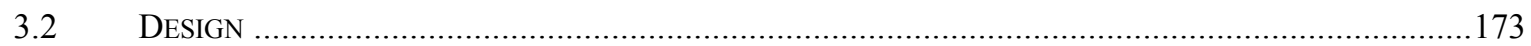

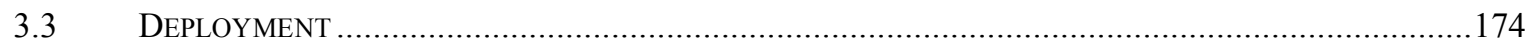

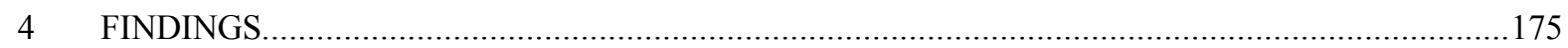

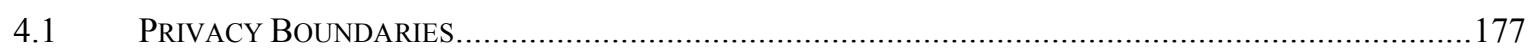

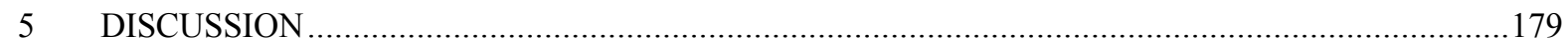

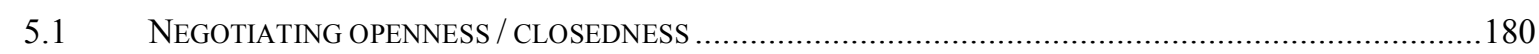

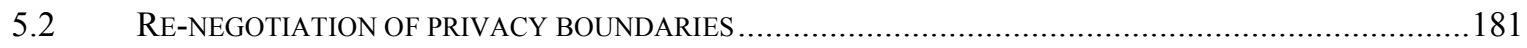

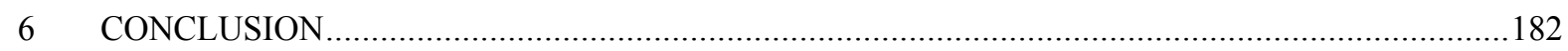

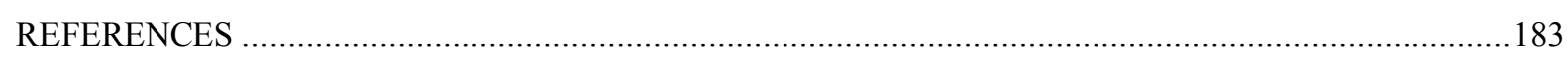

ARTICLE 4: ALIGNING PARTICIPATION WITH AUTHORSHIP: INDEPENDENT TRANSMEDIA

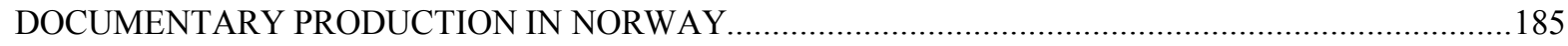

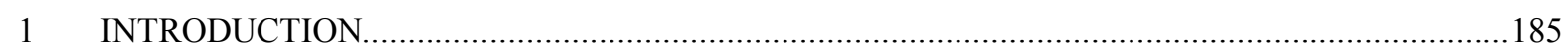

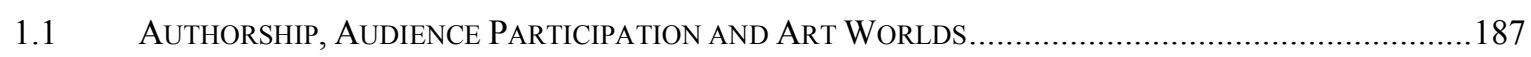

2 INTERVIEWING AND WORKING WITH INDEPENDENT DOCUMENTARY PRODUCERS ......190

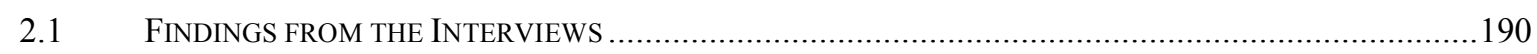

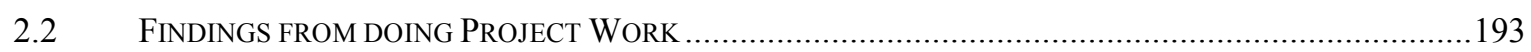

3 ALIGNING AUDIENCE CENTRED WITH AUTHOR CENTRED PRACTICES..............................195

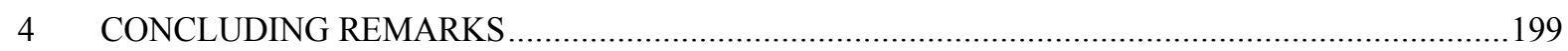

ARTICLE 5: "YOU CAN DANCE YOUR PROTOTYPE IF YOU LIKE": INDIE FILMMAKERS

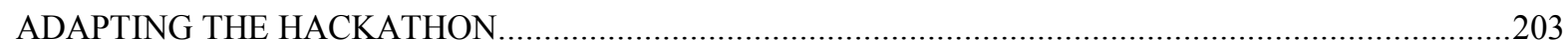

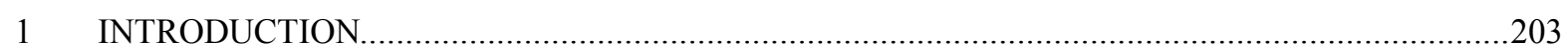

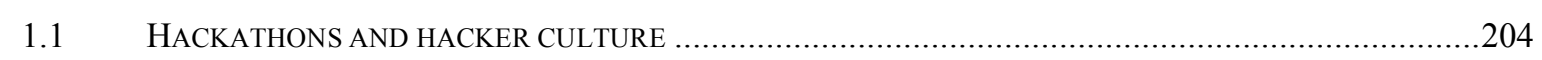

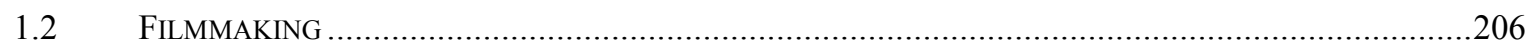

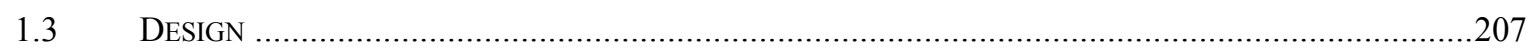

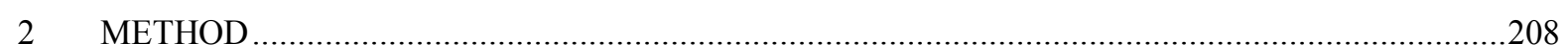

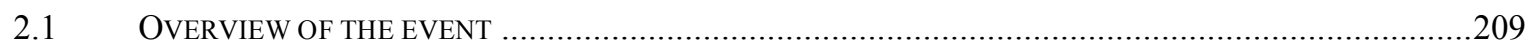

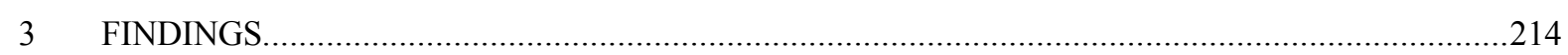

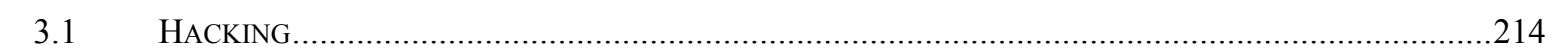

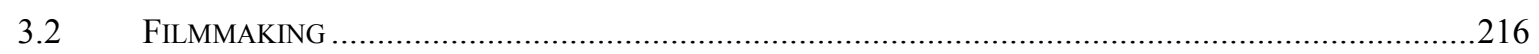

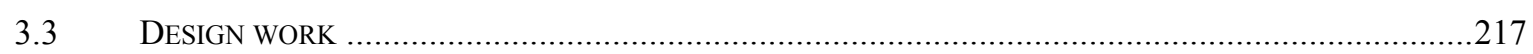

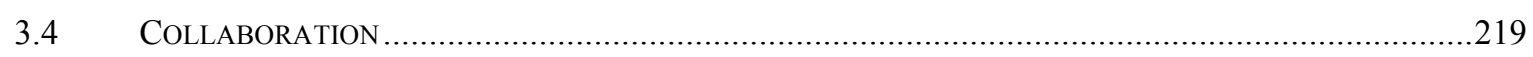

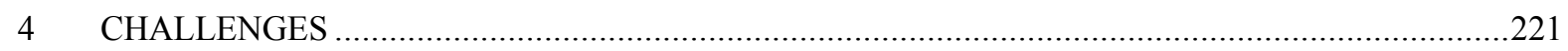

4.1 CONCLUSIONS AND IMPLICATIONS FOR FUTURE HACKATHONS .......................................................22

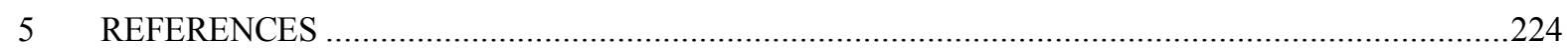




\section{Tables}

Table 1: Relating computation, interactivity and collaboration in digital

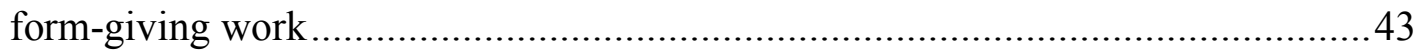

Table 2: Bowker and Stars eight salient features of infrastructure ...................................46

Table 3: Cooperative activities in Art Worlds .................................................................48

Table 4: Relating the salient features of infrastructure and conventions ............................51

Table 5: Activities to undertake when infrastructuring media worlds ..............................55

Table 6: The two worlds of journalism framing reinvention differently............................ 106

Table 7: Three entry points to invention in media worlds and their potential for

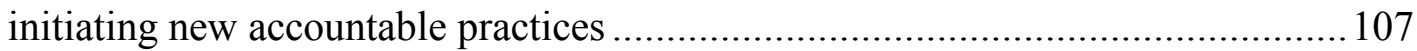

\section{Figures}

Figure 1: Configuring the prototype before the event (left), and the prototype worn in the finishing area (right).

Figure 2: Screenshots showing the main pages of the mobile web application prototype, enabling the sharing of text, images and video to a local store. 26

Figure 3: A clipping from the article in the newspaper on the day of the launch (Elmung 2013). The boys in the picture were recruited some days before to use the app, and by this provided some initial content to seed the platform. 

Part I: Summary of the research contribution 



\section{Introduction}

Journalists have a strong obligation to tell the truth, hold the powerful accountable for their actions and give the weaker parties in society a voice (Kovach and Rosenstiel 2007), and by following these ideals, they contribute to democratic societies. The emerging forms of journalism with the computer as the medium, studied in this thesis, have been seen to strengthen the accountability function of journalism (Hamilton and Turner 2009) and to facilitate the resurrection of participatory documentary modes (Gaudenzi 2014). This background provides the motivation for the work undertaken in this thesis: to understand processes of reinvention in journalism, what conditions them, how they can be supported and the role information technology has in those processes. To capture the dynamics of these processes and what conditions them, two categories of journalism, belonging to two media worlds, have been studied: newsroom journalism and independent documentary film production. Newsworkers skilled in digital making working in larger newsrooms, and who have been reinventing journalism by making new forms of news have been studied as the first case. As for the second case, independent documentary film producers, challenged to invent new forms of documentaries for multiple platforms, have been studied. Together, these cases have enabled a closer investigation and comparison of the conditions for reinventing journalism and how processes of reinvention can be initiated and supported. There is no simple relationship between adopting new technologies for new purposes and changing journalistic practices. Information technologies offer little in themselves if they are not accompanied by longer processes of reciprocal adaption of the technologies at hand and the practices they are meant to support (Bowker and Star 2002). It is therefore crucial when investigating technology-driven processes of reinvention to understand and address the technologies in question and the social processes conditioned by and conditioning them. This means that it is uncertain whether the technology-driven reinvention of journalism strengthens or weakens the accountability function of journalism or resurrects the participatory modes of documentary; it all depends on the local practices developing with new information technologies and how this development is supported. These developing local journalistic practices are the main concern of this thesis.

In journalism studies, there has been continuous interest in understanding the role of technology in newsrooms, with technology-optimistic (Pavlik 2000) and more technology-critical 
streams of research (Boczkowski 2004; Domingo 2008; Steensen 2010). Research in the field of computer supported cooperative work (CSCW), has focused on providing computer support in newsrooms (Bellotti and Rogers 1997; Bødker and Petersen 2007, 210; Fagrell and Ljungberg 2000; Handler and Conill 2016; Heath et al. 2000; Kensing, Simonsen, and Bødker 1998; Sidiropoulos and Veglis 2017; Stockleben and Lugmayr 2016). The main findings from these studies in CSCW are that newswork is knowledge-intensive, cooperative, time-critical and oriented towards producing content, and that journalists would benefit from better systems to support them in producing news more efficiently. In the context of technology-driven journalism in newsrooms, often labelled as computational journalism, suggestions for a "cloud for the crowd" have been given (Cohen et al. 2011), and within humancomputer interaction (HCI) there has been undertaken research to develop tools as computational journalism (e. g. Diakopoulos 2016; Diakopoulos and Shamma 2010; Diakopoulos, De Choudhury, and Naaman 2012). It is possible to identify how the research undertaken in CSCW and journalism studies can inform each field so that we can better understand the relationship between information technology and newswork. A combination of the micro-level attention to how information technology supports work, often present in CSCW combined with the technology-focused stream of research in journalism studies, could open doors to deeper knowledge on how information technology conditions and is conditioned by newsroom practices. Pablo Boczkowski's $(2005,2014)$ studies on the digitization of newswork have partially paved the way for this research agenda; however, with a focus on journalists as end users rather than as technologically-skilled form-givers.

Research in the more open and disorganized space of independent documentary film production has mostly been undertaken within the field of documentary studies. In documentary studies, research on documentaries using computers as the medium, has so far mostly focused on aesthetical categories, but lately it is possible to identify a "design turn" in this line of research, exploring how methods, tools and techniques from design fields can contribute to knowledge on how to develop web, interactive, database and transmedia documentaries (Gambarato 2013; Gaudenzi 2017; O’Flynn 2015). Research undertaken in the technology design fields, going beyond tool building, has paid some attention to transmedia and interactive documentaries. When it comes to transmedia, this has mostly been seen as an entertainment format with a focus on fictional story worlds and gaming (Bardzell et al. 2007; Blumenthal and Xu 2012; Esch, Wiklund-Engblom, and Staffans 2011; Ghellal et al. 2014; Murray 2012). Designing interactive documentaries was recently introduced to HCI in a 
study where the researchers collaborated with a community to design one (Green et al. 2017). The article presents a useful frame for understanding the main challenges involved in designing interactive documentaries that prioritize participation before authorship. It is possible to identify how the documentary studies' community view how the technology design fields can contribute with a better understanding of how to design documentaries using the computer as the medium, which was signalled by Gaudenzi holding a workshop in the international conference on interactive experiences for TV and Online Video in 2015 (Gaudenzi 2015). If one widens the scope and frames this as interactive storytelling, interactive television or educational games, then more contributions have been made in the technology design fields, but the focus in this thesis is on the specific contexts of journalistic work taking place in newsrooms and in independent documentary film studios.

The theoretical position in this thesis has been developed to capture processes of reinvention in media worlds, and the two cases under study are examples thereof. The understanding of the workings of media worlds is informed by Howard Becker's (1984) sociology of art worlds, Geoffrey Bowker and Susan L. Star's (2002) theory of infrastructure and theories of form-giving with the computer as the medium. When the sociologist and pragmatist Howard Becker sums up what he has been interested in throughout his career, he answers with “work" and "doing things together" (Plummer 2003). Understanding both work and doing things together has been important in CSCW, where work has been defined as an activity that is "necessary or useful in a practical way" (Schmidt 2011, 374) requiring "effort and concentration and [that] presumes mastery of all sorts technicalities" (ibid., 376). Doing things together, or cooperative work, has been defined by using an example of two people moving a table and its chairs (Schmidt 2008). When deciding whether work is cooperative or individual, one needs to look at the granularity of the task at hand. The moving of the chairs can be done by one person, while moving the table requires two. If the task is broken down into moving chairs and moving the table, then the moving of chairs is individual work. Seeing the table and chairs as a set changes this, and both moving the chairs and moving the table is an example of cooperative work. To understand work and doing things together as more than local and time-bounded accomplishments, we need an additional concept to understand how people are able to know what to do both individually and together. This is what is often referred to as practice, capturing both work and cooperative work as rule-governed activities, based on formal and informal agreements on how things should be done, or conventions. According to Kjeld Schmidt (2011), a practice is not a specific activity 
(whereas work is), but "a species of regularly performed activity" (377). These species of regularly performed activities or practices depend on each other and combine to create social worlds. Social worlds are often labelled according to what the point of the activities undertaken in them are. When suggesting a social worlds' approach to the study of news production, Roger Dickinson (2008) proposes seeing the "people engaged in that activity that involves the production of news as belonging to the "news world"" (16). In his sociology of art, Howard Becker (1984) defines art worlds as "the network of people whose cooperative activity, organized via their joint knowledge of conventional means of doing things, produces the kind of art works that art world is noted for" (x). In this thesis, two distinct social worlds are studied: newsroom journalism and independent documentary film-making. They are two cases of media worlds, organized differently according to what these media worlds are noted for: news and documentary film. These two species of regularly performed activities rely on conventions or "earlier agreements now become customary, agreements that have become part of the conventional way of doing things" (ibid., 29), which are necessary to regulate the terms of cooperation between the many workers involved and cover "all the decisions that must be made with respect to works produced" (ibid.).

Bowker and Star (2002) see Becker's analysis of art worlds as an example of infrastructural inversion, of uncovering the material artistic infrastructure of art worlds. They use several examples from his study to explain this. The convention that a musical concert lasts for about 2 hours "ramifies throughout the producing organization. Parking attendants, unions, ticket takers and theatre rentals are arranged in cascading dependence on this interval of time" (ibid., 153). Paintings have a certain size that makes them hang "comfortably on a wall" and a painting "fits rolls of canvas, the skills of framers and the very doorways of museums and galleries" (ibid.). For Bowker and Star (2002), infrastructure is that which is in between, always a relational concept, meaning that what can be framed as infrastructure depends on perspective. Railroad tracks are infrastructure for people taking the train, but they are structure for the railroad engineer who is responsible for the control and maintenance of the tracks. To explain this, they use the example of studying body language, where the infrastructure when studying body language is "human emotions and situations" (ibid., 152). The rationale for undertaking infrastructural inversion is to make what is in the background visible for critique and potential improvement. This is what is meant by the verb infrastructuring as an answer to the question regarding how to infrastructure. 
Based on these key definitions, the theoretical position of this thesis can be articulated, which, together with the problem area and the identified research gap, frames the research questions. To initiate processes of reinvention in media worlds, conventions regarding how things are done and what is made need to be challenged. This challenge can be undertaken by individual workers or in cooperation with others by invention and can be successful or not, depending on whether existing cooperative networks in the media world in which it is situated, can be mobilized in its support. Successful inventions that are appreciated as such by the media world in question and copied by enough of its members may become new conventions and thus support new practices and change. This process of reinvention depends on many socio-technical factors, including how information technology shapes and is shaped by the work undertaken to challenge earlier conventions through form-giving work with the computer as the medium. The concept of infrastructure captures these factors that together condition processes of reinvention. Processes initiated to improve these conditions are infrastructuring. This position gives rise to the following research questions, where the first research question is the starting point for understanding processes of reinvention in media worlds, answered by infrastructural inversion, and the second research question is the starting point for undertaking attempts to support processes of reinvention, framed as infrastructuring.

RQ1: What are the salient conditions for successfully mobilizing cooperative networks for reinventing journalism using the computer as the medium?

RQ2: How can cooperative activities be initiated in support of the reinvention of journalism using the computer as the medium?

Two cases can exemplify successful reinvention within media worlds: a long-form multimedia feature made by the New York Times in 2012, "Snowfall, the avalanche at Tunnel Creek" (Branch 2012) and a transmedia fiction project made by the Norwegian Broadcasting Cooperation (NRK), "Skam" (Skam 2015). Both projects were invented as part of an ongoing sustained focus on exploring the potential of the computer as the medium within the hosting media organizations and were successful beyond the producers' wildest dreams. The success of "Snowfall" has inspired many similar projects by both newsroom journalists and independent documentary makers (Johnson 2013) and has provided both the Snowfall-template and has established snowfalling as a verb in newsrooms (Dowling and Vogan 2015). 
The more recent success of "Skam" both in Norway and internationally has opened the door up for the development of similar projects in Europe, the USA and Canada (Donadio 2016; Hopewell 2017; Roxborough 2017; Sweney 2016). Both these projects signal an open space between newsroom journalism and the independent documentary, by exploring new storytelling formats using the expressive capabilities of the computer as the medium.

"Snowfall" drew 3.5 million page views with an average visit time of 12 minutes, in the days following its release on the New York Time's web site. The Snowfall template is a contained multimedia package relying on written text and extra textual features, mainly video, scrolling and the curtain effect (Dowling and Vogan 2015). The template has been used extensively in newsrooms around the world since (Johnson 2013) and is still heavily used by the New York Times (New York Times 2017) and by Norwegian newsrooms in projects developed by the informants in study 1 . The template is appreciated by readers and is relatively easy to make, but depends on strong feature storytelling, using written text and attractive audio-visuals. Dowling and Vogan (2015) describe the Snowfall project as borrowing heavily from the conventions of documentary film to provide "a visceral nearness to the subject" (214).

"Skam" was not a documentary project, but the fictional universe that was portrayed was close to the truth (Magnus 2016). The storylines were based on extensive research on the target group, 16-year-old girls, and the characters "reflected the needs, attitudes, tastes and values identified through this extensive research process" (Sundet 2017, 7). In addition to the series being a truthful and relevant account of the lives of 16 year old girls, the project chose a publication strategy that further blurred the lines between the fictional and the real (Pearce 2017). The storyline unfolded in real time through daily video clips, pictures, chat messages and appearances by the fictional characters on social media. Through this, the fictional world reflected events happening in the real world and vice versa, thus blending the worlds on online platforms where boundaries between truth and fiction are already porous. This blurring experience is summarized by Pearce:

By integrating the world of the show with the online world, and by using instant messaging applications as part of the dialogue of the series, Skam blurs the boundary between reality and fiction to create a unique participatory aesthetic experience and in so doing critically reflects upon the purported realness of the media we consume and the connections between the screen and the reality we inhabit (ibid., 261). 
"Skam" was a successful application of storytelling across media or transmedia, where "each medium does what it does best" (Jenkins 2003), but it has so far attracted little attention from documentary film-makers in Norway. It may be worth exploring how the project model of "Skam" with its real time publishing strategy could be adopted by hybrid documentary projects where it is possible to see how fictional and non-fictional storylines could be combined in the same transmedia project.

The methodology chosen for this thesis has been interpretative, relying on semi-structured interviews, observations with varying degrees of participation and research through design. To investigate how journalists skilled in digital making worked to reinvent news by making new forms of online news in newsrooms and how independent documentary film producers worked to reinvent documentary films by mobilizing resources for making transmedia, practitioners across newsrooms and small film-production companies in Norway have been interviewed. To investigate how independent film-makers can be supported in processes of reinvention, participant observation has been undertaken in a transmedia documentary project and a hackathon was observed, where film-makers where challenged to reinvent film concepts for online and mobile media. To investigate the reinvention of journalism from the perspective of technology design, I have undertaken the design and evaluation of a prototype device for shooting and sharing live videos on social media when on the move. Together, these studies have, by combining interviews, project work, attending events and technology design, provided evidence to shed light on processes of reinvention in journalism.

\subsection{Contributions}

Several contributions to fields of research, methodology and to practice are developed in this thesis.

1. When it comes to contributing to relevant fields of research, four contributions are developed in this thesis: a) an early account of technically-advanced journalism in newsrooms; b) a rare comparison of how processes of invention and change are undertaken in the media worlds of news and documentary films; c) charting a relatively new domain for the technology design fields; and d) developing a model of form-giving with the computer as the medium that relates computation, interactivity and collaboration. 
a. The account of how newsroom practitioners describe how they reinvent or try to reinvent journalism, with sensitivity towards its technical aspects and with informants belonging to multiple organizations has been extensively used and referenced by researchers in media studies, but also by researchers in IS.

b. The rare comparison of two distinct media worlds, newsroom journalism and independent documentary film production, and how these have engaged in reinventing journalistic forms for online- and mobile media, give a more nuanced understanding of the main opportunities and challenges to reinventing journalism using the computer as the medium.

c. The description of a domain that has received relatively little attention by researchers in the technology design fields opens it up for more research from these perspectives. Audiences are moving to platforms that are familiar to researchers in these fields, and newsworkers and media organizations need all the help they can get from technology design scholars to uphold their democratic obligations to society.

d. The model of form-giving with the computer as the medium relates how computation, interactivity and collaboration are needed for inventing computational artefacts for communicative purposes. Programming, interaction design, and designing for collaboration come together in a maker-oriented practical perspective on the skills needed to invent new media.

2. The main contribution to the methodology developed in this thesis is an operationalization of the concepts of infrastructure and infrastructuring for researchers willing to engage with processes of reinvention in media worlds. Using a conceptualization of how media worlds come into being, are supported and change as the starting point, infrastructuring activities aimed at helping media practitioners with technology-driven processes of reinvention are proposed. This contributes to the research that looks for ways in which to use the analytically powerful concept of infrastructures to define activities that may improve them.

3. The main contribution when it comes to initiating processes of invention and change in media worlds was the active participation in the development of a transmedia documentary project in cooperation with a small Norwegian film studio. Through this, new trails were broken in collaboration with film practitioners, challenging the main stakeholders 
in this media world to make resources available for developing transmedia. A secondary contribution to practitioners has been the talks that have been given on several occasions on what transmedia is and how to approach developing documentary storytelling on multiple platforms.

The main part of this thesis consists of five individual research articles. This part is a summary that puts the individual articles and the thesis into a larger contextual, theoretical and methodological frame. The detailed structure of the thesis is further explained in section 1.4.

\subsection{Previous work}

Research on both news and film work has mostly been undertaken in the field of media studies, often under the label of "production studies". In a recent article, Chris Paterson et. al. (2016) give an overview of this line of research with its roots in the 1970s and 1980s. Much of the early work on media work focused on "singular news organizations within highly unionized and relatively stable fields of employment" (Paterson et al. 2016, 4). Questions of power, influence, ideology, truth, objectivity and impartiality were addressed in relationship to how the news work was organized (Elliott 1972; Gans 1979; Tuchman 1980). More recent research on media production has widened the focus and includes studies of more types of work in the media industries. There are several topics that have been addressed in this discourse that are relevant to the understanding of media worlds: how media products are an expression of the underlying production culture (Caldwell 2008), the importance of genre when understanding media production (Alacovska 2016), the blurred lines between authors and audiences (Ross 2014) and how shifts in media technologies present the main challenges to media companies and individual professionals alike (Deuze 2016).

To understand production cultures, John Thornton Caldwell (2008) focuses on conventions and craft habits or how "conventionalized sense making is animated in practitioners' tools, trade artifacts, and social behaviours" (loc. 122). Inspired by Becker's analysis of art worlds, and what he sees as Becker's "sociology of occupations in the 'art world"' (ibid., loc. 4563), he includes all the activities needed for film and television production in the Los Angeles area in his analyses, both work that is above and below the line, both credited and uncredited. While Caldwell mainly focuses on how conventions for how to produce film and television influence the media product, other researchers in the field of production studies have 
emphasized how conventions for what to make, or genres, influence production practices. Media producers are seen as genre specialists first, working in genre-based production worlds, being genre participants, where genres "enable and facilitate the 'process of formation, making, poièsis"” (Alacovska 2016, 182). Media producers depend on genres when cultivating audience images to reduce the risk of making the wrong thing and they depend on their belonging to the same social situation as the audience (Ross 2014). The producer is also a member of the audience and merely takes on a different role, bringing personal experiences or prior feedback to bear on the choices made in production (ibid.).

The understanding of the generative capacity of genres in media production is tied to traditional media such as film and television. The question then is how this plays out with the shifts in media technologies taking place in the media industries. Mark Deuze (2016) claims that these shifts present the main challenges to media companies and individual professionals alike. First, there is the "constant challenge of adaptation to a continually emerging range of new technologies" (ibid., 332) and second, "a broad shift in the formulation of business models from an emphasis on mass media to personalized content and to participatory and user-generated content" (ibid., 333). Media work in the current situation is therefore "not only about what gets produced in terms of spoken and written words, audio, still, or moving images but (and increasingly) also is about providing platforms for people to make, edit, and exchange their own content" (ibid., 334). The skillsets in need are first and foremost the ability to understand personalized, participatory and user-generated media when "making content and designing experiences" (ibid., 333). From this, the generative capacity of genres is still important in terms of understanding media work, but it is possible to see how new genres are evolving with emerging personalized, participatory and user-generated media.

\subsubsection{Inside the newsroom}

The relationship between technology and work in the newsroom has been studied extensively since online platforms became important for the distribution of news. The focus in most of these studies has been on "regular" online journalism, understanding the relationship between the work done by online journalists, and the technology they use to accomplish this. I will review this literature, where journalists are mainly seen as end-users, before moving on to previous work on journalism where regular journalistic skills are combined with advanced 
computing skills, either in individual work or in collaboration between technologists and journalists.

\subsubsection{Journalists as end-users}

In an early account of how technology has an impact on journalism, John Pavlik (2000) identify four broad areas for change: "(1) how journalists do their work; (2) the content of news; (3) the structure or organization of the newsroom; and (4) the relationships between or among news organizations, journalists and their many publics" (229). He describes how technology can, among other things, help journalists gather and publish information more rapidly, tell stories in new ways, flatten the structure of news rooms, and facilitate a dialogue with the public. This mainly technology-optimistic account of how technology changes newsrooms has been criticized in the later literature that articulates the complexities of these processes. Pablo Boczkowski (2004) draws on literature from the field of science and technology studies (STS) and emphasizes the mutual shaping of technology and newswork. He reports on how the adoption of multimedia and interactivity in three online newsrooms in actual use varies and that the journalists mostly continued working as before. Later studies have similarly described how the adoption of new technologies in newsrooms has depended on social factors such as norms, skills and organization, and have reported a strong inertia in these processes (Domingo 2008; Schmitz Weiss and Domingo 2010; Steensen 2010).

More recently, from a technology design perspective, Stockleben and Lugmayr (2016) have conceptualized "fluid publishing" to describe how information technology has an impact on journalism, turning newswork into a continuous $24 / 7$ process, driven by the real-time metrics of the readership rather than being defined by single moments of publishing. Based on this conceptualization, they propose a publishing system that should: 1) be flexible when it comes to editing and updating news articles; 2) be available to all reporters and editors (including freelancers); 3) support organizational learning by analysing "micro-strategies continuously developed by the employees" (314); and 4) include metrics when it comes to both reading patterns and journalistic quality (ibid.).

Their first and second suggestions are supported by research undertaken in CSCW where researchers have described newswork as complex, cooperative and time-critical (Hössjer and Eklundh 2009), requiring continuous coordination between journalists (Heath et al. 2000). 
This gives an orientation towards making better systems for cooperatively planning, producing, broadcasting and administering news content (Kensing, Simonsen, and Bødker 1998). When investigating instruments for cross-media publishing in a Danish newsroom, Bødker and Petersen (2007) suggest that they should support the content rhythm by making the process more visible to all the involved journalists with integrated tools for planning and coordinating the work. They identify how tensions between when the content is published (content rhythm) and how it was produced (production rhythm) increase with the multiple streams of work in cross-media publishing (ibid.).

Stockleben and Lugmayr's (2016) third suggestion points towards the need for a knowledgemanagement system for newswork, supporting the continuous exploration and elaboration needed to "identify, assess, validate, frame, [and] research" news items (Fagrell and Ljungberg 2000, 62). A repository view on knowledge management can inform the design of such a system, but with some adaptions, as suggested by Fagrell and Ljungberg (2000), to provide information on evolving tasks, a context for coordinating contributions and information about the authors and their accessibility. When looking closer at an existing repository for story ideas however, Bødker and Petersen (2010) find that this was used little by the journalists. The repository was seen as extra work and was not integrated with the ongoing articulation of work in the newsroom to "divide, allocate, coordinate, schedule, mesh, and interrelate the individual work" (ibid., 117). In addition, the journalists did not want to make their story ideas available to everyone, and administered them outside the system, pointing to well-known problems concerning making repositories for knowledge management in CSCW (Ackerman et al. 2013).

Stockleben and Lugmayr's (2016) fourth suggestion moves the focus from producing content as efficiently as possible to how the audience is becoming more important in newswork. Metrics can be included in a news-production system and also support for the work involved in flagging, moderating and engaging with reader comments on news stories (Diakopoulos 2015; Diakopoulos and Naaman 2011). When readers take a more active part in the creation of content, however, problems with planning and coordination arise. This signals a contingent and open space, that requires a process not product-oriented focus (Bødker and Petersen 2010). Recent research in CSCW has investigated some of these processes linked to what is often labelled as "crowdsourcing” (Dailey and Starbird 2014; Handler and Conill 2016). Crowdsourcing has different meanings and can be undertaken as outsourcing, as was the 
case with The Guardians MP expenses investigation (Andersen 2009) where the audience was used to scan and flag massive numbers of records (Handler and Conill 2016). A different meaning emerges if crowdsourcing is understood as a wider emergent cooperative network framed in response to a larger issue, where journalists facilitate the movement of information to those who need it (Dailey and Starbird 2014).

In summary, it seems that Stockleben and Lugmayr's (2016) suggestions for the system he labels "fluid journalism" is supported by the sporadic research in CSCW on newswork for facilitating continuous, time-critical, knowledge-intensive, varied, complex, cooperative and content-oriented work.

\subsubsection{Journalists as technologists}

According to Melisma Cox (2000), computers were used in newswork immediately after they had been introduced in business and industry. In the 1952 presidential election, a Remington Rand UNIVAC (Universal Access) computer was used to predict, based on early returns, which of the candidates would win: Dwight Eisenhower or Adlai Stevenson. The computer predicted that Eisenhower would win by a landslide, but Walter Cronkite at the CBS was reluctant to publish the results because everyone thought the race was going to be close. The computer was right, and the CBS was ridiculed for not trusting its results. Polling and predictions have since been important in journalistic coverage of elections in the USA and the rest of the world. Philip Meyer (2002) has labelled the type of journalism where computers and methods from the social sciences are used as scientific journalism. In 1967, he won a Pulitzer Prize for a story about the Detroit riots in 1967. Analysing survey data with an IBM 360 mainframe, he showed that the level of education did not predict participation in the riots by African-Americans, a finding that was contrary to what was assumed. From 2005, driven by the open data and interactive visualization movements, new types of journalism have emerged in newsrooms, where computational skills have been applied to telling news stories, utilizing the possibilities afforded by the rapidly developing online and mobile platforms.

In his $\mathrm{PhD}$ thesis, Eirik Stavelin (2014) maps computer-oriented approaches to journalism where the practitioners use more advanced computer skills in their work than is expected from regular journalists. These practices have been given many names over the years: computer-assisted reporting, precision journalism, database journalism, data journalism, data- 
driven journalism and computational journalism (Stavelin 2014). Stavelin is open to the fact that these are different names for similar practices, given that the practices are framed as new and fresh, but he maps out the differences between them using their foci and the skills applied. He summarizes the differences as follows.

In essence, precision journalism emphasizes the use of scientific methods, CAR emphasizes digital tool use, database journalism emphasizes structure of information storage and retrieval, data and data-driven journalism emphasizes finding stories in data sets, while computational journalism emphasizes the merging of computing and journalistic values in tool creation and method application (ibid., 46).

His main goal is to define and operationalize computational journalism as a distinct practice and he defines computational journalism as: 1) platform-centric instead of storycentric, 2) able to add computable models, and 3) applying computational thinking. The main problem with this definition is that it does not delineate a practice as it is performed in journalistic contexts, by journalists, technologists or journalist-technologists, but idealises and canonizes certain aspects of the practice, especially programming and computational thinking. I will revisit this argument in the discussion and show how the practice framed as computational journalism in study 1 only partially fits Stavelin's definition, and requires a broader understanding of form-giving with the computer as the medium to be characterized well.

When describing the promise of computational journalism six years ago, Terry Flew (2012) outlined an agenda where information technology specialists and journalists come together "in order to develop new computing tools that are associated with the aim of providing information that is accurate, original, reliable, and socially useful" (158), with the goal of freeing "journalists from the low-level work of discovering and obtaining facts, thereby enabling greater focus on the verification, explanation and communication of news" (ibid., 167). In line with this agenda of building tools for journalists, Nicholas Diakopoulus et al. (2016) claim that computational journalism has inherited its focus from computer science, of producing "novel and inventive computational artifacts" (1) and they emphasize how these artefacts should become more than single-story devices, and how it is important to develop, through abstraction, "re-usable pieces or even a platform" (ibid., 2). Diakopoulus is a computer scientist who, along with his fellow researchers, has contributed with a series of studies on developing such tools for: assessing the quality of online political videos (Diakopoulos, Goldenberg, and Essa 2009), extracting news value from social media using visual analytics (Diakopoulos, Naaman, and Kivran-Swaine 2010), applying gamification to information 
graphics (Diakopoulos 2010), doing sentiment analysis on Twitter (Diakopoulos and Shamma 2010; Diakopoulos et al. 2011), finding and assessing sources in social media (Diakopoulos, De Choudhury, and Naaman 2012), automatically generating visualisations (Gao et al. 2014; Hullman, Diakopoulos, and Adar 2013) and supporting comment moderators (Diakopoulos 2016). There have been several articles assessing the impact, both actual and hypothetical, of computational tool use in the newsroom, such as web analytics for attracting more readers through the selection and deselection of news stories (Tandoc 2014, 2015), and robot journalism, which is seen as freeing journalists from routine tasks (van Dalen 2012) with the risk of making them redundant (Carlson 2015).

Sarah Cohen et al. (2011) envision a cloud for the crowd, combining "computational resources as well as human expertise to support more efficient and effective investigative journalism" (148). They describe a system facilitating collaboration by enabling the "sharing of data, results, and computational tools" (ibid.), helping with the management, integration and analysis of structured data, planning and coordinating crowd efforts, and fact-checking. In a study using recent research on data-driven journalism, including article I, dal Zotto and Lugmeyer (2015), recommend designing tools and systems "so that data projects can been easily and more quickly processed and managed" (1). These calls for designing cooperative systems for computational journalism have so far been unmet by researchers in CSCW, but a starting point could be to map how systems for similar work practices could be applicable in this context, more specifically, for knowledge work. The system suggested by Cohen et al. (2011) could be informed by research on knowledge repositories, giving an understanding of how to "use, maintain, and reuse both formal and informal information" (Ackerman et al. 2013, 533). This repository could be seen as bridging the practices involved (Star and Griesemer 1989), thus becoming a common information space (Schmidt and Bannon 1992) and a useful ordering system (Schmidt and Wagner 2004).

Astrid Gynnild (2014), however, sees the value of technologists in newsrooms as more than providing better tools for journalists, by challenging how journalists think when collaborating with them on finding "innovative ways of doing investigations" (725). For instance, technologists bring with them a different understanding of the audience, seeing them as users who want to interact with, comment on and contribute content themselves, rather than as merely readers (Nielsen 2012). This understanding of the audience, challenges the profes- 
sional norms commonly held by journalists who are used to being gatekeepers rather than facilitators. Tellingly, journalists have been slow to embrace a more reciprocal relationship with their audiences with the proliferation of collaborative media (Holton, Lewis, and Coddington 2016; Lewis 2012). An indication that technologists view users mainly as competent and active, lies in how technologists have asserted the value of letting datasets speak for themselves, emphasizing a focus on developing tools and platforms for people to do their own research rather than giving them stories based on the data that has been analysed and interpreted by the journalist (Parasie and Dagiral 2013). Some researchers see technologists first and foremost as hackers, bringing with them a high regard for openness as representatives of the hacker culture. In conceptualizing what they label as open-source journalism, Lewis and Usher (2013) identify the values of transparency, iteration, tinkering and participation as ingrained in technologists' (hackers') work ethic, challenging the norms of traditional journalism by providing journalism not only with the tools for reinvention, but also with the necessary ideology and thinking to navigate the emerging media landscape.

An initiative taken by news organizations towards openness, largely driven by these technologists or hackers, has been to provide application programming interfaces (APIs) to their news content (Aitamurto and Lewis 2013; Ananny 2013). These have been found to foster innovation by involving developers outside the newsroom (Aitamurto and Lewis 2013) and have also been considered as design moves taken by news organizations to support public spheres (Ananny 2013). APIs can become places to "see system design in tension with public sphere ideals because they bring journalists, system architects, hackers, and reading publics into conversation" and "collaboration" (ibid., 613). These tensions become visible when considering how independent entrepreneurs have created tools and services based on news content as their primary asset, becoming the "liminal press", "embedded within logics of software design, algorithmic personalization, and dot-com entrepreneurship" (Ananny and Crawford 2015, 205). By interviewing app designers in companies such as Storify and Google News, Ananny and Crawford identify them as "interstitial designers", who create "novel news experiences that live in between news content production and consumption" (ibid., 194). The designers saw themselves as providing flexible, open and participatory frameworks for news in partnership with mainstream media, being curators not aggregators and app-designers not gatekeepers (ibid.). 
Many of the designers and hackers referred to here are external to the newsrooms, but technologists have also become integrated members of many newsrooms, being hired to undertake computational journalism in tight collaboration with journalists. Some of these are journalists turned technologists, and some are technologists turned journalists. When we did the study of computational journalism in Norwegian newsrooms (Karlsen and Stavelin 2014), there had been few studies of this practice, with the exception of Cindy Royal's (2012) study of the New York Times Interactive News Technology Department. Being one of the first accounts of this practice from the perspective of these workers themselves, study 1 has contributed to later research on computational journalism (e.g. Appelgren and Nygren 2014; Fink and Anderson 2015; Hannaford 2015; Young and Hermida 2015). In an early account of multimedia journalism, Bellotti and Bly (1997) describe practices inside the newsroom where more advanced computer skills were applied. Just a couple of years after online journalism had bacome relatively common, they saw how the web had expanded the editorial process and how "online publishing required an additional set of skills to not only create and edit, but also to engineer, test, maintain and update dynamic content (such as animations, hotlinks and live chat shows)" (ibid., 279). They described how producing content for online publishing in a competitive environment, demanded multidisciplinary collaboration, new skills and new processes.

\subsubsection{Independent transmedia documentary}

The history of documentary films has often been very focused on the study of authors and films (Cohen 2012) and on how the form has developed and progressed in consecutive historical stages. The most cited genealogy of documentary films has been proposed and re-proposed by Bill Nichols (1991, 2001), who sees documentary films as expressions of different geographically- and historically-situated communities of practice, belonging to different institutional and cultural set ups, with different technological challenges and opportunities. Each of these expressions constitute a different documentary mode. The question then is how the challenges and opportunities with using the computer as the medium give rise to new documentary practices and new documentary modes? As with the technologically-advanced

journalistic practices reviewed in the last chapter, the emerging practices in the field of documentaries have been given many definitions such as web documentaries, interactive documentaries, database documentaries and transmedia documentaries. The most encompassing term, the transmedia documentary, has largely been understood in line with Henry Jenkins' 
(2007) definition of transmedia storytelling as "a process where integral elements of a fiction get dispersed systematically across multiple delivery channels for the purpose of creating a unified and coordinated entertainment experience." A transmedia documentary then, is a non-fiction narrative that is distributed "across more than one platform" (O'Flynn 2012, 143), accommodating "both analog and digital forms, including linear documentary films, historical books, i-docs, AR games/historical tours, serious games, serious alternate reality games, performances and/or realtime installations" (Kerrigan and Velikovsky 2016, 256). Idocs are here seen as a unifying term for self-contained presentations such as web, database and interactive documentaries (Aston and Gaudenzi 2012) that can become part of a transmedia documentary, but not necessarily.

When describing how interactive media technologies give new possibilities for representing reality, Sandra Gaudenzi (2013) has updated Nichols' genealogy with four documentary modes expressing different ways in which authors place the audience/users in relation to technology: conversational, hypertextual, participatory, and experiential interactive modes. Her distinction between the hypertextual- and participatory interactive modes opens the discussion up that has become important in the literature on interactive documentaries, regarding the types of participation being facilitated. She defines the hypertextual interactive mode as when the user chooses between pre-made and linked content and the participatory interactive mode as when the user can contribute to an open and changeable database. Siobhan O'Flynn (2015) states that the "proliferation of Web 2.0 technologies and the ubiquity of the social web as a networked many-to-many communicative platform" (78), enables responsive and improvisational performances by the audience, shifting the platform from closed to open, from finite to processual with priority being placed on participation, co-creation and emergent publics (ibid.).

The challenges posed by making documentaries for many-to-many communicative platforms have given rise to a "design turn" in the recent discourse on interactive documentaries, building on an understanding that, with the new modes of documentary, "the role of the author has to move from 'narrator of a story' to "facilitator of other people's stories"” (Gaudenzi 2014, 133). Renira Rampazzo Gambarato (2013) has addressed the "essential features of the design process behind transmedia projects" with the aim of "support[ing] the analytic needs of transmedia designers" (81), and she emphasizes the importance of considering what kind of user engagement the project facilitates when designing transmedia projects. She makes a 
distinction between an interactive project, that is a closed system where the user decides "the path to experiencing it, but not being able to co-create and change the story", and a participatory project, as an open system that "invites the audience $[\ldots]$ to influence the final result" (ibid., 87), which is very close to the distinction Gaudenzi makes between the hypertextual and participatory interactive modes of documentary. When introducing i-doc design to HCI, Green et al. (2017) criticize many existing interactive documentary projects for having the same "centralized, authorial production structures and tokenistic forms of participation that have characterized traditional, linear documentaries" (6318) and they claim that while giving the users executionary agency these interactive documentaries do not provide structural agency or the "ability to inform the context in which this dialogue occurs, or allow users to initiate their own conversations" (ibid.). In a field study when developing a participatory interactive documentary with a community working to save the red squirrel in north England, they tried to find ways to develop an infrastructure that supported structural participation. They frame this as undertaking infrastructuring, to seek "sustainable configurations of creative making, interactive artifacts and design, with different stakeholders, at different times" (ibid., 6319).

Adopting the move from being the "'narrator of a story' to 'facilitator of other people's stories" (Gaudenzi 2014, 133), demanding a "flexibility and willingness to experiment with the means of communication and a commitment to engage in communication" (O'Flynn 2015, 152), is not an easy thing for film-makers to do; however, this is something that Gaudenzi (2017) has documented by attending a series of workshops on i-doc making for storytellers. In this, she investigated "if, and how much, i-doc makers were incorporating design practices in their work" (ibid., 117), and observed "how much novice i-doc makers are unaware of their own resistance to adopting design methodologies in their own work process" (ibid.). From this, she hypothesizes that the merging of "methodologies of work go[es] beyond the practical adoption of new processes, touching upon core beliefs of individual responsibilities and power structures within a team that need to be addressed if we want them to change" (ibid., 118). According to Gaudenzi, the biggest problem for this process, is how the storytellers are reluctant to adapt the linear project model common in film production to the iterative user-oriented model common in design. The storytellers want to retain control as authors because "the satisfaction they get from their work is precisely in the expression of a personal and coherent view of the reality they want to portray" (ibid., 121). The user, and especially the participative user, with her differing views and tastes, can easily become disruptive for 
the storyteller, who has been trained to craft stories for and not with an audience. When summarizing several studies of small film studios undertaking transmedia productions in the Nordic countries, Indrek Ibrus (2016) reports that the film-makers' identity as educated storytellers explained their hesitance to give up control of their stories to their users. The practices linked to film-making, and the identity following on from that, resulted in resistance to the new rules implied by transmedia.

Ibrus Small (2016) further finds that independent film studios have a positive attitude towards transmedia, seeing opportunities for new roles, new career paths, multiple long-term revenue streams, increased control over distribution and a more intimate relationship with their audiences. With some production experience, however, they have become demotivated by how difficult it is to become visible in online media, acknowledging how they depend on established well known media brands to achieve visibility. He concludes by stating that because of their established identity as film-makers, lack of resources for collaboration with ICT professionals and the difficulties of gaining visibility online, "the endeavours to develop independent crossmedia strategies in the saturated Internet marketplace have been failing, at least in Europe's affluent North" (ibid., 170). The problem with gaining visibility for i-docs is also reported by Green et al. (2017), who, in their project, had problems reaching a critical mass of participants. As the producers investigated by Ibrus, they suggest the need to engage sponsors and spokespersons to help "raise the profile of the i-doc via existing media, social networks, or in physical locations where encounters with the i-doc might be meaningful to members of the public" (ibid., 6326). Attracting a critical mass of users when designing collaborative media requires extensive resources in addition to what is needed for designing the media itself. Löwgren and Reimer (2013a) indicate, based on a field study, that there is a ratio of 20/80 between technical design and efforts "enabling and supporting the social process" (92).

The reluctance of film-makers to embrace the participatory interactive modes of documentary, combined with their need to secure visibility for their work, can motivate a different approach to transmedia, which can be framed as outreach rather than as designing documentaries for multiple platforms. This framing can allow film-makers to adopt the strategies needed to communicate with users on many-to-many communicative platforms in a more gradual manner. Many small documentary film producers are already involved in campaigns based on their film projects, with the film as one aspect. Kate Nash and John Corner (2016) 
outline such a strategy for producing social change "by integrating documentary production and strategic communication" (228). In this, they consider the documentary film as a basis for transmedia social action campaigns, as one element that is then combined with "online elements - social media, websites, online petitions -, [and ]written elements such as information packs, educational and promotional materials, and forms of face-to-face communication including grassroots events and specific lobbying activities" (ibid., 231). The goal for such a campaign would be that the different elements work together to "persuade audiences to take specific action" (ibid.). This approach to transmedia has already been taken by the organizer of the 2014 hackathon for film-makers studied in this thesis. At the time, she preferred the term "outreach" to the term "transmedia", with a rationale that this signals a smaller and more feasible step to take towards engaging with the public for resourcestrapped film-makers already suffering from transmedia-fatigue.

\subsection{Introduction to the articles}

\subsubsection{Computational journalism in Norwegian newsrooms}

The article reports on a study undertaken in collaboration with Eirik Stavelin from 20122013 (Karlsen and Stavelin 2014). We interviewed practitioners undertaking computational journalism in Norwegian newsrooms, trying to understand how they worked, what their reasons were, and how this work was embedded in their hosting newsrooms. The motivation for the study was to address the mostly hypothetical flavour of the research on computational journalism to date. The findings can be summarized according to the categories: material; form; methods, tools and techniques; purpose; and the newsroom.

Material: The material for computational journalism was data. In the Norwegian context, the access to public data was good, but there were some problems concerning how to know what data was available, the commercialization of data and unresolved issues with getting usable data from public agencies.

Form: They had identified problems with publishing drillable datasets on the web, seeing as how this format attracted little interest from the audience, and worked on ways in which convey the stories hidden in the data as clearly as possible, through providing simple info graphics and storytelling. 
Methods, tools and techniques: They emphasized the primacy of applying methods for investigative reporting and used technical skills opportunistically in this process by choosing the most efficient tools and techniques for the job.

Purpose: They subscribed to fulfilling the accountability function of journalism with an obligation to finding and conveying truths.

The newsroom: They said they belonged in their hosting newsrooms and disassociated themselves with their respective ICT departments. They felt respected and that they had a high degree of autonomy in their work. The main issue when it came to collaborations with the larger newsroom, was in securing enough time to be able make what they wanted to make.

The article was accepted and published in Journalism Practice in 2014.

\subsubsection{The transmedia turn in Norwegian Independent Documentary Film Pro- duction}

The article reports on a study undertaken from 2012-2013 (Karlsen 2014) where I interviewed independent documentary film producers shortly after they had been called upon by their main funder, the Norwegian Film Institute (NFI), to make transmedia. There had been few studies on independent documentary film practices in Norway up until then. The interview guide developed for the first article, was adapted for this study. Since many of the informants had little experience in making transmedia, I prepared hypothetical questions adapting "How do you make transmedia?" to "How do you think you are going to make transmedia?" To be able to analyse and summarize the interviews, I conceptualized the following four scales (slightly simplified here): 1) material: from records to processes; 2) form: from situation to system; 3) methods, tools and techniques: from film making to rule making; and 4) purpose: from identification to abstraction. The findings can be summarized according to the categories: material; form; purpose; and methods, tools and techniques.

Material: They struggled with understanding how to include audience participation as an integral part of a documentary project, or how to facilitate a process involving the audience rather than using film to document events.

Form: They struggled with understanding how to combine storytelling with interactivity. They were reluctant to let go of the dominant form, person-process narratives, and 
move towards a more open, networked, participative and heterogeneous form depicting a system rather than a situation.

Methods, tools and techniques: They had little experience with programming and design and with mobilizing these skills for their projects. They conveyed that they had little appetite for opening the "black box" of technology production and thought that they could outsource this work if necessary.

Purpose: They saw the potential that transmedia could strengthen the documentary project, but at the same time, they struggled with going from advocating change by making the audience identify with an issue through a person's life story to identifying with the issue in abstract form.

The article was published in the book "Hvor går dokumentaren?: Nye tendenser i film, fjernsyn og på nett” in 2014.

\subsubsection{Probing privacy in practice: Privacy regulation and instant sharing of video in social media when Running}

The article reports on a study undertaken with Susanne Koch Stigberg and Jo Herstad (Karlsen, Koch Stigberg, and Herstad 2016). The initial motivation for undertaking the study was to invent a tool for journalists, both professionals and citizens that accommodated shooting videos in situations where it is inconvenient to stop and hold up a phone with both hands. For example, crowded situations that can potentially turn violent, such as the demonstration in Tahir square in 2011 requiring a nearly invisible tool for shooting and sharing live videos on the move with minimal interaction. Further, to work as a tool for crowdsourced and participatory journalism, we hypothesized that the most promising way to do this was to rely on each individual's motivation for sharing live streams with their friends and, at the same time their willingness to share their streams with the public. This initial motivation was negotiated to accommodate collaboration between the researchers, leading to a narrower focus on exploring privacy concerns when sharing live video on social media from running events.

In the study, we developed a prototype for a wearable device for instantly sharing videos on social media by opening and closing the hand. We combined off-the-shelf components (a smart phone, a flex sensor, a Bluetooth controller, and arduino LilyPad, a glove and a waist 
belt with a see through pocket) to make the prototype, which we evaluated "in the wild" during two running events in Norway and Germany. See figure 1 for pictures of the prototype in use.

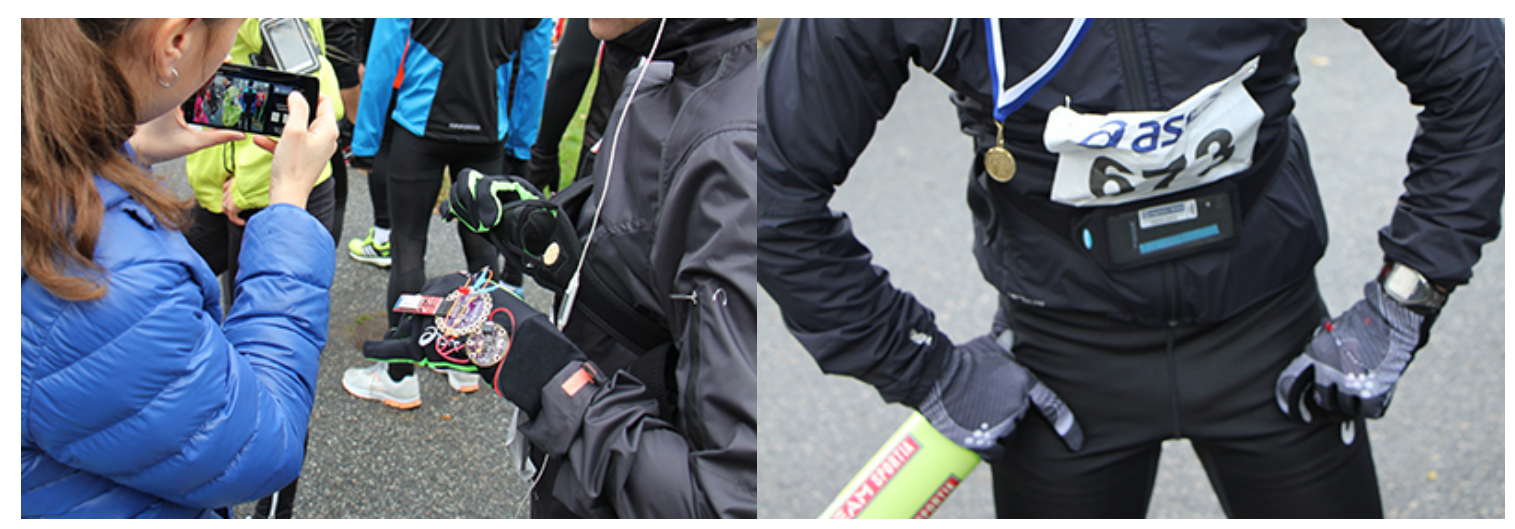

Figure 1: Configuring the prototype before the event (left), and the prototype worn in the finishing area (right).

In the two events, six informants used the probe, and we conducted interviews with them afterwards to capture how they had used it and their reflections on how they had negotiated their privacy concerns when doing this. To be able to analyse and summarize the material from the field studies, we mainly used Palen and Dourish's (2003) concept of privacy genres, a negotiation in practice of the disclosure boundary, the identity boundary and the temporal boundary. Disclosure boundary: audio would not be shared much in this context, since it captures audible signs of fatigue. Identity boundary: sharing performance indicators was problematic, so it is more likely that the probe would be used to mediate the general experience of taking part in a running event. Temporal boundary: the informants were uncomfortable with immediate sharing and would have liked to have had the option of removing recordings and of having strict control over recipients.

In the context of crowdsourced and participatory videos for journalistic purposes, related to the initial motivation for the study, this reluctance to share indicates that in the recruitment of large numbers of citizen journalists for crowdsourcing projects, the willingness to share with an identifiable group of friends, does not necessarily transfer to a willingness to share with an unidentifiable public, which comes down to each individual's negation of their privacy boundaries.

The article was published in the proceedings of ACHI 2016. 


\subsubsection{Aligning participation with authorship: Independent transmedia docu- mentary production in Norway}

The article (Karlsen 2016) uses the interviews collected for article 2 as the background for reporting on the project work undertaken to make transmedia based on the documentary film "Our Daily Bread". From the interviews, I report on the findings related to the informants' difficulties in understanding how to combine strong storytelling with audience participation, and with problems concerning how to mobilize resources to make a transmedia documentary. This brief background frames the issues uncovered by participating in the project from 2012-2013.

From the project work, I identified challenges with facilitating audience participation: negotiating a fitting project model, adapting the scope of the transmedia project to the scope of a film made for broadcast and legitimizing the transmedia documentary as a work of art. The first issue of negotiating a fitting project model was about adapting iterative prototyping to the existing project model common in independent documentary film production. The second issue, related to the first, is how to work with the scope implied by broadcasting a film on national television when designing a transmedia documentary. A prime-time television event is broad and short term, the opposite of participative media that is narrow and long term. The third issue involved problems with legitimizing transmedia documentary concepts as works of art when trying to secure further funding from the NFI. The bureaucratic practice upheld by the government institution, was tightly bound to the existing conventions of what counts as a legitimate output from a documentary film project.

In the project, we made a mobile web application prototype to stand on its own two feet in its meeting with the audience. Even with a well-visited launch event on 3 September 2013, with a demonstration of the prototype, an article in the local newspaper on the same day, announcements on Facebook, posters outside the store and addressing a topic the townspeople cared about, no one contributed any media. See figure 2 for screenshots and figure 3 for a clipping from the newspaper article.

The article was published in the VIEW Journal of European Television History and Culture in 2016 

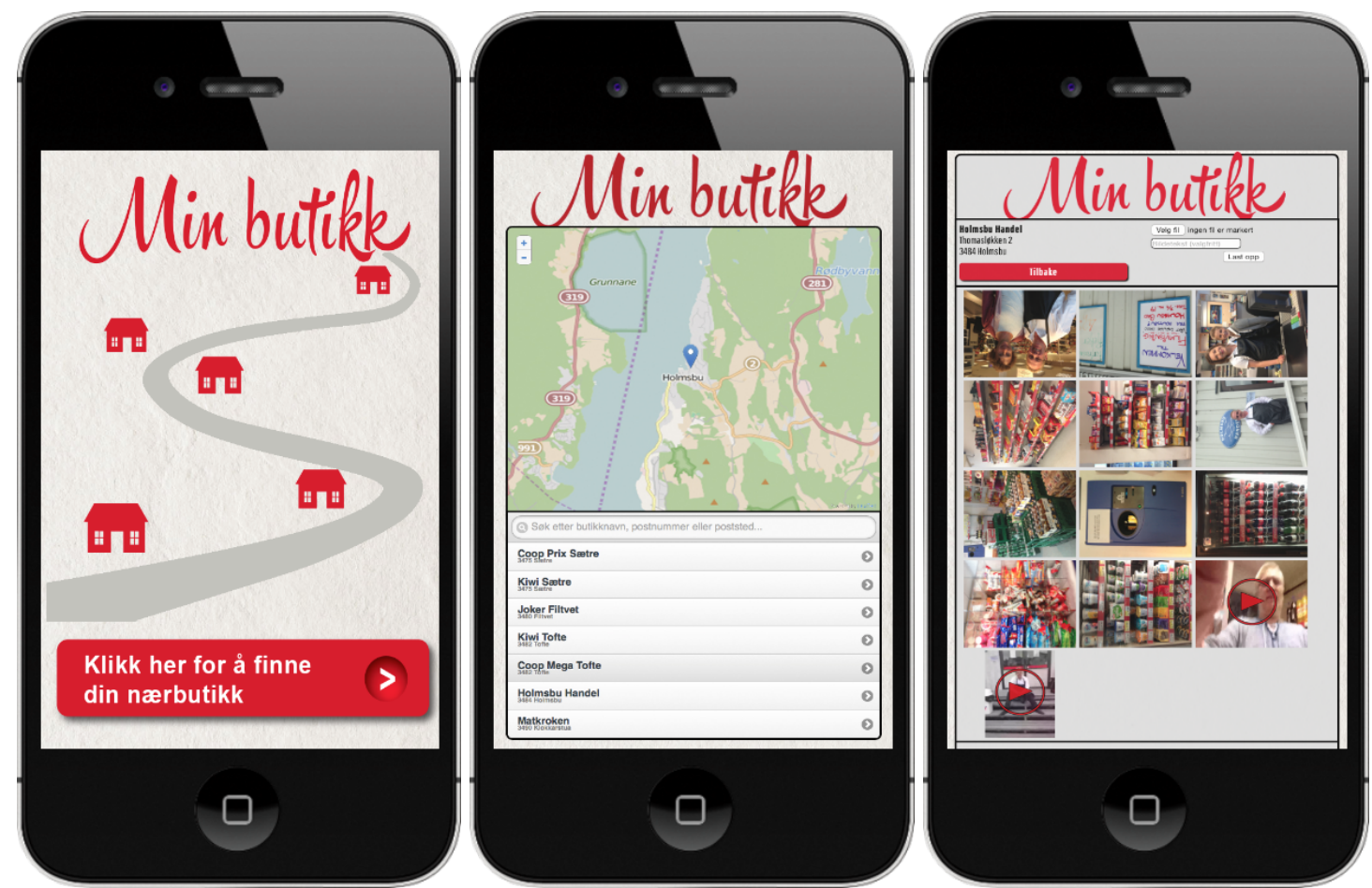

Figure 2: Screenshots showing the main pages of the mobile web application prototype, enabling the sharing of text, images and video to a local store.

som rår.

- Vi har tatt for oss en liten del av en stor problemstilling, sier han.

\section{Egen butikkapp}

I forbindelse med filmen er det også laget en testapplikasjon hvor hver av oss kan gả inn og si noe om den butikken vi har $\mathrm{i}$ nærområdet

- Det er foreløpig en test, og derfor fikk vi med oss noen av elevene pả Folkestad skole til ả se på bruken av den, sier utviklingsansvarlig Joakim Karișen som til vanlig forsker på bruk av formidling i digitale medier ved Høyskolen i Østfold.

Mảlet er at applikasjonen er ferdig utviklet og klar til bruk når filmen vises på NRK.

- Det finnes foreløpig en link til

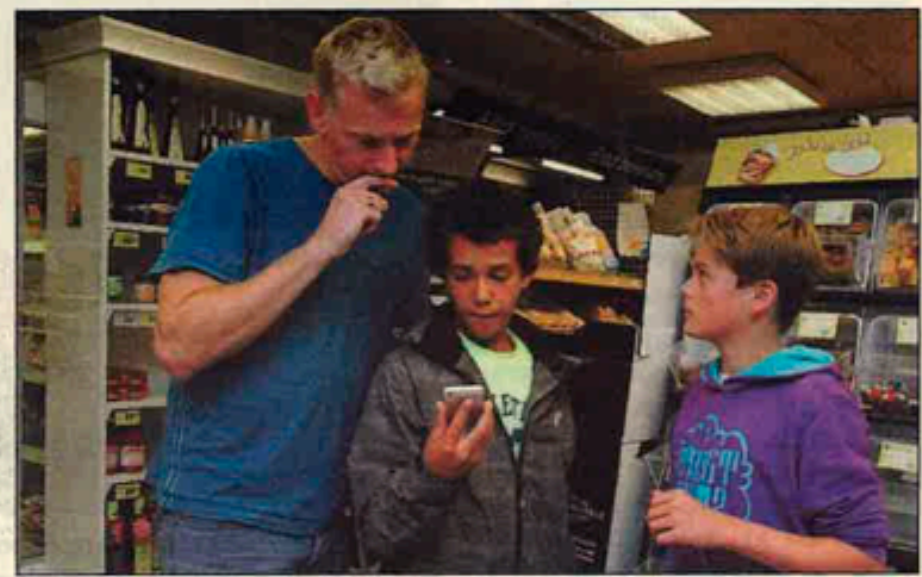

TESTERE: Joakim Karlsen viser Tony Bagroen og Vebjørn Sandaker hvordan de skal legge inn kommentarer, bilder og video på applikasjonen «Butikken min». «Butikken min» er et nettsted som skal utvikles for at alle skal kunne legge ut informasjon og si noe om sin nærbutikk. - Vi håper den kan bidra til å bevisstgjøre folks holdning og bruk av nærbutikken, sier Ånund Austenå som står bak filmprosjektet.

Figure 3: A clipping from the article in the newspaper on the day of the launch (Elmung 2013). The boys in the picture were recruited some days before to use the app, and through this, they provided some initial content to seed the platform. 


\subsection{5 "You can dance your prototype if you like": Independent film-makers adapting the hackathon}

The article reports from a study undertaken together with Anders Sundnes Løvlie (2017). We got access to and observed the 2014 hackathon at the Nordic Panorama film festival, set up to facilitate multidisciplinary work, collaboration, innovation and learning for a group of mostly independent creatives, with backgrounds in film, television, art, game- and systems development. The motivation for the study was to investigate a hackathon set up for this purpose targeting independent media workers. Previous research had mostly been done on game jams and hackathons set up to explore societal issues, and the study was a timely contribution to the literature on organizing hackathons outside their originating contexts. We approached the event with an open and exploratory perspective and took on the role of marginal participant observers throughout the event. During the weekend, we were able to visit all seven groups many times and spend a significant amount of time observing each group. To analyse and summarize the findings from the event, we relied mainly on an understanding of the similarities and differences between the work cultures of film-making, software development and design, the relationship between the phases of groupwork and time constraints, and between the nature of the task given and the participant's background.

The main finding from observing the event, was that the majority of the teams in the hackathon were unable to engage in making activities that measured up to their own ideals for the hackathon. Even if the organizer had faciltated all kinds of making, both digital and non-digital, the participants had the expectation that they would be contributing to the making of working digital prototypes. They lacked the methods, tools and techniques necessary for doing so within the strict time frame of the event and were somewhat disappointed by this. This indicates that many of the participants lacked experience with rapid timed prototyping and that they did not have a working understanding of what it takes to materialize concepts and ideas in digital media within a short timeframe. Further, we saw how ideals for authorship, embedded in the working cultures of film and TV professionals, impeded the group's ability to involve all participants on an equal footing, which resulted in lengthy debates focusing on conceptual issues rather than on finding ways to engage in making.

The article was published in Digital Creativity in 2017 


\subsection{Structure of the thesis}

The thesis consists of two main parts, a "kappe" or summary that draws together the individual articles and the articles themselves as published. In the following, I will develop a common theoretical framework for the five studies that frames how the five studies contribute in answering the two research questions. Studies 1, 2 and 3 inform the first research question, by comparing how two types of journalism, computational, interactive and collaborative journalism and the transmedia documentary are supported in the media worlds of newsroom journalism and independent documentary film production. Studies 3-5 inform the second research question, by comparing how three initiations of processes of invention in media worlds have the potential to support reinvention.

I will outline the theoretical position for the thesis in chapter two. In chapter three, I give an account of the methods used. I have relied on an interpretative framework and used interviews, observations and research through design. After relating the main overall findings in chapter four, I will discuss these findings in chapter five. 


\section{Theoretical position}

The theoretical position argued for in this thesis relies on Bowker and Star's (2002) concept of infrastructure, operationalized by using Becker's (1984) definition of cooperative activities and conventions. The rationale for using these concepts is to enable a description of processes of reinvention in media worlds that relies on a) invention and b) change. Invention relies on cooperative activities undertaken to challenge existing conventions of a media world, both for how things should be done and for what should made. For inventions to lead to change however, requires that existing or new cooperative networks are captured in support of what has been invented. Successful change is framed as reinvention within a media world.

The understanding of the cooperative activities where conventions are challenged, the basic work needed for change to happen, relies on what has been categorized as form-giving work and more specifically as form-giving work with the computer as the medium. The understanding of the processes of capturing cooperative networks for inventions in media worlds, relies on how Bowker and Star (2002) use the concept of infrastructure, which helps with in making the underlying factors visible, including information technologies, that conditions and shapes these socio-technical processes, potentially leading to change. When visible, these underlying factors, giving the inertia of media worlds, can be addressed by interventions to overcome them through infrastructuring. Before developing this argument further, I will argue for an understanding of form-giving work with the computer as medium attuned to the challenges faced by media practitioners when exploring the capabilities of the computer as the medium. The approach taken in the following, relies on a vision of the computer as both a malleable and unexplored medium, as professed by Alan Kay when resolving whether the computer should be seen as a tool or a medium.

Is the computer a car to be driven or an essay to be written? Most of the confusion comes from trying to resolve the question at this level. The protean nature of the computer is such that it can act like a machine or like a language to be shaped and exploited. It is a medium that can dynamically simulate the details of any other medium, including media that cannot exist physically. It is not a tool, although it can act like many tools. It is the first metamedium, and as such it has degrees of freedom for representation and expression never before encountered and as yet barely investigated. (Kay 1984, 59) 


\subsection{Form-giving work with the computer as the medium}

Work is a purposeful practical activity that requires some training to do well (Schmidt 2011). What is this purposeful practical activity when it comes to making journalism? There are several ways to answer this question, depending on the perspective taken. If one sees the newsroom as a factory churning out news items, then journalists are workers in a modern sense. They are cogs in the wheels of a larger machinery, managed by editors and owners, trained to do specific jobs that they do again and again with only a partial perspective of the whole undertaking. When new technologies are developed in support of their work by someone outside the newsroom, they need to be retrained to work according to the new demands embodied by the new technology. If one sees the newsroom as a workshop, however, where news is crafted by highly trained workers for higher purposes, this will look different. They are seen to take responsibility for what they make, and also for adapting the tools and techniques they apply in their making to new circumstances, for new purposes. Both these perspectives will probably make sense when it comes to understanding the work undertaken by newsworkers in newsrooms. Journalists will probably feel like factory workers sometimes and craftworkers at other times. When it comes to the independent documentary filmmakers this looks different. It is easier to compare small film studios to a workshop than to a factory. The independent film workers are definitely craftsmen, maybe even artists, and relate to each other as such. A small team making a documentary film often consists of a producer, a director, a cameraman and an editor, all with autonomy in contributing to the film being made and where the final say rests with the master (director). Based on these considerations, theories of form-giving work are used to describe the work undertaken by the informants in the studies undertaken in this thesis.

The perspective on form-giving as argued for in the following, informed by theories of craftwork, articulates form-giving work as more than the mere rational application of techniques to coax materials into pre-determined, purposeful forms. I will argue for an understanding of form-giving that avoids the dualism between thinking and doing implied by how Langdon Winner (1977) explains technique as "the whole body of technical activities-skills, methods, procedures, routines that people engage in to accomplish tasks" (12) and how he emphasizes that "technique has been distinguished from other modes of human action by its purposive, rational step-by-step way of doing things" (ibid.,). One perspective, avoiding dualisms be- 
tween thinking and doing, form and matter has been given by Tim Ingold (2013), who discards views of making as imposing forms, internal to the mind on material, and writes that making "is a process of growth" where the maker is "a participant in amongst a world of active materials" (21). The relationship is not between form and matter, but between "forces and materials" (ibid., 46), it is "a question of 'surrendering' to the material and then 'following where it leads"" (ibid.). Materials "think in us, as we think through them" (ibid., 6). According to Ingold, the essence of making is to mix movement with materials, but where movements and material depend on each other. In his view, making is a form-generating process that requires engagement with materials, a process of bringing forth "potentials immanent in a world of becoming" (ibid., 32). From this it is possible to see how doing, thinking and materials become inseparable and the form is the output of, not the input to the process of making. The question then is what kind of thinking is there room for in Ingold's theory of making? It makes little sense in most context to just make something randomly and expect the result to be of much value to the maker or people around him. Ingold addresses this and uses the terms "anticipatory foresight" to describe this thinking with materials. Anticipatory foresight is to open up, to improvise, to bring pieces together, "following and reconciling the inclinations of alternately pliable and recalcitrant materials" (ibid., 70) in breaking a trail. This trail-breaking is not easy, according to Ingold, and the anticipatory foresight is up against the frictional drag of material abrasion that requires what he calls myopic engagement with materials, of being attentive "to the conditions of a task as it unfolds" (ibid., 116).

The reinvention of journalism is mainly carried out by the journalists themselves in the act of making new media. Making is therefore essential, not incidental, to these processes, and concepts such as anticipatory foresight, myopic engagement with materials and trail breaking are useful when understanding them. What is becoming new media is made first, by someone in a particular situation. This person, most likely working in a small team, needs to become a digital maker or form-giver with a broad enough repertoire of skills and experience to challenge what has been made before, to make new, not old media. In the following three major forms (as outputs of the process) will be articulated that this maker needs to relate to in this form-giving work with the computer as the medium: computation, interactivity and cooperation. It is possible to find accounts of new media journalism that emphasize programming, or design, or collaboration, but a journalist working with making the next new thing in journalism needs to relate to all three. After a consideration of each form separately, a tentative model of how the forms relate to each other, is given. 


\subsubsection{Computation}

In Richard Sennet's view, craftwork is more than masonry and pottery, and he includes Linux programming as an example: "Craftsmanship cuts a far wider swath than skilled manual labor; it serves the computer programmer, the doctor, and the artist" $(2009,9)$. There are some obvious differences however, between pottery and programming, that need to be addressed to be able to say that both are examples of craftwork. Clay is a physical material that can be found in nature, that can be brought to the workbench and that can be given a form directly by using the hands. The material of computation however, is not found in nature and cannot be directly manipulated in the same way as clay. The directness of working with clay however, can be used as a metaphor for what making with computers can become (Kay and Goldberg 1977), but the material of computation is very different from clay. This being so, there have been attempts to bridge traditional form-giving work such as pottery with formgiving with the computer as the medium, theoretically. In the late 1990s, Malcolm McCullough (1998) explored "the possibility of craft in the emerging realm of information technology - with the computer as medium" (21) based on and understanding of "what matters in traditional notions of practical form-giving work" (ibid., 19).

To define craft in the realm of digital media, it is important for McCullough (1998) to understand what material is worked on when the computer is the preferred medium. He identifies the paradox of an intangible craft as described above, with the digital medium having no material, and develops a theoretical understanding of this material. In this, he explains how software is characterized by data structure, "what you can do, and how a program looks and feels, depends on its underlying abstractions and assumptions" (ibid., 96). Even if a "limitless variety of formal elements can be described, from words to sounds to forms to motions" (ibid., 97), software establishes certain kinds of elements and operations that determine its expressive capabilities. The set of abstracted elements and operations become generative grammars with high level object-oriented programming as an example. A class library "is a powerful generative structure" allowing "the ability to operate on abstractions as if they were things" (ibid., 98). The level of abstraction varies according to McCullough, from being close to the hardware to being object oriented to being elements on the screen that can be directly manipulated by pointing, clicking and dragging. 
Working with the computational medium's material (as defined by elements and notation in software), can bear a resemblance to traditional form-giving work. As in music, where the composer works with notational systems when creating a piece of music, the digital craftworker manipulates elements and notation to create his preferred kind of digital media. It is not on the level of different media, however, where the basic form of computational media is located, but on the level of computation itself. The difference between traditional media forms and computational media forms is the computer's ability to simulate processes, and the creative locus of authoring digital artefacts is writing them (Mateas 2005). To be able to manipulate processes, programming becomes an essential skill, required to achieve what Mateas coins procedural literacy, which according to him, is a precondition for being able to "grapple with the essence of computational media" (ibid., 101) and to "tap the true representational power of computation as a medium" (ibid., 113). In the same vein, Reas and Fry (2006) claim that "to fully explore the computer as an artistic material, it's important to make the 'arcane art or computer programming' into widely understood principles" (530). The identification of a process as the basic form of computational media makes the writing of processes central to understanding form-giving with the computer as the medium.

This emphasis on writing processes by coding as the creative locus of computational media, is somewhat at odds with what McCullough (1998) identifies as the most favourable conditions for digital craftwork. He claims that direct manipulation and continuous action are what bridge traditional and digital crafts. This points to a dilemma surfacing in McCullough's attempt to bridge traditional and digital crafts that is partially unresolved. He locates the best conditions for craftwork with the computer as the medium when working with high level abstractions using direct manipulation. At the same time, he emphasizes that learning a new medium "consists of exploring its affordances and constraints" (ibid., 248). According to him, all craftwork "is not just technique, or hard work on form, but also a probing of their medium's capacity" (ibid., 29). Working on a high level of abstraction by direct manipulation however, will require specialized software that can potentially limit the exploration of the given mediums capacity. This dilemma is expressed by Fischer and Giaccardi (2006) in the context of finding a balance between standardization and improvisation when designing software. They see this dilemma of being in or out of the Turing tar pit. The Turing tar pit is when "everything is possible, but nothing of interest is easy" (ibid., 428) and where the inverse applies with over-specialized systems, "when operations are easy, but little of interest is possible" (ibid., 428). 
Who then, determines what is interesting or not? This question needs to be answered for the dilemma of the Turing tar pit to make any sense. One answer can be found in McCullough's explanation for why the probing of the digital medium's capacity is important in digital craftwork. The probing of the medium's capacity, as more than the mere application of techniques, is central to the process of making something interesting, where what is interesting is decided by the context given by the genre. According to McCullough (1998), genres are artistic types that are transmitted and which give the necessary context for "developed interpretation" (203). The making of something interesting or invention consists of "criticizing existing types as well as creating new types" (ibid., 181). The ability to criticize existing types as well as making new types or prototypes result from connoisseurship, or the exposure to many artefacts, that enable an understanding of "familiar categories of forms within an acquired medium" (ibid., 205). According to McCullough, prototyping becomes an expressive medium supporting the invention of new types in a dialogue with the old.

When what is interesting has been defined this way, the dilemma expressed by Fischer and Giaccardi makes sense. It can be directly interpreted as expressing the position that it is in the Turing tar pit where new media most likely are invented, where interesting types are made. Media-authoring software "for creating, interacting with, and sharing media" (Manovich 2013, 2) has been developed to escape the tediousness of programming, enabling practitioners to work in specialized media, but the software embodies artistic types and conventions that may restrict the freedom of expression and the capacity for making new types. The inventors behind the programming language Processing see the constraints imposed by specialized software tools as a problem in creative work (Reas and Fry 2006). John Simon Jr. claims that programming is needed to "break the boundaries of commercial tools" modelled on earlier media (Maeda 2004, 46).

The dilemma of being in or out of the Turing tar pit can be resolved however, in the design of media-authoring tools. The level of abstraction the tool allows the user to work on varies greatly between them. Specialized media-authoring tools often have templates, filters and elements installed, but can also offer the author the ability to make them from scratch by writing programs. The question then is whether the ability to write code in itself sets the new media practitioner free from the constraints imposed by software, with the purpose of creating something interesting, to go beyond the easy application of mere technique. If we go back to 
McCullough's definition of abstractions as the material for digital crafts, and that most programming languages have a high level of abstraction, then it becomes clear that programming languages can restrict the new media practitioner too. The difference between programming and software use is only a matter of degree when it comes to the freedom afforded to the author. It is also possible to turn this argument on its head, as McCullough does, and emphasize the generative aspects of the available abstractions, being programming concepts or elements open to direct manipulation. What is interesting or not depends on how the media made contributes to the development of a new media type. Sometimes easy tool-use can produce interesting expressions and sometimes being in the Turing tar pit will produce little of interest. In summary, it is possible to see how McCullough would agree with the advocates for programming as an essential skill for new media practitioners, as it increases their ability to create new types, but at the same time, he seems to think that specialized mediaauthoring software also affords the making of these.

\subsubsection{Interactivity}

It is possible to construe programming as form-giving work, of crafting code, as writers craft text, underpinning using carpentry, pottery or playing an instrument as metaphors for understanding this type of work? This directness is less evident when considering how interaction design can be conceptualized as form-giving work. Interaction designers make plans, sketches and prototypes, thus they definitely make something, but do not always get involved in actually making the final product itself. Instead of crafting an idea into a finished artefact, designers work towards specifying it well enough for others to build it, which is the reason why both Ingold and Sennett are critical of the professionalized practices of design. Löwgren and Stolterman (2004) identify this separation of design and production that has developed with increased complexity in building processes and refer to David A. Wroblewski's (1991) attempt to define design as a craft, mainly to motivate a holistic understanding of the abilities an interaction designer needs to develop in his work.

Wroblewski (1991) defines craft as "any process that attempts to create a functional artifact without separating design from manufacture" (2) where the distinction between tools and materials disappears in the process. A water pitcher made of clay needs to hold water without leaking and is an example of a functional artefact. When it comes to avoiding a separation between design and manufacture, of making sure that the construction of the artefact is 
not the mere application of techniques, nor pure performance, he identifies two ways of working that unify design with manufacture. The first is to rapidly shift between design and making in construction and the second is to let the design element recede "from conscious consideration into a continuous and simultaneous influence on the making of the artifact" (ibid.). When it comes to the disappearance of the distinction between tools and materials, he uses blacksmithing as an example, where the craftworker often makes the tools for the job in making the artefact itself. The unfinished artefact itself can be considered as a tool too, by guiding the craftworker in the subsequent alterations. Wroblewski's perspective on craftwork is thus compatible with how both craftwork and form-giving have been conceptualized so far, aligning design with form-giving by positing a tight coupling between the two.

To see interaction design as a form-giving practice, overcoming the dualism of thinking with forms and doing with materials, the question regarding what the basic materials in interaction design are, needs to be answered. Löwgren and Stolterman (2004) define interaction design as the "creation and shaping of digital artifacts" (xi) where they emphasize the open and unbounded nature of this practice, of composing "both technical artifacts and social systems" (3), to achieve what they label as use-oriented qualities. They divide use-oriented qualities into structural, functional, ethical and aesthetic qualities. Structural qualities are decided by the choice of material and technology, functional qualities are decided by use, ethical qualities are decided by relevant values and ideals and aesthetic qualities are decided by composition and appreciation. These qualities together combine to create a gestalt, only understood as a whole, not reducible to individual qualities and which only "emerges in the interaction with the user over time" (ibid., 137). When it comes to the material used in interaction design, Löwgren and Stolterman identify information technology and people. Information technologies and how people use them change so rapidly, however, that it is difficult to pin down this material, and they therefore claim that this is "the material without qualities" (ibid.). They compare this material to language and the designer to an author and claim that both the author and the interaction designer have almost complete freedom to create anything they want with few material restrictions.

Anna Vallgårda (2013) seeks to move beyond the definition of the material of interaction design as being without qualities and articulates concepts to understand both the physical and abstract materials of interaction design. She frames interaction design as "the practice of giving form to artifacts or environments rather like any of the other design disciplines that we 
have known for centuries" (ibid., 578) and establishes the role of the interaction designer as crafting "the computational material's temporal form in combination with physical forms" (ibid.). The temporal form is produced by the computer and is a pattern of state changes. The physical form is what we can perceive, both a three-dimensional tangible shape and "intangible materials like light, sound, air streams" (ibid.). According to Vallgårda, the computer does not have "any useful properties before it is combined with other materials" (ibid., 581). The physical and temporal forms together create an interaction gestalt, where the interaction gestalt is what the "user(s) will do in relation to the thing or environment" (ibid.). There is a reciprocal relationship between what the user will do with the thing and what the thing makes the user do. What is the basic material of interaction design according to this definition? First it is possible to see how crafting the temporal form uses the material of computation as defined in the last chapter. An interaction designer has all the notations and abstractions offered by the computer to work with as materials when crafting the temporal form. Second, the interaction designer works with physical materials in crafting interfaces and artefacts that bridge the computation and real environments. This bridging, this working with physical interfaces, uses materials associated with traditional crafts.

In both these definitions of interaction design, the distinction between material and form becomes blurred however, by treating what people do as both material and form, frames interaction design as a kind of social design. Use can definitely inform design and design can create conditions for use, but use cannot be designed directly (Bratteteig 2004). In research on new media this is echoed in problems with defining interactivity. Is interactivity a property of a media artefact or an activity that the artefact accommodates? Dag Svanæs (2018) clears this up by distinguishing between interactivity and interaction. Interactivity is a property of an artefact such as its visual appearance, a property that can be experienced if the artefact allows for interaction, defined as "mutual or reciprocal action or influence" (ibid.). This distinction, together with Vallgårda's definitions of the material of interaction design, provides a more modest understanding of interaction design as form-giving work, where both physical and abstract materials are used to construct interactive artefacts, with the purpose of accommodating interactions. This distinction also makes it possible to divide Löwgren and Stolterman's use-oriented qualities into structural qualities (form) and functional, ethical and aesthetic qualities (purposes). The structural qualities are the locus of interaction design, aiming 
for the purposes of use, values and appreciation. An important question then is how the designer should work with achieving these purposes when forming physical and abstract materials in working with the structural qualities of an artefact? How should one determine this?

In the literature on interaction design it is common to rely on design methods for this, a body of work that devises methods, tools and techniques for making sure that the final artefact will have the desired effects, of predictably solving the problem at hand. After having defined craftwork, Wroblewski (1991) addresses this, and questions the evolutionary model of craftwork. How should craftworkers, without "deeper explicit knowledge of the principles behind successful designs" (ibid., 8), be able to "prioritize alternative responses to change?" (ibid.) Referring to Donald Schön's theory of the "reflective practitioner" and Rittel and Webber's concept of "wicked problems", he explains why their understanding of professional design is compatible with the craftsman model. Design problems are unique in nature and require that the "designer engages in a sort of dialogue with the problem situation to uncover the most appropriate means and goals, rather than through the rigorous application of technical knowledge toward predefined ends" (ibid., 9). Based on these premises he considers whether making human-computer interfaces is a craft and concludes that in practice "the distinctions between design and implementation are necessarily so blurred that the construction of human computer interfaces can surely be considered a craft" (ibid., 12). The evolutionary model associated with craft also supports an understanding of interaction design as solving new problems using a developed understanding of how similar problems have been solved in the past. Löwgren (2008) is a proponent of this approach and argues for how important it is for interaction designers to gain an understanding of the aesthetics of interaction design and how this aesthetic is mainly determined by historically-constituted genres. Therefore, he argues for design criticism as important to learning and practicing interaction design, where design criticism is to criticize existing designs as a basis for developing the repertoire needed for designing new ones (Bardzell, Bolter, and Löwgren 2010). This in line with McCullough's definition of form-giving work in the digital domain, where the main activity for the form-giver is probing the medium's expressive possibilities in making new types or prototypes in constant dialogue with existing types. 


\subsubsection{Collaboration}

Löwgren et al. (2013a; 2016) have argued for a perspective that frames the making of collaborative media as a challenge for interaction designers. To design for collaborative media practices is a difficult challenge however, and when it comes to finding ways to do this, we are according to him, all novices (Löwgren 2016). Löwgren and Reimer (2013b) characterize collaborative media as frameworks for textual everyday practices based on "media services and tools that are easy to use and can be used creatively and pleasurably in many different ways" (loc. 268) and which are collaborative, where "people work together to create things that are not possible for the lone user to create" (ibid., loc. 269). When developing a design perspective on collaborative media, Löwgren and Reimer (2013b) emphasize; how it is crucial to design for openness and flexibility, how this is an ongoing collaborative process interwoven with use, how the major role in this work is facilitation, how the outcomes depend on specific articulations, and how the goal should be to assist in creating meaningful experiences. Further, they emphasize one main insight from their work with designing collaborative media - it is difficult to predict how collaborative media are going to be appropriated and used when made available, meaning that the designer can work to create a framework, but that the success of the framework depends on the creative appropriation by a community of people. The complexity involved in this is according to them, too high to be predicted by using the standard methods, tools and techniques of interaction design.

Creating lightweight prototypes and testing them with intended users in an iterative process before committing to implementation is a pointless activity in situations where use is fundamentally constituted by a critical mass of actual users and actual communicative practices, meaning that the whole notion of upstream explorative design preceding a set delivery date is voided (Löwgren and Reimer 2013a, 88).

Löwgren (2010) therefore frames the design of collaborative media as an ongoing interventionist process, where the interventions can address: infrastructural features by "stringing multiple media channels together over time, technically as well as organizationally" (13), tool capabilities by designing or integrating the "means to make collaborative creation possible" (ibid., 14) and directional values by providing initial directions and ongoing facilitation (ibid.). He likens the task of designing collaborative media to producing an interactive performance where the producer "sets the stage, provides the props and hires the actors" (ibid.). After this point however, when "the lights come on at the opening night, the producer can only sit back with the rest of the audience and see how the performance comes out" (ibid.). When suggesting relevant research programs and frameworks that could inform 
the work of designing collaborative media, he points to infrastructuring, supported by metadesign and participatory design (PD).

Meta-design explicitly addresses collaborative creation (Fischer and Giaccardi 2006) and is "an emerging conceptual framework aimed at defining and creating social and technical infrastructures in which new forms of collaborative design can take place" (427). The aims of these socio-technical environments are that they are flexible and develop "at the hands of the users" (ibid., 429), who should be seen as skilled and who "see the computer as a means rather than as an end" (ibid., 431). The framework expresses meta-design as designing the in between or the "relational settings and affective bodies" (ibid., 452) supporting existing social networks or the shaping of new ones. When giving examples of how meta-design approaches could be applied, they propose interactive art and social creativity. In interactive art, "interaction itself" is "the real object of creative production" (ibid., 439) and in social creativity, collaborative design depend on open systems. In PD and co-design, methods, tools and techniques have been developed in support of co-creative processes as addressed by meta-design. In this tradition there has been a continuous focus on providing the means for groups of people to express themselves, to negotiate multiple perspectives in an open, creative and inclusive manner. One program has facilitated for creative acts of "construction and transformation of meaning" (Sanders and Stappers 2014, 6) by designing and providing generative toolkits. Sanders and Stappers (2014) define generative toolkits as:

A participatory design language that can be used by non-designers (i.e. future users) in the front end of design so that they can imagine and express their own ideas about how they want to live, work and play in the future (7).

Sanders established the motivations for the generative toolkit approach in a paper written in 1999, with a fresh outlook on design, influenced by the proliferation of the Internet, inspired by early collaborative media and the changing conceptions of users (Sanders 1999). She wanted to create new tools that "focused on what people make, i.e., what they create from the toolkits we provide for them to use in expressing their thoughts, feelings and dreams" (ibid., 4). The main resource is self-expression, which is an "emerging visual language that people, all people, can use to express and interpret those ideas and feelings that are often so difficult to express in words" (ibid., 7). In a later paper, the idea was developed further to establish the making of generative toolkits as the creation of languages.

We put a large number of components together into "toolkits". People select from the components in order to create "artifacts" that express their thoughts, feelings and/or 
ideas. The resulting artifacts may be in the form of collages, maps, stories, plans, and/or memories. (Sanders 2000, 4).

Creating generative toolkits, informed by meta-design and PD as the means for both designers and users to express themselves, is something that can be viewed as form-giving work, of making a framework for expression by using the digital mediums capacity for computational and interactive forms.

The forms that collaborative media take are collaborations between people expressing themselves collectively. It is difficult to see how these can be designed directly as noted by Löwgren, as it is about designing for performances and not about designing the performances themselves. An approach to designing for these collaborative processes involving larger groups of people is given in the literature as infrastructuring publics. To understand the role of designers in the formation of publics, Pelle Ehn (2008) uses the Latourian concept of "things" and refer to its meaning in pre-Christian Nordic and Germanic societies as assemblies and places "where disputes were solved and political decisions made" (92). He claims that the ultimate challenge for design is to participate in the making of public things, enabling a heterogeneous public to constructively deal with its disagreements. Carl DiSalvo (2009) sees this as providing resources for articulating "the conditions and consequences of an issue" (52) and devises the design tactics of projection and tracing. Projection implies tactics to make representations of "future consequences associated with an issue" (ibid.). Tracing is "the use of designerly forms to detail and communicate, and to make known, the network(s) of materials, actions, concepts, and values that shape and frame an issue over time" (ibid., 55). Projection has a future orientation, while tracing has an orientation towards the past. The goal for these and other design tactics is to federate "individuals in the discovery of unknown issues" (Dantec and DiSalvo 2013, 247) by providing the scaffolding for articulation and form-giving; to expose and re-imagine issues and problematic situations through artifacts, systems and events; and to engage in prototyping "new social, economic, and political arrangements" (DiSalvo et al. 2014, 2405).

New trails need to be broken with uncertain outcomes when it comes to finding good ways to design collaborative media, and so far, this is still open terrain for further exploration. In summary, the designer needs to work with the abstractions of computation and the interfaces needed to make artefacts interactive when designing collaborative media. In addition, the de- 
signer must engage actively in supporting the multiple interactions accommodated by computational and interactive forms by interweaving media channels, by developing tool capabilities, by giving initial directions and by undertaking ongoing facilitation. Interactions, as defined in the last chapter, is a social concept, it is what people do together, they are performed. The means that are provided or generated in support of these collective performances are socio-technical ensembles or what Löwgren labels infrastructure and the ongoing design work addressing and improving these is infrastructuring.

In the next chapter, I will shift perspective from form-giving with the computer as the medium as a challenge for media practitioners and look closer at concepts and theories to support an understanding of how meeting this challenge or undertaking invention have the potential to lead to reinvention in media worlds, by articulating the workings of media worlds or their infrastructure. Before this, the relationship between computation, interactivity and collaboration will be put forward, mapping out a space for digital form-giving with the computer as the medium, including programming, interaction design and the design of collaborative media.

\subsubsection{Computation, interactivity and collaboration}

Based on these considerations of the material, form, purposes and techniques of form-giving with the computer as the medium on three levels (computation, interactivity and collaboration), a tentative model for form-giving with the computer as the medium is proposed. The main point of the model is how it articulates the way in which the three levels are related. The categories of material, form and purpose in form-giving were established in studies 1 and 2 and rely on Martin Heidegger's (1954) definition of technê as an understanding of causation, as given by Aristotle's ontology, in bringing forth artefacts. He uses a craftsman's making of a silver chalice as an example to explain the relationship between material, form and purpose in this. The material cause is what the artefact is made of (silver). The formal cause is the form or shape given to the artefact (a cup). The final cause is what the artefact is used for, in Heidegger's example, a sacrificial rite. The moving cause is the craftsman, whose duty is to bring forth the artefact, in this example the chalice, letting the end determine the choice of material and form. 
The first level in the model is computation, where the materials worked on are abstractions; from hardware, to objects, to elements available for manipulation by software. The form given involves computations performed by the computer with the purpose of making a working process or procedure. The processes or procedures made, the purpose of working on the level of computation, is the material when giving form to interactive artefacts on the second level. In addition, the practitioner needs to combine working processes with physical interfaces to bridge processes with environments. The form given is interactivity with the purpose of supporting interactions. The interactions designed for, the purpose of working on the level of interactivity is the material when working with the third level of collaboration. In addition, the practitioner needs to combine the interactions with a shared infrastructure. The form given is collaborations with the purpose of supporting practice.

\begin{tabular}{|c|c|c|c|}
\hline Cause & Computation & Interactivity & Collaboration \\
\hline Material & Abstractions & $\begin{array}{c}\text { Processes / } \\
\text { Interfaces }\end{array}$ & $\begin{array}{l}\text { Interactions / } \\
\text { Infrastructure }\end{array}$ \\
\hline Form & Computation & Interactivity & Collaboration \\
\hline Purpose & Process & Interaction & Practice \\
\hline
\end{tabular}

Table 1: Relating computation, interactivity and collaboration in digital formgiving work

\subsection{The infrastructure of media worlds}

Tim Ingold (2013) describes the building of Chartres as the "ad-hoc accumulation of the work of many men [...] under the direction of no fewer than nine master masons in some thirty separate, short-term campaigns over a period of more than three decades" (57). These workers were often organized in guilds and workshops and learned the craft from more experienced craftsmen from a young age. The making skills were based on long traditions, and the different guilds were part of a slow-changing system with consensus concerning what should be made and how. This consensus or conventions supported the cooperative activities needed to erect cathedrals in medieval guild worlds. The focus in the following is on devel- 
oping an understanding of the cooperative activities supporting the making of media in media worlds, and how these activities rely upon agreed upon conventions for both what to make and how. Further, how media worlds changes via successful challenges to existing conventions by inventions that are able to mobilize cooperative networks in its support. In this I will rely on Howard Becker's (1984) sociology of art worlds, understood as an operationalization of Bowker and Star's (2002) concept of infrastructure for the purposes of this thesis.

Becker belongs to the school of symbolic interactionism, which has been important in $\mathrm{CSCW}$ research and more specifically for field-based research of the interpretivist sort. According to Ackerman and Kaziunas (2017), the micro-sociological approach, as laid down by Chicago school researchers such as Strauss, Blumer, Becker and Goffman have proven valuable for system design and have provided important concepts, including articulation work. They give reverence to Beckers research on art worlds, but without qualifying this further. When explaining their concept of infrastructure, Bowker and Star (2002), who are influenced by symbolic interactionism (Star 1998), refer to Becker's Art Worlds (1984), and frame his analysis of art worlds as an example of infrastructural inversion. They define infrastructural inversion as looking "closely at technologies and arrangements which, by design and by habit, tend to fade into the woodwork" (Bowker and Star 2002, 153). They claim that Becker's project is to make the infrastructure supporting art worlds visible by examining "the conventions and constraints of the material artistic infrastructure, and its ramifications" (ibid., 153). In the following, Bowker and Star's (2002) theory of infrastructure will be used to frame the exposition of Becker's (1984) theory of art worlds. This is taking their claim seriously that Becker does provide an exemplary case of infrastructural inversion. Becker's sociology of art worlds and the concepts he defines, are seen as generalizable and useful when analysing and articulating the infrastructure of media worlds.

Bowker and Star (2002) argue that understanding infrastructure is "key to the design of new media applications in our highly networked, information convergent society" (151). Infrastructures are that which is in between, always a relational concept, meaning that what can be framed as infrastructure is dependent on perspective. Schmidt and Bansler (2016) are critical of the definition of infrastructure as a purely relational concept and claim that this provides a lack of precision or confusion in many CSCW studies when it comes to clearly delin- 
eating between information technology and the practices it supports. They clarify what infrastructure is by using Suchman's concept of computational artifacts and how infrastructure is computational artefacts or assemblies of computational artefacts that exhibit functional unity, being "a technical complement of a given cooperative work practice or family of practices" (ibid., 13) and the "organized practices through which 'infrastructures' [...] are constructed and maintained" (ibid., 14). They clarify infrastructure for the purposes of research in $\mathrm{CSCW}$, with a focus on designing information systems in support of cooperative work. This narrower focus on computational artifacts and the practices of constructing and maintaining them becomes too limiting for the purposes in this thesis however. Conventions supporting media worlds are embodied in computational artefacts, and can be challenged by them, but they are also embodied in non-computational artefacts and all the material arrangements supporting the cooperative activities needed to produce what the media world is known for. It also seems that Bowker and Star (2002), have already accommodated this critique by deliberately delineating between information technology and the practices it supports, taking a design perspective on improving infrastructures with a focus on information technologies and on emphasizing how designing technology is not enough when improving infrastructures, as "technical innovation must be accompanied by an organizational innovation in order to work" (153).

Analysing infrastructures becomes a question of problematizing the relationship between the "foreground" and "background". Becker (1984) does this by focusing on "cooperative activities" and the "conventions" supporting these, where simply put the cooperative activities are understood as structure (foreground) and conventions are the infrastructure for these activities (background). Bowker and Star (2002) have articulated eight salient features of infrastructure (summarized in table 2). After giving an account of how Becker defines and uses his main concepts and how he sees art worlds changing, these salient features of infrastructure will be used to summarize Becker's concepts and frame his analysis of art worlds as an example of infrastructural inversion. 


\begin{tabular}{|c|c|}
\hline Feature & Definition \\
\hline edness & $\begin{array}{l}\text { Infrastructure is sunk into, inside of, other structures, social ar- } \\
\text { rangements and technologies. }\end{array}$ \\
\hline Tran & $\begin{array}{l}\text { Infrastructure is transparent to use, in the sense that it does not } \\
\text { have to be reinvented each time or assembled for each task, but } \\
\text { invisibly supports those tasks. }\end{array}$ \\
\hline Reach or scope & $\begin{array}{l}\text { This may be either spatial or temporal: infrastructure has reach } \\
\text { beyond a single event or one-site of practice. }\end{array}$ \\
\hline $\begin{array}{l}\text { Learned as part of } \\
\text { membership }\end{array}$ & $\begin{array}{l}\text { The taken-for-grantedness of artefacts and organizational ar- } \\
\text { rangements is necessary for membership in a community of prac- } \\
\text { tice. }\end{array}$ \\
\hline $\begin{array}{l}\text { Links with conven- } \\
\text { tions of practice }\end{array}$ & $\begin{array}{l}\text { Infrastructure both shapes and is shaped by the conventions of a } \\
\text { community of practice. }\end{array}$ \\
\hline $\begin{array}{l}\text { Embodiment of stand- } \\
\text { ards }\end{array}$ & $\begin{array}{l}\text { Modified by scope and often by conflicting conventions, infra- } \\
\text { structure takes on transparency by plugging into other infrastruc- } \\
\text { tures and tools in a standardized fashion. }\end{array}$ \\
\hline $\begin{array}{l}\text { Built on an installed } \\
\text { base }\end{array}$ & $\begin{array}{l}\text { Infrastructure does not grow de novo; it wrestles with the inertia } \\
\text { of the installed base and inherits strengths and limitations from } \\
\text { that base. }\end{array}$ \\
\hline $\begin{array}{l}\text { Becomes visible upon } \\
\text { breakdown }\end{array}$ & $\begin{array}{l}\text { The normally invisible quality of working infrastructure becomes } \\
\text { visible when it breaks: the server is down, the bridge washes out, } \\
\text { there is a power blackout. }\end{array}$ \\
\hline
\end{tabular}

Table 2: Bowker and Stars eight salient features of infrastructure

\subsubsection{Cooperative activities}

Art is "the work some people do" (Becker 1984, ix), and an art world is "the network of people whose cooperative activity, organized via their joint knowledge of conventional means of doing things, produces the kind of art works that art world is noted for" (ibid., $\mathrm{x}$ ). He develops a provisional list of cooperative activities that upholds an art world, summarized in table 3. Works of art can be produced without all these activities being performed, a work of art merely becomes a different work of art and these activities can be "performed in a variety of ways with an equal variety of results" (ibid., 5). Becker, being a trained jazz musician, 
stresses that all activities are important for the making of an art work, not only the ones undertaken by the artist, who is often understood as having special talents in the Western tradition (ibid. 14).

\begin{tabular}{|c|c|}
\hline Activity & Explanation \\
\hline Having an idea & What kind of work to make and its specific form. \\
\hline Executing the idea & $\begin{array}{l}\text { The idea needs to be given a physical form, either as an } \\
\text { object or a performance such as a dance. This requires } \\
\text { skills, training and judgement. (ibid., 3) }\end{array}$ \\
\hline $\begin{array}{l}\text { Manufacturing and distri- } \\
\text { bution of materials and } \\
\text { equipment needed. }\end{array}$ & $\begin{array}{l}\text { This can be for example: "musical instruments, paints } \\
\text { and canvas, dancers' shoes and costumes, cameras and } \\
\text { film" (ibid.). }\end{array}$ \\
\hline $\begin{array}{l}\text { Raising money to pay for } \\
\text { time and equipment }\end{array}$ & $\begin{array}{l}\text { This often, but not always, means raising money by dis- } \\
\text { tributing the works of art "to audiences in return for } \\
\text { some form of payment" (ibid.) }\end{array}$ \\
\hline Supporting activities & $\begin{array}{l}\text { This is everything that is needed to execute the art, both } \\
\text { mundane activities such as "sweeping up the stage and } \\
\text { bringing coffee", but also "all sorts of technical activi- } \\
\text { ties - manipulating the machinery people use in execut- } \\
\text { ing the work" (ibid., 4). }\end{array}$ \\
\hline Response and appreciation & $\begin{array}{l}\text { The work needs a response from and audience by creat- } \\
\text { ing an emotional or intellectual reaction to it that they } \\
\text { appreciate (ibid.). This activity must occur for an art } \\
\text { work to exist. }\end{array}$ \\
\hline $\begin{array}{l}\text { Creating and maintaining a } \\
\text { rationale for all the above } \\
\text { activities. }\end{array}$ & $\begin{array}{l}\text { A rationale needs to be maintained, often in the form of } \\
\text { an "aesthetic argument, a philosophical justification } \\
\text { which identifies what is being made as art, as good art, } \\
\text { and explains how art does something that needs to be } \\
\text { done for people and society" (ibid.). }\end{array}$ \\
\hline
\end{tabular}

(continued) 


\begin{tabular}{|l|l|}
\hline Activity & Explanation \\
\hline Training & $\begin{array}{l}\text { People need to know how to do all these things, includ- } \\
\text { ing the audience, and someone must educate and train } \\
\text { them (ibid., 5). }\end{array}$ \\
\hline $\begin{array}{l}\text { Maintaining order and sta- } \\
\text { bility }\end{array}$ & $\begin{array}{l}\text { For all this to happen some stability and order needs to } \\
\text { be in place, often in the hands of the state, through laws, } \\
\text { regulation and support. }\end{array}$ \\
\hline
\end{tabular}

Table 3: Cooperative activities in Art Worlds

Becker's list of cooperative activities in art worlds seems to include not only foreground activities but also activities that address the underlying structure or infrastructure for these activities, such as, for example, creating and maintaining a rationale for the activities and maintaining the order and stability needed. It is certainly the case however, that someone is responsible for each of the activities listed and depending on whose perspective you take, what the foreground is and what the background is varies. For the dancer, the intricacies involved in manufacturing the shoes needed for dancing, is taken for granted and is part of the underlying infrastructure and so is the work undertaken by state bureaucrats to regulate and support the world of dance. The point is, in line with Bowker and Star's argument, infrastructure is a relational concept depending on one's perspective and this perspective therefore needs to be qualified in each case of infrastructural inversion.

\subsubsection{Conventions}

It is possible to see how Bowker and Star's salient properties of infrastructure can be used to understand how cooperative activities in art worlds, as described by Becker, depend on underlying structures or infrastructures, both social and technical. I will come back to this after explaining how Becker uses the concept of conventions to understand these underlying structures or what he defines as follows "earlier agreements now become customary, agreements that have become part of the conventional way of doing things in that art" (ibid., 29). According to Becker, conventions are necessary to regulate the terms of cooperation between the many workers involved in producing an artwork and cover "all the decisions that must be made with respect to works produced" (ibid.). He builds on this simple definition to explicate the importance of conventions for the workings of an art world. Conventions have many 
roles and are embedded differently depending on what kind of cooperative activity one is trying to understand. The roles that conventions have, is important to this thesis. First, how can conventions be materially embodied and therefore constrain what kind of artwork can be made? Second, how do conventions regulate the relationship between artists and audiences?

Conventions regulate artistic decisions concerning; what materials to use, what kinds of abstractions need to be used in conveying an idea or experiences, how materials and abstractions are combined in a form, and the appropriate dimensions of a work such as its length, size and shape. When making these decisions, the artist is constrained by conventions being embodied in "equipment, materials, training, available facilities and sites, systems of notation, and the like" (ibid., 32). Becker uses photography as an example and the conventions embodied in a 35-millimetre camera. Learning to use the camera implies learning the conventions of photography, just as you learn the conventions of music by learning to play an instrument. Becker explains how the coercive nature of the equipment could be a barrier if the artist wants to challenge existing conventions.

Conventions also regulate the "relations between artists and audience, specifying the rights and obligations of both" (ibid.) and help the audience in understanding the work. The shared knowledge of conventions, between the artist and audience is important for securing appreciation for a work of art. This is not an easy set of conventions to follow, however, with the difficulty of knowing "with any assurance what conventions this mass audience appreciates and accepts, what class or professional artistic cultural understandings might inform their choices" (ibid., 123). In book publishing, the film industry and in television artists "make work without knowing who will consume it under what circumstances and with what results" and need to "construct an imaginary audience out of fragments of information they assemble by various means" (ibid., 125). Becker claims that the artist makes artistic choices based on experience with the art world, and that the artist is better equipped than non-artists to "predict the likely response of others correctly and create, more or less, the effect they want" (ibid., 203). The conventions constrain what choices are acceptable or not but they can be challenged by the self-conscious artist, who can also teach the art world to appreciate new standards. 


\subsubsection{Change}

There is one further topic covered in Becker's analysis of art worlds that is of special interest to this thesis and that further explicates the infrastructural properties of art worlds, and that is how art worlds change and how new art worlds come into being. He articulates how art worlds change both gradually and radically by challenging conventions. For changes to survive however, they need to capture "existing cooperative networks or developing new ones" (ibid., 300). These are determined by complex relationships between materials, equipment, skills and conventions. The resources available:

...make some things possible, some easy, and others harder; every pattern of availability reflects the workings of some kind of social organization and becomes part of the pattern of constraints and possibilities that shapes the art produced (ibid., 92).

To capture gradual changes or the "drift" of art worlds, he compares this to how language changes by small imperceptible adaptions in language use. These changes do not require any reorganization of the cooperative activities of an art world. Innovations that change the established body of conventions, however, "inevitably change who can act together to do what" (ibid., 304). He describes these changes as attacks on the standard activities of an existing art world, and if its originators succeed in mobilizing some or all the members of the relevant art world to cooperate in the new activities that their vision of the medium requires, others may lose out. In general, breaking with conventions is, according to Becker, a risky undertaking and the artist wanting to do so, must be "prepared to pay the price in increased effort or decreased circulation of" (ibid., 33) his work.

According to Becker, a new art world can be born "when it brings together people who never cooperated before to produce art based on and using conventions previously unknown or not exploited in that way" (ibid., 310). The invention of a new technology, often in a scientific and commercial context, can also bring about a new art world, such as photography and motion pictures. This bringing about though, is not the result of the invention itself, but of how it is taken up by people:

What people actually do with the innovation depends on what it makes possible, on what version they have of contemporary traditions and interests, and on the people and resources they can attract. Innovations, with their associated possibilities, often spread quickly. It takes longer for the people who experiment with them to find each other and to establish communication (ibid., 314). 
The technology opens possibilities up for creating an art world, but this undertaking depends on the establishment of cooperative networks that can support the making of the new art form, something that is not inevitable.

In table 4, Becker's analysis of art worlds is related to Bowker and Star's (2002) eight salient features of infrastructure. The comparison is in many ways straight forward as pointed out by Bowker and Star themselves.

\begin{tabular}{|c|c|}
\hline $\begin{array}{l}\text { Salient features of in- } \\
\text { frastructure }\end{array}$ & e of art worlds \\
\hline $\mathrm{E}$ & $\begin{array}{l}\text { Becker clearly describes how the successful making of an art } \\
\text { work depends on both social arrangements and technologies, on } \\
\text { earlier agreements that have now become customary. }\end{array}$ \\
\hline Trar & $\begin{array}{l}\text { Most of what makes Becker's art world hum away is not ques- } \\
\text { tioned and is taken for granted by all members of the art world, } \\
\text { including the audience. }\end{array}$ \\
\hline Rea & $\begin{array}{l}\text { An art world extends beyond one site of practice and is not a } \\
\text { single organization, for example a theatre or a museum, but in- } \\
\text { cludes "the network of people whose cooperative activity, orga- } \\
\text { nized via their joint knowledge of conventional means of doing } \\
\text { things, produces the kind of art works that the art world is } \\
\text { noted for" (Becker 1984, x). When it comes to the temporal } \\
\text { scope, art worlds have a duration. It takes some time to estab- } \\
\text { lish them, to mobilize the resources necessary for continuous } \\
\text { production and some time for them to disappear completely. }\end{array}$ \\
\hline $\begin{array}{l}\text { Learned as part of mem- } \\
\text { bership }\end{array}$ & $\begin{array}{l}\text { The members of an art world include everyone that takes part } \\
\text { in the cooperative activities necessary for its workings, includ- } \\
\text { ing the audience. According to Becker, all those involved need } \\
\text { to learn what it takes to perform their role properly. The musi- } \\
\text { cians need to master their instruments, the assistant making } \\
\text { coffee needs to know when it is the right time to bring it and } \\
\text { the audience needs to learn how to appreciate the art form. }\end{array}$ \\
\hline
\end{tabular}

(continued) 


\begin{tabular}{|l|l|}
\hline $\begin{array}{l}\text { Salient features of in- } \\
\text { frastructure }\end{array}$ & The infrastructure of art worlds \\
of practice & $\begin{array}{l}\text { In Beckers analysis, conventions are one of the main concepts. } \\
\text { Conventions play a role in the workings of an art world, both } \\
\text { when doing the cooperative activities needed to accomplish a } \\
\text { work of art, and in terms of what the finished art work should } \\
\text { become. }\end{array}$ \\
\hline ards & $\begin{array}{l}\text { According to Becker, an art world depends on many standards } \\
\text { that are embodied in the equipment and materials used to make } \\
\text { the art work, but also for making it available to the audience. } \\
\text { He underlines how many artistic conventions are the result of } \\
\text { material constraints, embodied in cameras, printing tools or the } \\
\text { size of the doorways in museums and galleries (as noted by } \\
\text { Bowker and Star). }\end{array}$ \\
\hline $\begin{array}{l}\text { Built on an installed } \\
\text { base }\end{array}$ & $\begin{array}{l}\text { The inertia of art worlds is well described in Becker's analysis, } \\
\text { in terms of how difficult it is for a new art world to come into } \\
\text { being, and how change often needs to be incremental within ex- } \\
\text { isting ones. Breaking with the conventions of an art world, in- } \\
\text { curs great risk for the artist. }\end{array}$ \\
\hline $\begin{array}{l}\text { In Becker's analysis, there are numerous examples of break } \\
\text { downs in the interstices between the artist's ideas, established } \\
\text { conventions, materials, equipment and the cooperation needed } \\
\text { to make the art work. In many of these break downs he sees an } \\
\text { opportunity for innovation and change, both incrementally and } \\
\text { radically. }\end{array}$ \\
\hline bingle
\end{tabular}

Table 4: Relating the salient features of infrastructure and conventions

\subsection{Infrastructuring media worlds}

Invention happens all the time in media worlds, and many of these challenge existing conventions both in terms of how things should be done and what should be made. Most often these inventions are incremental and often lead to gradual change, but they can also constitute larger steps, potentially leading to more radical changes. New media worlds can come into being when new people start working together to create media that has not been created 
before or when new media technologies are invented. Most inventions never lead to change, however, if they are not captured by existing or new cooperative networks. The question then is how to infrastructure media worlds to accommodate change?

A good starting point would be to address the cooperative activities needed for an invention to lead to change, put them in the foreground and look at the underlying conditions for this activity to take place. This is in line with Bowker and Star (2002), who define infrastructure as a relational concept and to decide what the infrastructure of something is, requires putting this something in the foreground and trying to understand what this something depends on in the background. When this has been identified, it is possible to engage in improving what is in the background. Seen like this there are many activities that can be understood as answers to the question regarding how to infrastructure or infrastructuring. When infrastructure is defined as a relational concept, then infrastructuring needs to be defined relationally too. To infrastructure is to engage in activities that address and improve the underlying conditions of the activity undertaken, or other activities. This also means that the same activity can be infrastructuring or not, depending on perspective. A good example is playing a board game. If one plays the game according to its rules with no thoughts about whether these rules result in the best possible game, then this is what it is, playing a game. If one plays the game and constantly tries to subvert and adapt the rules while playing however, then this can be seen as a metaphor for infrastructuring, of trying to change the underlying conditions of the game itself.

In table 5, infrastructuring activities that address the underlying conditions for the cooperative activities in a media world are suggested. These activities can be undertaken by the practitioners themselves or other stakeholders invested in supporting processes of reinvention. This inclusive definition of who can undertake infrastructuring is supported by Pipek and Wulf (2009) claiming that infrastructuring at work can be undertaken by workers themselves or "everybody involved in [...] deliberate, creative activity directed toward what they consider a lasting improvement (455-56). However, improving infrastructures is not a simple task, which is something that has been emphasized in the literature on infrastructuring in $\mathrm{CSCW}, \mathrm{PD}$ and IS. Infrastructuring projects are characterized by their ongoingness (Karasti and Baker 2008), the need for continuous facilitation (Löwgren and Reimer 2013b), continuous matchmaking (Björgvinsson, Ehn, and Hillgren 2012), scaffolding (DiSalvo et al. 2014) 
and participation is ensured by openness and flexibility (Löwgren and Reimer 2013b), under-design (Fischer and Giaccardi 2006) and generativity (Monteiro et al. 2012). Karasti (2014) has explored the challenges involved in infrastructuring for communities and sees infrastructuring as "a process of inscribing knowledge and activities in new material forms" (142). She emphasizes how communities have "open, dynamic, and heterogeneous structures for participation" (ibid., 143) and therefore underlines the importance of sharing, trust building, learning and awareness of a common raison d'être when infrastructuring for them. Infrastructuring requires ongoing attention to "the collective interweaving of people, objects, and processes" (ibid.).

A study by Erling Björgvinsson (2014) exemplifies how infrastructuring can be undertaken in media worlds. He helped a small film studio in Sweden undertake a project exploring alternative ways of producing, funding and distributing films. From this he identifies how a frozen discourse or infrastructure was challenged by the project, a discourse upheld by the "SFI [the Swedish Film Institute], regional film centers, theater owners, and film production companies" (ibid., 202), stretching "across state institutions, markets, private artistic ambitions and norms, and technical aspects" (ibid., 203). He claims that when a partially crowdfunded film was released by the project on Pirate Bay, a new temporary infrastructure emerged which depended on the "ability to gather the right resources, the knowledge, skills, networks of people, and technologies at the right time and have them perform well in a loosely connected and distributed manner" (ibid., 198). Björgvinsson emphasizes the deliberate choice of working with a small studio in this, which according to him, rarely has the opportunity to explore alternative futures. The collaboration benefitted the studio but also the researchers, who could explore and try out new mediated practices by undertaking innovation "across academia, the public and private spheres" (ibid., 187). This is an example of infrastructuring in a loosely connected media world through engaging in ongoing project work to undertake inversion and improvements in the organizational, social and technical aspects in place, and thus, to open up for alternative practices and change. 


\begin{tabular}{|c|c|}
\hline Cooperative activity & Infrastructuring \\
\hline Having an idea & $\begin{array}{l}\text { Activities that address and challenge established conven- } \\
\text { tions for what should be made and, based on this, support } \\
\text { the development of unconventional forms. }\end{array}$ \\
\hline Executing the idea & $\begin{array}{l}\text { Activities that address and challenge established conven- } \\
\text { tions for how things are made, and support the develop- } \\
\text { ment of the skills, training and judgment needed for mak- } \\
\text { ing unconventional forms. }\end{array}$ \\
\hline $\begin{array}{l}\text { Manufacturing and distribu- } \\
\text { tion of material and equip- } \\
\text { ment }\end{array}$ & $\begin{array}{l}\text { Activities that make and introduce unconventional materi- } \\
\text { als and equipment to existing practices or that are in sup- } \\
\text { port of the development of new practices. }\end{array}$ \\
\hline $\begin{array}{l}\text { Raising money to pay for } \\
\text { time and equipment }\end{array}$ & $\begin{array}{l}\text { Activities that seek revenues in support of unconventional } \\
\text { forms by addressing and challenging existing models of } \\
\text { distribution and audience appreciation, and that support } \\
\text { the development of new ones. }\end{array}$ \\
\hline Supporting activities & $\begin{array}{l}\text { Activities that mobilize both existing and new activities in } \\
\text { support of making unconventional forms, including sup- } \\
\text { port with manipulating new machinery needed in this. }\end{array}$ \\
\hline Response and appreciation & $\begin{array}{l}\text { Activities that address and develop how unconventional } \\
\text { forms create emotional or intellectual reactions that have } \\
\text { the potential of being appreciated by an audience. }\end{array}$ \\
\hline $\begin{array}{l}\text { Creating and maintaining a } \\
\text { rationale for all the above ac- } \\
\text { tivities }\end{array}$ & $\begin{array}{l}\text { Activities that address and challenge the aesthetic and util- } \\
\text { itarian rationale for conventional practices and explore al- } \\
\text { ternative rationales in support of unconventional practices. }\end{array}$ \\
\hline Training & $\begin{array}{l}\text { Activities that provide training in support of exploring and } \\
\text { appreciating unconventional forms. }\end{array}$ \\
\hline $\begin{array}{l}\text { Maintaining order and stabil- } \\
\text { ity }\end{array}$ & $\begin{array}{l}\text { Activities that address and challenge laws, regulations and } \\
\text { support for conventional practices or that support the de- } \\
\text { velopment of laws, regulations and support for unconven- } \\
\text { tional practices. }\end{array}$ \\
\hline
\end{tabular}

Table 5: Activities to undertake when infrastructuring media worlds 


\section{Methodology}

The overall aim of this chapter is to give a richer description of the methods used in this thesis than can be fitted into the individual articles. The methodological approach taken will be described and discussed, giving an account that is open to critique and methodological concerns, and it does not provide a narrative that suggests, "an orderly, standard model of the research process" (Van Maanen, Sørensen, and Mitchell 2007). To accommodate this, a "thick" decription (Ponterotto 2006) of the methods used and how they have led to the findings summarized in the next chapter are provided. This chapter has three main parts, covering the three methods of inquiry used in this thesis: interviews, observations and research through design.

\subsection{Interviewing practitioners}

The enlightenment encyclopaedists emphasized the importance of giving detailed descriptions of the crafts in the $18^{\text {th }}$ century to support the development of society. This is how Diderot described the project at the time:

We addressed ourselves to the most skilled workers in Paris and the kingdom at large. We took the trouble to visit their workshops, to interrogate them, to write under dictation from them, to follow out their ideas, to define, to identify the terms peculiar to their profession (Sennett 2009, 94 in Furbanks "Diderot" 40).

This empirically-grounded enlightenment project is similar to the approach taken in studies 1 and 2, both in spirit and in terms of the rationale. In the first study, undertaken with Eirik Stavelin, we set out to describe the work undertaken by technologically-skilled journalists working in Norwegian newsrooms. This line of work had not at the time been described well, and had mostly been addressed as hypothetical practices (Flew et al. 2012; Hamilton and Turner 2009). Together we interviewed practitioners and tried to get as close to the participant's view as is possible, to understand their sense-making activities, seeing them as persons-in-context, of being a part of a meaningful world (Larkin, Watts, and Clifton 2006). In the second study, I interviewed independent documentary film producers who had been challenged by the NFI to reinvent documentaries for multiple platforms. At the time, they had little experience at meeting this challenge but worked actively in initiating projects aiming to do so. 
The general recommended procedure for doing qualitative interviews is to: 1) develop an understanding of the purpose and theme of the interviews; 2) design and plan the study and chose a format for the interviews; 3) write an interview guide and conduct the interviews; 4) prepare the analysis by transcribing the interviews; 5) analyse the interviews to answer the research questions; 6) consider and establish the validity, reliability and generalizability of the findings; and 7) report the findings according to scientific criteria (Brinkmann, Tanggaard, and Hanssen 2012; Kvale 2007). We have, to a large degree, undertaken these steps when gathering and analysing the data for studies 1 and 2 . We did not blindly follow the rules, but instead took the steps as an interpretive, hermeneutical process to shed light on emerging practices. In the following, the focus will be on step 6 in the recommended procedure and on a discussion of the strengths and shortcomings in our use of methods when it comes to securing the validity of our findings. Assessing the reliability - whether our findings can be reproduced by other researchers at other times (Kvale 2007, loc. 2555) - comes down to how well the studies have been documented and described. In practice, this means giving a good enough description of the methods used to arrive at the reported findings.

What is important for assessing the validity of the findings reported in studies 1 and 2 is whether our use of methods helped us reach a truthful account of how the informants worked with reinventing journalism within their respective media worlds. According to Kvale (2007, loc. 2555), validity in interview research comes down to considering the quality of the research craftsmanship undertaken when designing, undertaking and reporting an interview study. The overarching question is whether interviewing as a method has contributed to arriving at a credible account of the work described by the informants. For many researchers of practice, observations are preferred over interviews, with the basic explanation for this being that we do not say what we do, that the actual practice is never truly reflected in conversation with a researcher. The language used when answering questions from an outsider fail to capture the contingencies and situatedness of work as it is performed. Most schools of practice theory would provide sound explanations for why this is the case (Nicolini 2012), building on the notion that most of our performances in daily life and work are tacit (Polanyi 2012), involve blind rule following (Wittgenstein 1997) or are taken for granted (Heidegger 1996). While I agree with this objection and its explanation, I still believe that we have been sensitive to these problems and tried to frame the findings of the studies in such a way as to avoid making invalid claims about the work practices studied. 
The main technique has been to frame the studies as analysing and summarizing personal "accounts of practice", not describing how the practices themselves are performed. True, interviews emphasize the rationality, productivity and orderliness of work over its confusing, contingent and messy aspects. This rationality, however, is also an important resource for the practitioners in their daily work and has its own value as an object of study. Using interviews, we have been able to capture how work is rationalized by practitioners across multiple organizations. This said, some of the messiness of the informant's daily work also shone through in the accounts given. In study 1, a journalist described his work flow as going from data, to description, to analysis, to storytelling, to programming and lastly, to publication. Later in the interview, however, it became evident that this was a too orderly description of his work when he gave examples of projects where he started with a method, a story, a dataset, a piece of code, a question from a colleague and so forth. This is an example of how the interviewees described both the orderliness and the messiness in their work without this being expressed as contradictory. Observation of the practitioners in their daily work could have provided vignettes and examples of how they battled with overcoming the resistance of their materials and tools, but some of this is also to be found in their oral accounts. However, these battles are often fought by silent typing away at a computer, something that provides little information in itself if not articulated in a dialogue or interview with a researcher.

In the first phases of study 1, when defining the purpose and theme of the interview study reported in article I, three researchers were involved: Harald Holone, Eirik Stavelin and myself. After the initial phases, Holone left the project and Stavelin and I did the rest of the study together. We had slightly different interests in the study but negotiated a common ground. The purpose of the study has already been described - getting empirical accounts of a practice not previously described in the literature. Further, we defined three themes for the study: First, we wanted to interview practitioners who could share experiences with making technically-advanced journalism in newsrooms. Second, we wanted the interviewees to tell us about technical aspects of their work and how their work related to the production of news in their newsrooms. Third, we wanted the practitioners to give normative articulations of what they thought was good, important, correct and useful in their line of work. Initially, we wanted to accommodate a holistic understanding of the practitioner's accounts and framed the practice as craftwork. The theoretical perspective accommodating this has been developed in the article and more fully in the theory chapter. 
The purpose and theme of study 2 was similar to study 1 . The main difference between the studies was that the practitioners interviewed in study 1 described a practice that was already established in the newsrooms, while most of the practitioners in study 2 had not really got started with making documentaries for multiple platforms or transmedia. This changed the focus in study 2 from how workers described already established practices to how they worked with coming to grips with and securing resources for emerging or future work practices. To accommodate understanding this, I redefined the theoretical framework from the first study to capture the future-oriented nature of the accounts given. With the concept of technê as the starting point, I compared Bill Nichol's $(1991,2001)$ theories of film documentaries with Ian Bogost's (2007) theory of documentary games and how the two theories expressed the material, moving, formal and final causes of both types of documentary. This accommodated an understanding of how far the practitioners had come in their understanding of the challenges involved in making transmedia documentaries compared to making traditional documentary films.

Designing and planning the interview studies consisted of two main activities: making guides for conducting semi-structured interviews and finding, selecting and recruiting informants for the studies. According to Steinar Kvale (2007), an interview guide for a semistructured interview needs to address the what and how of the interview by having questions that elicit the themes you are after and that promote good interview interactions. In both studies, we mainly asked questions to elicit the interviewees' normative understanding of practice and how they rationalized working with emerging forms of journalism. At the same time, we encouraged the informants to give examples, something many of them did, to get more insights into how they worked. When it came to designing questions to develop good dynamics in the interview situation, there were differences between the two studies. The interview guide in study 1 was more carefully worded to accommodate multiple researchers doing the interviews. We took care to make the questions "easy to understand, short and devoid of academic language" (ibid., loc. 1353). Examples are: "What is computer-supported journalism to you?" and "Can you describe the best methods for doing computer-supported journalism?" In study 2, however, as I was the only researcher for the project, I used the more theoretical terms for the themes in the guide, but with several easily understandable questions for each of the themes. When it came to finding, selecting and recruiting the informants, different strategies were chosen in the two studies. In study 1, we needed to find, select and recruit informants based on their expertise in using computers as a medium for 
journalistic purposes. This process has been thoroughly described in the article, leading to interviews with 11 high-profile expert practitioners in Norwegian newsrooms. The independent documentary film producers, however, had little experience with making transmedia documentaries at the time, so a more procedural sampling method was devised, aiming for a group of 14 informants who were representative of the community of Norwegian documentary film producers. This has enabled an understanding of how this group of practitioners relate to transmedia, and has captured both the positive and negative perspectives on the challenge of making transmedia.

All the interviews for study 1 were conducted in the newsrooms where the informants worked, and for study 2, the interviews were done face to face in Oslo and Bergen, and on Skype for the producers located in Tromsø. This type of practitioner, easily described as an "elite informant", produced two methodological challenges in the studies. First, they generally had little time to spare, making recruiting them harder. Second, they were good at promoting their viewpoints. According to Kvale (2007), the last point requires the researchers to have expertise in the interview topic to be able to go beyond the elite informants' "talk tracks" (1569). When it came to the first issue, in study 1, we asked for relatively little time from the informants for conducting the interviews. We knew that the informants were generally busy, and proposed setting aside 1-2 hours, something we believed they could fit into their schedules without the need to secure permission from their editors. This proposition was accepted by all the informants we selected for the study. It is more difficult to assess whether we were able to get beyond the "talk tracks" of the newsroom journalists. We believe we did, as we were two researchers with different areas of expertise, knowledgeable both when it came to technical topics and how journalism is produced in the newsroom. It seemed like the informants acknowledged this and talked openly about their work, also probing how we understood the issues brought up in the interviews. The newsroom journalists accepted us as knowledgeable enough to establish a symmetric power relation in the interview situation. In the second study, almost all the selected informants were recruited, and it seemed like the informants had more time on their hands. The interviews were more openended. When it came to the power asymmetry between the interviewer and interviewee, easily cancelled out when interviewing elite informants, this was more "normal" in this study. In addition to having similar work experiences as the informants, I was more knowledgeable 
when it came to transmedia. In several of the interviews, the informants attempted to interview me about the emerging form, something I was able to relegate to the debriefing afterwards.

How the interviews were analysed is briefly explained in the two articles and this was very similarly performed in the two studies. The interviews were taped, transcribed and imported into "TAMS Analyzer", a tool for computer-assisted qualitative data analysis (Weinstein 2006). When analysing the data from the interviews, we followed Creswell's (2009, 185-90) suggestions for steps to take when coding qualitative data, transcribing, reading, coding, grouping and writing. The mode of analysis undertaken is what Kvale classifies as "focusing on meaning", as when coding for meaning, keywords are attached to segments of the text for later identification (Kvale 2007, loc. 2203). The themes given by the interview guide were the starting point for defining codes and attaching them to text segments. Interesting segments, taking up additional themes, led to definitions of new codes. Thus, the top-down ordering given by the interview guide was negotiated with the bottom-up understanding of what emerged in the analysis. This thematic coding of transcripts required the questioning and requisitioning of the individual codes, how they were related and how they together represented the salient themes articulated in the interviews. The goal of this coding was not to quantify the occurrence of themes in the data, but to order the transcripts according to themes across the interviews. The main analysis that led to the findings reported in the article was undertaken after this ordering of the interview material via thematic codes. We spent a substantial amount of time interpreting and condensing the interview segments for each theme, gradually refining what became the findings' chapter in the article. As we were two researchers doing this analysis together, this supported the validity of the findings reported in the first study. We both coded the data thematically and discussed the choices taken in the last step of including or omitting themes and citations and the wording of the summaries for each of the themes. In study 2, I did the analysis alone, relying on my interpretation of the accounts.

In both studies, there were ethical considerations taken regarding securing both informed consent and the confidentiality of the interviewees. All the interviewees signed a letter of consent after being informed about the purpose of the studies and how the material was going to be used. Being elite informants, most of them said that it did not matter whether they were named in the article or not, but we still secured their confidentiality by anonymising 
their accounts in the articles. In the interview situation, there were two aspects that had ethical implications. First, many of the interviews were undertaken with more than one informant, with the other one keeping the proper distance in the interviews. Interviewing informants together can lead to informants sanitizing their accounts in the presence of a co-worker, not saying what they really mean or keeping quiet. In several of the interviews, one of the informants was senior to the other, maybe giving the junior journalist less space for articulating opinions that could indicate incompetence or be understood by the senior journalist as critical remarks concerning the workplace. Such remarks, if given, can have potentially negative consequences for the junior informant. The argument for doing this, however, was that the dual interviews gave us more information than what we otherwise would have got. We observed several cases of discussions between the interviewees when defining aspects of their work. The informants corrected or followed up on each other's accounts, and we could get a feel for the discussions going on when it came to framing their practice within the newsroom. Keeping a distance was more difficult in study 2 than in study 1 . The media world of independent documentary films is small and transparent, so I needed to take care not to share information that could have negative consequences when posing questions and giving explanations or examples. I solved this mainly by restricting the information given in the interviews to what I believed was generally known to the informants.

\subsection{Observing practitioners}

Colin Robson (2002) classifies observation as a method with two dimensions: the role adopted by the observer and the degree of pre-structure. He posits two ideal types when it comes to the role of the observer: participating fully or being a "pure" observer (ibid., 313). He further dichotomized pre-structure as formal and informal observation, with the latter being an open and flexible approach to what is observed. In studies 4 and 5, observations were relied upon as the main method while taking an open and flexible approach in both studies: in study 4 as a full participant and in study 5 as a marginal participant. The use of observation as a method will be described and discussed for the two studies separately, since they are very different studies when it comes to their scope, both in terms of space and time, and how observation as a method was used. 


\subsubsection{Participant observation}

When reflecting on the methodological approach for study 4, where I participated fully in developing a transmedia documentary project with a small independent film studio, I have considered whether what I did can be classified as action research. The main reason for this is that I actively participated in the project to improve practice, to help the studio in its initial exploration around making transmedia. This aligns well with how Robson (2002) defines the purpose of action research as improving practice, both regarding how practitioners understand their practice and the "situation in which the practice takes place" (215). A second reason is how the active participation in the project resembles the required participation by the researcher when doing action research. I was a full participant in the project and did the work in collaboration with a film producer, a director and one of the students at my faculty. In addition, the director of the project contributed to undertaking the research by being the co-author on a conference paper presented after the project. This points to the third reason for classifying my approach as action research, where collaboration is important and how this has the potential to democratize the research process. Robson (2002) makes the point that practitioners do not necessarily have the expertise needed, but if they undertake the learning of social research in the process, this may also have the potential to contribute to change. These resemblances with action research, however, are not enough for the methodological approach taken to be classified as action research. Action research is often based on cycles of "planning a change; acting and then observing what happens following the change; reflecting on these processes and consequences; and then planning further action" (ibid., 217). Cycles of planning, acting, observing, reflecting and planning were not undertaken systematically in the study and would have been at odds with my role in the project. I participated fully mainly as a practitioner and not as a researcher, and there would have been little to gain from structuring the project heavily according to my research needs. The film studio provided the main rationale for the project, closely tied to how projects are undertaken in the media world of independent documentary films. It would have been difficult to negotiate this rationale with a systematic action research approach. However, this benefitted the study as I got the opportunity to work directly with the opportunities and constraints for making transmedia in this context. The methodological approach, even if resembling action research in many respects, was participant observation, where I needed to participate fully as a practitioner and, at the same time, gather the data I needed for my study. Participant observation is, according to Michael Angrosino (2007), not a research method in itself, but a strategy for 
data collection when doing field studies, where observation can be combined with surveys, archival searches and interviews.

The main strategy to reach a valid account of the transmedia documentary project, lasting for almost two years, was to continuously develop a narrative description and timeline for the project, including insights reached in the process. Informing this developing timeline was the archival data generated during the project: project descriptions, plans, budgets, e-mails, SMS messages, newspaper articles, photos, sketches, versions of the prototype made and more. Several interviews were conducted with the producer and director during the project to validate the narrative account of the project and the preliminary insights that had been reached. Framing this was the observations made when working on the project, but often with little opportunity for making in situ field notes. A more thorough analysis of these materials was conducted at the end of the project, informing the creation of a timeline that was discussed at length with the director and then revised. Before writing up the article for study 4, the preliminary findings were reviewed by reflecting on the events on the timeline and what general insights they supported. To secure the validity of these insights, the director read through a late draft of the article and confirmed the account given. In summary, the data analysis was an ongoing exercise, conducted in several iterations in close collaboration with the director. The understanding of the opportunities and obstacles for making transmedia in the Norwegian context (reported in article three and in this summary) rely on this work of understanding transmedia documentary work through practice.

My role in the project was somewhere between being a participant-as-observer and a complete participant. When being a participant-as-observer, the activities as a researcher are not hidden and are acknowledged by the other participants. A complete participant can at times forget the research agenda, being fully engaged with the ongoing activities, and "go native". Even if my role as a researcher was subordinate to my role as a project worker at times, I did not "go native" and mostly stayed in the role as a participant-as-observer during the project work. I never tried to hide my double role from the practitioners in the project. The premise for the collaboration, from the start, was that I was both a project member and a researcher. We had an open dialogue throughout the project and negotiated explicitly how the activities that were undertaken could benefit both the transmedia project and my research. There were even concerns along the way when our applications were not funded regarding whether I would get what I needed from the project. The closest I came to going native in the process 
was when making and releasing the prototype "My Store" into the wild. For this, I took the main responsibility for establishing a viable model of audience appreciation on the ground, something that required my full attention because of the risk of failure. When this trial failed to do this, however, I needed time and reflection afterwards to regain the analytical distance needed to see this trial in the larger context of my study as signalling the difficulties of making this type of trial relevant and productive in this particular context.

\subsubsection{Direct observation}

The primary method when studying the 2014 Nordic Panorama Hackathon in Malmö was direct observation. I, together with Anders Sundnes Løvlie, observed the whole event from Friday to Monday. The organizer was interested in having researchers present to document the event and maybe get a better understanding of how well it worked. There were several reasons for us getting primary access to the event. First, I had attended the event as a full participant the year before, together with the independent documentary director I worked with on "Our Daily Bread". We joined with another project titled "Overheating" where we investigated making an application for a group of anthropologists wanting to share material and insights with the public when doing fieldwork. Second, in the autumn of 2013, the organizer and I were both hired as speakers at the yearly Norwegian documentary convention to speak about transmedia documentaries. During this 3-day event, we got the chance to discuss our experiences when it came to the opportunities and challenges involved in making transmedia documentaries in Norway at the time. She had worked with the NFI organizing workshops and had mentored film-makers developing independent transmedia documentaries.

When observing the event, we chose an open and flexible and not a pre-structured approach, taking few decisions before the event when it came to theories and topics. Having said that, we took care to discuss what we were looking for beforehand in broad terms to ensure that the material collected by both researchers was compatible for analysis. During the event, we came close to being what Robson (2002) labels as "marginal participants", of being "largely passive, though completely accepted participants" (318). We were flexible when it came to moving from passive observation to taking part in the group discussions. Everyone taking part in the hackathon knew that we had attended the event as researchers. We presented our- 
selves as researchers in the opening event and had everyone sign letters of consent immediately after that. Consequently, even if at some stages in the process we got involved directly in group discussions, we were never viewed as full participants. In the article, we give a detailed narrative account of the event where we have more or less covered the dimensions proposed by Robson (2002) when describing the setting being observed: space, actors, activities, objects, acts, events, time, goals and feelings. In the following, two related aspects of our use of methodology will be considered that were not given room in the article: potential observational biases and the validity of our findings.

Robson (2002) classifies potential observational biases into selective attention, selective encoding, selective memory and interpersonal factors (324-25). As already noted, we chose an open approach, but there was so much going on in the event that some selection needed to take place. Fortunately, two researchers were present and we could cover more ground between us, but most of the activities taking place in the hackathon were not observed. I was partially guided by the overarching research goal of this thesis and chose to observe groups and activities that were most interesting when it came to reaching an understanding of how the media workers got engaged in making activities related to digital tools and platforms. In addition, my focus was journalism and documentaries, so I spent more time with the groups who worked on the documentary projects. Further, I gave most attention to episodes where groups battled with technology or where they negotiated digital-making skills. This indicates a bias of selection, encoding and memory. This bias became most evident when I did small ad hoc interviews with the participants along the way, asking questions that could accommodate these research interests. I was conscious about these biases during the event, however, and discussed this several times with my co-researcher. He covered the other groups more and looked for other angles to understand what was going on. In addition, I tried to broaden my attention as much as possible to keep a wider perspective and we checked in on each other's groups from time to time. As became evident when analysing the material afterwards, I also had some bias when it came to the interpretation of some of the groups' actions, as I viewed episodes as examples of media practitioner deficiencies when approaching both technology and working with software developers, but this bias was corrected in collaboration with the co-researcher. There were some interpersonal factors too that may have played a role in the event. A few of the groups felt that we somewhat intruded on their work, especially when we asked questions about their progress. We know this because this was re- 
ported to the organizer near the end of the event. Other groups seemed to appreciate the attention and more readily engaged us in discussions. A couple of the groups used us to test their solutions along the way and some were happy to share their frustrations and concerns with us. These dynamics could possibly lead us to favouring observing some groups over others. We were also conscious about this potential bias, however, and continued throughout the event to observe all groups, maybe becoming more passive or silent when observing the more reluctant groups.

When it comes to the validity of our findings, of how we made sure that they were a sound interpretation of what went on in the hackathon, there are two aspects of this that will be discussed. The first issue is how we, by doing the analysis and writing the narrative accounts of each of the group processes together, helped each other in securing the validity of our findings. We had some disagreement concerning what our observations really meant. One specific disagreement was with the framing of the hackathon, which provides direction when it comes to understanding the material. I evaluated the hackathon as a digital-making event, in line with how this type of event has been conceived of in software development communities, with the focus on engaging media practitioners with digital tools. This led me to understand the hackathon as less successful with more talking than walking taking place. Further, I adopted the prescriptive agenda of much of the research on design, leading to suggestions of how the hackathon could be improved. My co-researcher framed the event more as a "culture hack" and had a more open approach towards the making taking place, of giving more attention to any kind of creative work undertaken by the participants, digital or not. He has a background in media studies where a descriptive approach is the norm with no need to give recommendations in the end. The negotiation of our two approaches - media studies and design research - was productive in our case, being a practical example of the advantages of transdisciplinary research collaborations. The second issue when it comes to validity is how it was difficult to establish what kinds of professionals the participants really were, how they represented their professions and whether they chose to misrepresent themselves in the event. Even if we had the participants fill out a simple questionnaire asking them to give information about their background, it was difficult to classify them into clear categories such as film-maker, developer, game designer and so forth. Many of them had backgrounds and skillsets that did not necessarily fit the role they played in the hackathon. We recorded many accounts that helped us to understand who the participants were, but generally, a hackathon is somewhat unaccountable to the outside world and gives its participants the freedom to 
take on different roles. Based on this, we have tried to be careful not to frame participants as clear-cut representatives of particular practices.

\subsection{Research through design}

In both media studies and HCI, making as a method of doing research has received increasing attention over the years under the label of "media/medium design" (Liestøl 1999; Nyre 2014) and "research through design" (Koskinen et al. 2011; Zimmerman, Stolterman, and Forlizzi 2010). Two prototypes have been developed as part of the work undertaken in this thesis: a web-application "My Store" as part of the transmedia project work and "Our Daily Bread" and a wearable mobile artefact (Hand Open) for shooting and sharing live videos on the move. In both cases, the prototypes were conceived based on the research interests in this thesis of exploring processes of reinvention in journalism driven by explorations of the capabilities of the computer as the medium. Making was central in both research processes and the methodological approach has been informed by both media/medium design and research through making.

Researchers in media studies have developed an agenda for making when legitimizing a theoretical and methodological position between the mainly humanistic tradition of describing and understanding new media and the design tradition of making new media. The main concern in this line of research has been to establish and defend the legitimacy of making as a methodological strategy in media studies. The argument for this move is clearly made in Gunnar Liestøl's PhD thesis (1999) where he defines and defends what he labels as the synthetic-analytic approach. His thesis is based on several explorative attempts at producing hypermedia to experiment with the potential of what he saw as a new medium, not as lab experiments, but projects that are followed through to publication. To defend this as humanistic media research, he frames the synthetic-analytic method as finding procedures for "channelling the often highly relevant humanistic knowledge and competencies back into production processes" (ibid., 26). To this end, he devises a prescriptive rhetoric, framing rhetoric as a "general method of making" with an application for "different domains of materials and expression" (ibid., 34). This prescriptive rhetorical practice is synthetic-analytic, where the humanistic knowledge of media in general, of knowing the particulars of the expressive capabilities of different media, is used in the creation of new media. As an example of this prac- 
tice he uses the film director Sergei Eisenstein, who did extensive searches for expressive capabilities of other media forms to develop his films and written theories of montage in their support. Liestøl includes design as important to his prescriptive rhetoric and aligns design to rhetoric by tracing the etymological origin of the word "design" to the renaissance and the writings of the design theorist Richard Buchanan (2001).

Anders Fagerjord (2011) explains the synthetic-analytical method:

From the analysis of earlier works, one lifts techniques and devices, usually called conventions in Liestøl's vocabulary, and uses them in new contexts. The results can then be analysed again for evaluation as well as to further theoretical insight into digital composition or communication (ibid., 257-58).

He aligns this to Stuart Moulthrop's "heuretics" to make versions of known genres, with the aim of making invisible aspects of existing media visible for critique (Fagerjord 2012). He emphasizes how design research is normative and aligns his agenda with Hefner's formulation of design science to ensure a rigorous methodological framework for media design as research. He exemplifies this approach in two studies of a mobile application designed to give the user access to pieces of music situated both historically and geographically by visiting churches in Rome (Fagerjord 2011, 2015). When outlining design as a method in the media sciences, he focuses on how this could be based on the humanistic tradition of analysing texts, but also on social sciences-based media research focusing on media practices. He refers to Lars Nyre's normative formulation of this as medium design.

Nyre (2009) devises a critical research agenda of making alternative prototypes of new media, which should then be promoted in public life. He does this to explore the role of media researchers "in relation to this growth in new communicative practices" (ibid., 3). Media researchers should be able to make prototypes based on knowledge constructed in media science in support of developing democratic media practices. Nyre suggests the improvement of technical platforms where "researchers can test various set-ups of the technology, and see how participants react in terms of communicative qualities" (ibid., 11), editorial procedures where the prototypes intervene in "the organization of editorial work among journalists and other media employees" (ibid., 13) and citizen participation where the prototype facilitates increased "public participation by ordinary citizens" (ibid., 14). Outlining this agenda, he admits that the "failure to change the media is a more-than-likely outcome" (ibid.,16). Based on experiments with locative journalism, he reaches the conclusion that "it is very difficult to 
reorient the established journalistic procedures and textual conventions so that they effectively exploit the possibilities of the new medium. It is easier to design a new technology than to establish a new journalistic practice" (Nyre et al. 2012, 312). In a later paper, he formulates the medium design method in six steps (Nyre 2014). First the researcher needs to formulate a program of action for a medium or "the communicative gain the medium might have in the contemporary society" (ibid., 92). The second step is building a prototype medium according to this program of action. Then, as the third step, content for the new sensorial interface should be produced trying out different editorial procedures in this. The fourth step is to evaluate both the prototype and content with test users and return to step two if necessary. After iterating between steps two to four until the evaluation in step four is deemed satisfactory, the researcher can proceed to the fifth step, which is to evaluate the program of action critically and return to step one if necessary. The last step is to initiate an innovation strategy by bringing the new medium to market by setting up a company.

When setting out an agenda for making as research in media studies, these researchers criticize HCI for naively following the cognitive approach inherited from psychology combined with an instrumental approach inherited from engineering, constituting what is often referred to as first-wave HCI, ignoring the sustained focus on both work and everyday practice in the second and third waves of HCI (Bødker 2006, 2015). Fagerjord (2015) claims, for instance, that HCI research black boxes the particulars of individual pieces of information under the general term "content": "UX methods are meant to test the success of a user's access to system data, or 'content', but not to discern between different kinds of 'content', such as images, stories, or music" (108). It is well understood in the design literature, however, that the particulars of the information made and communicated matters a lot when understanding what is often referred to as context (Dourish 2004) and how information technology materially conditions both the content of communicative practices (Gross, Bardzell, and Bardzell 2013) and its social implications (Dourish and Mazmanian 2013).

When outlining HCI's making agendas, Bardzell et al. (2017) describe making as a research activity where maker practices are used "as part of a research method, a process of inquiry aimed at novel contributions to knowledge" (174). They highlight trends in design research that follow this agenda, mainly "research through design" (Zimmerman, Forlizzi, and Evenson 2007) and "constructive design" (Koskinen et al. 2011). Research through design's rationale is to provide "some kind of knowledge contribution, and design practice - design 
methods - are viewed as research methods, and design artefacts are the medium (or at least one medium) of research articulation" (ibid.). Constructive design research is defined by Koskinen et al. (2011) as "research in which construction - be it product, system, space, or media - takes center place and becomes the key means in constructing knowledge" (5). Motivated by Christopher Frayling's (1993) claim that thinking can be embodied in artefacts, the act of construction or making is seen as a form of inquiry in itself, building knowledge that becomes embodied in the object that is made. To make this construction of knowledge matter as research, however, it needs a context that frames the construction or making as a contribution to an academic discourse. Koskinen et al. (2011) have identified how the research cultures of natural science, social science and art give context to constructive design research: the lab, the field and the showroom, accordingly. These three contexts are different and require different research designs. Controlled experiments, fields studies and artistic explorations rely on very different epistemological assumptions informing how the construction of knowledge is undertaken. These contexts frame the role of making in this differently. In artistic research, the artefact itself can be presented as a contribution to knowledge in its own right (Arrigoni 2016). In the two other research cultures, the artefact becomes a vehicle for theory development or for addressing real-world problems (Zimmerman, Forlizzi, and Evenson 2007). A variety of motives bridge the making of an artefact and research (Bang et al. 2012), something implied by framing this as research through design and not as research for design.

The prototypes made in this thesis exemplify how in research through design, the making of the artefact and the artefact itself become vehicles rather than the focus of the research. The making of the first prototype "My Store" became a vehicle for understanding the conditions for making transmedia in the media world of independent documentary film in Norway. Making and deploying the prototype in the field had a central role in facilitating the observation of particular media-production practices. The making of the second prototype for shooting and sharing videos on the move became a vehicle for exploring how real people in real situations negotiated their privacy boundaries, with the premise that they

...may simply not know or be aware of how they really feel or what they really need until they find themselves in a real situation in which they experience and reflect on those feelings or in which those needs arise (Mancini et al. 2009, 1).

Both explorations relied on taking technical prototypes into the field and using participant observation to understand social aspects of their use. Even if the two field studies have 
many similarities, being examples of research through design, by using established methods from the social sciences, they have been framed very differently in the articles. The first one, "My Store", has been framed as a contribution to media studies, providing an understanding of changing media practices, and the second, "Hand Open", to HCI, providing an understanding of how privacy concerns are negotiated by people using new interfaces for shooting and sharing live videos on social media. Both studies can be reframed as contributions to the other field, however.

The making of the prototype "Hand Open" can be reframed, as has been done in this summary, as being the initial stages in inventing new technologies for journalism practice, or what in media studies has been framed as medium design (Nyre 2014). The making can also be seen as a technology-oriented process of inventing new media, of challenging existing conventions for social media-sharing practices by providing opportunities for new practices. I observed this process in a systematic way by participating in making a prototype together with co-researchers, with the need to articulate and document this as an ongoing collaborative research project. It is common for researchers to work with developing technologies that can have uses in multiple domains, but it is important to note that I was open about my double agenda when collaborating with the two co-researchers. They both knew that I was motivated by the possibility of evaluating the prototype in the context of journalistic work after our joint study. Using the framework developed in the discourse of media/medium design, I could have developed a contribution to media studies by focusing on this process of invention and its rationale according to the agenda set out by Liestøl (1999). What is missing, however, to make this a strong contribution to media studies in the context of this thesis, is a field study that evaluates the prototype for journalistic purposes, something that would be required according to Nyre's (2014) formulation of the medium design method.

The making of the prototype "My Store" can be reframed as a contribution to HCI, as an attempt to make collaborative media from a design perspective (Löwgren and Reimer 2013b). The field trial re-established the problems involved in bootstrapping audiences for collaborative media but did not contribute much, however, to the current understanding of how to overcome this problem from a design perspective. What is missing in this study is documentation of additional attempts to mobilize a collaborative audience, where I could have reached a deeper understanding and have given recommendations on the where, what, when, who and of how such mobilization processes can be planned and executed. This would have 
required substantial resources in addition to making and deploying the prototype as we did. As already discussed in the chapter on participant observation, however, I did not take a design perspective when making and deploying the prototype "My Store", being preoccupied with being a participant-as-observer in the project and not of becoming a pure participant by "going native".

This articulation of how the field studies could have been reframed as a contribution to the other academic field have few basic methodological implications for the studies themselves. It exemplifies the flexibility and openness of research through design as an overarching framework for doing research, but also indicates the challenges involved in designing research where construction and making is "the key means in constructing knowledge" (Koskinen et al. 2011, 5). As already noted, for making to become research it needs a context, and this research context will often challenge the role of the making itself, relegating this activity to a means to an end rather than an end in itself. Tellingly, the focus in both prototype deployments in this thesis was to support not-yet-existing practices, centred on using mobile media technology to record and share media online. In both cases people were recruited and given the opportunity to use the prototype as intended by the researchers. In "My Store", we went one step further and released the prototype to a local community, resulting in no additional use. Both user trials have much in common with what Crabtree frames as "breaching experiments", where technologies are deployed in real-world settings in support of not-yet-existing practices and where the goal is to understand what these may become (Crabtree 2004). With the goal of developing a position that "intends to open up the design space and propel innovation by exploring the social through technological development" (ibid., 207), he suggests the following model where breaching experiments play a role:

1. Let designers build whatever they want with whomever they want, subject to their own constraints.

2. Deploy the objects of design in real-world settings.

3. Treat deployment as a breaching experiment.

4. Explicate the accountable structures of practical action made visible in the breach.

5. Explore the topics identified in the breach through the study of perspicuous settings.

6. Use the studies of perspicuous settings to flesh out abstract design concepts.

7. Deploy the new design solution in real-world settings and study its use.

In both the field trials that were undertaken, we clearly did steps 1-5 but did not feed the results from this into further development of the prototypes. Points 4-5 were more explicitly 
addressed in "Hand Open" where use was studied more systematically than in "My Store", where users were mobilized to provide seed materials, but where the targeted users (the local community) did not materialize. Crabtree's rationale for developing this position is to establish "how design might adopt the analytic mentality of ethnomethodology [...] by moving the deployment of novel technologies out of the research lab and into in real-world settings where their accountable use might be studied" (ibid.).

In an attempt to frame the challenges and opportunities involved in deploying technology in a real-world setting or in the wild, Brown et al. (2011) review Crabtree's framing of this as "breaching experiments" and criticize him as being too focused on "disrupting" existing practices rather than supporting them. This is a misreading, however, as Crabtree makes the point that " "bewilderment, consternation, and confusion ... anxiety, shame, guilt, and indignation' are not an essential feature of the breaching experiments" (Crabtree 2004, 203). The advice given by Brown et al. (2011) on how to strengthen field trials in the wild's contribution to $\mathrm{HCI}$ is to give explicit explanations of the relationship between the stakeholders taking part, including the researchers themselves, when reporting on the study: how investigators participate, how participants investigate and how the informal details of the trial influence the results of the study. They do not mention participant observation as a methodological framework for this, but the descriptions asked for would be natural to include within such a framework to make the reporting of a field trial accountable to the emerging practices supported by the deployment of the prototype. I have already described and discussed participant observation as a research strategy in the last chapter, including some concerns with the deployment of "My Store" in the context of a real-world transmedia documentary project. In the following, I will focus on describing issues with the deployment of the "Hand Open" prototype.

In the methods chapter, in the article we adhered to the genre common in the HCI literature with an objective account of our use of methods, placing ourselves mostly as researchers "outside" the study. This is not a problem in itself and I believe we have given a truthful account of what took place in the trial, how the prototype initiated new practices and what these practices were. What is problematic, however, is that the description became too "thin" and that particularities of the trials (maybe influencing the results) are hidden in the account. There are three aspects I will bring forward here: how we participated as researchers in the trials and how this can or cannot be seen as an "in the wild" study, how the observations and 
interviews together contributed to our results and how the trials can be seen as breaching experiments by documenting accountable but not-yet-existing practice.

When it comes to our participation as researchers in the trials, the main contribution before the trials was the making of the artefact itself, making sure that we gave the informants something that was robust, easy and fun to use. We thoroughly planned the trials beforehand and they were mostly conducted accordingly. First, we fitted the wearable prototype to the participants and explained to them how they should use it. At the same time, we informed them about the destination for the captured videos: a Facebook page. When the participants ran and used the prototype, we did not interact with them, but when they crossed the finish line, we immediately helped them remove the prototype before doing the post-interviews. The post-interviews were semi-structured following a prepared interview guide. The running and using part of the trial can be characterized as being "in the wild", but considering the trial in total, it can be viewed as a lab experiment conducted outdoors. The degree of preplanning and facilitation, however, was beneficial considering the research focus and the state of the early prototype.

Participant observation is a research strategy to facilitate collecting empirical data, and in the trials, we relied on observations, video recordings and interviews. We got relatively little usable data from observing the events. After the races started, we were bound to the finish area, with the informants scattered along the running track. The only information we have from this part of the study is the videos shared by the informants. We could have used small wearable video cameras to film how they used the devices but chose not to do this. This introduced an observational bias in our study of "selective attention" (Robson 2002). Most of our findings came from the post-interviews that were planned and conducted as described earlier for studies 1 and 2. The interviews were shorter and more focused, however, providing material that required less time for analysis. To secure the validity of the findings, making sure that they were a sound interpretation of what went on in the events, the first and second authors both coded the entire material, then compared the two sets of codes before agreeing on the findings.

The trials can be framed as breaching experiments as defined above. None of the participants had posted live videos to social media using hand gestures before. They were invited to perform a not-yet-existing practice facilitated by the prototype. The prototype worked well 
enough and was simple to use, so they were able to concentrate on what, when and why to share videos during the event. In the interviews, we focused on these choices and especially their concerns with and motivation for sharing. The findings will not be repeated here, but the prototype and trial gave very pernicious articulations of both privacy concerns and conditions for sharing live videos on social media in the interviews. The informants were engaged and forward-leaning when talking about their experience. One very salient aspect of their answers concerned how they framed the new practice in relation to their existing practice of using social media. The prototype had facilitated disrupting these existing practices, both positively and negatively, but future use was quickly and explicitly aligned with them. The proposed practice seemed to be highly relevant to the informants, addressing something they relate to, think about and do on a regular basis. In summary, the methodological choices that informed the making of the prototype, the design of the trials and their execution led to an accountable description of a not-yet-established practice. The study explicitly addressed issues with sharing live videos on social media when participating in a running event, something that the informants understood well and found relevant for their everyday lives and media-sharing practices. 


\section{Findings}

\subsection{First research question (RQ1)}

What are the salient conditions for successfully mobilizing cooperative networks for reinventing journalism using the computer as the medium?

To identify the salient conditions for successfully mobilizing cooperative networks for reinventing journalism using the computer as the medium, the two media worlds studied in this thesis, newsroom journalism and independent documentary film production, have been compared. The two cases inform the answering of the question by being examples of successful and unsuccessful processes of reinvention in media worlds. In the first case, Norwegian newsrooms, the necessary cooperative networks had been mobilized to uphold the cooperative activities necessary to produce computational, interactive and collaborative forms of news. In the second case, Norwegian independent documentary film producers challenged by the NFI to make transmedia had made attempts to mobilize cooperative networks for this, but without success. Based on a comparison of the two media worlds using the findings from studies 1 and 2, and according to the theoretical position developed in this thesis, I will highlight three salient conditions explaining why cooperative networks have been successfully mobilized in the media world of newsrooms and not in the media world of independent documentary films, articulating differences in the rationale for what is made, the relative importance of target platforms and economic incentives for reinvention.

\subsubsection{The rationale for reinventing journalism}

The first observation is that while the informants in newsrooms reinvented the type of journalism that was traditionally held in the highest regard in the newsroom (investigative journalism), the informants in the small independent documentary film studios were challenged to reinvent a type of documentary held in the lowest regard traditionally (the participatory documentary).

The informants in the study of computational journalism subscribed to the tradition of investigative reporting explicitly, and many of the projects they had made have won awards at the yearly event held by the Norwegian Association for Investigative Reporting ("SKUP: Stiftel- 
sen for En Kritisk Og Undersøkende Presse” 2012). The forerunner of computational journalism, computer-assisted reporting (CAR), used data, computers and quantitative methods from the social sciences in investigative projects, what Meyer (2002) has labelled as scientific journalism. Based on this, it is not controversial to claim that computational journalism has inherited a strong rationale for its existence, supporting the successful mobilization of resources in the newsroom for this line of work.

Transmedia documentaries can also be construed as a continuation of the longer tradition of participatory documentaries which became feasible with the Portapak video camcorder in the 1970s (Tripp 2012). The informants in the study acknowledged how transmedia documentaries could support the ethos of participation, but they had little experience of using participatory methods in their film-making. As discussed in article 3, participative methods for making documentaries have always been a marginal undertaking outside the mainstream of documentary film production, supported by funders, festivals, theatres and broadcasters. Based on this, it is possible to claim that the transmedia documentary has inherited a weak rationale, connected with a film-production practice that is given lip service, but which is not regarded as a viable production model for professional documentary film-makers.

\subsubsection{The relative importance of target platforms}

The second observation is that while the informants in newsrooms reinvented journalism for the newsrooms' main platform (online), the informants in the small independent film studios were challenged to reinvent documentary films for a subsidiary platform (online).

The longer trend for news outlets is the transition from print and broadcast to online distribution. Online newspapers, to a large degree accessed on mobiles and tablets, have gradually overtaken print and broadcast as the main platforms for distributing news. The trend is stronger when it comes to print, but it is also true for television. The findings from the interviews with journalists in newsrooms showed that they mastered the online platform and had the skills to push its limits. Consequently, they have become the avant-garde of online journalism, exploring what kinds of news stories are possible to make online. It is possible to see how they have explicitly been tasked to reinvent journalism for what is becoming the main platform for news and have been given the necessary resources for doing so. 
Cinema theatres, television and festivals are continuing to be stable platforms for distributing documentary films. Documentary films have traditionally drawn small and dedicated audiences to cinema theatres, and the small decline in cinema going has not changed this. Television has been how documentary film has reached larger audiences, and while there has been a slow decline in viewership, documentary films still attract audiences in comparable numbers to before. Film festivals are stable arenas for screening documentary films, attracting mostly insiders and connoisseurs. These are the main platforms for documentary films that are accommodated by the NFI's mandate for giving funds, and the ones that the independent documentary film producers worried about in the interviews. To them, the online platform was a subsidiary platform for screening regular documentary films (already distributed on one of the main platforms) and "online only" seemed to be problematic. When talking about transmedia documentaries, most of them saw this as an addition to a full-length documentary made for the main platforms. Based on this, it is possible to see how the informants in study 2 have been challenged to reinvent documentaries for a platform that in this context has yet to become important.

\subsubsection{Economic incentives for reinvention}

The third observation is that while the informants in newsrooms reinvented journalism as an answer to failing revenues for news organizations, the informants in the small independent documentary film studios were challenged to reinvent documentaries with revenues that come in addition to or instead of existing and stable funding schemes.

The last 10 years have seen a crisis in journalism with falling readership, failing advertising revenues and consequently, staff reductions. News organizations have acknowledged the need to find a new sustainable business model, but the jury is still out on this. Much of the advertising revenue has moved online and has been taken over by technology giants such as Facebook and Google, but also the liminal press and web-native news providers. The competition for attention or eye-balls has become fiercer and the battle is going on mostly online and across borders. The informants in study 1 continuously explored the many interfaces between their platforms and the wider ecology of news platforms and applications and applied their skills to reinvent many aspects of their online platform, indirectly addressing their organization's search for a sustainable business model. 
The sources for funding independent documentary films have been stable with the continued commissioning of films by the NFI and NRK. Potential revenue from making transmedia documentaries is therefore not needed in the current situation and would be earned in addition to the funds received from the government funders. Based on this, it is possible to see how there is no pressing need for reinventing documentaries, at least not by the informants in study 2 , who were established and successful documentary film producers. As the findings from my interviews suggest, the short flurry of experimentation documented in this thesis from 2012-2013 was triggered by what was considered a policy change by the NFI. When the producers understood that this was not really the case, however, they went back to business as usual. When taking the perspective of the established producers, they have little incentive for making themselves more independent of government funding with the risk of these funds being reduced or spread more thinly. A related aspect conveyed in the interviews is how funds for transmedia documentaries have so far been taken from funds meant for film production, something several of the informants saw as completely wrong.

\subsection{Second research question (RQ2)}

How can cooperative activities be initiated in support of the reinvention of journalism using the computer as the medium?

Three studies have been undertaken in this thesis that can be framed as the initiation of cooperative activities aiming to support the reinvention of journalism using the computer as the medium. The studies explore different entry points to reinvention and address different cooperative activities. In study 3 , the entry point was developing a tool for shooting and sharing videos on social media while running. In study 5 , the entry point was a hackathon with media practitioners where they were challenged to reinvent media over a short weekend. In study 4, I participated in a project with the explicit aim of reinventing independent documentary films and got first-hand experience with the many obstacles for processes of reinvention in an established media world. In the following, the infrastructuring activities initiated in each of the studies will be identified, and how they were the first steps in longer processes of the reinvention of journalism using the computer as the medium. 


\subsubsection{Reinvention by designing new equipment for journalists}

In study 3, we undertook several of the infrastructuring activities suggested in table 5 to initiate change in media worlds by inventing a wearable interface for shooting videos in situations where it is inconvenient to stop and hold up a phone with both hands.

- Having an idea: Established conventions for what should be made were challenged by inventing an interface where journalists, both professionals and citizens, alone or as part of crowdsourcing initiatives, can record and share videos on the move by just opening and closing their hand.

- Executing the idea/manufacturing and distribution of material and equipment: Established conventions for how things are made were challenged by designing an unconventional tool for journalists in the field, opening up the development of new journalistic forms. The experience and skills needed to make a prototype of a wearable hand-gesture interface relied on the ability to coax an array of technologies, platforms, standards, materials and tools into a viable form.

- Supporting activities: New activities were mobilized in support of journalists by making a new interface for shooting and sharing videos on the move, relying on the knowledge and skills of a team of technology designers.

- Response and appreciation: How the audience responded to being part of a crowdsourcing project, exploring each individual's motivation for sharing live streams to friends and how that transferred to a willingness to share these streams with the public were investigated. They were happy to shoot and share videos with selected friends on social media but several of the participants were reluctant to share with an undefined public. In the context of crowdsourced and participatory videos, this reluctance to share indicates that the successful recruitment of a large number of citizen journalists via crowdsourcing requires extensive facilitation.

The invention of a new interface for shooting and sharing videos on the move opens new potential possibilities up for journalism practitioners, but without knowing how these possibilities will be realized in practice. This can be framed as the starting point for a longer sociotechnical process of infrastructuring, of making the tool available and accommodating for it being adapted and used in specific journalistic practices. 


\subsubsection{Reinvention by hacking film concepts}

In study 5, several of the infrastructuring activities suggested in table 5 to initiate change in media worlds were undertaken by the participants in the Nordic Panorama hackathon. The observation of media practitioners making concepts, sketches and prototypes together over a long weekend revealed how they were able to invent new media in this context.

- Having an idea: The groups were challenged to invent new media on the basis of old media and they engaged in exploring computational, interactive and collaborative forms together. Many of the groups got stuck in longer discussions to establish authorship when working out their ideas.

- Executing the idea: The groups worked on making prototypes, and through this, explored new skills and cooperative activities needed to materialize unconventional ideas using the computer as the medium. Most of the groups fought with overcoming the resistance of digital materials and ended up working out non-digital concepts.

- Manufacturing and distribution of material and equipment: The groups were introduced to unconventional materials and equipment, both when it came to those offered by the computer and physical materials present in the well-stocked makerspace. Most of the groups were not able to mobilize the materials and tools needed to make what they initially envisioned.

- Raising money to pay for time and equipment: The groups worked with challenging existing models of distribution and audience appreciation by making unconventional media. The participants were very conscious about how what was made would be appreciated by their peers, potential funders and the audience and were effective in working out how the reinvented concept could be pitched, hiding uncertainties, open questions, dilemmas and incongruences.

- Supporting activities: Practitioners with the skills necessary to explore the capabilities of the computer as the medium had been recruited to the event and most groups had at least one such member to help them in making digital prototypes. When overcoming the material abrasion of digital form-giving, however, several of the groups immediately tried to mobilize skills from outside the group. The digital form-givers in most of the groups did not have the specific skills needed for realizing the concept in making.

- Response and appreciation: The groups were explicitly tasked by the organizer to test out their prototypes several times during the weekend. When working out a viable model 
of response and appreciation for what they were making, however, they used a lot of time to negotiate and agree on this, constantly shooting down each other's ideas with reference to the probability that the idea would not be appreciated by the audience.

- Creating and maintaining a rationale for all the above activities: The groups worked with exploring alternative rationales in support of unconventional practices they were introduced to in the hackathon. When working out a rationale for reinventing the hacked film concepts, the groups sought rationales connected to the new position of the viewer/user, of facilitating engagement, interaction, participation and democracy.

- Training: Many of the participants had little prior experience in exploring the computer as the medium and little training was provided by the organizer. The training was undertaken in the hackathon itself. When overcoming the material abrasion of digital materials, the groups lacked the necessary skills to manifest their ideas in a digital prototype (see "Executing the idea").

- Maintaining order and stability: The hackathon itself was part of the Nordic Panorama film festival, financed by the Nordic governments and the goals of the hackathon are in line with policies to support innovation in the Nordic film sector. It is an example of an attempt to create an open space for innovation and the forging of new cooperative networks with the hope that this will lead to the reinvention of existing practices.

This led to findings concerning how well the hackathon worked as the first steps taken in longer processes of reinvention in the media world of independent film-making. The observations of the event indicate that the participating media practitioners would have needed more training, tools and support to be able to fulfil the rationale for the hackathon given by the Nordic Panorama film festival to initiate processes of reinvention by introducing media practitioners to digital form-giving with the computer as the medium. The event initiated potential for change, however, first and foremost by bringing people together with different backgrounds, experiences and skills. A Facebook group was set up for the event, and after the event, this has been used by the participants to update each other from time to time, mostly in relation to the further development of the projects that were hacked. This forging of new cooperation in the media world of independent film-making in the Nordic countries was maybe the most promising outcome of the event. 


\subsubsection{Reinvention by developing a transmedia project}

In study 4, several of the infrastructuring activities suggested in table 5 were undertaken to initiate change in the media world of independent documentary films by developing a transmedia project based on a television documentary produced for the NRK with funding from both the NRK and NFI.

- Having an idea/training: The ideas developed in the initial phases of the project challenged existing conventions for what should be made in the media world of independent documentary film production. The director, the producer and me worked together to come up with ideas for expanding the documentary film project "Our Daily Bread" via multiple media on multiple platforms. This work relied on my knowledge of existing transmedia projects and most discussions were initiated due to ideas proposed by me.

- Raising money to pay for time and equipment: Most of the work undertaken in the project involved working out high-level concepts and applications for funding based on them. When unsuccessful, we made a lightweight prototype (My Store) funded by a small grant from the NFI and by my academic institution to establish a viable model of audience appreciation on the ground, with the rationale that this could increase our chances of raising money for the full project.

- Executing the idea/training: The main challenge to established conventions for how things are made in this world was in developing a new project model underlying the applications for funding. The director, the producer and me worked out a budget with new activities, a plan for producing the different media and a plan for the who, what, when and why of launching the different media to the audience. This work relied on my tentative knowledge of transmedia project design and on my suggestions for how to plan the project. The making and field testing of the prototype (My Store), an unconventional activity in this media world, were undertaken by me, in collaboration with a student at my faculty, with some contributions from the director.

- Supporting activities: The project relied on my contributions when it came to having ideas, describing them and designing the transmedia project. In addition, I was relied upon to mobilize the necessary supporting activities when needed such as the student who was engaged in developing the prototype. Unlike how the informants in study 1 described their access to people skilled in digital making, who were willing to work for 
next to nothing, the project had easy access to support personnel, with a good understanding of the media world of independent documentary film production.

- Response and appreciation: A trustworthy model of audience appreciation needed to be established and argued for in the project to secure major funding through the field testing of the prototype. The failure to get members of the audience to use the prototype after the initial premiere of the film in the local community portrayed in the film became the proof that the model of appreciation underpinning the idea and embodied in the prototype did not work.

- Creating and maintaining a rationale for all the above activities: The project challenged the rationale in place in the media world of independent documentary film production, tied to producing and distributing documentary films. There were multiple rationales for extending the documentary film into a full transmedia project: my rationale as a researcher exploring transmedia production, the director's rationale of exploring new ways to tell stories, the producer's rationale of being seen as innovative and forwardlooking and the NFI's rationale of supporting what they considered an important international trend. These multiple rationales could have been negotiated in a full transmedia project and thus could have mounted a challenge to the existing rationale of this media world.

- Maintaining order and stability: The NFI and NRK, the main external stakeholders in the project, have mandates from the government decided on by parliamentary politicians. What we attempted to do has not yet been mandated and the potential resources set aside to support transmedia rely on the willingness of bureaucrats to reprioritize funds for new purposes. In practice, this meant that to get funds, the transmedia project needed to be defined as being within the mandate, with the minimum requirement of relying on strong audio-visual storytelling (like a documentary film).

This led to findings concerning how well the project worked as the first steps taken in longer processes of reinvention in the media world of independent film-making. The people involved in the project either as project members or the stakeholders at the NFI and NRK were challenged to understand the how, what and why of transmedia documentary production. In the project, we had to invent a new structure for the project description, include new activities in the budget, come up with a plan for launching multiple media across several channels, develop a convincing model for audience appreciation and so forth. All these inventions, made and included in the project description, were read, discussed and evaluated by all 
stakeholders in the project. The point is that much articulation work was undertaken in the project, seen as the first steps towards changing established practices. The attempts at securing funding for this project failed, but there is a chance that the project will open doors for future projects by articulating the particularities of a transmedia documentary project that is radically different from a documentary film project. Regarding the project itself, the rare collaboration between the director, the producer and me facilitated mutual learning both when it came to the difficulties involved in securing the needed resources for expanding a documentary film project into a transmedia documentary project and when it came to exploring the capabilities of the computer as the medium for documentary purposes.

The overall finding from the three interventions undertaken or observed in this thesis is that to initiate processes of invention is relatively easy, but to turn these inventions into reinventions within existing media worlds is exceedingly hard. This would require longer ongoing processes addressing a plethora of technical and social aspects of these worlds, of addressing the infrastructure of these worlds through infrastructuring. In the second part of the discussion, I will address this, with a focus on how infrastructuring interventions in media worlds are accountable to practice, and how this matters in terms of the likelihood that these interventions will lead to change. 


\section{Discussion}

The discussion is in three parts, where the first two sections (5.1 and 5.2) discuss the findings from research question one, each part informed by one of the two cases of media worlds studied in this thesis. The third part (section 5.3) addresses the findings from research question two, mainly informed by the studies undertaken to investigate initial attempts at reinvention in media worlds.

RQ1: What are the salient conditions for successfully mobilizing cooperative networks for reinventing journalism using the computer as the medium?

RQ2: How can cooperative activities be initiated in support of the reinvention of journalism using the computer as the medium?

\subsection{Processes of invention and change in the newsroom}

The informants interviewed in study 1 had challenged the technical and social infrastructure of the newsroom by inventing new media, relying on skills in making computational, interactive and collaborative forms and were able to sustain the continuous making of new forms of journalism on a daily basis. This case is an example of a successful process of reinvention within an existing media world. I will use the findings from the study to discuss how this emerging practice can be characterized and to what degree this practice should be supported by a specialized information system. Then, I will discuss to what degree they have subordinated their technical work to the rationale given by journalism when becoming a member of the newsroom.

\subsubsection{How can the practice be characterized?}

In the introduction, I reviewed Stavelin's (2014) operationalization of computational journalism, characterized in relation to precision journalism, computer-assisted reporting (CAR), database journalism, data journalism and data-driven journalism. He sees how these practices, as described in the literature, have different foci: precision journalism focuses on using quantitative methods from the social sciences, CAR focuses on digital tool use, database journalism focuses on information storage and retrieval, data journalism and data-driven journalism focus on finding stories in datasets and computational journalism focuses on tool 
creation and making computable models by computational thinking (ibid.). Here, I will discuss this taxonomy of journalistic practices that depends on more advanced computer skills than those expected from regular journalists by using the findings from study 1 and the model of digital form-giving developed in the theory chapter. From this, I will suggest a new definition of the practice that has been accounted for.

To be able to do this, I will first outline the kinds of form-giving the practitioners who were interviewed in the study described. Was their main focus computation, interactivity and/or collaboration?

- Computation: Most of the practitioners emphasized programming as an important part of their work, not to make computable models via computational thinking but to make a variety of digital and online media by writing the code necessary to make it work. This meant that they mostly made lightweight JavaScripts using the libraries and frameworks available for the task at hand. They were pragmatic when it came to tool use and many of them had explored the available toolkits to speed up processes of cleaning, structuring and presenting data.

- Interactivity: Being responsible for the media being made, also after it was published to the web, the practitioners also emphasized the importance of making it work for the readers. They did not delegate this down-stream but took responsibility for working out interactive forms online that would likely be appreciated by the audience. At the time, they had not adapted systematic design methods in their work, but often used colleagues and random users from the street to evaluate the interactive properties of the media in development.

- Collaboration: Most of the media made by the practitioners had a single-user focus, with few openings for contributions by the audience, but the practitioners also spoke about making media that depended on contributions from the audience. They were mostly interested in crowdsourcing, both in terms of getting help from the audience to handle data, but also to source photos, videos and comments from them.

It is clear that the practitioners interviewed in study 1 applied the full range of digital formgiving skills in their work to make computational, interactive and collaborative forms of journalism. 
From this, I will argue that Stavelin's definition of computational journalism is too narrow to capture the variety of skills applied and the forms made in the work accounted for in study 1. If one includes the foci and skills of the other types of technically-advanced journalistic practices (precision journalism, CAR, database journalism, data journalism and data-driven journalism), then more of the accounts given by the informants in study 1 are captured by including both tool building and tool use, working with databases, creating descriptive statistics and finding and conveying stories in datasets. This indicates the need to move to the more general definition as journalistic practices depending more on advanced computer skills than those skills expected from regular journalists, giving room for the open, explorative, opportunistic, contingent and skill-based form-giving work undertaken by the informants.

What then could inform a good labelling of this practice? Its use of abstract materials such as abstractions, processes, interfaces, interactions or infrastructure? Its use of techniques and tools for advanced form-giving: programming, computational thinking, tool use, design, design thinking, facilitation or infrastructuring? The main forms of journalism that were undertaken: computational, interactive and/or collaborative? The main purposes behind the given form: processes, interactions or collaboration in support of democratic values? One possible label is the general term "digital journalism", which is now the name of a specific journal covering research on these practices. This is too wide however, as it fails to capture the distinction between mere digital tool use by regular journalists and the technically-advanced practices accounted for in the study.

In line with the argument so far, I propose to use the forms and purposes worked with by the practitioners, expanding computational journalism to computational, interactive and collaborative journalism.

\subsubsection{Do they need a specialized information system?}

As outlined in the chapter on previous work, technology design researchers have mostly investigated how regular journalists can be supported by information technology in their work. When it comes to designing technologies in support of computational, interactive and collaborative journalism, it is possible to delineate two approaches. The first is to provide better 
tools for journalists exploring the capabilities of online platforms in their newswork (Diakopoulos, Eldridge, and Franklin 2016). The second is to design systems facilitating collaboration by enabling the "sharing of data, results, and computational tools" (Cohen et al. 2011, 148) and to give support "so that data projects can been easily and more quickly processed and managed" (dal Zotto, Schenker, and Lugmayr 2015, 1).

The findings from study 1 indicate that the second approach of making a specialized system supporting their work fails to acknowledge the characteristics of their work. The technicallyskilled journalists interviewed in study 1 belong to the workshop not the factory and demand high degrees of autonomy in their form-giving work. The best indication of this is how they have related to the online news platforms in place, often the online newspaper of the newsroom in question, and have made this work well for both web and mobile readers. Platforms for online news have been developed over many years and they are driven by content management systems (CMSs). These systems use templates for authoring news content, facilitating efficient use by workers with an end-user level of computer skills. The informants told us that they did not work within the constraints of these CMSs, but had set up their own publishing stacks, giving them control from database to screen, only adapting the existing CMSs to place their work on when finished. Based on this, it is fair to claim that they have gone around the conventions embodied in the CMSs in place and have related instead to the conventions embodied by the stack of their choosing. Further, they related that in most cases, they needed to develop code to make what they wanted, and rarely relied solely on existing software tools and templates. In general, they preferred to make custom-made content and have the final say in how the finished medium was going to look and behave. Using the concepts from the chapter on form-giving with the computer as the medium, the informants had chosen the Turing tar pit (Fischer and Giaccardi 2006) and had invested time in becoming computer literate (Mateas 2005; Reas and Fry 2006) to ensure that they had high degrees of freedom and autonomy in their form-giving work.

The first approach of making specialized tools for specific purposes, thus fitting the needs of technically-skilled journalists in their form-giving work, holds more promise. The informants in study 1 depended on a range of different information systems, tools, libraries and templates in their work, comparable to what web developers need, and just like web developers, the informants worked opportunistically, replacing libraries and tools when required via rapid technological shifts or new functional and aesthetical requirements. It is evident that 
they were open to new tools that could help them accomplish specific tasks, but without restricting their expressive freedom in the end. In many respects, the informants were toolbuilders themselves. They related how they had made successful custom-made interactive news stories into templates for less technically-skilled journalists to reuse, in line with how computational journalism has been defined (Diakopoulos, Eldridge, and Franklin 2016). They also, as do most web developers, worked with streamlining their work by re-using as much as possible from earlier projects. In some respects, it is also possible to see how much of their work regarding technical infrastructures is infrastructuring within the work place, undertaken by the workers themselves (Pipek and Wulf 2009), to challenge and improve the underlying infrastructure in support of their own form-giving work and to help less technically-skilled journalists take advantage of the capabilities of the computer as the medium.

\subsubsection{Subordinating technical work to the rationale given by journalism}

When considering the rationale given by the informants in study 1 for their emerging practice, the accounts indicate a tension between the specific technical work they undertook and the need to align this work with the work undertaken in the rest of their newsroom. They took some pride in the specific technical work they did but stressed that they were journalists first and not technologists. The informants explicitly subscribed to the value system of journalism, of providing facts, holding the powerful accountable and contributing to an enlightened debate around important societal issues. From this, it is possible to hypothesize that they have "hidden" the technical rationale for their work and have needed to frame themselves as journalists to become an integral part of their newsrooms. Framed differently, the subordination of technical work has been a necessary condition for the mobilization of resources for this type of journalism in Norwegian newsrooms. Based on the accounts given in the interviews, this does not seem to be a conscious choice taken by the informants, however, and this choice was, to a small degree, problematized. Two findings from the interviews support this argument: how they described their teamwork and how they described what they made.

This coordination between the team members, as described by the informants, seemed to be supported by the common identity of being journalists first and technically-skilled workers second. Several of the newsrooms had teams with a developer, a designer and a journalist, 
signalling a practice with more specialized workers collaborating to make this type of journalism. The accounts indicate, however, that they mostly had an opportunistic approach to "who does what when" in their work. They took on bundles of tasks according to their individual skills to meet the deadlines with as little cost as possible, meaning that if the designer was most proficient in coding JavaScript, she would do it. Developers with some technical training who know the basics of iterative design would likely take responsibility for evaluating early design sketches. The point is that the teamwork, as described by the informants, was fluid, informal and geared towards making the artefact at hand rather than upholding the professional boundaries between developer, designer and journalist. Being journalists first, working according to the rationale given by journalism, the practitioners, to a small degree, needed to define themselves according to the technical skills that they applied.

When talking about what they made, they made it clear that they did not want to make applications to show off technological possibilities, but to meet the obligations of journalism and reach an appreciative audience. They admitted that the drillable datasets that they made previously with all the "bells and whistles" had limited appeal and that they knew this from taking detailed measurements of how the applications were used after being published online. At the time of the interviews, they seemed to be searching for new ways to attract audiences to the artefacts they made. After the study, some new developments seem to have answered some of their worries, with some recognizable forms taking shape such as scrolling multimedia (Dowling and Vogan 2015; Johnson 2013) and visually-striking but also simple interactive visualizations (Cairo 2016). From this, it is possible to argue that to the informants, making it work in a technological sense had been subordinated to making it work as journalism.

In summary, the rationales of technology design and development were neither mobilized in collaboration with the rest of the newsroom nor in the small teams making computational, interactive and collaborative forms of journalism. They emphasized, however, the ability to think both as a developer and a journalist and that people with only one of these mind-sets would perform poorly in this line of work. Thus, they frame themselves as a rather exclusive club of design/developer-journalists, distinctive from both the regular online journalists and the people working in the ICT department. It is evident, however, that they had, to a large degree, adopted the mind-set of journalists, something that may be detrimental to further reinvention, at least as seen in the perspective taken by Astrid Gynnild, where technologists 
challenge how journalists think when collaborating with them on finding "innovative ways of doing investigations" (Gynnild 2014, 725).

\subsection{Mobilizing resources for transmedia documentaries}

The investigation into how independent documentary film-makers met the NFI's call to make transmedia documentaries was more extensive than in the first study, with interviews and hands-on project work. The material collected is used to discuss how the media world of independent documentary film production in Norway supported the challenge. This case is an example of an unsuccessful process of reinvention in media worlds and I will use the findings from studies 2 and 4 to discuss the underlying conditions regarding why the mobilization of cooperative networks for reinvention failed.

In study 2, I evaluated the documentary film producers' progress towards transmedia documentaries by using four axes developed by comparing Bill Nichol's theory of documentary film (Nichols 1991, 2001) with Ian Bogost's theory of documentary games (Bogost 2007): 1) from the reality represented by film footage to the reality represented by processes and rules, 2) creating affect by identification to creating affect by abstraction, 3) developing voice as a situated perspective to developing a process as a systemic perspective, and 4) securing authorship through film production to securing authorship through programming and interaction design. This framework was used to highlight the findings in the article and supported the conclusion that the documentary producers had not come very far in their understanding of transmedia documentaries. This theoretical framework, however, was not ideal to capture the underlying reasons for the challenges accounted for by the informants. The framework developed in this thesis enabled me, to a larger degree, to identify the underlying conditions unfavourable to invention and change in the media world of independent documentary film in Norway.

In summary, the independent documentary film producers lacked resources such as money, time and the skills to get started with exploring transmedia, having to do with, 1) funding schemes with a narrow and well-supported mandate to fund documentary films not transmedia, 2) problems with negotiating a rationale for the undertaking that aligns strong authorship with deep audience participation, and 3) a lack of developed platforms for reaching appreciative audiences. I will use the findings from studies 2 and 4 to discuss two unfavourable 
conditions that seemed to matter when it came to the ability to mobilize cooperative networks to make transmedia documentaries: the transactional approach taken by the informants when it came to devising strategies for recruiting technically-skilled form-givers to their projects and the NFI's narrow definition of transmedia documentaries as mainly participatory in their initial call to action. Then, I will relate these conditions to a recent study of one of the two projects funded by the NFI between 2011 and 2012, exemplifying how prioritizing participation breaks the current logic of the media world of independent documentary film in Norway.

\subsubsection{Taking the transactional approach when recruiting technically-skilled form-givers}

The NFI's call for transmedia applications triggered the need to mobilize a new set of people proficient in digital making, most notably for online and mobile media. As the interviews with independent film producers in Norway show, these people did not exist in this media world before this call, and the producers therefore needed to recruit them. The production advisor at the NFI had few worries on behalf of the producers and compared recruiting developers and designers to recruiting human rights lawyers or other experts. In his view, the producers had long experience at hiring specialists when needed and they would apply this when mobilizing people with the necessary skills. Most of the producers framed this as a problem of affording to buy the needed skills in the market. An exception was one producer who had realized that he needed to hire a technically-skilled person with a documentary mind-set. He or she should become part of the project, in the same way as a photographer, sound engineer and editor would, and just as they would, the technically-skilled person should work for recognition rather than for money. The producer for the project I participated in had the same understanding. He framed the technically-savvy people that he needed as a new type of creative who would choose to apply themselves to documentaries as an art form.

The two identified strategies result in very different approaches to finding the right people to undertake the development of transmedia documentaries. A purely transactional approach, as voiced by the NFI's production advisor and most of the producers, will likely make it hard to recruit people with digital-making skills. Developers and designers who are willing to work for next to nothing would most likely want to be given artistic credit. Some credit probably 
does need to be shared to be able to attract the right people, something a minority of producers seemed to understand. This stands in contrast to how skilled workers were recruited to work in Norwegian newsrooms where they were welcomed as co-journalists rather than as technical specialists.

\subsubsection{Finding a rationale for transmedia documentary}

The production advisor at the NFI conveyed three main reasons for making transmedia documentaries. First, he articulated the need for documentary film-makers to create alternative platforms to television for reaching the audience. He saw this as an opportunity for the independent documentary film producers to make themselves less dependent on the NRK. Second, he believed that transmedia was a way to reach younger audiences that spend little time watching television and use online and mobile media first. Third, he saw the democratic potential of the new medium in that transmedia could open the door to more audience participation. The third reason, evidently a criterion applied by the NFI when considering applications for funding transmedia, was problematic according to the findings from studies 2 and 4. First, the NFI's alignment of their mandate with the logic of collaborative media led to a definition of transmedia that was almost impossible to operationalize both for the NFI and for the independent film producers. Second, neither the NFI nor the producers were ready to accept the narrow reach that the collaborative documentary projects with deeper audience engagement risked having.

When defining transmedia documentaries according to the NFI's mandate, the production advisor focused on combining strong audio-visual storytelling with high degrees of audience participation. As has been well documented in the early literature on digital media and storytelling, it is challenging to design interactive stories (Murray and Horowitz-Murray 1997), and it is even more challenging to design stories that depend on ongoing collaborative activ-

ity (Laurel 1993). A radical solution to this definitional conundrum was suggested by the advisor, however, in that any kind of collaborative event in the real world could be understood as a collaborative story, something that has been well argued against in research on digital literature by considering whether a football match is a narrative (Aarseth 1997). It is clear, however, that in the call to action for the independent film producers to explore transmedia, the almost intractable problem of combining strong storytelling with collaboration was apparent. The producers were tasked to find a solution to one of the trickiest problems in the 
design of digital media and this lack of an operationalizable understanding of transmedia documentaries, shared by both the producers and the NFI, gave few grounds for forging the cooperative networks necessary for undertaking processes of invention in this media world.

The NFI's and the producers' lack of a clear understanding of this emerging form are mirrored in how little experience the audience have had with it. Transmedia documentaries have received relatively little attention outside a smaller circle of practitioners and enthusiasts and this type of documentary is not an established genre. Most people have never seen or used a documentary that would fit this category. For transmedia to become more than experiments in form, or a narrow artistic discipline, it needs an appreciative audience. For this to happen, some of these projects needs to be realized, attract large enough audiences and thus trigger a mutual learning process where producers and audiences can make sense of the new form together. The interviews and project work showed, however, that neither the producers nor their main funder really wanted to take the risks involved in commencing this learning process. To make an innovative well-designed transmedia documentary that would most likely become a non-event online was not a very attractive prospect for the producers who were used to mobilizing audiences in the hundreds of thousands. As evidence for the NFI's risk aversion, several of the producers related how the NFI had wanted guarantees that their transmedia documentary concept would generate an audience before giving funds. The risks involved in finding an appreciative audience for transmedia documentaries, as understood by the NFI and the producers, seemed to be a non-starter in the Norwegian context.

\subsubsection{Breaking the conventions of independent documentary film production}

I will use a recent study of an ongoing transmedia documentary project, "Project Moken", to discuss the underlying conditions unfavourable to invention and change in the media world of independent documentary film in Norway (Karlsen forthcoming). Project Moken (Munthe-Kaas, Jensen, and Wiik 2013) aims to tell the story of the Moken sea nomads living in the Mergui archipelago off the coast of Myanmar and Thailand to help them save their rapidly vanishing culture. The project was funded by the NFI in $2011 / 2012$, and the negotiation of strong authorship with the goal of attracting an appreciative audience was described in the application for funding, which led the producers to take a story-centred approach where transmedia were designed, planned and produced in a mostly top-down fashion. They made an interactive story on the web, a mobile app and a social media campaign, in addition 
to a full-feature documentary film. The audience was given the opportunity to participate, but minimally, by selecting, sharing and signing a petition. Such a top-down approach gives the producer authorship and control, securing a strong story, but facilitates only minimal or shallow audience participation. When the web page, mobile app and social media campaign failed to attract an audience, this first phase of the project was then portrayed as a failure and as a misallocation of the NFI's scarce funds.

After this first phase, they changed strategy and now work with Project Moken as a bottomup and open process. From working with a transmedia documentary to create attention and engagement around the documentary film, they have now refocused the project to help the Moken people, taking what can be framed as a "participatory approach". Munthe-Kaas explains their choice:

It all started with the goal of making the Moken people known to the world, to bring some light to the issue. [...] Now we take initiatives to help them help themselves. [...] In addition to the MAP [Moken Against Plastic] project, which aims to give them the opportunity to stay on the ocean, we have a project aiming to build a Kabang boat, where they will build it themselves and we will provide the necessary funds. [...] But now we have spent so much of our private money on this, something we can't do, so we have started campaigns to raise money so they can preserve their culture before it is completely gone (Karlsen forthcoming, 9).

She relates these initiatives to the initial transmedia project: "I feel that we have started an NGO [non-governmental organization], but it still continues to be a transmedia project because it still lives on these different platforms" (Karlsen forthcoming, 9). However, this choice has had consequences. The participatory approach, as taken in the later stages of this project, and how this has been operationalized in the project, falls outside the NFI's mandate for funding and the ongoing collaborative activities that have been facilitated are too small in scale and fragmented to be of interest to the NFI or to most of the informants in study 2. This has required other strategies to secure funding for the project and Project Moken has undertaken several crowdfunding campaigns with some success.

This example shows how facilitating deep and ongoing audience participation is at odds with the current rationale established for making documentary films and that taking a purely transactional approach to securing expertise in form-giving with the computer as the medium is unfeasible with the limited and short-range funding given by the NFI and NRK. In the first phase of the project, they took a largely transactional approach when recruiting technicallyskilled creatives, buying from an advertising agency. The funds were used up rather quickly, 
giving few opportunities for maintaining and developing the web page, mobile apps and campaigns further. After this first phase, the project has mostly relied on the producer's own skills when it comes to using web-publishing tools and social media, and on the skills developed and offered by the online community they have built around improving the conditions for the Moken people.

Some of the problems concerning how difficult it is for small independent media companies in the Nordic context to mobilize resources for innovation have been addressed by earlier studies (Björgvinsson 2014; Ibrus 2016). When it comes to the relationship between distribution platforms and funding, Björgvinsson (2014) makes some of the same observations that I have made here, attesting to the difficulties of challenging the current link between funding and distribution, codified in government cultural policies (the Swedish and Norwegian cases being very similar). A cross-national study, for example, a comparison between the Scandinavian and Canadian cases, would be useful to understand the challenges faced by independent documentary film-makers when exploring transmedia. The National Film Board of Canada ("NFB/Interactive - National Film Board of Canada" 2012) implemented a platformneutral funding policy for documentary journalism a few years ago, and Canadian independents have become the leading actors in inventing transmedia documentaries and interactive documentaries.

\subsection{Infrastructuring for invention and change}

Supporting processes of reinvention by infrastructuring requires extensive resources over time and an openness towards different types of participation. In studies 3-5, I undertook projects that could hardly be characterized as infrastructuring considering their relatively small scope. However, they can be seen as initiations of longer, more involved processes of supporting reinvention in media worlds. The studies give a context for discussing infrastructuring as operationalized in the theory chapter, where infrastructuring is defined as cooperative activities that are undertaken to make visible, criticize and change conventions of a media world. These are similar to cooperative activities already taking place in the media world being addressed, but with the intention of changing current conventions. Infrastructuring media worlds is discussed in terms of how researchers can engage in supporting processes of reinvention in them. Whether infrastructuring leads to change depends on the results of the activities undertaken, often relying on how the activities have been able to mobilize new or 
existing cooperative activities for change. The rationale for operationalizing infrastructuring in this way is to ensure that the infrastructuring activities undertaken are accountable to the practices they address. Accountability here means that attempts at inventing new media are followed by activities to make the invention matter for media practice.

The inventions made in studies 3 and 4 can be categorized according to what I understand as the difference between "medium design" and "media design". Medium design, as undertaken in both studies, involved adapting and integrating media technologies to make a platform for new communicative practices. Media design was undertaken in study 4, where we conceptualized transmedia, relying on familiarity with the emerging genres of transmedia documentaries. Many of the studies undertaken in media studies framed as medium or media design have relied heavily on the initial authoring of technologies and/or on particular media by the researchers. The inventions have then been the starting point for varying degrees of evaluation and dissemination, making the inventions more or less accountable to media practice. Liestøl $(1999,2011)$, an early pioneer in this line of research, has often taken care to make his inventions accountable both to real stakeholders outside academia and to an audience by finishing and publishing the media that have been made. Løvlie (2010) has also taken care to release his inventions "in the wild", to better understand real-life communicative practices that have been supported. Other researchers such as Fagerjord (2011), Nyre (2012), Aam (2013) and Stavelin (2014) have undertaken user studies, sometimes with journalism students, similar to what has been common in user-oriented design. There has been a move by some of these media researchers to seek support from the literature on technology design to adapt methods, tools and techniques from this field to their purposes as media researchers (Fagerjord 2015; Nyre et al. 2012; Stavelin 2014).

When adapting technology design research to their purposes, the studies undertaken in the context of medium and media design risk inheriting conventions from this field, with the risk of becoming unaccountable to everyday practices in media worlds. The invention and evaluation of a prototype for shooting and sharing videos on the move is an example of this type of research, emphasizing the authoring of technologies from a research standpoint with a user evaluation as the endpoint of the study. The conventions for doing technology design studies exemplified by study 3 have been criticized from within the technology design field, most notably by Lucy Suchman et al. (2002) through characterization design that is unaccountable to particular and situated practices as design from nowhere, a critique that offers 
guidance when considering how to undertake medium and media design aiming to support new media practices. In the context of designing technologies for work places, Suchman et al. (2002) see the prototype "as an artefact with particular performative characteristics within the work of new technology design" (164). As an alternative to viewing prototyping practice as "uncovering user needs", they take the position that "prototyping simultaneously recovers and invents work requirements and technological possibilities" (ibid., 166). They question the clear distinction between design and use and how, in many cases, design continues in use. With this as a background, they develop how prototypes "are made to work as occasioned practices of technology design and use" (ibid., 167) and see the prototype as "constituted in and inseparable" from "designer-user interactions" (ibid., 168). In this formulation, the prototype makes designers accountable by demonstrating what they are up to (ibid.). The questions are: "What have we got at this point, and what can we say about it and do with it, vis à vis the circumstances at hand?" (ibid., 174). An alternative approach to medium or media design, when taking this critique seriously, is to go from authoring technology in the "academic lab" to doing this together with the community addressed by the technology being developed to ensure that what is invented makes sense for the specific and situated practice. This move has been suggested by well-known researchers in the discourse on medium or media design (Boczkowski and Siles 2014; Krippendorff 2006). They point to the field of PD with its methods, tools and techniques for making processes of invention accountable to specific practices but have, only to a small degree, developed how this should be undertaken in the context of medium or media design.

In studies 4 and 5, I go beyond the "academic lab" and have observed and participated in processes of inventing new media together with media practitioners. In the hackathon, media practitioners came together to challenge existing conventions both for what to make and how. When working with developing transmedia, this was undertaken in a real project together with media practitioners. These studies are accountable to media practice in different ways. The hackathon included media practitioners but was neither accountable to their everyday practice nor more generally to the outside world. Irani (2015) has criticized the hackathon format for creating islands separated from the rest of the world, emphasizing what she labels technological authorship. As per Karasti (2010), the short-term community that emerged in the 48 hours could not possibly develop any sense of ongoingness and a common purpose. After the final presentations, everyone could leave the premises and go on with their work lives as before. Thinking back on what took place during the event, the event had 
uncertain outcomes, just as likely leading to apathy rather than inspiration when it comes to further explorations of the computer as the medium. Further, it is questionable whether the short-term cooperation led to commitments to work together afterwards. This is what infrastructuring tries to accommodate - an ongoing commitment that continues until real improvements have been achieved in practice, something I attempted when undertaking the project work with a small Norwegian film studio. The project work undertaken was accountable to media practice as it was undertaken on site and in the context of this same practice. To use Pipek and Wulf's (2009) suggestion for infrastructuring at work, I addressed the transparency of the media work infrastructure and challenged and changed the conventional practices of the media practitioners I cooperated with. By working with them in making transmedia and trying to follow the rules of the current system, these rules and how they made our undertaking difficult became visible. The importance of the lack of conventions regarding what a transmedia documentary was, the inflexible templates and routines in the NFI's application process and how the prototype "My Store" was understood by team members and stakeholders in the project were insights from this. Project work such as this addresses multiple aspects of infrastructure and facilitates working directly to challenge and improve them. Yet, this was not easy to do due to the inertia embedded in the infrastructure of the media world of independent documentary film production that worked against us. Still, I believe this to be the accountable way of infrastructuring media worlds, to try to support reinvention "from within". If one relies on the resources available on site, stays with the project for as long as it takes, articulates concerns all the way through, confronts stakeholders when needed and stomachs the many disappointments, then this becomes the hard but accountable way in which to approach reinvention in media worlds.

This approach is similar to how Löwgren (2010, 2013a, 2013b, 2016) has undertaken infrastructuring collaborative media over the years by engaging with and involving himself with media practice, facilitating ongoing and real media projects, and challenging the established conventions for what to make and how. A small difference between his perspective and the perspective taken in this thesis is that I have mostly focused on professional media practices, while he focuses on media practice in general, a distinction that become blurred, however, when working with infrastructuring collaborative media projects. The main point for the following is that he combines the bottom-up, open, inclusive, critical, interactionist and interventionist socio-technical approach suggested by infrastructuring with the sensibilities devel- 
oped in PD to ensure that the interventions are accountable to media practice and to overcome barriers to participation. The importance of the last point can be attested to when considering the findings from both studies 4 and 5. From a PD perspective, many of the practices that developed at the hackathon were raw expressions of the power struggles common in the media worlds of its participants. Fights over creative leadership, over recognition, over having the last word, over applying particular audience images, over deciding on the rationale for the undertaking and so forth established many barriers to participation and led to many muted voices and disengaged participants. In the two groups with a designated leader and where the negotiations over skills and tasks were simple, they quickly formed a creative hierarchy. In the one group, taking what can be framed as a more participatory approach, they devised an open, fun and heterogeneous process, with more care taken over the process than over the end result. Further, and still from the perspective of PD, there were many unresolved conflicts in the project work undertaken to make "Our Daily Bread" into a transmedia documentary, both within the project and between the project and its main stakeholders. Many of these conflicts were never addressed, articulated or resolved. One example was the question of what my role in the project really was: a co-creative or hired technologist? To uncover the infrastructure of this media world and the conditions for making transmedia in this context, the occurrence of these conflicts improved my findings, but the conflicts should have been addressed more directly to open mutual learning and reinvention up. In this, the sensibilities informed by PD and framed by the perspective given by infrastructuring are both fitting and constructive.

Based on the discussion so far, the discourse in media studies on medium or media design can be informed by the approach outlined by Löwgren and Reimer (2013b), at least when it comes to developing new media practices by undertaking research-led interventions. When Nyre (2014) devises a model for how media inventions made in an academic context can be made to matter for media practice, he recommends a longer process of commercialization. After conducting several evaluations and improvements of the new medium in development, and finding that it is robust enough, it is made available to media practitioners as a product. The media practitioners are then free to include the tool in their everyday practice or not, depending on their needs. The premise of this model is that the normative rationale informing the development of the medium becomes embodied in the invented artefact itself and, if used, the invention will have the desired effects on media practice. This addresses the developed discourse on technological determinism vs. social determinism, articulated in media 
studies (Williams 1975) and in the technology design fields by science and technology researchers (Winner 2001). I am not claiming that Nyre is being naïve when it comes to laying down the premise that democratic norms can be embodied technologies, but this argument can be read in line with recent attempts to conceive new media technologies as positively contributing to the democratization of society (Bruns 2007; Jenkins 2008; Rosen 2008; Shirky 2009). In their approach to designing collaborative media, Löwgren and Reimer (2013b) frame the media technology itself in more neutral terms, and posit that for media technology to have an impact on practice requires ongoing and involved processes of sociotechnical infrastructuring informed by PD. This more neutral stance towards media technology has been articulated by Nico Carpentier (2011) when developing a model to understand participatory media. He criticizes what he claims is "enthusiastic and sometimes messianistic discourses of novelty" (ibid., 517): how new media technologies change the relationship between authors and audiences, the shift from one-to-many to many-to-many communication as articulated by Jay Rosen (2008), the re-articulation of the audience into the "produser" as articulated by Axel Bruns (2007) and the convergence of top-down business with bottom-up consumption and production practices as articulated by Henry Jenkins (2008) and Clay Shirkey (2009). Carpentier claims that deep audience participation is not necessarily a consequence of new media technologies and needs to be anchored in and protected by strong organizational structures.

The findings from studies 3-5 support the more neutral stance as to whether media technologies embody certain media practices, a stance taken by both Carpentier and Löwgren. Inventing new media, even with extensive user studies, relies on form-giving skills and expertise combined with proficiency in methods for technology design, but is, to a large degree, unaccountable both to professional and everyday media practices. In study 3 , we made a prototype that was evaluated with users in the wild, but the study says little regarding whether and how the technology would be used if it was made available as a tool for journalists in the field. In study 4 we made a collaborative media prototype, but even though we invested some resources to mobilize small-scale use, it resulted in no contributions. In both cases, extensive resources would be needed to support a longer process of making the prototypes work in practice, involving both attention being paid to developing the technologies themselves further and addressing the relevant social practices involved. 
More importantly, and in support of Carpentier's claim and Löwgren's approach, is how my findings when answering both RQ1 and RQ2 articulate the complex cooperative networks supporting media worlds, consisting of a variety of cooperative activities undertaken by larger groups of people, including the audience. For inventions to matter for media practice, these complex cooperative networks need to be captured effectively, something that requires the long-term commitment implied by infrastructuring. Infrastructuring in this context is to undertake a wide variety of cooperative activities by addressing the rules of the game: how they can be made visible, addressed and improved. 


\section{Conclusion}

The studies summarized in this "kappe" have contributed to a better understanding of the conditions for reinventing journalism using the capabilities of the computer as the medium. In the first two studies, I interviewed practitioners in newsrooms and in independent film studios about their current and future practices, and they told me about the main challenges and opportunities for reinvention in the media worlds to which they belong. The journalists proficient in digital making in the newsroom spoke about their sustained practice where cycles of invention and change were undertaken daily. The independent film producers, however, had problems with mobilizing resources for producing transmedia and most of the projects they had sketched out had not been realized at the time of the interviews. The troubles accounted for in the second study were confirmed in a field study, where I participated as a full member in a transmedia project based on a television documentary "Our Daily Bread". In this work, I experienced the dilemmas faced by the producers, where the main funders in their media world, the NFI and NRK, considered ideas for transmedia projects, but without a proper mandate to fund them. The three studies have together informed the answering of research question one in this thesis.

What are the salient conditions for successfully mobilizing cooperative networks for reinventing journalism using the computer as the medium?

A comparison of the two media worlds indicates that it has been much easier to mobilize the cooperative networks necessary for making computational, interactive and collaborative journalism in newsrooms than for independent documentary film producers to make transmedia. The newsrooms that were studied have managed to secure people with the necessary skills for inventing new forms of journalism, something that the independent producers have not managed. Further, the newsworkers have been given the time and freedom to explore new forms online, while the independent film producers have used their exploration of transmedia mainly to understand what forms are eligible for funding from the NFI and NRK. The main finding from investigating why computational journalism has emerged as a sustained practice in Norway and transmedia documentaries have not is that the two media worlds of newsroom journalism and independent documentary films frame these processes of reinvention differently. These differences are summarized in table 6 . 


\begin{tabular}{|l|l|l|}
\hline Reinvention? & The newsroom & Independent documentary film \\
\hline Rationale & $\begin{array}{l}\text { Reinvents the kind of journalism } \\
\text { in highest regard in the newsroom } \\
\text { traditionally (investigative jour- } \\
\text { nalism). }\end{array}$ & $\begin{array}{l}\text { Reinvents the kind of documen- } \\
\text { tary film production in lowest re- } \\
\text { gard traditionally (participatory } \\
\text { documentary). }\end{array}$ \\
\hline Platform & $\begin{array}{l}\text { Reinvents journalism for the main } \\
\text { platform (online). }\end{array}$ & $\begin{array}{l}\text { Reinvents journalism for a subsid- } \\
\text { iary platform (online). }\end{array}$ \\
\hline Revenues & $\begin{array}{l}\text { Reinvents journalism as an an- } \\
\text { swer to failing revenues for news } \\
\text { organizations. }\end{array}$ & $\begin{array}{l}\text { Reinvents journalism for revenues } \\
\text { that come in addition to or instead } \\
\text { of existing and stable funding } \\
\text { schemes. }\end{array}$ \\
\hline
\end{tabular}

Table 6: The two worlds of journalism framing reinvention differently

In studies 3-5, I observed and undertook interventions to support processes of reinvention in media worlds using the computer as the medium. I have framed these studies as different entry points to initiating invention and change in media worlds. In study 3 , the entry point was designing a new tool for journalistic purposes to enable the shooting and sharing of live videos on the move with minimal and clandestine interaction. In study 5 , the entry point was a hackathon set up to support reinvention of the world of independent film-making in the Nordic countries. In study 4 , the entry point was working with developing a transmedia project with a small Norwegian film studio. Together, these three studies have informed the answering of research question two in this thesis.

How can cooperative activities be initiated in support of the reinvention of journalism using the computer as the medium?

When comparing these three entry points to reinvention, it is possible to hypothesize how these interventions may lead to changing practices in media worlds. In the discussion, I frame this as a question regarding how the interventions are accountable to the ongoing development of these practices. Inventing new tools and equipment by undertaking user-oriented design, as was done in study 3 , is, to a small degree, accountable to current and future journalistic practices. This finding is reached by taking a cautious stance on how technology may embody future practices. Bringing people together to hack concepts and media technologies in a 48-hour hackathon is an event more accountable to practice by involving media 
practitioners directly in processes of invention. However, this type of event is generally unaccountable to the outside world, creating a closed short-term space with few constraints for the participants when it comes to how they relate the "hacking" to their everyday practices. Working with media practitioners to undertake processes of invention and change, as was done in study 4, by exploring opportunities and overcoming the challenges with them in their media world makes them, to a large degree, accountable to their practice. In this, the process of inventing a concept that challenges existing conventions comes up against the realities of mobilizing resources for its making. Working to overcome this inertia of media worlds together with practitioners over some time has the greatest potential for changing practice. In table 7 , I summarize the findings from studies 3-5 when answering research question two.

\begin{tabular}{|l|l|l|}
\hline Study & Entry point & Accountability \\
\hline Hand Open & $\begin{array}{l}\text { Inventing tools and platforms by hy- } \\
\text { pothesizing future media practice } \\
\text { with a normative rationale embodied } \\
\text { in the technologies and platforms } \\
\text { made. }\end{array}$ & $\begin{array}{l}\text { Not accountable to journal- } \\
\text { istic practice before being } \\
\text { used for journalistic pur- } \\
\text { poses in the context of eve- } \\
\text { ryday journalistic work. }\end{array}$ \\
\hline Hackathon & $\begin{array}{l}\text { Bringing people together to invent } \\
\text { new media in short-term and closed } \\
\text { events signalled by the "hackathon } \\
\text { format". }\end{array}$ & $\begin{array}{l}\text { Accountable to practice by } \\
\text { involving media practition- } \\
\text { ers in processes of inven- } \\
\text { tion, but unaccountable to } \\
\text { everyday work practices. }\end{array}$ \\
\hline Our Daily Bread & $\begin{array}{l}\text { Working with media practitioners on } \\
\text { inventing new media in "real" pro- } \\
\text { jects relying on the resources availa- } \\
\text { ble in the media world where the } \\
\text { work is undertaken. }\end{array}$ & $\begin{array}{l}\text { Accountable to media prac- } \\
\text { tice both when it comes to } \\
\text { processes of invention and } \\
\text { processes of change. By } \\
\text { challenging the conventions } \\
\text { of media worlds directly, in } \\
\text { practice, they can poten- } \\
\text { tially be made visible, ad- } \\
\text { dressed and changed. }\end{array}$ \\
\hline
\end{tabular}

Table 7: Three entry points to invention in media worlds and their potential for initiating new accountable practices 
The overall contribution made in this thesis is to shed light on processes of reinvention in media worlds, relying on sustained cooperative activities to invent new media by exploring the capabilities of the computer as the medium and mobilizing cooperative networks in support of both the activities undertaken and the media made. This contribution can be exemplified by revisiting the examples of reinvention in media worlds that were given in the introduction: "Snowfall" and "Skam". Both were inventions relying on earlier media forms, where the creators had moderate expectations of how these were going to be appreciated by the audience. The inventions were the result of everyday practice in the two media worlds, where the practitioners mastered the methods, tools and techniques to challenge existing conventions. With moderate appreciation, these inventions would have been examples of incremental change in their media worlds, but with the unexpected massive readership in both cases, they led to radical changes in media practice. Both projects are now viewed as templates for storytelling on online platforms and have been widely copied all over the world, and consequently, new conventions and genres are emerging. In "Skam", a collaborative audience was mobilized, not expressed in the series itself, but by spawning a wider media phenomenon from its fictional universe, being a clear example of the dynamics referred to as transmedia. In summary, the two projects exemplify how invention led to change, becoming reinventions, and how these processes rely on a successful mobilization of cooperative networks including an appreciative audience.

It is possible to see how the sustained practice of inventing new media within Norwegian newsrooms, as described in this thesis, increases the chance that the next "Snowfall" will be made in this context. The continuous everyday crafting of computational, interactive and collaborative forms in newsrooms will probably lead to successes, providing new examples of journalism reinvented. In the media world of independent documentary film in Norway, however, the exploration of new forms is currently not happening, and the potential for invention and change is therefore minimal. The most promising avenue for further change is the work undertaken to create online campaigns around the films they make. One example is Project Moken, where a documentary film, screened in cinemas and on television, supports an open and participatory campaign on multiple platforms to save the Moken people, thus becoming a transmedia project. In summary, invention and change in media worlds depend on ongoing form-giving activities, the exploration of new media technologies in this and the mobilization of cooperative networks in its support. The best way to engage with and support these processes for researchers is through working with media practitioners in their 
form-giving work with the computer as the medium and to undertake infrastructuring activities to secure the necessary resources for its continuation. It is uncertain whether the technology-driven reinvention of journalism will strengthen the accountability function of journalism or resurrect the participatory modes of the documentary, but supporting local journalistic practices developing with new information technologies increases the likelihood of these outcomes.

\subsection{Future work}

There are several avenues for future work when it comes to supporting processes of invention and change in media worlds that can take this thesis as a starting point. Using the approach in this thesis, I will briefly discuss these avenues as 1) supporting form-giving work with the computer as the medium, 2) supporting collaborations between people who do not normally work together to invent new media, 3) understanding how audiences can be mobilized for collaborative media, and 4) challenging the inertia in media worlds by infrastructuring.

Media practitioners wanting to invent new media need the skills and confidence to explore the capabilities of the computer as the medium. Based on the findings in this thesis, they do not need better authoring tools or more capable CMSs, but they need to become computer literate. Computer literacy, the ability to both understand and give form to computer media, does not merely mean coding skills but also the skills to design interactive media and to design for collaborative practices. The question then is how to facilitate processes of learning that give media practitioners the opportunity to become computer literate, applicable to media work and how media worlds work. I see two arenas where this research could be undertaken in educating the new media practitioner and in educating practitioners in media organizations. Research in these two arenas should inform each other, providing the opportunity to develop a better curriculum in support of both current and future media workers becoming computer literate, a basic premise for the further reinvention of media worlds. This line of research has been suggested in the literature (Løvlie 2016; Mateas 2005; Murray et al. 2006), but there are still many questions left unanswered when it comes to developing better curricula for teaching programming and design to current and future media workers. This work 
will be undertaken in developing the program "Digital media and design" at Østfold University College and in future collaborations with practitioners in media organizations to develop new media.

This leads to the second avenue for future research: finding ways to support collaborations between people who do not normally work together to invent new media. Based on the findings in this thesis, these collaborations need to be accountable to everyday media work, and therefore they should not be organized as short-term events or happenings like a hackathon. It is possible to hypothesize three main types of participants in these collaborations: 1) media workers with little or no knowledge of form-giving with the computer as the medium; 2) media workers, developers or designers with the technical skills, experience and confidence to explore the computer as the medium; and lastly 3) professional developers and designers with little experience of media development. The question then is the relative importance of practitioners in category 2 for these collaborations to be successful by mitigating between the cultures of technology development and creative media work. The informants in study 1 were clearly in this category, with many of them having a hybrid membership in these two cultures, and several of the producers in study 2 looked for people that could think like a documentary film-maker but have the skills in programming and design. The rationale for both my research and teaching relies on the premise that hybrid practitioners are needed in media organizations to undertake processes of reinvention, but it is an open question as to whether this is true and how these hybrid practitioners should contribute to these processes.

The third avenue of research framed by this thesis is further exploration into how audiences are mobilized when producing collaborative media. A better understanding of this will support processes of reinvention in media worlds by addressing the need in media organizations to establish a good enough model of audience appreciation for a project before prioritizing resources to it. As Löwgren (2016) has pointed out, in this we are all novices; it is extremely hard to predict how an audience will react when designing collaborative media. The questions then are whether technology design fields such as HCI and CSCW have good methods for predicting a critical mass of users for collaborative media designs, whether new methods need to be developed for this purpose and whether this is too complex a problem to be addressed by predictive design methods at all. Löwgren and Reimer (2013b) have outlined a path to take in this, relying on meta-design, PD and infrastructuring, of following the collaborative media project from the early design stage to long after the medium has been launched 
to the audience, where most of the effort involved in the project is in facilitating the mobilization of a critical mass of users. However, this happens after the decision to commence the project has been made and fails to address the need for a trustworthy model of appreciation before the early decision to develop the project has been made. I therefore see how the use of methods developed in PD can be helpful to develop a good enough model of appreciation together with members of the audience and the use of meta-design to find the right balance between what should be easy to do and what should be hard, between the executionary and structural participation (Green et al. 2017) facilitated by the collaborative media in question.

The fourth avenue for future work is to undertake more open processes of infrastructuring media worlds using elements from what I have suggested so far. The entry point would be to get access to media organizations that see the need to reinvent themselves but have not yet found a way to do so. This research would rely on the long-term observation of how the media organization in question works with making the transition to new media platforms, and the identification of the underlying causes for both inertia and possibilities for invention and change. Based on this, the researcher should then engage with these underlying causes and find ways to address them with the goal of finding ways to overcome them. The first phase would rely on observational methods to uncover the underlying causes, leading to infrastructuring activities in the second phase that address them. In this thesis, I have operationalized a list of infrastructuring activities that address the cooperative work undertaken in media worlds in general. This would be a good starting point for further developing how media worlds can be infrastructured in support of ongoing processes of invention and change. 


\section{References}

Aam, Pål. 2013. "Fjernsynsforskaren - frå kritikar til innovatør: Som døme: mediedesign av interaktiv journalistikk med levande bilde”. PhD diss., Norwegian University of Science and Technology.

Aarseth, Espen. 1997. Cybertext: Perspectives on Ergodic Literature. Baltimore, Md.: Johns Hopkins University Press.

Ackerman, Mark, and Elizabeth Kaziunas. 2017. "A New Generation of CSCW: Reinvigorating CSCW Field-Based Research Through A Theory-Inspired Reboot". In Proceedings of 15th European Conference on Computer-Supported Cooperative Work - Exploratory Papers, Sheffield, UK, August 28-September 1, European Society for Socially Embedded Technologies.

Ackerman, Mark S., Juri Dachtera, Volkmar Pipek, and Volker Wulf. 2013. "Sharing Knowledge and Expertise: The CSCW View of Knowledge Management". Computer Supported Cooperative Work (CSCW) 22 (4-6): 531-73.

Aitamurto, Tanja, and Seth C. Lewis. 2013. "Open Innovation in Digital Journalism: Examining the Impact of Open APIs at Four News Organizations". New Media \& Society 15 (2): 314-31.

Alacovska, Ana. 2016. 'From 'Poetics' to 'Production': Genres as Active Ingredients in Media Production", In Advancing Media Production Research. Global Transformations in Media and Communication Research, edited by Paterson C., Lee D., Saha A., Zoellner A., 181-99. London: Palgrave Macmillan.

Ananny, Mike. 2013. "Press-Public Collaboration as Infrastructure: Tracing News Organizations and Programming Publics in Application Programming Interfaces". American Behavioral Scientist 57 (5): 623-42.

Ananny, Mike, and Kate Crawford. 2015. “A Liminal Press”. Digital Journalism 3 (2): 192208.

Skam 2015. Directed by Julie Andem. Norway: NRK.

Andersen, Michael. 2009. "Four Crowdsourcing Lessons from the Guardian's (Spectacular) Expenses-Scandal Experiment." Nieman Journalism Lab, June 23, 2009.

http://www.niemanlab.org/2009/06/four-crowdsourcing-lessons-from-the-guardiansspectacular-expenses-scandal-experiment.

Angrosino, Michael. 2007. Doing Ethnographic and Observational Research. Kindle Edition. Qualitative Research Kit. London: SAGE Publications.

Appelgren, Ester, and Gunnar Nygren. 2014. "Data Journalism in Sweden". Digital Journalism 2 (3): 394-405.

Arrigoni, Gabriella. 2016. "Epistemologies of Prototyping: Knowing in Artistic Research". Digital Creativity 27 (2): 99-112.

Aston, Judith, and Sandra Gaudenzi. 2012. "Interactive Documentary: Setting the Field". Studies in Documentary Film 6 (2): 125-39.

Bang, Anne Louise, Peter Krogh, Martin Ludvigsen, and Thomas Markussen. 2012. "The Role of Hypothesis in Constructive Design Research". In Proceedings of The Art of Research Conference IV, Aalto University, Helsinki, November 28-29, 2012.

Bardzell, Jeffrey, Shaowen Bardzell, Cindy Lin, Silvia Lindtner, and Austin Toombs. 2017. "HCI's Making Agendas". Foundations and Trends ${ }^{\circledR}$ in Human-Computer Interaction 11 (3): 126-200.

Bardzell, Jeffrey, Jay Bolter, and Jonas Löwgren. 2010. "Interaction Criticism: Three Readings of an Interaction Design, and What They Get Us". Interactions 17 (2): 32-37.

Bardzell, Shaowen, Vicky Wu, Jeffrey Bardzell, and Nick Quagliara. 2007. "Transmedial Interactions and Digital Games". In Proceedings of the International Conference on 
Advances in Computer Entertainment Technology, 307-308. ACE '07. New York, NY, USA: ACM.

Becker, Howard Saul. 1984. Art Worlds. University of California Press.

Bellotti, Victoria, and Yvonne Rogers. 1997. "From Web Press to Web Pressure: Multimedia Representations and Multimedia Publishing". In Proceedings of the ACM SIGCHI Conference on Human Factors in Computing Systems, 279-286. CHI '97. New York, NY, USA: ACM.

Björgvinsson, Erling. 2014. "The Making of Cultural Commons: Nasty Old Film Distribution and Funding". In Making Futures: Marginal Notes on Innovation, Design, and Democracy, edited by Pelle Ehn, Elisabet M. Nilsson, and Richard Topgaard, 187225. The MIT Press.

Björgvinsson, Erling, Pelle Ehn, and Per-Anders Hillgren. 2012. "Agonistic Participatory Design: Working with Marginalised Social Movements". CoDesign 8 (2-3): 127-44.

Blumenthal, Hank, and Yan Xu. 2012. "The Ghost Club Storyscape: Designing for Transmedia Storytelling”. IEEE Transactions on Consumer Electronics 58 (2): 190-96.

Boczkowski, Pablo J. 2004. "The Processes of Adopting Multimedia and Interactivity in Three Online Newsrooms". Journal of Communication 54 (2): 197-213.

Boczkowski, Pablo J. 2005. Digitizing the News: Innovation in Online Newspapers. MIT Press.

Boczkowski, Pablo, and Ignacio Siles. 2014. "Steps toward Cosmopolitanism in the Study of Media Technologies: Integrating Scholarship on Production, Consumption, Materiality, and Content". In Media Technologies: Essays on Communication, Materiality, and Society, edited by Tarleton Gillespie, Pablo J. Boczkowski, and Kirsten A. Foot. Cambridge, Massachusetts: The MIT Press.

Bødker, Susanne. 2006. "When Second Wave HCI Meets Third Wave Challenges". In Proceedings of the 4th Nordic Conference on Human-Computer Interaction: Changing Roles, 1-8. NordiCHI '06. New York, NY, USA: ACM.

. 2015. "Third-Wave HCI, 10 Years Later-participation and Sharing". Interactions 22 (5): 24-31.

Bødker, Susanne, and Anja Bechmann Petersen. 2007. "Seeds of Cross-Media Production". Computer Supported Cooperative Work (CSCW) 16 (6): 539-66.

- 2010. "Between Casual Commitment and Cross-Media Articulation: The Faith of the Napkin". From CSCW to Web 2.0: European Developments in Collaborative Design, 115-29.

Bogost, Ian. 2007. Persuasive Games: The Expressive Power of Videogames. Cambridge, MA: MIT Press.

Bowker, Geoffrey C., and Susan Leigh Star. 2002. "How to Infrastructure”. In Handbook of New Media, edited by Leah A. Lievrouw and Sonia Livingstone, 151-163. London: SAGE.

Branch, John. 2012. "Snow Fall: The Avalanche at Tunnel Creek". The New York Times, 2012. http://www.nytimes.com/projects/2012/snow-fall.

Bratteteig, Tone. 2004. "Making Change: Dealing with Relations between Design and Use." $\mathrm{PhD}$ diss., University of Oslo.

Brinkmann, Svend, Lene Tanggaard (eds). 2012. Kvalitative metoder: empiri og teoriutvikling. Oslo, Gyldendal Akademisk.

Brown, Barry, Stuart Reeves, and Scott Sherwood. 2011. "Into the Wild: Challenges and Opportunities for Field Trial Methods". In Proceedings of the SIGCHI Conference on Human Factors in Computing Systems, 1657-1666. CHI '11. New York, NY, USA: ACM. 
Bruns, Axel. 2007. "Produsage". In Proceedings of the 6th ACM SIGCHI Conference on Creativity \& Cognition, 99-106. CC '07. New York, NY, USA: ACM.

Buchanan, Richard. 2001. "Design and the New Rhetoric: Productive Arts in the Philosophy of Culture". Philosophy and Rhetoric 34 (3): 183-206.

Cairo, Alberto. 2016. The Truthful Art: Data, Charts, and Maps for Communication. 1 edition. New Riders.

Caldwell, John Thornton. 2008. Production Culture: Industrial Reflexivity and Critical Practice in Film and Television. Kindle Edition. Durham: Duke University Press.

Carlson, Matt. 2015. “The Robotic Reporter”. Digital Journalism 3 (3): 416-31.

Carpentier, Nico. 2011. "Contextualising Author-Audience Convergences". Cultural Studies 25 (4-5): 517-33.

Cohen, Hart. 2012. "Database documentary: From Authorship to Authoring in Remediated/Remixed Documentary". Culture Unbound: Journal of Current Cultural Research 4 (June): 327-46.

Cohen, Sarah, Chengkai Li, Jun Yang, and Cong Yu. 2011. "Computational Journalism: A Call to Arms to Database Researchers". In Proceedings of the 5th Biennial Conference on Innovative Data Systems Research, January 9-12, 148-51. Asilomar, California, USA: ACM.

Cox, Melissma. 2000. "The Development of Computer-Assisted Reporting”. Paper Presented to the Newspaper Division, Association for Education in Journalism and Mass Communication, Southeast Colloquium, March 17-18, 2000, University of North Carolina, Chapel Hill.

Crabtree, Andy. 2004. "Taking Technomethodology Seriously: Hybrid Change in the Ethnomethodology-design Relationship". European Journal of Information Systems 13 (3): 195-209.

Creswell, John W. 2009. Research Design: Qualitative, Quantitative, and Mixed Methods Approaches. 3rd ed. Los Angeles: SAGE.

Dailey, Dharma, and Kate Starbird. 2014. "Journalists as Crowdsourcerers: Responding to Crisis by Reporting with a Crowd". Computer Supported Cooperative Work (CSCW) 23 (4-6): 445-81.

Dalen, Arjen van. 2012. "The Algorithms Behind the Headlines". Journalism Practice 6 (56): $648-58$.

Dantec, Christopher A. Le, and Carl DiSalvo. 2013. "Infrastructuring and the Formation of Publics in Participatory Design". Social Studies of Science 43 (2): 241-64.

Deuze, Mark. 2016. "Managing Media Workers". In Managing Media Firms and Industries, edited by Gregory Ferrell Lowe and Charles Brown, 329-41. Media Business and Innovation. Springer International Publishing.

Diakopoulos, Nicholas. 2010. "Game-y Information Graphics". In CHI '10 Extended Abstracts on Human Factors in Computing Systems, 3595-3600. CHI EA '10. New York, NY, USA: ACM. . 2015. "The Editor's Eye: Curation and Comment Relevance on the New York Times". In Proceedings of the 18th ACM Conference on Computer Supported Cooperative Work \& Social Computing, 1153-1157. CSCW '15. New York, NY, USA: ACM. - 2016. "CommentIQ: Enhancing Journalistic Curation of Online News Comments". In Proceedings of the 25th International Conference Companion on World Wide Web, 715-716. WWW'16 Companion. Republic and Canton of Geneva, Switzerland: International World Wide Web Conferences Steering Committee. . 2016. "Computational Journalism and the Emergence of News Platforms". The Routledge Companion to Digital Journalism Studies, edited by Scott Eldridge II and Bob Franklin. 
Diakopoulos, Nicholas, Munmun De De Choudhury, and Mor Naaman. 2012. "Finding and Assessing Social Media Information Sources in the Context of Journalism". In Proceedings of the SIGCHI Conference on Human Factors in Computing Systems. CHI '12. Austin, Texas, USA: ACM.

Diakopoulos, Nicholas, Sergio Goldenberg, and Irfan Essa. 2009. "Videolyzer: Quality Analysis of Online Informational Video for Bloggers and Journalists". In Proceedings of the SIGCHI Conference on Human Factors in Computing Systems, 799-808. CHI '09. New York, NY, USA: ACM.

Diakopoulos, Nicholas, M. Naaman, and F. Kivran-Swaine. 2010. "Diamonds in the Rough: Social Media Visual Analytics for Journalistic Inquiry". In Proceedings of the IEEE Symposium on Visual Analytics Science and Technology, 115-122, Lake City, UT: IEEE.

Diakopoulos, Nicholas, and Mor Naaman. 2011. "Towards Quality Discourse in Online News Comments". In Proceedings of the ACM 2011 Conference on Computer Supported Cooperative Work, 133-142. CSCW'11. New York, NY, USA: ACM.

Diakopoulos, Nicholas, Mor Naaman, Tayebeh Yazdani, and Funda Kivran-Swaine. 2011. "Social Media Visual Analytics for Events". In Social Media Modeling and Computing, edited by Steven C. H. Hoi, Jiebo Luo, Susanne Boll, Dong Xu, Rong Jin, and Irwin King, 189-209. Springer London.

Diakopoulos, Nicholas, and David A. Shamma. 2010. "Characterizing Debate Performance via Aggregated Twitter Sentiment". In Proceedings of the SIGCHI Conference on Human Factors in Computing Systems, 1195-1198. CHI '10. New York, NY, USA: ACM.

Dickinson, Roger. 2008. "Studying the Sociology of Journalists: The Journalistic Field and the News World". Sociology Compass 2 (5): 1383-1399.

DiSalvo, Carl. 2009. "Design and the Construction of Publics". Design Issues 25 (1): 48-63.

DiSalvo, Carl, Jonathan Lukens, Thomas Lodato, Tom Jenkins, and Tanyoung Kim. 2014. "Making Public Things: How HCI Design Can Express Matters of Concern". In Proceedings of the 32Nd Annual ACM Conference on Human Factors in Computing Systems, 2397-2406. CHI '14. New York, NY, USA: ACM.

Domingo, David. 2008. "Interactivity in the Daily Routines of Online Newsrooms: Dealing with an Uncomfortable Myth". Journal of Computer-Mediated Communication 13 (3): 680-704.

Donadio, Rachel. 2016. “Will 'Skam' a Norwegian Hit, Translate?” New York Times, 9 December 2016. https://www.nytimes.com/2016/12/09/arts/television/will-skam-a-norwegian-hit-translate.html.

Dourish, Paul. 2004. Where the Action Is: The Foundations of Embodied Interaction. MIT Press.

Dourish, Paul, and Melissa Mazmanian. 2013. "Media as Material: Information Representations as Material Foundations for Organizational Practice". How Matter Matters: Objects, Artifacts, and Materiality in Organization Studies 3: 92.

Dowling, David, and Travis Vogan. 2015. "Can We 'Snowfall' This?” Digital Journalism 3 (2): 209-24.

Ehn, Pelle. 2008. "Participation in Design Things". In Proceedings of the Tenth Anniversary Conference on Participatory Design 2008, 92-101. PDC '08. Indianapolis, IN, USA: Indiana University.

Elliott, Philip. 1972. The Making of a Television Series: A Case Study in the Sociology of Culture. London: Constable. 
Esch, Michaela, Annika Wiklund-Engblom, and Simon Staffans. 2011. "Experience As a Starting Point of Designing Transmedia Content". In Proceedings of the 9th European Conference on Interactive TV and Video, 249-252. EuroITV'11. New York, NY, USA: ACM.

Fagerjord, Anders. 2011. "Between Place and Interface: Designing Situated Sound for the IPhone". Computers and Composition, 28 (3): 255-63.

—. 2012. "Design Som Medievitenskapelig Metode". Norsk Medietidskrift 2012 (3): $198-215$.

- 2015. "Humanist Evaluation Methods in Locative Media Design". Journal of Media Innovations 2 (1): 107-22.

Fagrell, Henrik, and Fredrik Ljungberg. 2000. "Empirically Informed Knowledge Management Systems in Mobile Domains". In PDC 2000 Proceedings of the Participatory Design Conference, 60-69. PDC '2000. New York, NY, USA.

Fink, Katherine, and C. W. Anderson. 2015. "Data Journalism in the United States". Journalism Studies 16 (4): 467-81.

Fischer, Gerhard, and Elisa Giaccardi. 2006. "Meta-Design: A Framework for the Future of End-User Development". In End User Development, edited by Henry Lieberman, Fabio Paternò, and Volker Wulf, 9:427-57. Human-Computer Interaction Series. Dordrecht.

Flew, Terry, Christina Spurgeon, Anna Daniel, and Adam Swift. 2012. "The Promise of Computational Journalism". Journalism Practice 6 (2): 157-71.

Frayling, Cristopher. 1993. "Research in Art and Design". Royal College of Art Research Papers 1 (1).

Gambarato, Renira Rampazzo. 2013. "Transmedia Project Design: Theoretical and Analytical Considerations". Baltic Screen Media Review 1 (1): 81-100.

Gans, Herbert J. 1979. Deciding What's News: A Study of CBS Evening News, NBC Nightly News, Newsweek, and Time. Northwestern University Press.

Gao, Tong, Jessica R. Hullman, Eytan Adar, Brent Hecht, and Nicholas Diakopoulos. 2014. "NewsViews: An Automated Pipeline for Creating Custom Geovisualizations for News". In Proceedings of the 32Nd Annual ACM Conference on Human Factors in Computing Systems, 3005-3014. CHI '14. New York, NY, USA: ACM.

Gaudenzi, Sandra. 2013. "The Living Documentary: From Representing Reality to Co-Creating Reality in Digital Interactive Documentary”. PhD diss., Goldsmiths, University of London.

- 2014. "Strategies of Participation: The Who, What and When of Collaborative Documentaries". In New Documentary Ecologies: Emerging Platforms, Practices and Discourses, edited by Kate Nash, Craig Hight, and Catherine Summerhayes, 129-148.

- 2015. "To Hack or Not To Hack: Interactive Storytelling in the 21st Century". In Proceedings of the ACM International Conference on Interactive Experiences for TV and Online Video, 201-202. TVX'15. New York, NY, USA: ACM.

—. 2017. "User Experience versus Author Experience: Lessons Learned from the UX Series". In I-Docs: The Evolving Practices of Interactive Documentary, edited by Judith Aston, Sandra Gaudenzi, and Mandy Rose, 117-29. Columbia University Press.

Ghellal, Sabiha, Ann Morrison, Marc Hassenzahl, and Benjamin Schaufler. 2014. "The Remediation of Nosferatu: Exploring Transmedia Experiences". In Proceedings of the 2014 Conference on Designing Interactive Systems, 617-626. DIS '14. New York, NY, USA: ACM. 
Green, David Philip, Simon Bowen, Jonathan Hook, and Peter Wright. 2017. "Enabling Polyvocality in Interactive Documentaries Through 'Structural Participation'”. In Proceedings of the 2017 CHI Conference on Human Factors in Computing Systems, 6317-6329. CHI '17. New York, NY, USA: ACM.

Gross, Shad, Jeffrey Bardzell, and Shaowen Bardzell. 2013. "Structures, Forms, and Stuff: The Materiality and Medium of Interaction". Personal and Ubiquitous Computing 18 (3): 637-49.

Gynnild, Astrid. 2014. “Journalism Innovation Leads to Innovation Journalism: The Impact of Computational Exploration on Changing Mindsets". Journalism 15 (6): 713-30.

Hamilton, James T., and Fred Turner. 2009. "Accountability Through Algorithm: Developing the Field of Computational Journalism”. Center for Advanced Study in the Behavioral Sciences Summer Workshop: Stanford.

Handler, Reinhard A., and Raul Ferrer Conill. 2016. "Open Data, Crowdsourcing and Game Mechanics. A Case Study on Civic Participation in the Digital Age". Computer Supported Cooperative Work (CSCW) 25 (2-3): 153-66.

Hannaford, Liz. 2015. "Computational Journalism in the UK Newsroom". Journalism Education 4 (August).

Heath, Christian, Paul Luff, Gillian Nicholls, and Dirk vom Lehn. 2000. "Textuality and Interaction: The Collaborative Production of News Stories". Intellectica 1 (30): 151-175.

Heidegger, Martin. 1954. The Question Concerning Technology and Other Essays. New York \& London: Garland Publishing 1996. Being and Time: A Translation of Sein Und Zeit. SUNY Press.

Holton, Avery E., Seth C. Lewis, and Mark Coddington. 2016. "Interacting with Audiences". Journalism Studies 17 (7): 849-59.

Hopewell, John. 2017. 'Mipcom: 'Shame' Gets European Remake Roll-Out from NRK, Beta Film". Variety, 15 October 2017.

Hössjer, Amelie, and Kerstin Severinson Eklundh. 2009. "Making Space for a New Medium: On the Use of Electronic Mail in a Newspaper Newsroom". Computer Supported Cooperative Work (CSCW) 18 (1): 1-46.

Hullman, Jessica, Nicholas Diakopoulos, and Eytan Adar. 2013. "Contextifier: Automatic Generation of Annotated Stock Visualizations". In Proceedings of the SIGCHI Conference on Human Factors in Computing Systems, 2707-2716. CHI '13. New York, NY, USA: ACM.

Ibrus, Indrek. 2016. "Micro-Studios Meet Convergence Culture: Crossmedia, Clustering, Dialogues, Auto-Communication”. In Media Convergence Handbook - Vol. 2, 155-73. Media Business and Innovation. Springer.

Ingold, Tim. 2013. Making: Anthropology, Archaeology, Art and Architecture. Routledge. Irani, Lilly. 2015. "Hackathons and the Making of Entrepreneurial Citizenship". Science, Technology \& Human Values 40 (5): 799-824.

Jenkins, Henry. 2003. "Transmedia Storytelling”. MIT Technology Review. 15 January 2003. http://www.technologyreview.com/news/401760/transmedia-storytelling/. - 2007. "Confessions of an Aca/Fan: Archives: Transmedia Storytelling 101". 22 March 2007. http://henryjenkins.org/2007/03/transmedia_storytelling_101.html. 2008. Convergence Culture: Where Old and New Media Collide. New York: New York University Press.

Johnson, Bobbie. 2013. “Snowfallen”. Medium. 2013. https://medium.com/@bobbie/snowfallen-66b9060333ad.

Karasti, Helena. 2014. "Infrastructuring in Participatory Design". In Proceedings of the 13th Participatory Design Conference, 141-150. PDC '14. New York, NY, USA: ACM. 
Karasti, Helena, and Karen S. Baker. 2008. "Community Design: Growing One’s Own Information Infrastructure". In Proceedings of the Tenth Anniversary Conference on Participatory Design 2008, 217-220. PDC '08. Indianapolis, IN, USA: Indiana University.

Karasti, Helena, Karen S. Baker, and Florence Millerand. 2010. "Infrastructure Time: LongTerm Matters in Collaborative Development". Computer Supported Cooperative Work (CSCW) 19 (3-4): 377-415.

Karlsen, Joakim. 2018. "Transmedia Documentary: Experience and Participatory Approaches to Non-Fiction Transmedia". In The Routledge Companion to Transmedia Studies, edited by Matthew Freeman and Renira Rampazzo Gambarato. London: Routledge.

. 2014. "Transmediavendingen i Ny Norsk Uavhengig Dokumentarfilm". In Hvor Går Dokumentaren? Nye Tendenser i Film, Fjernsyn Og På Nett, edited by Henrik Grue Bastiansen and Pål Aam, 1st ed., 195-220. Bergen: Fagbokforlaget.

_. 2016. "Aligning Participation with Authorship: Independent Transmedia Documentary Production in Norway". VIEW Journal of European Television History and Culture 5 (10): 40-51.

Karlsen, Joakim, Susanne Koch Stigberg, and Jo Herstad. 2016. "Probing Privacy in Practice: Privacy Regulation and Instant Sharing of Video in Social Media When Running". In Proceedings of the the Ninth International Conference on Advances in Computer-Human Interactions, 29-36, ACHI 2016. Venezia, Italy.

Karlsen, Joakim, and Anders Sundnes Løvlie. 2017. "You Can Dance Your Prototype If You like': Independent Filmmakers Adapting the Hackathon”. Digital Creativity 28 (3): 224-39.

Karlsen, Joakim, and Eirik Stavelin. 2014. "Computational Journalism in Norwegian Newsrooms". Journalism Practice 8 (1): 34-48.

Kay, Alan, and Adele Goldberg. 1977. "Personal Dynamic Media". Computer 10 (3): 31-41. Kay, Alan. 1984. "Computer Software". Scientific American 251 (3): 52-59.

Ken Plummer. 2003. "Continuity and Change in Howard S. Becker's Work: An Interview with Howard S. Becker”. Sociological Perspectives 46 (1): 21-39.

Kensing, Finn, Jesper Simonsen, and Keld Bødker. 1998. "Participatory Design at a Radio Station”. Computer Supported Cooperative Work (CSCW) 7 (3-4): 243-71.

Kerrigan, Susan, and J. T. Velikovsky. 2016. "Examining Documentary Transmedia Narratives through The Living History of Fort Scratchley Project". Convergence: The International Journal of Research into New Media Technologies 22 (3): 250-68.

Koskinen, Ilpo, John Zimmerman, Thomas Binder, Johan Redstrom, and Stephan Wensveen. 2011. Design Research through Practice: From the Lab, Field, and Showroom. Elsevier.

Kovach, Bill, and Tom Rosenstiel. 2007. The Elements of Journalism: What Newspeople Should Know and the Public Should Expect. 1st rev. ed. New York: Three Rivers Press.

Krippendorff, Klaus. 2006. The Semantic Turn: A New Foundation for Design. Boca Raton, Fla.: CRC/Taylor \& Francis.

Kvale, Steinar. 2007. Doing Interviews. Kindle Edition. Vol. 2. London: SAGE.

Larkin, Michael, Simon Watts, and Elizabeth Clifton. 2006. "Giving Voice and Making Sense in Interpretative Phenomenological Analysis". Qualitative Research in Psychology 3 (2): 102-20.

Laurel, Brenda. 1993. Computers as Theatre. Reading, Mass.: Addison-Wesley.

Lewis, Seth C. 2012. "The Tension Between Professional Control and Open Participation". Information, Communication \& Society 15 (6): 836-66. 
Lewis, Seth C., and Nikki Usher. 2013. "Open Source and Journalism: Toward New Frameworks for Imagining News Innovation”. Media, Culture \& Society 35 (5): 602-19.

Liestøl, Gunnar. 1999. "Essays in Rhetorics of Hypermedia Design”. PhD diss., University of Oslo

Liestøl, Gunnar, Terje Rasmussen, and Tomas Stenarson. 2011. "Mobile Innovation: Designing and Evaluating Situated Simulations". Digital Creativity 22 (3): 174-86.

Løvlie, Anders Sundnes. 2010. "Textopia: Experiments with Locative Literature". PhD diss., University of Oslo.

. 2016. "Designing Communication Design". The Journal of Media Innovations 3

(2): $72-87$.

Löwgren, Jonas. 2008. "Five Things I Believe about the Aesthetics of Interaction Design". In The Study of Visual Aesthetics in Human-Computer Interaction, edited by Marc Hassenzahl, Gitte Lindgaard, Axel Platz, and Noam Tractinsky. Dagstuhl Seminar Proceedings. Dagstuhl, Germany: Schloss Dagstuhl.

- 2010. "Designing for Collaborative Crossmedia Creation". In Digital Content Creation: Perceptions, Practices, \& Perspectives, edited by Kirsten Drotner and Kim Christian Schrøder, 15-35. Peter Lang Publishers.

. 2016. "The Collective Novice: A Designers Reflections on Emergent Complexity in Collaborative Media". In Ubiquitous computing, complexity and culture, edited by U1rik Ekman, Jay David Bolter, Lily Díaz, Morten Söndergaard, Maria Engberg, 364374. Oxford: Routledge.

Löwgren, Jonas, and Bo Reimer. 2013a. "The Computer Is a Medium, Not a Tool: Collaborative Media Challenging Interaction Design". Challenges 4 (1): 86-102.

2013b. Collaborative Media: Production, Consumption, and Design Interventions.

Kindle Edition. Cambridge, Massachusetts: The MIT Press.

Löwgren, Jonas, and Erik Stolterman. 2004. Thoughtful Interaction Design: A Design Perspective on Information Technology. Cambridge, Mass.: MIT Press.

Maanen, John Van, Jesper B. Sørensen, and Terence R. Mitchell. 2007. "The Interplay between Theory and Method". Academy of Management Review 32 (4): 1145-54.

Maeda, John. 2004. Creative Code. London: Thames \& Hudson.

Magnus, Mari. 2016. "SKAM-når Fiksjon Og Virkelighet Møtes". Nordicom Information 38 (2): 31-38.

Mancini, Clara, Keerthi Thomas, Yvonne Rogers, Blaine A. Price, Lukazs Jedrzejczyk, Arosha K. Bandara, Adam N. Joinson, and Bashar Nuseibeh. 2009. "From Spaces to Places: Emerging Contexts in Mobile Privacy". In Proceedings of the 11th International Conference on Ubiquitous Computing, 1-10. Ubicomp '09. New York, NY, USA: ACM.

Manovich, Lev. 2013. Software Takes Command: extending the language of new media. New York: Bloomsbury Academic.

McCullough, Malcolm. 1998. Abstracting Craft: The Practiced Digital Hand. Cambridge, Massachusetts: MIT Press.

Meyer, Philip. 2002. Precision Journalism: A Reporter's Introduction to Social Science Methods. 4th Revised edition. Oxford: Rowman \& Littlefield Publishers.

Michael Mateas. 2005. "Procedural Literacy: Educating the New Media Practitioner". On the Horizon 13 (2): 101-11.

Monteiro, Eric, Neil Pollock, Ole Hanseth, and Robin Williams. 2012. "From Artefacts to Infrastructures". Computer Supported Cooperative Work (CSCW) 22 (4-6): 575-607.

Munthe-Kaas, Mette Cheng, Christian Lien Jensen, and Runar Jarle Wiik. 2013. "Project Moken”. http://www.projectmoken.com/. 
Murray, Janet, Ian Bogost, Michael Mateas, and Michael Nitsche. 2006. "Game Design Education: Integrating Computation and Culture". Computer 39 (6): 43-51.

Murray, J. H, and J. Horowitz-Murray. 1997. Hamlet on the Holodeck: The Future of Narrative in Cyberspace. Free Press.

Murray, Janet H. 2012. "Transcending Transmedia: Emerging Story Telling Structures for the Emerging Convergence Platforms". In Proceedings of the 10th European Conference on Interactive TV and Video, 1-6. EuroITV '12. New York, NY, USA: ACM.

Nash, Kate, and John Corner. 2016. "Strategic Impact Documentary: Contexts of Production and Social Intervention". European Journal of Communication 31 (3): 227-42.

New York Times. 2017. "2017: The Year in Visual Stories and Graphics”, 21 December 2017. https://www.nytimes.com/interactive/2017/12/21/us/2017-year-in-graphics.html.

NFB/Interactive - National Film Board of Canada. 2012. 15 March 2012. http://www.nfb.ca/interactive/.

Nichols, Bill. 1991. Representing Reality: Issues and Concepts in Documentary. Bloomington, Ind.: Indiana University Press.

- 2001. Introduction to Documentary. Bloomington: Indiana University Press.

Nicolini, Davide. 2012. Practice Theory, Work, and Organization: An Introduction. Oxford: Oxford University Press.

Nielsen, Rasmus Kleis. 2012. "How Newspapers Began to Blog". Information, Communication \& Society 15 (6): 959-78.

Nyre, Lars. 2009. "Normative Media Research". Nordicom Review 30 (2): 3-17.

- 2014. "Medium Design Method". The Journal of Media Innovations 1 (1).

Nyre, Lars, Solveig Bjørnestad, Bjørnar Tessem, and Kjetil Vaage Øie. 2012. "Locative Journalism: Designing a Location-Dependent News Medium for Smartphones". Convergence: The International Journal of Research into New Media Technologies 18 (3): 297-314.

O’Flynn, Siobhan. 2012. "Documentary's Metamorphic Form: Webdoc, Interactive, Transmedia, Participatory and Beyond". Studies in Documentary Film 6 (2): 141-57. h

- 2015. "Designed Experiences in Interactive Documentaries". In Contemporary Documentary, edited by Daniel Marcus and Selmin Kara. London: Routledge.

Palen, Leysia, and Paul Dourish. 2003. "Unpacking 'Privacy' for a Networked World". In Proceedings of the SIGCHI Conference on Human Factors in Computing Systems, 129-136. CHI '03. New York, NY, USA: ACM.

Parasie, Sylvain, and Eric Dagiral. 2013. "Data-Driven Journalism and the Public Good: 'Computer-Assisted-Reporters' and 'Programmer-Journalists' in Chicago'. New Media \& Society 15 (6): 853-871.

Paterson, Chris, David Lee, Anamik Saha, and Anna Zoellner. 2016. "Production Research: Continuity and Transformation". Advancing Media Production Research, 3-19.

Pavlik, John. 2000. "The Impact of Technology on Journalism". Journalism Studies 1 (2): 229-37.

Pearce, Connor. 2017. "Reality and Fiction in Contemporary Television: The Case of Skam". TDR: The Drama Review 61 (4): 156-61.

Pipek, Volkmar, and Volker Wulf. 2009. "Infrastructuring: Toward an Integrated Perspective on the Design and Use of Information Technology". Journal of the Association for Information Systems 10 (5): 447.

Polanyi, Michael. 2012. Personal Knowledge. Routledge.

Ponterotto, Joseph. 2006. "Brief Note on the Origins, Evolution, and Meaning of the Qualitative Research Concept Thick Description". The Qualitative Report 11 (3): 538-49.

Reas, Casey, and Ben Fry. 2006. "Processing: Programming for the Media Arts". AI \& SOCIETY 20 (4): 526-38. 
Robson, Colin. 2002. Real World Research. 2nd edition. Blackwell Publishing.

Rosen, Jay. 2008. "Afterword: The People Formerly Known as the Audience". In Participation and Media Production: Critical Reflections on Content Creation, edited by Benjamin De Cleen and Nico Carpentier, 1st Unabridged edition, 163-65. Newcastle, UK: Cambridge Scholars Publishing.

Ross, Philippe. 2014. "Were Producers and Audiences Ever Separate? Conceptualizing Media Production as Social Situation". Television \& New Media 15 (2): 157-74.

Roxborough, Scott. 2017. "MIPCOM: European Networks Jump on Adaptations of Scandi Sensation 'Shame'”. The Hollywood Reporter, 14 October 2017. https://www.hollywoodreporter.com/news/mipcom-european-networks-jump-adaptations-scandi-sensation-shame-1048903.

Royal, Cindy. 2012. "The Journalist as Programmer: A Case Study of The New York Times Interactive News Technology Department". \#ISOJ The Official Research Journal of the International Symposium on Online Journalism 2 (1).

Sanders, Elizabeth B.-N. 1999. "Postdesign and Participatory Culture". In Proceedings of Useful and Critical: The Position of Research in Design. Tuusula, Finland: University of Art and Design, Helsinki.

- 2000. "Generative Tools for Co-Designing”. In Collaborative Design, edited by Stephen A. R. Scrivener, Linden J. Ball and Andrée Woodcock, 3-12. Springer London.

Sanders, Elizabeth B.-N., and Pieter Jan Stappers. 2014. "Probes, Toolkits and Prototypes: Three Approaches to Making in Codesigning". CoDesign 10 (1): 5-14.

Schmidt, Kjeld. 2008. "Cooperative Work and Coordinative Practices". In Cooperative Work and Coordinative Practices, 3-27. Computer Supported Cooperative Work. Springer, London.

. 2011. "The Concept of 'Work' in CSCW". Computer Supported Cooperative Work (CSCW) 20 (4-5): 341-401.

Schmidt, Kjeld, and Liam Bannon. 1992. "Taking CSCW Seriously”. Computer Supported Cooperative Work (CSCW) 1 (1-2): 7-40.

Schmidt, Kjeld, and Jørgen Bansler. 2016. "Computational Artifacts: Interactive and Collaborative Computing as an Integral Feature of Work Practice". In Proceedings of the 12th International Conference on the Design of Cooperative Systems, 21-38. COOP 2016. Trento, Italy: Springer

Schmidt, Kjeld, and Ina Wagner. 2004. "Ordering Systems: Coordinative Practices and Artifacts in Architectural Design and Planning". Computer Supported Cooperative Work (CSCW) 13 (5-6): 349-408.

Schmitz Weiss, Amy, and David Domingo. 2010. "Innovation Processes in Online Newsrooms as Actor-Networks and Communities of Practice". New Media \& Society 12 (7): 1156-71.

Sennett, Richard. 2009. The Craftsman. 1 edition. New Haven: Yale University Press.

Shirky, Clay. 2009. Here Comes Everybody: How Change Happens When People Come Together. London: Penguin.

Sidiropoulos, Efstathios A., and Andreas A. Veglis. 2017. "Computer Supported Collaborative Work Trends on Media Organizations: Mixing Qualitative and Quantitative Approaches". Studies in Media and Communication 5 (1): 63-78.

SKUP - Stiftelsen for En Kritisk Og Undersøkende Presse. 2012. 18 April 2012. http://www.skup.no.

Star, Susan Leigh. 1998. "Working Together: Symbolic Interactionism, Activity Theory, and Information Systems". In Cognition and Communication at Work, edited by Yrjö Engeström and David Middleton, 296-319. Cambridge: Cambridge University Press. 
Star, Susan Leigh, and James R. Griesemer. 1989. “Institutional Ecology, 'Translations' and Boundary Objects: Amateurs and Professionals in Berkeley's Museum of Vertebrate Zoology, 1907-39”. Social Studies of Science 19 (3): 387-420.

Stavelin, Eirik. 2014. "Computational Journalism. When Journalism Meets Programming". $\mathrm{PhD}$ diss., University of Bergen.

Steensen, Steen. 2010. "Online Journalism and the Promises of New Technology". Journalism Studies 12 (3): 311-27.

Stockleben, Björn, and Artur Lugmayr. 2016. "The Impact of Fluid Publishing on Media Information Management-A Survey of Latest Journalistic Trends as Data-Driven Journalism, Journalism as Process and Metrics-Driven Journalism”. In Information Systems and Management in Media and Entertainment Industries, 299-318. Springer.

Suchman, Lucy. 2002. "Located Accountabilities in Technology Production”. Scandinavian Journal of Information Systems 14 (2).

Suchman, Lucy, Randall Trigg, and Jeanette Blomberg. 2002. "Working Artefacts: Ethnomethods of the Prototype". The British Journal of Sociology 53 (2): 163-79.

Sundet, Vilde. 2017. "From 'Secret' Online Teen Drama to International Cult Phenomenon: The Global Expansion of SKAM and Its Public Service Mission". In The Scandinavian Invasion: The Nordic Noir Phenomenon and Beyond, edited by Richard McCulloch and William Proctor. Peter Lang.

Svanæs, Dag. 2018. "Philosophy of Interaction". The Interaction Design Foundation. 25 January 2018. https://www.interaction-design.org/literature/book/the-encyclopedia-of-human-computer-interaction-2nd-ed/philosophy-of-interaction.

Sweney, Mark. 2016. "Norwegian Teen TV Hit Shame to Be Remade for US Viewers". The Guardian, 9 December 2016, International edition. https://www.theguardian.com/me$\mathrm{dia} / 2016 / \mathrm{dec} / 09 /$ norwegian-teen-tv-hit-shame-to-be-remade-for-us-viewers.

Tandoc, Edson C. 2014. "Journalism Is Twerking? How Web Analytics Is Changing the Process of Gatekeeping”. New Media \& Society 16 (4): 559-75.

Tandoc, Edson C. 2015. "Why Web Analytics Click". Journalism Studies 16 (6): 782-99.

Tripp, Stephanie. 2012. "From TVTV to YouTube: A Genealogy of Participatory Practices in Video". Journal of Film and Video 64 (1): 5-16.

Tuchman, Gaye. 1980. Making News. Later Printing edition. New York: Free Press.

Vallgårda, Anna. 2013. "Giving Form to Computational Things: Developing a Practice of Interaction Design". Personal and Ubiquitous Computing 18 (3): 577-92.

Weinstein, Matthew. 2006. "TAMS Analyzer Anthropology as Cultural Critique in a Digital Age". Social Science Computer Review 24 (1): 68-77.

Williams, Raymond. 1975. Television: Technology and Cultural Form. New York: Schocken Books.

Winner, Langdon. 1977. Autonomous Technology: Technics-out-of-Control as a Theme in Political Thought. MIT Press.

—. 2001. "Where Technological Determinism Went". In Visions of STS: Counterpoints in Science, Technology and Society Studies, edited by Stephen H. Cutcliffe, 11-17.

Suny Series in Science, Technology, and Society. State University of New York Press.

Wittgenstein, Ludwig. 1997. Filosofiske undersøkelser. Vol. 17. Pax palimpsest. Oslo: Pax.

Wroblewski, David A. 1991. "The Construction of Human-Computer Interfaces Considered as a Craft". In Taking Software Design Seriously, edited by John Karat, 1-19. San Diego, CA, USA: Academic Press Professional.

Young, Mary Lynn, and Alfred Hermida. 2015. "From Mr. and Mrs. Outlier To Central Tendencies". Digital Journalism 3 (3): 381-97.

Zimmerman, John, Jodi Forlizzi, and Shelley Evenson. 2007. "Research Through Design As a Method for Interaction Design Research in HCI". In Proceedings of the SIGCHI 
Conference on Human Factors in Computing Systems, 493-502. CHI '07. New York, NY, USA: ACM.

Zimmerman, John, Erik Stolterman, and Jodi Forlizzi. 2010. "An Analysis and Critique of Research Through Design: Towards a Formalization of a Research Approach". In Proceedings of the 8th ACM Conference on Designing Interactive Systems, 310-319. DIS '10. New York, NY, USA: ACM.

Zotto, Cinzia dal, Yoann Schenker, and Artur Lugmayr. 2015. "Data Journalism in News Media Firms. The Role of Information Technology to Master Challenges and Embrace Opportunities of Data-Driven Journalism Projects". ECIS 2015 Research-in-Progress Papers, May. http://aisel.aisnet.org/ecis2015_rip/49. 

Part II: The Articles 



\title{
Article 1: Computational journalism in Norwegian newsrooms
}

Joakim Karlsen

Eirik Stavelin

\begin{abstract}
This article examines computational journalism as a craft practiced in Norwegian newsrooms. Based on in-depth interviews with expert practitioners in six of the largest newsrooms in Norway we find that computational journalism represents a continuation of traditional (investigative) journalism. While the skills and tools necessary to do this kind of journalism diverge from the typical journalist's, the values and aims align well with tradition. Even though computation enables journalists to cope with the size and scale of journalistically appealing datasets, we find little evidence for computational journalism to increase the efficiency of doing journalism or in any other way rid journalists from low-level technical work.
\end{abstract}

Keywords: communication technology; computer assisted reporting; computational journalism; journalism; online journalism; rhetorical craft

\section{Introduction}

Computational journalism is a contemporary term for journalistic work done in the intersection between journalism and computing. This type of work seems to be more common now, and according to Terry Flew et al. (2012) this has to do with the increasing availability of data and tools and the dynamics often associated with Web 2.0. In this article we are not claiming that computational journalism is a growing trend or that this practice is going to improve or save journalism. The aim of this study is to identify, describe and analyse the work practices of "computational" journalists in Norwegian newsrooms. We are going to find out who they are, what they think is a good computational news story, why and how they create news stories, and how they see their place in their respective newsrooms. To frame and analyse these findings we are going to develop an understanding of computational journalism as a rhetorical craft, using the Aristotelian concept of techné, building on theory from design-, writing-, and science studies (Buchanan 2001; Johnson 2010; Wickman 2012). This paper offers some insights necessary to avoid the pursuit of research on this phenomenon propelled only by hopes, promises and hype. 
In the following we will review the literature on computational journalism before framing computational journalism as a rhetorical craft. After a presentation of the findings from interviewing practitioners of this craft in Norway, we will analyse and discuss these results to reach a better understanding of computational journalism as a performative and productive activity in Norwegian newsrooms.

\subsection{Journalism and Computing}

According to Melisma Cox (2000) computers have been used by journalists to produce news stories since 1952. This practice has often been labelled "computer-assisted reporting" (CAR), and has been supported by an active international community. The organization for Investigative Reporters and Editors (IRE) holds an annual conference on CAR, and the community offers a wealth of books on the topic in bookstores. From the early 1970s, Philip Meyers' book, Precision Journalism: A Reporter's Introduction to Social Science Methods (2002), included advice on how to use computers in reporting. The book describes a work process that is very similar to what other textbooks on journalism recommend (collect, store, retrieve, analyse, reduce and communicate), and offers advice on how computers and methods from the social sciences can support each activity. Depending on what part of the work process that has been emphasized, other labels have been proposed for similar practices, such as data journalism (Gray, Bounegru, and Chambers 2012), data-driven journalism (Mirko Lorenz 2010), and database journalism (Loosen 2002).

As noted by Chris Anderson (2011) the empirical literature on computational journalism is sparse. We have found only one study that investigates how computational journalism is actually performed in the context of the newsroom. Cindy Royal (2012) has undertaken an ethnographic study of the work practices of the New York Times Interactive News Technology Department. Her findings are relevant for this study. The first is that the people working in the department see themselves as journalists first. They value technology in so far as it supports their journalistic work. The second finding is that the NYT group understands the process of producing news applications as lightweight, fast and flexible. The third finding is that the group identifies with the hacker culture emphasizing creativity, innovation and collaboration. The fourth finding is that the important skills needed besides journalism are general problem solving and the mastering of web technology. 
Matthew Powers (2012) identifies three ways of understanding new technologies in news production, as exemplars of continuation, as threats to be subordinated and as the basis for journalistic reinvention. The first perspective is common and researchers find that traditional values in journalism are resilient (Weinhold 2010), and that technophobia is rare amongst journalists who easily see new tools as useful if they support existing practices (O'Sullivan and Heinonen 2008). The second perspective is observed by researchers who focus on conflicts and friction occurring when technology and new forms of work are introduced in newsrooms (Mitchelstein and Boczkowski 2009; Robinson 2011). Turf wars are common and journalists are reluctant to accept innovative technologies in their newsrooms (Singer 2004; Boczkowski 2005; Deuze 2005). The practice of data-driven or computational journalism is seen by some as posing core epistemological challenges to journalism (Parasie and Dagiral 2012). A majority of research conducted specifically on "computational journalism", can be placed within Powers (2012) third perspective of "technology as the basis for journalistic reinvention". This research can again be separated into two groups. The first group offers a hypothetical perspective, exploring ideas on what computational journalism might be. The second group offers a practical design science perspective, creating and testing prototypes of tools for doing computational journalism.

Starting with the hypothetical, Flew et al. (2012) argue "that computational journalism techniques may provide new foundations for original investigative journalism and increase the scope for new forms of interaction with readers". They explain that the utility value of computational journalism comes when it frees journalists from the low level work of discovering and obtaining facts to allow greater focus on the verification, explanation and communication of news. This utility value was emphasized in a recent study of journalists reaction to robot journalism as performed by the Statsheet network (van Dalen 2012). Hamilton and Turner (2009) report from a workshop on computational journalism and explain that:

[...] computational journalism aims to enable reporters to explore increasingly large amounts of structured and unstructured information as they search for stories. At the same time though, computational journalism offers a new way to help sustain the watchdog reporting on which democratic citizenship so clearly depends.

Sarah Cohen et al. (2011) turns the question of how computer scientists can participate in shaping computational journalism to the database community and outlines ideas for a system which is - "a cloud for the crowd" - to support cooperative investigative journalism. Nicho- 
las Diakopoulos (2012) suggests a model for systematic innovation in this field by construction a framework for combining journalistic and computer science concepts into new ideas for computational journalism.

More practical approaches build on methods from computer science (how to achieve various goals using computation) and theory from journalism (what is important to journalists and journalism), and are typically evaluated with journalists as participants to reveal journalistic utility. Examples of this includes a framework for media bias mitigation (Park et al. 2011), tools for finding sources and eyewitnesses (Diakopoulos, De Choudhury, and Naaman 2012) and tools for computer-supported analysis for user-generated content (Diakopoulos et al. 2011).

\subsection{Computational Journalism as a Rhetorical Craft}

Scholars have used an Aristotelian view of craftsmanship to explain productive activities like scientific inquiry (Wickman 2012), writing (Johnson 2010) and design (Buchanan 2001). In line with this we promote an understanding of computational journalism as an activity that depend on a certain kind of techné or a deep understanding of the underlying causality of the practice. In Questions concerning technology (2003) Martin Heidegger explains Aristotle's fourfold causality of artefacts by using a silver chalice as example. The material cause is what the artefact is made of (silver). The formal cause is the form or shape given to the artefact (a cup). The final cause is what the artefact is used for, in Heidegger's example, a sacrificial rite. The moving cause is the craftsman or silversmith. Heidegger underlines the co-dependence of the four causes and that the craftsman duty is to bring forth the artefact, in this example the chalice, letting the end determine the choice of material and form. We will continue by explaining computational journalism by its fourfold causality. After this we will relate this concept of techné to the concepts of episteme and rhetoric.

Data is the material cause of computational journalism. In this context data generally refer to quantitative variables, structured in tabular, tree or graph structures. Tax records, school examination results, financial reports, membership lists, election results and stock prices are frequently used examples. Unstructured data, such as documents, images and audio-visual material can also be subject to computation and is used. For an overview of what data has been used in previous journalistic projects, see The data journalism handbook (Gray, 
Bounegru, and Chambers 2012) or the data journalism awards gallery (Global Editors Network 2012).

The formal cause of computational journalism is most often information visualizations or info graphics. To relax the differences between the subject area of information visualization in computer science and the more pedagogical and artistic info graphics style (both in graphics and subject matter) an alternative term, casual infovis, have been proposed for this kind of graphics (Pousman, Stasko, and Mateas 2007). Narrative theory has been applied to understand online interactive graphics as storytelling (Segel and Heer 2010). Ian Bogost et al. (2010) give a good overview of the different types of interactive news storytelling being developed today. Susan Jacobson (2012) has analysed multimedia news packages produced by the New York Times, emphasizing the use of hypertextual, interactive and social media elements. Steen Steensen (2010) claim that terms like the ones used by Jacobson are to narrow and technology oriented to be useful when understanding new forms of online journalism.

The final cause of computational journalism, or what function it is meant to have in society, is not that different and can easily be aligned with how traditional journalism has been perceived to play a role in society. Kovach and Rosenstiel's $(2007,4)$ nine principles to help journalist to fulfil their task to "...provide people with the information they need to be free and self-governing" applies to computational journalism too. They report that most journalists think that pursuing the truth is important and that journalism must serve as an independent monitor of power.

The journalist or programmer or the journalist-programmer is the moving cause of computational journalism. She combines journalistic skills and value systems with programming skills to bring forth the finished story based on the data, the form and the purpose of the case she is working on. The skills involved in transforming data into a useful form can be classified according to Bloom's taxonomy of learning objectives (Bloom et al. 1956; Kratwohl, Bloom, and Masia 1964; Harrow 1972). The taxonomy consists of a cognitive, psychomotor and affective domain. We propose that in computational journalism computational thinking (Wing 2008; Hu 2011) or programming in an abstract sense are important cognitive skills together with proficiency in investigative reporting. The mastery of applied programming techniques is important psychomotor skills. The affective skills associated with computational 
journalism are to value the traditional journalistic principles as revealed or described by Kovach and Rosenstiel (2007).

There are two more aspects of the ancient understanding of techné that are useful when framing computational journalism. The first is the close relation between techné (craftsmanship) and episteme (science). The second is how techné relates to, or can be understood as, rhetoric. The work practice of computational journalists resembles that of researchers, where the commitment to truth is paramount. Philip Meyer (2002, viii) relates science to journalism: "Scientific method is still the one good way invented by humankind to cope with its prejudices, wishful thinking, and perceptual blinders. And it is definitely needed in journalism [...]". Chad Wickman (2012) conceptualizes scientific inquiry as a productive technical art using the Aristotelian concept of techné and the four causes. He locates rhetoric in the production of artifacts needed by the scientist in the process of inquiry. He writes that: "Knowledge production for these scientists involves an on-going negotiation between instruments, technical procedures, material artefacts, visual representations, and the physical reality that they construct through their inquiry." When the scientist uses these artefacts to communicate and support his knowledge claims the technical and the rhetorical merges. Framed this way it is possible to see how technology, knowledge and rhetoric plays together in scientific inquiry, and we think this the case also for "journalistic inquiry" performed by computational journalists.

\section{Research Design - Finding, Selecting and Interviewing the Journalists}

To find these journalists we started with Eirik Stavelin's lists of news applications (2012) and the names of journalists found in each of the by-lines. One of several criteria for inclusion in this list was that the application, “[...] convey news, where the journalist has written code, himself or in collaboration with a developer [...]”. There are only a few Norwegian newsrooms that have contributed to the list so we were able to create a shortlist of potential candidates quickly. After this we called the informants to assess whether they fit our criteria: producing journalism by computational means. These conversations lead to the inclusion of additional candidates. The reason for this is that people who work with journalistic programming often are omitted in the by-lines. 
During the preliminary telephone interviews we realized that having programming skills was too narrow a criterion for inclusion in the study. Journalists belonging to the computer-assisted-reporting (CAR) tradition, without knowledge of programming, can still have good knowledge of traditional information retrieval methods, practical database management and quantitative methods and can be said to perform computational journalism. We included two journalists within this tradition in the sample. We ended each pre-interview by asking who else we should talk to, thus discovering relevant sources unknown to us beforehand.

We conducted full interviews with eleven people, but have included only nine in our analysis because two were not working in a newsroom context. In our sample we have representatives for three types of newsrooms; television broadcasting, newspapers (still in print) and online newspapers. Six large (national/regional) news organizations are represented: the two largest news producing television channels; the two largest daily national tabloids; and the two largest regional daily papers. These are the biggest media organizations in Norway, with the largest reach in the population. All organizations also produce online newspapers, and the data journalists interviewed produced content for all platforms. The organizations have their base in Oslo or Bergen (or both), the two biggest cities in Norway. The lack of local news producers and small town affiliations is likely a product of the snowball sampling methodology and the possibility that very few local newsrooms practice computational journalism on a regular basis.

We chose a qualitative approach with semi-structured interviews. The interview guide consisted of 5 relatively open questions. The first question was definitional; what is computational journalism to you? We deliberately left this question ambiguous to better capture the interviewees' perspective on the phenomenon. Journalism can refer to both their work practices and the finished news stories. The next question was about good methods and techniques when doing computational journalism. To be certain that we covered the topic we prepared four follow-up questions. How do you get access to data? How do you prepare the data for analysis? How do you analyse the data? How do you tell stories about the data to the readers? The third question focused on the skills needed to do computational journalism, both general and specific. The fourth question was about what kind of support the journalists doing computational journalism need? The follow up questions focused on composition of teams, cooperative work processes, technical infrastructure and tools. The last question was about how the production, publication and form of the "computational" news stories themselves are different from other types of journalism. 
The interviews took between 50-110 minutes. All the interviews were taped, transcribed and imported into TAMS Analyzer, a tool for computer assisted qualitative data analysis (Weinstein 2006). Here we followed John Creswell (2009) suggestions for steps to take when analysing qualitative data. After transcoding the interviews we read the transcripts to get a general sense of the data. The next step consisted of detailed coding. We used both contextual codes linking answers to questions and a hierarchy of thematic codes. Some of the topics were coded based on the goal of the study and some of the codes emerged by reading the transcripts. The last two steps consisted of selecting and grouping statements based on codes and prepare the summary of the results.

\section{Findings}

We have explored computational journalism as a craft, focusing on the work practices of the interviewees. This means that we learn about this phenomenon from the single perspective of the craftsperson. We can relate what they say about the newsrooms they belong to, without being able to verify this by other accounts. We will now summarize how the interviewees perceive themselves and their work practice in the newsrooms before going on to relate our findings from the interviews according to the fourfold causality of computational journalism, material-, formative-, final- and moving cause.

\subsection{In the Newsroom}

When asking about the role played by the computational journalists in the newsrooms, we anticipated stories of conflict. When no conflicts were related, we asked more directly and got answers describing this as a problem of the past.

Now we have developers working in the newsroom, but it wasn't like that before. It felt like I was stepping on everybody's toes back then, as you were partly designer, partly developer, partly journalist, and partly operations person, right. I remember that as being very tiresome.

Now the dependency between journalists and developers seems stronger than the differences in work cultures. One respondent reported that they most often work in teams to “...exploit each other strengths". While some worked in formal groups (multimedia journalism; newsroom IT; etc.), all worked in loosely coupled non-formal cooperation with other journalists and newsroom staff. 
All our respondents had positions inside the newsrooms and not in the ICT departments. These departments are often separated, and cross-departmental cooperation is rare. One respondent told us that: “... the relationship to IT is increasingly institutionalized and formalized and alienated. It is a sad tendency, but that's that". An effort to bypass organizational ICT infrastructure was found in all the newsrooms. Extra software that needed installing, databases that needed to be created, and the setup of servers to host web applications, are all examples of tasks that were done without the help from ICT department. This said, the respondents also reported that in extraordinary cases, e.g. large WikiLeaks dumps, this noncooperation state could be overcome.

The respondents reported that resources in the form of soft- or hardware are not a problem. The technology needed to undertake computational journalism is relatively cheap and available and for the most part already exists in newsrooms. The limiting factors are not the technical infrastructure but according to one of the interviewees, “...time and goodwill” granted from the editors. He continued and said that it is difficult to get the other newsroom staff to understand that, "...computational journalism takes time. Visualization takes time. Analysing takes time. Fetching [data] takes time". Time and goodwill from editors were repeatedly mentioned as key resources when doing computational journalism; "Time is always a limited resource. And of course a boss that trusts you a hundred per cent, because time is ticking...".

\subsection{The Material Cause: Data}

The main findings when it comes to data concern access. In Norway access to public data is regulated by freedom of information legislation that favours transparency and public inspection. Although all interviewees had stories of troublesome bureaucrats complicating matters, there was a clear consensus among them indicating that the access to data is good. One informant told us that: "The available [data sources] are rather good, and people have been very helpful in those cases I've been out nagging. I have almost been surprised by how well it has gone". One interviewee, a senior reporter with a long track record in computer assisted reporting revealed: "I've only used a right of access application once".

While data access offers few problems, some issues of the commercialization of public data were recurring in interviews. Some governmental bodies are allowed to charge money for 
data, and put barriers around the data in ways the current legislation does not (arguably) address. The lack of quality geographical data is one example of this, which was mentioned by several of the interviewees. One of them put it like this: "What annoys me the most is map data in Norway, it is a pain in the ass, that county borders and municipality borders, that I shall not be able to fetch them somewhere in shape-file format".

Getting an overview of what data exist offers a challenge to journalists investigating public records. One interviewee said: “...the job of finding out what data actually exist, that is perhaps the largest job, I think." Further, the public servants who serve the data access requests from journalists are often not trained to export and transfer digital records. One of the interviewees put it like this: “...there is often a lack of knowledge at the other end. They do not know how to retrieve the data. They have data and they have databases, they have all sorts of stuff, but they have no clue how to export it." A common obstacle is the PDF file format, intended to store documents with a stable visual form across platforms, but which is often used to store tabulated data. This creates an extra headache for a computational journalist, who has to scrape the PDFs to get the data into a table format.

\subsection{The Formal Cause: Info Graphics and Storytelling}

The informants described the ideal of "drillable" interfaces to data where both the overall and the detailed view are represented. This presentation should frame and empower the reader to become an investigator / journalist. The global and the local, the journalist and the user are connected by data aggregated to generalities from singular facts. One journalist said that he wanted to convey the "...the unbroken line between the general and the particular". But at the same time they emphasized the difficulty in finding the right balance between the drillable dataset and storytelling. To make data available on the web with search and filtering tools generates little interest. One of the informants puts it like this: “...when we have a large dataset we often give the audience the whole package with lots of buttons and analytic tools etc. Then people aren't really interested." Computational journalists need to filter, select and tell the major trends in the data to attract readers. Several of the informants reported that after experimenting a lot, they have ended up treating datasets more as "internal sources" than artefacts to be published online. One said that it is a "...human being, a journalist, an editor, that chooses the facts that should be mapped". 
Most of the interviewees were wary of their own technological interest and passion, and seek to resist the temptation to add all the possibilities afforded by web technology. They try to overcome “...the 'see what I can do' phase”. One interviewee with a technical background said it is "...very easy to become a technician..." and he had to remind himself not to "forget that there is a reader in the other end". The most important thing is to convey a clear message to the reader, and most readers aren't experienced data wranglers. The end products need to be "'for dummies' to get the message out".

\subsection{The Moving Cause: Journalism by Computation}

The backgrounds of our respondents included both journalism school and IT-related degrees. All but one had higher education of some form. While some had no formal technical education, and had worked their way into more technical tasks, those with journalism degrees mentioned training courses in various technical fields. Of the technically educated interviewees none had studied journalism. When asked what kind of backgrounds would be relevant in a computational journalism team, the respondents mentioned programming, design, typography, info graphics, usability, databases, web and journalism. They all emphasized that to be a computational journalist you need the double vision of technology and journalism, regardless of how teams are put together or the development of editorial support functions. The journalist in our sample with the highest formal education in computer science put it like this: "... we have had developers here, but when it comes to the journalistic bit it all falls to pieces. We have also had journalists here, but when it comes to the development bit it all falls to pieces. That combination is terribly hard. There are very few that have that competence."

When it comes to cognitive skills the logic of investigative reporting has primacy. Almost all of the respondents claimed that curiosity is the one trait you cannot do without, clearly formulated by one experienced journalist with an IT background as: "Curiosity. Curiosity. Curiosity. That is... the essence". This curiosity has to go hand in hand with problem solving capabilities and a sense of logic. As one journalist put it "I guess they [computational journalists] have a... pronounced sense of logic. [...], problem solving is very important". This curiosity and problem solving is not equivalent to what a programmer or developer do, but is scripted by the long tradition of doing investigative reporting. One of the respondents went 
so far as to claim that investigative journalism is programming. He says: "Systematically going through material is investigative journalism and investigative journalism is really a manual form of programming."

When characterizing the hands-on or psychomotorical skills involved in computational journalism work, several of the informants indicated end-user programming as most relevant. They use common applications marketed and sold by technology giants such as Microsoft (excel, access) and Google (docs, maps, refine, fusion tables). The spreadsheet is a central tool, also when cooperating with non-technical journalists. One of the informants put it bluntly “...the essential skill to do data journalism in one: learn Excel”. According to many of the interviewees L/M/W+AMP (linux/mac/windows, apache, mysql and php) is important. This stack of technologies includes a database, a web server, and a scripting language for presentation. Statistical methods and packages are rarely used, but some informants reported using simple methods for cluster, network and regression analysis. The informants were explicitly cautious about using statistical methods - considering this outside their field of competence. Overall they had a pragmatic relationship to technology and emphasized that it is important to be "...able to easily obtain new skills" and "...choose the right tool for the job".

\subsection{The Final Cause: Accountability}

The respondents view on what affective skills a computational journalist should have, are in line with the journalistic tradition. One of the interviews said that a computational journalist should "...feel committed to the social contract of the press". All in all most of the respondents were committed to hard news and fulfilling the accountability function of journalism.

When asked to define computational journalism the respondents didn't offer narrow or distinct definitions. They all gave wide and open definitions that included many different activities and forms. One of the respondents said that he, “...use computational journalism for everything from research and fetching data to visualizations" and that computational journalism is to "...find new ways to both find stories, and to tell stories". Another respondent offer a similar wide definition, “...computational journalism is everything from the simplest use of Excel to heavy tools that enables journalism that is impossible without these tools". They emphasized that computational journalism empower them to do more. Analysis of data is 
central to this. They were able to "analyse large datasets and find support for existing theories, or find new truths, new trends".

\section{Discussion}

We will now interpret and discuss our findings according to the fourfold causality of computational journalism as craft and its newsroom context. To begin with data, as the material to obtain analyse and convey, data is at the core of computational journalism. Access to data is perceived as good by the Norwegian journalists interviewed in this study. This is crucial to them, but must represent a risk to the data owners. The transmission of, or denied access to data is an important event in the constant negotiation for control and power between these parties. Several strategies can be effective when you own data that you don't want to share with the public. One is to "flood" the journalists with data, and hope that they will never be able to analyse it. Another strategy is to make a bet that the journalists have little time on their hand and package the data strategically. The journalist's main tool is a computer, and available sources in the right format will be preferred. Non-controversial data can be made available as well structured excel sheets and controversial data can be hidden or given out in rasterized PDFs. This said, our results indicate that this isn't a big problem with the journalists in our study. Several of them report that they get funding to do "deeper" investigative reporting regularly, resulting in "fresh" stories based on previously unused data.

When it comes to info graphics and storytelling our results show that most of the journalists interviewed for this study have ended up preferring traditional linear storytelling, emphasizing computation as useful for research rather than presentation. Consequently the journalists focus less on giving the readers access to "raw" data. They choose design elements that support linear narrative rather than free exploration. Examples of this are the use of timelines, maps, writing, sound and video. These forms are simple, relatively quick to make and limited in functionality. Graphics, lists, tables, grids, searching and filtering are elements that demand more skills and time. One explanation for this trend can be that the advanced journalistic artefacts, as for instance the drillable dataset, do not get enough positive feedback from the readers to make it worth the (considerably lengthy) time it takes to create it. A positive take on this is that the audience needs time to understand and appreciate these new forms of online journalism. That new genres will develop over time, which have a useful balance between data and story. Another explanation can be that the established tradition of 
journalistic storytelling gives primacy to linearity. The function of journalistic stories is seldom to let the audience explore, but to explain and convey ideas already thought out. Form follows function or rephrased by journalist and information graphics expert Alberto Cairo as "function constrains the form" (Cairo 2012).

When it comes to skills, the training necessary to undertake computational journalism is different from what has traditionally been on offer at journalism schools. A computational journalist needs to master both the inverted pyramid structure of journalistic storytelling and basic iteration statements found in any programming language such as the "while", "for each" and "for" statements. To a certain extent programming is manual and repetitive work, especially when preparing data for analysis. There are general rules to follow when putting together a database and making sure that the quality of the data is good. The fundamental activity is to normalize the database using SQL (Codd 1970). When doing this, errors in the data are often discovered. When this "drawing by numbers" job has been completed the journalistic inquiry can begin. How data are joined, analysed and presented is the direct result of journalistic sense-making combined with proficiency in programming. This is often an inductive process of trial and error, not guided by reasoning alone. The programming becomes inseparable from journalism and vice versa. That said, this "programming-as-journalism" should not be mystified unnecessarily. Programming can be directly compared to other journalistic modes of expression like writing and photography, but as you do not want to hire any photographer as photojournalist - you do not want to hire any programmer to do computational journalism. The development of computational journalism has led to the hiring of new hands and the acquisition of new skills by older journalist. But our respondents, of both these types, gave primacy to journalism skills when explaining what they do. "The journalist's way" of doing things is a prerequisite for doing computational journalism within a news organization. The technical skills are subordinated to the unbroken tradition of journalism. Why do the computational journalist themselves subordinate their technical skills to journalism? One possible explanation is that the cognitive and affective skills necessary to do computational journalism are easily aligned with the journalistic tradition, while the psychomotor skills are not. This represents the difference in how mental and manual labour is valued in the society and in the newsroom. To put it bluntly: programming is viewed as only a technique and therefore something not worth talking about. 
According to Terry Flew et al. (2012) the aim of applying computation to journalism is to free "journalists from the low level work of discovering and obtaining facts, thereby enabling a focus on verification, explanation and communication of news." More journalistic work can be done in less time with fewer errors. In tasks where work is, and also previously was computable, this is a reasonable result to expect. In our study on the other hand, aspects of speed, consistency or accuracy of computers, aspects that could be said to support the accountability function of journalism, are rarely mentioned. On the contrary, time is not something you use less of when doing computational journalism, but more. Programming is a tedious process and added complexity demands constant checking and rechecking of the facts. This is in line with how our respondents chose to define computational journalism. They said they use computers where their colleagues use telephones, microphones and shoe-leather. Sometimes they write a computer program in C\#, sometimes they find, install and use a new software tool to get a job done, and sometimes they use the more advanced features in Excel. Computing is just another tool in the toolbox when aggregating the knowledge needed to tell revealing news stories, alongside notebooks and physical archives. Computational journalism, as framed by programming journalists in Norwegian newsrooms, is a therefore mainly a continuation of journalistic work practices. One exception is worth mentioning though, and that is the use of crowdsourcing, a method interviewees spoke highly of. The potential of using human judgment on the web to gather and verify information is substantial, and it is possible to see how that can transform investigative journalism in some cases.

\subsection{In the Newsroom: Fading Conflicts and a Bright Future?}

To become a programming journalist you must accept that journalism goes before programming. You need to be a journalist "by conviction" to avoid conflict and to be able to thrive in the newsroom. It is important to distance yourselves from the technologists working in the ICT department. Your fellow journalists should not be in doubt whether you belong to the newsroom or ICT. You need to bypass ICT by choosing lightweight technical approaches and find solutions that don't require direct assistance from ICT. This finding is comparable to what Cindy Royal (2012) found in her study of the NYT Interactive Department. Programming journalists at NYT they see themselves as journalists first and technologists second. 
The NYT Interactive Department has established a lightweight "rapid prototyping" based work process, while we find that stable routines are not quite established in Norwegian newsrooms yet. It seems that it is unclear to many what the limitations and possibilities of computing are. There is no "Interactive News Technology Department" in any of the news organizations we visited. The computing journalists in our study are working alone and in small teams, figuring out how to best collaborate as they go. Royal (2012) describes a hacker culture emphasizing creativity, innovation and collaboration. Our informants subscribe to the same values, but are at the same time careful to emphasize that innovation should happen within the boundaries of the journalistic tradition. These differences in findings suggest a cross-national comparison of practices as future research. What differs among different media systems, and what properties of these systems facilitate high quality computational journalism?

The skills needed to do computational journalism are valued by the newsrooms, but are often "black boxed" by editors, non-programming newsroom staff and the computational journalists themselves. In the future it is important that the professionals interviewed in this study are allowed to share the knowledge with other journalists, including the more technical aspects of their practice. Computational journalism is a craft where journalism and computing merge into one process where both skillsets are used simultaneously. To be able to create innovative and journalistically sound products the performer of this craft need a whole understanding of material, form, technique and purpose. We think that it is impossible to outsource the programming and or create an ultimate journalistic machine. Technology in itself cannot solve the challenges that are important to journalists and democracy. Craftsmen with knowledge to build, wield and aim the technology are needed. The interviewees in this study are pioneers in a valuable craft, a craft that needs to be nurtured and given priority if it is to fulfil the potential so clearly identified by editors, researchers and the computational journalists themselves.

\section{Conclusion}

In this paper we have examined the work practices of computational journalism in Norwegian newsrooms. The traditional journalistic process and values are followed, but supplemented with software both as pre-fabricated and project specific programs. Typically the job starts with a dataset, either collected on the journalist's own initiative or by collaborators in 
the newsroom. The access to data in Norway is perceived as good, while the process also includes obstacles of both legal and practical matters. When the data are analysed and facts or trends are found, finding a suitable form to present the results can be a challenge. Advanced info graphics are considered too complex. Aversion for bells and whistles, and a preference for simplicity and clarity, results in the use of linear narratives with timelines, maps, text, sound and video. While the cognitive and affective skills needed to do computational journalism align smoothly with traditional journalistic values, the psychomotor skills (the use of computational techniques) represents a very different practice. When undertaking computational journalism, the creative process is not separable from coding, comparable to how writing can't be separated from authorship. In the current literature we find great hopes for computational journalism, but we suggest modest expectations in this regard, at least if we anticipate these changes coming from within newsrooms. According to the expert practitioners in Norway, the utility of computational journalism is not to free journalists from the low-level work of discovering facts or freeing up time. The utility of computational journalism is rather the development of new forms of data-driven and user-driven journalism that have the potential to fulfil the traditional hopes for and promises of journalism per se.

\section{$6 \quad$ References}

Anderson, Cristopher W. 2011. "Notes Towards an Analysis of Computational Journalism." HIIG Discussion Paper Series 2012 (1). http://papers.ssrn.com/sol3/papers.cfm?abstract_id=2009292.

Bloom, Benjamin S., Max D. Engelhart, Walker H. Hill, Edward J. Furst, and David R. Krathwhol. 1956. Taxonomy of Educational Objectives. The Classification of Educational Goals, Handbook I: Cognitive Domain. David McKay Company. New York: David McKay.

Boczkowski, Pablo J. 2005. Digitizing The News: Innovation In Online Newspapers. MIT Press.

Bogost, Ian, Simon Ferrari, and Bobby Schweizer. 2010. Newsgames: Journalism at Play. Cambridge, Mass.: MIT Press.

Buchanan, Richard. 2001. "Design and the New Rhetoric: Productive Arts in the Philosophy of Culture." Philosophy and Rhetoric 34 (3): 183-206.

Cairo, Alberto. 2012. The Functional Art: An Introduction to Information Graphics and Visualization. 1st ed. Berkeley, Calif.: New Riders.

Codd, Edgar F. 1970. "A Relational Model of Data for Large Shared Data Banks." Communications of the ACM 13 (6): 377-387.

Cohen, Sarah, Chengkai Li, Jun Yang, and Cong Yu. 2011. "Computational Journalism: A Call to Arms to Database Researchers." In The Biennial Conference on Innovative Data Systems Research. Asilomar, California, USA.

Cox, Melissma. 2000. "The Development of Computer-assisted Reporting." In Informe Presentado En Association for Education in Jornalism End Mass Comunication). Chapel Hill, EEUU: Universidad de Carolina Del Norte. 
Creswell, John W. 2009. Research Design: Qualitative, Quantitative, and Mixed Methods Approaches. 3rd ed. Los Angeles: SAGE.

Deuze, Mark. 2005. "What Is Journalism? Professional Identity and Ideology of Journalists Reconsidered." Journalism 6 (4): 442-464.

Diakopoulos, Nicholas. 2012. "Cultivating the Landscape of Innovation in Computational Journalism". Tow-Knight Center for Entrepreneurial Journalism. http://www.nickdiakopoulos.com/wp-content/uploads/2012/04/diakopoulos_whitepaper_systematicinnovation.pdf.

Diakopoulos, Nicholas, Munmun De De Choudhury, and Mor Naaman. 2012. "Finding and Assessing Social Media Information Sources in the Context of Journalism." In Proc. Conference on Human Factors in Computing Systems (CHI). http://research.microsoft.com/en-us/um/people/munmund/pubs/chi_2012.pdf.

Diakopoulos, Nicholas, Mor Naaman, Tayebeh Yazdani, and Funda Kivran-Swaine. 2011. "Social Media Visual Analytics for Events." In Social Media Modeling and Computing, edited by Steven C. H. Hoi, Jiebo Luo, Susanne Boll, Dong Xu, Jin Rong, and Irwin King, 189-209. London: Springer.

Flew, Terry, Christina Spurgeon, Anna Daniel, and Adam Swift. 2012. "The Promise of Computational Journalism." Journalism Practice 6 (2): 157-171.

Global Editors Network. 2012. "DJA 2012 | the Gallery of All the 2012 Data Journalism Awards Shortlisted Projects." http://www.wizehive.com/voting/dja2012.

Gray, Jonathan, Liliana Bounegru, and Lucy Chambers. 2012. The Data Journalism Handbook. Sebastopol, CA: O'Reilly Media.

Hamilton, James T., and Fred Turner. 2009. "Accountability Through Algorithm: Developing the Field of Computational Journalism. Report from Developing the Field of Computational Journalism." Center for Advanced Study in the Behavioral Sciences Summer Workshop: Stanford. http://dewitt.sanford.duke.edu/images/uploads/about_3_Research_B_cj_1_finalreport.pdf.

Harrow, Anita J. 1972. A Taxonomy of the Psychomotor Domain: A Guide for Developing Behavioral Objectives. New York: David McKay.

Heidegger, Martin, and Manfred Stassen. 2003. "The Question Concerning Technology." In Martin Heidegger: Philosophical and Political Writings. New York: Continuum.

$\mathrm{Hu}$, Chenglie. 2011. "Computational Thinking: What It Might Mean and What We Might Do About It." In Proceedings of the 16th Annual Joint Conference on Innovation and Technology in Computer Science Education, 223-227. New York: ACM.

Jacobson, Susan. 2012. "Transcoding the News: An Investigation into Multimedia Journalism Published on Nytimes.com 2000-2008." New Media \& Society 14 (5) (January 9). http://nms.sagepub.com/content/early/2012/01/05/1461444811431864.

Johnson, Robert R. 2010. "Craft Knowledge: Of Disciplinarity in Writing Studies." College Composition and Communication 61 (4): 673-690.

Kovach, Bill, and Tom Rosenstiel. 2007. The Elements of Journalism: What Newspeople Should Know and the Public Should Expect. 1st rev. ed. New York: Three Rivers Press.

Kratwohl, David R., Benjamin S. Bloom, and Bertram B. Masia. 1964. Taxonomy of Educational Objectives, the Classification of Educational Goals. Handbook II: Affective Domain. New York: David McKay.

Loosen, Wiebke. 2002. "The Second-Level Digital Divide of the Web and Its Impact on Journalism." First Monday 7 (8). 1996 - 2002. http://firstmonday.org/ojs/index.php/fm/article/view/977.

Meyer, Philip. 2002. Precision Journalism: a Reporter's Introduction to Social Science Methods. 4th Revised edition. Oxford: Rowman \& Littlefield Publishers. 
Mirko Lorenz. 2010. "Data-driven Journalism: What Is There to Learn? (Stanford, June 201..." Stanford. http://www.slideshare.net/mirkolorenz/datadriven-journalism-whatis-there-to-learn.

Mitchelstein, Eugenia, and Pablo J Boczkowski. 2009. "Between Tradition and Change A Review of Recent Research on Online News Production." Journalism 10 (5): 562586.

O’Sullivan, John, and Ari Heinonen. 2008. “Old Values, New Media.” Journalism Practice 2 (3): 357-371.

Parasie, Sylvain, and Eric Dagiral. 2012. "Data-driven Journalism and the Public Good: 'Computer-assisted-reporters' and 'programmer-journalists' in Chicago.” New Media \& Society. doi:10.1177/1461444812463345. http://nms.sagepub.com/content/early/2012/11/15/1461444812463345.

Park, Souneil, Minsam Ko, Ying Liu, Dal Yong Jin, and Junehwa Song. 2011. "Improving Journalism through the Web: Framework for Media Bias Mitigation." In Proceedings of the 3rd International Conference on Web Science. Koblenz, Germany. http://www.websci11.org/fileadmin/websci/Posters/88_paper.pdf.

Pousman, Zachary, John Stasko, and Michael Mateas. 2007. "Casual Information Visualization: Depictions of Data in Everyday Life." IEEE Transactions on Visualization and Computer Graphics 13 (6): 1145-1152.

Powers, Matthew. 2012. "'In Forms That Are Familiar and Yet-to-Be Invented' American Journalism and the Discourse of Technologically Specific Work." Journal of Communication Inquiry 36 (1): 24-43.

Robinson, Sue. 2011. "Convergence Crises: News Work and News Space in the Digitally Transforming Newsroom." Journal of Communication 61 (6): 1122-1141.

Royal, Cindy. 2012. "The Journalist as Programmer: A Case Study of The New York Times Interactive News Technology Department." The International Symposium on Online Journalism 2 (1).

Segel, Edward, and Jeffrey Heer. 2010. "Narrative Visualization: Telling Stories with Data." IEEE Transactions on Visualization and Computer Graphics 16 (6): 1139-1148.

Singer, Jane B. 2004. "Strange Bedfellows? The Diffusion of Convergence in Four News Organizations." Journalism Studies 5 (1): 3-18.

Stavelin, Eirik. 2012. "Nyhetsapplikasjoner: Journalistikk Møter Programmering." In Nytt På Nett Og Brett: Journalistikk i Forandring, edited by Martin 1956- Eide, Leif Ove 1961- Larsen, and Helle 1977- Sjøvaag, 107-125. Oslo: Universitetsforlaget.

Steensen, Steen. 2010. "Online Journalism and the Promises of New Technology." Journalism Studies 12 (3): 311-327.

Van Dalen, Arjen. 2012. "The Algorithms Behind the Headlines." Journalism Practice 6 (56): 648-658.

Weinhold, Wendy. 2010. "Letters from the Editors." Journalism Practice 4 (3): 394-404.

Weinstein, Matthew. 2006. "TAMS Analyzer Anthropology as Cultural Critique in a Digital Age." Social Science Computer Review 24 (1): 68-77.

Wickman, Chad. 2012. "Rhetoric, Tekne, and the Art of Scientific Inquiry." Rhetoric Review 31 (1): $21-40$.

Wing, Jeannette M. 2008. "Computational Thinking and Thinking About Computing." Philosophical Transactions of the Royal Society A: Mathematical, Physical and Engineering Sciences 366 (1881): 3717-3725. 


\section{Article 2: Transmediavendingen i ny norsk uavhengig dokumentarfilm}

Joakim Karlsen

\section{Innledning}

Dokumentarproduksjon for nye medieplattformer har blitt mer vanlig de siste årene (O’Flynn, 2012). En rekke dokumentarprosjekter har tatt i bruk mulighetene som ligger i forbedret webteknologi og nye bruksmåter som gjerne innrammes av begrepet "Web 2.0" (O’Reilly, 2007). Kjente eksempler på dokumentarer laget for flere plattformer er Artes "Prison Valley" (Dufresne and Brault, 2010) og National Film Board of Canadas dokumentarserie, "Highrise" (Cizek, 2010). Et ferskt eksempel på et lignende prosjekt i Norge er "Project Moken" (Munthe-Kaas et al., 2013).

I oktober 2011 tok Norsk filminstitutt (NFI) initiativ til å bevilge penger til produksjon av slike dokumentarer som de gir betegnelsen "transmedia" (Fagerholt, 2011). Det nevnte "Project Moken" er det første prosjektet som har fått innvilget slik støtte fra instituttet ("Project Moken - NFI”, 2012). Målet med denne studien er å undersøke hvordan det norske, uavhengige dokumentarfilmmiljøet har tatt imot og utnyttet dette initiativet samt beskrive hvilken praksis som har utviklet seg innen produksjon av transmediadokumentarer her i landet. Jeg har intervjuet 14 produsenter og regissører - tilhørende 11 produksjonsselskaper - og spurt dem om hva en transmediadokumentar er for noe, hva den er laget av, hvilken form den har, hvilke formål den har, og til slutt hvilken kompetanse som kreves for å lage den. Jeg har også spurt dem om hvordan de oppfatter NFIs initiativ og hvordan dette påvirker de generelle produksjonsbetingelsene for uavhengig dokumentar i Norge.

Når NFI etterlyser dokumentarprosjekter som tar i bruk flere medieplattformer, eller transmediadokumentarprosjekter, er dette radikalt nytt i norsk sammenheng. Ifølge intervjuene som er foretatt i denne studien, er initiativet motivert ut fra et ønske om nyskaping i det uavhengige dokumentarfilmmiljøet, og et håp om at Norge skal ha en ledende rolle i det som oppfattes som en viktig internasjonal trend. De siste årene har det vært en kontinuerlig "buzz" knyttet til transmediadokumentar internasjonalt, gjerne i forbindelse med viktige festivaler som International Documentary Film Festival Amsterdam ("IDFA", 2013) og Canadian International Documentary Festival ("Hot Docs”, 2013). Disse festivalene har løftet 
fram transmediaproduksjoner ved hjelp av spesialpriser samt arrangert egne paneler og workshops som omhandler temaet.

Det ser ut til at deler av bransjen er positive til utspillet fra NFI, men det er også tydelig at det stilles spørsmål ved satsingen på transmediadokumentar. På Dokumentarkonventet 2012 i Bergen, der jeg var invitert til å holde foredrag, uttrykte flere undring over hva transmediadokumentar egentlig er, hvordan den skal lages, og hvor pengene til innovasjonen skal komme fra. Magre økonomiske rammebetingelser er nok den viktigste faktoren for å forstå hvorfor mange er skeptiske til NFIs utspill. Pengene som skal gå til innovasjon av transmediadokumentar, tas fra den samme støtteordningen som skal finansiere tradisjonell dokumentarfilm. Denne potten er relativt liten i forhold til behovet i bransjen. Bransjen er også fragmentert, med mange små aktører som produserer få filmer. Manglende profesjonalisering og kontinuitet er et vedvarende stort problem for faglig og økonomisk utvikling (Berntsen, 2008; Köhncke, 2006; Stenderup, 1994). Det er få som kan ta risikoen som er knyttet til eksperimentering og innovasjon av nye formater. I sitt innspill til kulturløftet 2009 beskriver bransjeorganisasjonen Dokumentaristene situasjonen slik:

Dokumentarfilmen har lav støtteintensitet og høy egenfinansiering - og denne er hovedsakelig basert på gratisarbeid. [...] de færreste prosjektene som får støtte er i nærheten av å være fullfinansiert. Etter et par filmer forsvinner talentene til fiksjonssektoren eller kommersielle medier fordi det blir for uholdbart, til tross for at man drives av brennende engasjement. (Dokumentaristene, 2009)

Før jeg redegjør for hva de uavhengige dokumentarfilmprodusentene sier om produksjon av transmediadokumentar, skal jeg beskrive fire enkle akser som tydeliggjør grunnleggende forskjeller mellom produksjon av filmdokumentar og produksjon av transmediadokumentar. Aksene vil kunne brukes som verktøy for den uavhengige dokumentarfilmbransjen når den skal evaluere og utvikle sin praksis videre, men de gir også et godt grunnlag for å analysere og drøfte intervjuene i denne undersøkelsen. De gjør det mulig å vurdere hvor langt de uavhengige produsentene jeg har intervjuet, har kommet når det gjelder å forstå og ta i bruk mulighetene som har åpnet seg med forbedret webteknologi og et større mangfold av medieplattformer.

\section{Dokumentarhåndverk mellom film og spill}

Det er to hovedgrunner til at jeg mener det må utvikles noen nye begrepslige verktøy for å få en god forståelse for norsk uavhengig dokumentarfilmpraksis i møte med oppfordringen fra NFI om å eksperimentere med transmediafortellinger. Den første grunnen er at jeg ønsker å 
inkludere praktiske og håndverksmessige aspekter som essensielle for å forstå utviklingen fra dokumentarfilm til transmediadokumentar. Tidligere studier av transmediafortelling fokuserer i hovedsak på estetiske sider ved de nye formatene, det vil si den ferdige teksten og hvordan den konsumeres av publikum (Jenkins, 2008). Den andre grunnen er at den estetikken som blir resultatet av en slik fokusering, som regel lar begrepet om interaktivitet bli for sentralt. Forskere som beskriver den nye dokumentaren (webdokumentar, interaktiv dokumentar, databasedokumentar, transmediadokumentar), er i stor grad opphengt i ulike begreper om interaktivitet (Almeida and Alvelos, 2010; Aston and Gaudenzi, 2012; Galloway et al., 2007; Gaudenzi, 2013; Gifreu, 2011; Nash, 2012; Sørensen, 2013). Galloway et al. (2007) definerer denne typen dokumentarer som “...alle dokumentarer som bruker interaktivitet som en sentral del av sin avleveringsmekanisme". Begrepet om interaktivitet er viktig, men samtidig er det flere interessante aspekter ved de nye dokumentarformatene. Digitalisering, modularisering, automatisering og foranderlighet åpner for nye teksttyper, eller tekstsystemer, som ikke nødvendigvis trenger å være interaktive. Både Lev Manovich (2001), som jeg har hentet disse fire begrepene fra, og Espen Aarseth (1997) har utviklet generelle teorier for henholdsvis nye medier og kybertekst som gir en større bredde i forståelsen av nye mediers tekster enn det ulike begreper om interaktivitet klarer å fange inn.

Både dokumentarfilmproduksjon og produksjon av transmediadokumentar kan karakteriseres som håndverk. Med dette mener jeg en grunnleggende forståelse for hva som bestemmer uttrykksmåten: Hvilket materiale som brukes, hvilken form som gis, hvilke formål som legges til grunn samt hvilke teknikker og ferdigheter som anvendes. Jeg tar utgangspunkt i en klassisk aristotelisk forståelse av håndverk som er gitt en grunnleggende etisk ramme av Martin Heidegger i essayet Questions Concerning Technology (1954). Han forklarer Aristoteles’ firfoldige kausalitet ved å bruke et sølvbeger som eksempel. Den materielle årsaken er hva begeret er laget av (sølv). Den formale årsaken er den formen gjenstanden gis (beger). Den finale årsaken er hva gjenstanden blir brukt til (offerritual). Den bevegende årsaken er håndverkeren eller sølvsmeden. Heidegger understreker den gjensidige avhengigheten mellom de fire årsakene med håndverkerens plikt til å frambringe gjenstanden og la formålet bestemme valget av materiale og form. Jeg skal nå anvende denne forståelsen av håndverk og utlede fire akser som forteller noe kvalitativt om ulikhetene mellom produksjon av dokumentarfilm og produksjon av transmediadokumentar. For å gjøre dette har jeg sammenlignet teori om hva dokumentarfilm er (Nichols, 2001, 2001) med en 
teori om hva retoriske spill er (Bogost, 2007; Bogost et al., 2010). Teoriene er knyttet til forskjellige uttrykksmåter og er av den grunn ulike, men det er lett å få øye på en del likheter som antyder en kontinuitet mellom gamle og nye former for dokumentar. Grunnen til at jeg velger å la retoriske spill stå som ytterpunkt i denne sammenhengen, er at spill er en tydelig form som faller innenfor begrepet om transmediafortelling, men som bryter radikalt med film.

Den første aksen er knyttet til hva dokumentaren er laget av (den materielle årsak). Både Nichols og Bogost vektlegger det tette forholdet mellom verden og uttrykksformene de studerer. Nichols beskriver hvordan film representerer verden, og Bogost beskriver hvordan regelbaserte systemer eller spill gjør det samme. Den verden vi deler, dokumenteres, men ved hjelp av svært ulike teknologier. For Nichols representeres verden ved hjelp av en kronologisk strøm av video, lyd og tekst, men for Bogost representeres verden ved hjelp av prosesser og regler som kan programmeres på en datamaskin. Dette gir aksen: (verden representert som filmopptak) -> (verden representert som simulering).

Den andre aksen er et uttrykk for hvilket formål dokumentaren har (den finale årsak). Både Nichols og Bogost vektlegger at den har som oppgave å opplyse, overbevise og skape affekt hos publikum. Forskjellen mellom dokumentarfilmen og dokumentarspillet er hvilke forhold i samfunnet det er lett å beskrive eller representere. Det er forskjellige temaer som egner seg for nære, situerte og personlige standpunkter (dokumentarfilm) og modellering av abstrakte prosesser (dokumentarspill). Bogost skriver at retoriske spill, "[...] would deal with the exposition of the fundamental structure of situations intended to invoke support, doubt, or debate about their validity or desirability, or universality" (Bogost, 2007, p. 58). Praksisen knyttet til produksjon og publisering av de to hovedformene innebærer med andre ord to ulike epistemologier - eller måter vi får kunnskap om verden på. Dette gir aksen: (affekt ved identifikasjon) -> (affekt ved abstraksjon).

Den tredje aksen er et uttrykk for hvilken form dokumentaren skal ha (den formale årsak). Nichols og Bogost utvikler to ulike retorikker eller anbefalinger, knyttet til hvilke virkemidler som best kan overbevise publikum eller brukerne om et perspektiv eller standpunkt til verden. Nichols' retorikk er knyttet til stemme og hvordan denne stemmen kan styrkes ved hjelp av bilder, lyd og tale som er situert og nært forbundet med sosiale aktører og hendelser i den historiske verden. Bogosts retorikk er knyttet til sammenkoblingen av interaksjon og prosess, hvor brukerne er med å avdekke hvordan utvalgte deler av verden henger sammen og virker. Det paradigmatiske eksempelet Bogost trekker fram, er hvordan spilling av The McDonald's Videogame (Molleindustria, 2006) legger til rette for at brukerne 
må ta stilling til de vanskelige avveiningene kjeden må ta når det gjelder å renonsere på dyrehelse, arbeidsforhold og miljøhensyn for å maksimere profitt. Dette gir aksen: (stemme som situert perspektiv) -> (prosess som systemisk perspektiv).

Den fjerde aksen er et uttrykk for hvilken håndverksmessig praksis som må utvikles for å støtte opp under de to ulike hovedformene (den bevegende årsak). Det handler om den kompetansen og kunnskapen forfatterne må ha for å forme materialet med tanke på formål. Nichols beskriver praksisfellesskapet knyttet til dokumentarfilmproduksjon og legger vekt på diskursen som bestemmer de mulige valgene filmskaperen må ta angående planlegging, opptak og redigering av bilde, lyd og tale. Han plasserer dette i et institusjonelt rammeverk av støtteordninger, bransjeorganisasjoner, tv-kanaler og produsenter. Diskursene er historisk bestemt ved at de utvikler seg over tid og varierer fra land til land. Bogost (2007) beskriver ikke inngående hvordan retoriske spill produseres eller hvordan spillskaperne forholder seg til et praksisfellesskap, men i en artikkel skrevet sammen med kollegaer ved universitetet Georgia Tech i USA, redegjør han indirekte for dette ved å beskrive hvilken utdanning denne typen fagfolk trenger (Murray et al., 2006). Universitetet legger vekt på undervisning i flere disipliner, og det blir beskrevet på denne måten:

Instead of providing a one-track pipeline optimized for a single approach to games, the Georgia Tech program offers a range of perspectives, emphasizing connections with poetry, art installations, human-computer interaction, interactive television, film studies, science studies, information design, and computer science.

For å kunne tilby dette oppfordrer de lærekreftene til å dyrke og opprettholde tette bånd til ulike praksisfellesskap i industrien. Spillproduksjon er en aktivitet som stiller egne krav til spillskapernes kompetanse, og som er knyttet til metode, teknologi og form. Utvikling av programvare og 3D-verdener følger en annen logikk enn utvikling av film. Dette gir aksen: (forfatterskap ved filmproduksjon) -> (forfatterskap ved spillproduksjon).

Før jeg tar disse fire aksene i bruk for å analysere og drøfte intervjuene med de uavhengige dokumentarfilmprodusentene, skal jeg redegjøre for hvordan undersøkelsen er gjennomført.

\section{Utvalg og metode}

Det norske dokumentarfilmmiljøet er som nevnt lite, og det består av mange små selskaper som produserer nå og da. For å finne informanter til undersøkelsen brukte jeg flere kilder. Først brukte jeg hjemmesidene til NFI og oversikten over tildelinger til dokumentarfilm 
(“Tilskuddsordninger for dokumentarfilm - NFI," 2013). Jeg registrerte hvilke produksjonsselskaper som har fått støtte i perioden november 2010 til november 2012, og hvor mange tildelinger som ble gitt hver enkelt. Deretter ba jeg Norske film-, TV- og spillprodusenters forening om en liste over de mest aktive dokumentarfilmprodusentene blant deres medlemmer. Til slutt merket jeg av de produsentene som har laget dokumentar for flere plattformer eller som er i ferd med å gjøre det. Her brukte jeg delvis min forhåndskunnskap og delvis samtaler med kontakter i bransjen. Jeg jobbet selv med dokumentarfilm i siste halvdel av 1990-tallet og har derfor god kjennskap til deler av miljøet. Når denne informasjonen var sammenstilt, tok jeg kontakt med produsentene som sto øverst på listen. Kriteriet som var viktigst for sorteringen, var antall tildelinger fra NFI. Jeg intervjuet 11 av de 18 selskapene fra den øverste delen av listen. I noen av selskapene intervjuet jeg flere ansatte, og jeg har 14 produsenter og regissører med i utvalget. I tillegg til dette intervjuet jeg produksjonsrådgiveren for dokumentarfilm på NFI, som har formidlet mulighetene til å få støtte til transmediadokumentar og som er involvert i tilrettelegging for bransjen på dette området.

Jeg har valgt en kvalitativ tilnærming med semistrukturerte intervjuer til denne undersøkelsen. Intervjuguiden besto av seks ganske åpne spørsmål som ble stilt til de uavhengige produsentene og produksjonsrådgiveren på NFI. Ett spørsmål knyttet til hver av de fire aksene utviklet over. Hva lages en transmediadokumentar av? Hvilket formål har en transmediadokumentar? Hvilken form har en transmediadokumentar? Hvordan lages en transmediadokumentar? I tillegg ble informantene spurt om hva transmedia er og hvordan de har oppfattet NFIs transmediainitiativ. Intervjuene tok mellom 50 og 90 minutter, og de ble tatt opp på lydbånd, transkribert og importert til programmet TAMS Analyzer, et verktøy for kvalitativ datastøttet analyse (Weinstein, 2006). Her fulgte jeg John Creswells (2009) forslag til stegvis analyse av kvalitative data. Etter transkribering ble intervjuene lest for å gi grunnlag for en generell forståelse av materialet. Deretter ble materialet kodet med nøkkelord, knyttet til kontekst, spørsmål og temaer. Noen temaer var gitt av undersøkelsens fokus, mens andre oppsto underveis gjennom arbeid med materialet. De siste to stegene besto av å velge og gruppere sitater basert på nøkkelord, og lage et sammendrag. 


\section{Resultater}

Denne undersøkelsen er et bidrag til å forstå hvordan uavhengige norske produsenter av dokumentarfilm snakker om transmediadokumentarproduksjon (høsten 2012). For de fleste av dem representerer transmedia nye muligheter som de enda ikke har utnyttet og fått et bevisst forhold til. Mange av dem har erfaring med å bruke nye plattformer som støtte for eksisterende filmpraksis, og de har lett for å snakke om finansiering, lansering og distribusjon av dokumentarfilm på flere plattformer. Et eksempel er Line Halvorsens “Å leve uten penger”, som ble delvis realisert ved hjelp av kickstarter ("Living Without Money - Kickstarter", 2011) og lansert ved hjelp av Internett. Et nylig prosjekt som har blitt hjulpet fram av Nordisk Forum, er “The Accidental Rockstar", som når dette blir skrevet, nettopp har avsluttet en større og vellykket crowdfunding-kampanje ("Manymade - The Accidental Rockstar", 2013). Når det gjelder distribusjon av dokumentarfilm, så har "Distrify” fått mye oppmerksomhet i det norske miljøet. Selskapet tilbyr en økonomisk modell for uavhengige produksjoner ("Distrify", 2012). Firmaet tilbyr en "embeddable" strømmetjeneste hvor fordelingen mellom selskapet og produsenten er 70/30 i produsentens favør. Hvis andre velger å dele filmen på sosiale medier, får de $10 \%$ av inntektene - som tas fra produsentens og selskapets andel. Når jeg har vendt intervjuene mot produksjon av transmediadokumentar som en ny praksis, har svarene blitt vage, og det er stor forskjell mellom enkeltprodusentene med hensyn til hvilken kunnskap og erfaring de har. Heldigvis har de fleste produsentene i denne undersøkelsen vært modige og strukket seg langt for å beskrive et landskap som er nytt, noen med ryggen til, andre med løpefart inn i det nye.

\subsection{Produksjonsrådgiveren}

Overordnet så oppfordrer produksjonsrådgiveren på NFI den uavhengige dokumentarfilmbransjen til å være innovativ og nyskapende i sine prosjekter, og han etterlyser dokumentarprosjekter som tar i bruk flere av mulighetene som er knyttet til de mange nye plattformene som har blitt en del av dagens medievirkelighet. Selv om han synes det er vanskelig å ramme inn hvordan de nye "transmediale" prosjektene skal se ut, ønsker han at bransjen skal være med på å utvide rammene for audiovisuelle dokumentaruttrykk på denne måten. Selv om han antyder at alt er mulig, formidler han noen kriterier for hva transmediadokumentar er. Han skiller klart mellom lansering og produksjon, og sier:

For at det skal være en transmedial historie, som ikke bare er lansering, så må minst én ute i verden kunne påvirke handlingen for noen andre. 
Publikums rolle gis her en avgjørende betydning med tanke på hva som er transmedialt og hva som ikke er det. Han framhever forholdet mellom publikums involvering og det dokumentaren handler om som en grunn til at transmedia passer bedre som dokumentar enn som fiksjon.

Der har dokumentaren en fordel, ved at det som dokumentaren handler om er virkelig, og da fins det utenfor filmen, og det kan det hende at folk vil være med på og delta i, det som er filmens historie da, i utgangspunktet, sånn at det ikke lenger blir en historie filmen har, men hvor man er med også i historien, og hvor da historien ikke slutter ved utkanten av filmen for å si det sånn, men inkluderer den som ser på og kanskje er med.

Dette vil være produksjonsrådgiverens svar på hva en transmediadokumentar er laget av. Det er verden som blir involvert i representasjoner av seg selv. Når han skal beskrive hvilken form en transmediadokumentar kan ha, er han med vilje uklar. Han sier han ikke ønsker å beskrive dette for tydelig fordi transmedia enda ikke har funnet sin form. Bransjen må få lov til å definere det nye uttrykket gjennom prøving og feiling:

Så i utgangspunktet har vi sagt at alt er mulig selv om åpenbart alt er ikke mulig, men at vi kommer ikke til å støtte alt, men vi ønsker at folk skal utfordre oss på hva som er mulig, så får heller vi sette grensene etterhvert og stramme inn etterhvert.

Når det gjelder form, blir han allikevel tydeligere når han vektlegger forholdet mellom spill og dokumentar. Regissørens oppgave blir å bestemme reglene for hvor mye deltageren kan være med å påvirke historien. Han forteller at han ofte bruker online-spill når han skal forklare hva transmedia er.

Det er åpenbart at der har du hver din karakter, og alle kan interagere med hverandre etter ett eller annet system gitt av en regissør, og man kan kommunisere med andre i det spillet og også påvirke deres spill. Det er et transmedialt prosjekt sånn sett.

Videre bruker han orienteringsløp som eksempel på transmediadokumentar, hvis løpet blir filmet og lagt ut på nettet. Det er vanskelig å gripe hvordan rådgiveren ser for seg forholdet mellom dokumentarfilm, transmediadokumentar og støtteordningen han administrerer. Ifølge ham må et transmediaprosjekt som skal falle innenfor støtteordningen, ha et sterkt audiovisuelt uttrykk, men samtidig ønsker han radikale prosjekter som ikke er film. Om formålet med transmediadokumentar i forhold til filmdokumentar så sier han:

Men jeg ser jo at når man har et transmedialt prosjekt så er det jo istedenfor at du lager ferdig produktet ditt og så viser det til et publikum passivt. Hvis man lager dokumentar, så håper man at de skal gjøre noe med det, eller protestere, eller være enig, eller ett eller annet sånt. Så tar transmediaprosjektene mere hånd om den aktiviteten publikum kanskje har lyst til å gjøre da. 
Han framhever transmediadokumentaren som en ramme for aktivitet og engasjement som det ikke har vært mulig å skape ved hjelp av dokumentarfilm. Når det gjelder produksjon av transmediadokumentar, tror han at produsentene vil klare å finne nødvendig kompetanse når det trengs. Han sier at de har stor erfaring med å innhente fagressurser, og ser ikke forskjell på å hente inn en menneskerettighetsekspert og en teknolog som skal bidra i utviklingen av en webløsning. Rådgiveren formidler samtidig at det fort kan blir kostbart når nye fagressurser, gjerne knyttet til IT- og reklamebransjen, skal inn i prosjektene. De små produsentene har ikke vært vant til å jobbe med disse aktørene, og de kan fort gå på en økonomisk smell.

\subsection{De uavhengige produsentene}

\subsubsection{Hvordan oppfattes NFIs initiativ?}

Mange av produsentene jeg har intervjuet, er usikre på hva NFI vil med satsingen på transmediadokumentar. En av dem lurer på hvordan initiativet er forankret i organisasjonen.

[rådgiveren] som egentlig ikke bestemmer har motivert folk til å søke om det, og det har blitt lov å søke om det, og det finnes masse penger i Norge til film, og han har motivert folk på privaten er mitt inntrykk. Jeg aner ikke om han er ansatt i en rolle, og at dette har blitt avklart av noen, og at dette er viktig. Jeg vet ikke hvordan dette har kommet i gang. Hvem er initiativtaker egentlig? (\#10)

Hvis dette er en beslutning som er tatt av fast ansatte byråkrater hos NFI, og ikke de kunstnerisk ansvarlige konsulentene som er ansatt i åremålsstillinger, stiller flere av produsentene seg kritiske til satsingen. Det vil helst ta initiativ til slike prioriteringer selv, eller i samarbeid med fagkonsulentene, og basert på en naturlig faglig utvikling og interesse. Flere mistenker at initiativet er motivert av at NFI ønsker å henge seg på en internasjonal "hype" og ikke en helhjertet interesse for transmediadokumentar.

Det er et budskap som er sånn... nå har vi hatt besøk fra den og den i Arte eller den og den, sånn og sånn, så dette er noe vi skal satse mye på, og så ligger det en parentes $\mathrm{i}$ lufta... men vi har ikke så lyst til det egentlig. (\#1)

Mange av produsentene lurer på hva transmedia innebærer for det økonomiske forholdet mellom dem og NFI. Flere tror søknader med innslag av transmediaelementer nå vil vurderes positivt av instituttet. En informant antyder at mange nå vil komme til å søke om støtte til transmedia, uten at dette er godt forankret i et reelt ønske om å ta i bruk nye plattformer. 
Når NFI kommer hit og sier de har øremerka en del penger til transmedia. [...] Da blir det veldig sånn, åja, da skal vi lage transmedia. Da slenger vi sammen ett eller annet som har noe med nettet å gjøre og så kaller vi det transmedia og så søker vi. (\#12)

Flere etterlyser egne støtteordninger til satsing på transmediadokumentar. De frykter at de nye aktivitetene vil spise for mye av den lille potten som allerede går til dokumentarfilm. En av produsentene har en oppfatning av at transmedia koster mye penger og ønsker å beskytte det han kaller primærarbeidet, som er filmproduksjon:

Det [transmedia] kommer av og til i veien for det som er primærarbeidet som vi driver med og det er god historiefortelling, type TV- og filmform. Jeg ser og hører folk som har gjort transmediaprosjekter rundt dokumentarer som blir jævla frustrerte fordi de merker at pengene ryker ut og det er ekstremt vanskelig å lage... (\#13)

Ut fra intervjuene kan det se ut som utspillet fra NFI så langt er utilstrekkelig forankret i bransjen og i organisasjonen selv, både faglig og økonomisk. Når det er sagt, er det tydelig at NFI i stor grad har blitt hørt, og alle de uavhengige produsentene ser ut til å ta initiativet på alvor. Dette kan være et symptom på hvor avhengige de er av NFIs midler, men også hvor pragmatisk de jobber med støtteordningens varierende innretning.

\subsubsection{Hva er transmediadokumentar?}

Nesten alle produsentene jeg intervjuet, uttrykte liten interesse for hvordan transmedia skal defineres. Når jeg spurte dem hva transmedia er, refererte de fleste til produksjonsrådgiverens definisjon.

Jeg vet ikke. Jeg har bare [rådgiverens] sin definisjon av det og det er... Forstår jeg han rett så er påstanden at, i det publikum er med på å definere utformingen av et produkt, og at det dermed er et flyktig brukerbasert resultat da, så er det transmedia. (\#11)

De fleste sier at transmedia innebærer innhold som lages for flere plattformer, hvor plattformen er ubestemt. Det vil si at en plattform godt kan være et foredrag eller en hendelse i den virkelige verden. Men for at noe skal være transmedia, så må publikum kunne delta og påvirke hvordan dokumentaren blir til slutt. Produsentene uttrykker at de er lite opptatt av teori og refleksjon rundt hva transmedia er, og mer opptatt av hvordan transmediadokumentarer skal lages.

\subsubsection{Hva lages en transmediadokumentar av?}

Når jeg spurte produsentene om hva man lager transmediadokumentar av, beskriver de fleste et åpent og uavgrenset mulighetsrom på linje med rådgiverens definisjon. 
Den kan bestå av hendelser i virkeligheten. Den fysiske virkeligheten. Den kan bestå av utveksling av materiale på nett. Den kan bestå av selve filmen som da blir presentert i tradisjonelle kanaler. Da tenker jeg også streaming som tradisjonelle kanaler, sånn i moderne tid. Den kan bestå av spill. Generelt det at man utvider det til alt man kan komme på... (\#4)

De legger vekt på at transmediadokumentaren må involvere og representere publikum som en del av prosjektet, og flere av dem jobber med konkrete ideer til transmediakonsepter hvor det legges opp til at publikum bidrar med eget materiale. Samlet virker det som det er stor interesse og forståelse for mulighetene knyttet til det som ofte refereres til som crowdsourcing. Men informantene er bekymret for hvordan de skal ta vare på sin redaksjonelle kontroll når publikum involveres på denne måten. Hvordan skal de kunne kontrollere hva dokumentaren inneholder til slutt, når mye av eller alt materialet produseres av publikum? De velger å forholde seg til dette problemet på flere måter, men det er ingen av dem som ønsker å gi fra seg kontrollen helt eller å la dokumentarprosjektet "bli som det blir", bestemt av publikums bidrag.

Man kunne tenke seg at publikum bidro med data inn i en database, men hvis det var sånn instant produsering, uten noen form for kvalitetssikring og sånn, så tenker jeg vel at det ville bryte litt med det vi ønsker å gjøre som en egen produksjon da. (\#2)

De fleste er altså interessert $\mathrm{i}$ å bruke crowdsourcing, men da for å lage en klart definert innrammet fortelling. Teknikkene som produsentene allerede har utviklet - knyttet til framstillingen av verden på film ved hjelp av casting og redigering - ønsker de å videreføre når de skal håndtere materiale som er samlet inn av publikum. En av produsentene forklarer det på denne måten:

Men det som er viktig, og som er vanskeligst for oss, er jo det å åpne for at brukerne skal delta og det er det motstand mot, for instinktivt... fordi vi har blitt det vi har blitt fordi vi vil fortelle noe til folk, ikke at de skal fortelle noe til oss. (\#4)

Enkelte av produsentene har andre perspektiver på hvordan publikum kan involveres $\mathrm{i}$ sine dokumentarprosjekter. Vekten ligger på hvordan materialet gjøres tilgjengelig for publikum etter at det har blitt produsert. En av dem jobber med et prosjekt hvor han ønsker å gi fra seg kontrollen til publikum, men i en ramme hvor materialet som kan brukes, er gitt på forhånd.

Det er mange sånne prosjekter hvor folk bidrar med materiale. Vi gjør det annerledes. Vi bidrar med et materiale og så sitter den siste auteurvirksomheten hos brukerne. Det gjør at brukerne våre får en litt tyngre prosess, men egentlig mere kontroll enn de gjør i de andre prosjektene tror jeg. (\#10) 


\subsubsection{Hvilket formål har en transmediadokumentar?}

Produsentene i undersøkelsen er ganske samstemte når det gjelder formålet med transmediadokumentar. De legger vekt på at transmedia har en grunnleggende kontinuitet med tradisjonell dokumentar med tanke på hva man ønsker å oppnå.

...jeg tror alle som er interessert $\mathrm{i}$ å fortelle dokumentarer har for det første en veldig fascinasjon for virkelige mennesker og historier og skjebner, og har i tillegg lyst til å formidle disse historiene for forståelse og utvide horisonten til folk. Det tror jeg er den grunnleggende drivkraften i de fleste. [...]Ha noe på hjertet om du vil... og det vil jeg tro er formålet til transmedia også. Det er bare et nytt verktøy i å gjøre det. (\#12)

Ifølge de fleste av produsentene har en transmediadokumentar potensial til å skape mer engasjement enn en dokumentarfilm ved å åpne for publikums aktivitet. De kobler dette igjen til muligheter for påvirkning - ved at aktivitet gir engasjement, og engasjement kan skape endring. En av produsentene beskriver dette klart og tydelig.

Det er lett å tenke på transmedia kanskje som... du har lyst til å oppnå en konkret endring. Da ønsker du å engasjere en masse mennesker i å oppnå den endringen, for å oppnå den endringen og få større innflytelse. Da vil prosjektet avsluttes idet du har oppnådd endringen. (\#12)

Når folk kan delta og bidra med egne perspektiver som blir representert i den ferdige dokumentaren, kommenterer flere at dette utfordrer den autoritære fortellersituasjonen som har vært vanlig i dokumentarfilm. Flere av produsentene synes dette er en viktig og bra egenskap ved transmediadokumentar, og en av informantene betegner dette som en demokratisering av filmen.

Det er en demokratisering av filmen. Internett i seg sjøl, det å ha en mening. Det å ytre seg generelt. Da blir publikum dratt inn og ta en del i å ha en mening om det som du har en mening om og være med på å påvirke. En følelse av eierskap i en verden hvor vi har mye mindre påvirkningsmuligheter enn vi hadde før. (\#6)

To av produsentene vektlegger at transmediadokumentar kan gi større bredde og dybde i framstillingen. Det er større plass i et slikt prosjekt til mer av materialet som blir samlet inn, og flere perspektiver - både på små og store forhold i samfunnet - kan lettere representeres. Publikum kan "bli sin egen researcher" og dykke dypere ned i stoffet.

...så går det an for de som vil og de som er interessert i temaer og lettere fordype seg og lettere engasjere seg mer i en større bredde og i en større dybde ikke minst da. Det er kjempebra, det er supert. (\#1) 
Muligheten nettmediene gir for å kombinere nedenfra-og-opp-perspektiver med ovenfra-og-ned-perspektiver, vektlegges, og de ser også at den ikke-lineære formen kan egne seg til å presentere komplekse problemstillinger.

Så tenker jeg at en type transmedia, en type interaktiv produksjon kan innby til å fremsette framsette hypoteser og fakta basert på hypoteser på en litt annen måte en man ville klare i en mer sånn lineær filmfortelling. (\#2)

Produsentene er usikre på om de vil nå flere på de nye plattformene enn på TV, men de tror at transmediadokumentar kan nå ut til både riktigere og nye målgrupper, spesielt de unge. Det er vanskelig å skille mellom dem som vil nå et utvalgt, men engasjert publikum og dem som vil fortsette å nå en større del av befolkningen. Det kan virke som vurderingen av hva som er et tilstrekkelig stort publikum, avhenger av hva prosjektet vil oppnå. En av produsentene kaller dette en kritisk masse av publikum.

Det viktigste for meg er nå et riktig, men også en kritisk masse av publikum. Hvem og antall er det viktige, men ikke hvor. [...]Vi lager dokumentar først og fremst fordi vi ønsker å påvirke samfunnsdebatten og da er det viktigste å være til stede der man har påvirkning. (\#2)

\subsubsection{Hvilken form har en transmediadokumentar?}

Når det er snakk om hvordan en god transmediadokumentar skal se ut, har alle informantene problemer med å abstrahere dette. Dette henger antagelig sammen med vanskene produsentene har med å gi en overordnet definisjon av dette fenomenet. En generell definisjon vil ofte være tett knyttet til en forståelse for hvilken form det som skal defineres, har. Flere av informantene er negative til det de så langt har sett av dokumentarer på nett. De oppfatter dokumentarprosjekter som har fått mye oppmerksomhet på festivaler og lignende, som grunnleggende lineære og kjedelige.

En sånn type Prison Valley og sånn ligner jo egentlig på et spill med levels uten å være et spill, altså ja her er det levels og så var det ferdig og så forventes det at du gjør en eller annen operasjon for å komme til neste level. Så er du der og så... når kommer du egentlig til poenget, hva er det egentlig skal lære? Hva skal jeg egentlig erfare, hva skal jeg egentlig, hvor er underholdningen egentlig i dette her? Når det tar så lang tid og det går så treigt og det er egentlig, og jeg vet egentlig ikke hva jeg skal få svar på. Ikke sitter jeg igjen med noen spørsmål heller. Historien om historien gir meg ikke noen sånn klar følelse av at hvis jeg trykker her så kan jeg forvente å få svar på disse spørsmålene som dukker opp i hodet mitt. Relativt kjedelig. (\#2)

Men det er også flere informanter som er positive til dette formatet og trekker fram de samme eksemplene som inspirerende og forbilledlige. 
Og så sånn som den der Prison Valley, den der der du reiser i en fengselsdal borte i USA, det er også en veldig kul måte å gi innblikk. Hvis det hadde vært en dokumentar så kunne du satt deg ned og sett, men her kan du føle at du er med og nesten forsker sosialt. Det er nesten som å lese en avis der du leser litt der du vil. En flott artikkel i Morgenbladet eller noe sånt en helg, og så leser litt innimellom kaffekoppene, og så er det sånn innimellom at du kan bare være litt journalist sjøl på en måte. (\#7)

Når det gjelder å ta i bruk flere plattformer i samme prosjekt, er flere av produsentene opptatt av hvordan dette kan gi en merverdi til prosjektet. Hvis folk bruker mer tid på dokumentaren, og dermed får mer ut av den, er det vellykket. Flere legger vekt på - som i definisjonen av transmediadokumentar - at de ulike formatene må være likestilte og at det handler om å dele historien mellom plattformene.

Det må ikke bare fungere som at du har en hovedfortelling, hvor du på en måte dytter noe utfra i andre kanaler. Jeg tenker at hvis man kan få til å la de være avhengig av hverandre på en måte, eller å spille inn til hverandre, sånn at du får mere en ball som ruller en at du har en rakett som skyter ut noe fyrverkeri underveis, så blir det fort mye mere spennende da. (\#8)

Men flere av informantene har liten tro på at flere plattformer skal spille sammen for å fortelle en helhetlig historie. De mener hovedinnholdet uansett må være representert på alle plattformene som tas i bruk.

... puslespilltankegang hvor liksom ulike deler av en historie fortelles i ulike medier, hvor du er avhengig av å sirkle innom alle typer medier for å få helheten, det tror jeg ikke så veldig på foreløpig. At folk skal liksom gå veldig aktivt fra mobil til web til TV til kino for å oppsøke svaret på puslespillet på en måte. Den type tanker har jeg ikke så stor tro på. (\#2)

Hvordan deltagelse underveis skal gis en form, er abstrakt og utydelig når produsentene snakker om det. Det er tydelig at dette er upløyd mark for de fleste av dem, selv om nesten alle gjerne vil få det til på sikt. Det er lettere for informantene å snakke om websider og webdokumentarer. En av produsentene gir til kjenne en relativt avansert forståelse av interaktivitet:

Hvilke former for interaktivitet som der er ideell, det har jeg ikke svaret på. Jeg tenker at ytterpunktene er de man skal unngå. Er det helt statisk så funker det dårlig. Er det for mye interaktivitet, krever det for mye av brukeren, for mye klikking og for mye vanskelige sammenhenger eller for mye input $i$ form av liksom svar på spørsmål eller ting man må selv gi av input, så blir det relativt få som går igjennom hele siten. Hva som er det ideelle midtpunktet der, det vet jeg ikke. (\#2)

\subsubsection{Hvordan skal en transmediadokumentar lages?}

Funnene knyttet til produksjon av transmediadokumentarer handler om utfordringer ved planlegging, gjennomføring og vedlikehold av prosjektene. Når det gjelder planlegging, 
innrømmer de fleste produsentene at de har liten erfaring og at de trenger å gjennomføre flere transmediaprosjekter hvis de skal bli trygge på hva som må til for å lykkes.

Jeg tror ikke jeg kan nok om det nei. Hvis jeg skal begynne å prosjektere og finansiere og kalkulere kostnaden på et bredt transmediaprosjekt, så tror jeg at jeg vil trenge å få litt input på det ja, faktisk. (\#14)

Flere av produsentene har allikevel god selvtillit når det gjelder å skulle prosjektere transmediadokumentarer. De tror også det uavhengige dokumentarfilmmiljøet vil lære seg det de trenger ganske fort, og at de fleste har tilstrekkelig kunnskap om prosjektledelse. De ser dette i hovedsak som et økonomisk problem. Hvis de får tilstrekkelig med penger, vil dokumentarfilmprodusentene etter hvert bli flinke til å prosjektere innhold for flere plattformer. En av dem sier det slik:

Nei, jeg ser ingen praktiske hindre for å lykkes annet enn finansieringsspørsmålet. [...] vi er relativt strømlinjeforma på hva er det som skal til for å beskrive en idé fram til det stadiet hvor du får de første pengene, men hvordan man skal beskrive et transmediaprosjekt tilstrekkelig til at noen skal gi deg penger, når hverken vi eller den som gir pengene egentlig har noen klar idéom hvordan det bør beskrives... Jeg ser for meg at den dugnadsfasen blir litt lengre og litt større og litt mer armer og bein inntil noen setter en standard som gjør at den delen også kan strømlinjeformes. (\#2)

De av informantene som har gjort erfaringer med transmediaproduksjon, forteller derimot at de har møtt mange nye utfordringer. Kompleksiteten øker veldig sammenlignet med tradisjonell dokumentarfilmproduksjon. Prosjektene krever ny prosjektmodell og nye aktiviteter, med nye kostnader, og mye kan gå galt.

Du kan ikke slippe en mobilapplikasjon hvor ikke grafikken henger sammen med kodingen bak og hvor noe funksjon ikke funker og det er bugs og sånne ting. Så det er en skrekkblandet fryd knyttet til det. [...]Du er nødt til å ta den tankegangen med hvis du skal lage et transmedialt produkt, for jeg tror at hvis du går inn med en tradisjonell tvproduksjons tankegang når du skal lage noe som er transmedia, så tror jeg at du kommer til å få deg noen nesestyvere for å si det på den måten. (\#8)

Hva produsentene tenker om gjennomføring av transmediaprosjekter, er tett knyttet til tankene deres om hvordan de skal hente inn nødvendig håndverksmessig kompetanse og hvordan de skal forhandle fram en riktig pris for disse tjenestene. Flere av dem føler seg usikre på dette.

...jeg vet hvordan man dealer i filmverdenen, men jeg vet ikke hvordan jeg dealer med en programmerer. Jeg vet ikke hva det koster. Så dermed er man helt fritt vilt. (\#10)

De har forstått at de kan få hjelp av reklame-, kommunikasjons- og spillbransjene for å få laget elementene som skal utgjøre den ferdige transmediadokumentaren. Vendingen mot 
transmediadokumentar åpner dermed for et større samarbeid mellom dokumentarfilmprodusentene og kommersielle aktører og byråer. Problemet er at denne kompetansen koster langt mer enn det de relativt beskjedne budsjettene normalt vil klare å bære. En produsent sier dette om en erfaring han hadde med et kommersielt firma.

Litt av det jeg brant meg på er at vi har brukt en del av pengene på det her byrået som skulle være vår sparringspartner og lage førsteutkast og sånn. Når vi ikke kom dit vi vil, eller når dem ikke var vant eller villig til å ha samme tidslinja i arbeidet som oss, så trur jeg at jeg brant meg litt på fingrene og leter nå etter mindre flinke folk som kan jobbe litt sånn tettere med oss på en måte, som har en større egeninteresse. (\#7)

Det kan synes som denne produsenten er i ferd med å finne en løsning på dette problemet, en løsning som lettere lar seg integrere med hvordan dokumentarfilmprodusentene allerede jobber i dag. Flere av dem er inne på det samme. De har innsett at de ikke har råd til å kjøpe ferdige produkter fra kommersielle aktører, med det de oppfatter som urimelig overhead, men de må finne spesifikke personer som kan bidra til å løse spesifikke arbeidsoppgaver.

...så ofte så gjelder det å definere noen kjerneproblemstillinger eller kjerneutfordringer og finne noen spesifikke til å sette av noen timer eller dager eller uker til det arbeidet du ønsker på en måte, istedenfor å hyre et byrå som skal skrive masse timer på forskjellige ting. (\#11)

En bekymring som flere kommer inn på, er hvordan nettløsningene og samfunnene som blir styrket eller skapt i arbeidet med dokumentaren, skal følges opp etter at filmen er ferdig. Hvem skal holde liv i transmediadokumentaren når pengene på produksjonsbudsjettet er brukt opp? Det kan være vanskelig se for seg når prosjektet skal avsluttes.

Jeg ser det at man skal samle seg en hel del sånne spøkelser som man må forholde seg til. Det der nettstedet som du lagde for fem år siden. Hva skjer der nå? Nei jeg vet ikke helt jeg. Skal jeg gjøre noe med det, det har jeg ikke særlig lyst til lenger. Vet ikke. Det er bra med ting som avsluttes, så kan man gå videre. (\#1)

Et fåtall av produsentene er derimot ikke så bekymret for dette, og mener interessen på nett er lett og bare flytter seg videre til noe annet.

Forventer de noe av oss? Ja det gjør de. Vi må svare på henvendelser. Etterhvert vil det forsvinne litt. Publikum er sånn også, interessene skifter. Det er helt greit at det forsvinner. (\#9)

\section{$5 \quad$ Hvor langt har dokumentaristene kommet?}

Jeg skal nå drøfte hvor langt de uavhengige produsentene har kommet når det gjelder å møte utfordringen gitt av NFI, som beskrevet av produksjonsrådgiveren for dokumentarfilm. For å 
klargjøre dette tar jeg utgangspunkt i de fire aksene som angir fire kriterier de uavhengige produsentene kan vurderes etter.

\subsection{Representasjon: film til simulering}

Selv om dokumentarfilmprodusentene oppfatter at transmediafortellingen og filmfortellingen har et sammenlignbart forhold til verden, er det et tydelig at de ulike medieteknologiene knyttet til filmproduksjon og transmediaproduksjon representerer et brudd for dem. De to ulike representasjonsteknikkene gir forskjellige muligheter og begrensninger for produsentene. Informantene i undersøkelsen har lang erfaring og er framgangsrike i arbeidet med å lage dokumentarfilm, men de har liten erfaring i å legge rammer for uttrykksfull deltagelse for publikum. De står overfor dilemmaer som kan knyttes til det Axel Bruns (2007) kaller "produsage", som er en sammensetning av ordene produksjon og bruk. I en transmediadokumentar blir produsentens viktigste oppgave å legge til rette for aktivitet rundt innhold, ikke å lage innholdet selv. Konseptet "produsage" utfordrer de uavhengige produsentenes vanlige forståelse av hva som kan være med i en dokumentar og hva som ikke kan være med.

I dette perspektivet må man da stille følgende spørsmål: Hva er "materialet" i transmediadokumentar som integrerer brukerne som en del av dokumentaren? Når går produksjonsrådgiverens orienteringsløp fra å være en aktivitet på linje med andre aktiviteter i den virkelige verden, til å bli en del av en transmediadokumentar? Hvis orienteringsløpet er en dokumentar i seg selv, så kan all organisert aktivitet være det, og da blir det fort slik at hele verden er en eneste stor transmedial dokumentar! Verden representerer seg selv gjennom et materielt uttrykk - verden. Dette gir lite mening i denne sammenhengen. Rådgiveren selv sier at først når dette filmes og gjøres tilgjengelig, for eksempel på nett, er det en dokumentar. I praksis kan dette fort bli en relativt tradisjonell dokumentarfilmproduksjon. Denne fram-og-tilbake-logikken tydeliggjør uløste dilemmaer knyttet til hva en transmediadokumentar kan bestå av. På den ene siden er dokumentarfilmprodusentene avhengig av å lage sterke audiovisuelle uttrykk som kan formidles på festivaler og på TV, men samtidig oppfordres de til å eksperimentere med representasjonsteknikker som ikke fører til gjenkjennbare filmer, men publikumsaktivitet.

På en akse fra film som materiale til simulering som materiale, befinner produsentene seg i hovedsak nær filmmediet. De fleste tar utgangspunkt i filmrepresentasjon, og de knytter bruk 
av regler for deltagelse enten til researchtiltak (crowdsourcing) eller til lanseringstiltak. Et fåtall omfavner den radikale definisjonen av transmediadokumentar og har et ønske om å lage åpne, selvgående, regelbaserte dokumentarprosjekter.

\subsection{Affekt: identifikasjon til abstraksjon}

Et tydelig funn i denne undersøkelsen er hvordan de uavhengige produsentene ser formålet med transmediadokumentar i kontinuitet med dokumentarfilm. De fleste av dem identifiserer seg med, og har tatt på seg, samfunnsoppdraget som ofte knyttes til dokumentarfilm, og som handler om å avsløre, overbevise og forandre. Ifølge produsentene representerer transmediadokumentaren nye og kraftige verktøy til å løse det samme oppdraget, gjennom å legge til rette for publikums aktivitet og engasjement. Når de snakker om dette, er det tydelig at de bygger på en forståelse som kan knyttes til positive framstillinger av hvordan spesielt Internett, og de mulighetene for deling og samarbeid teknologien gir, har en demokratiserende effekt på samfunnet. Uten at jeg sier at produsentene kjenner denne litteraturen, kan det sammenlignes med tankegods som de siste årene er utarbeidet i flere velkjente bidrag til forskningen på nye medier og samfunn (Benkler, 2006; Gillmor, 2006; Shirky, 2009). Jeg går ikke inn i en større diskusjon om mediedeterminisme, men det er klart at dette er en forenkling av virkeligheten. Nye medieteknologier og nye måter å fortelle historier på kan bare få samfunnsmessig betydning hvis den sosiale konteksten åpner for det. Derfor er det mange forhold som må være på plass for at transmediadokumentaren skal kunne bli en mer effektiv metode for påvirkning av samfunnsdebatten enn den tradisjonelle dokumentaren. På en akse fra å skape affekt ved identifikasjon til å skape affekt ved abstraksjon, befinner de fleste dokumentarfilmprodusentene seg nær affekt ved identifikasjon. Når de ønsker å fortsette å påvirke samfunnsdebatten ved hjelp av transmediadokumentar, har de liten forståelse for hva publikums muligheter for aktivitet og deltagelse innebærer. Det er tydelig at når de - gjerne i optimistiske ordelag - beskriver transmediadokumentar, ser de hvordan deltagelse kan gi engasjement. Men det er like tydelig at de ikke har begynt å tenke på hvordan dette engasjementet er grunnleggende annerledes enn det som skapes ved hjelp av filmfortelling. Utfordringen er å forstå hva som skjer med publikum når de blir med på å forme dokumentarprosjektet sammen med andre, noe som er en abstrahering fra individ til samfunn. På hvilken måte kan dette påvirke samfunnsdebatten? Det kan synes som om produsentene vil ta med seg de gode karakterdrevne og situasjonsbestemte historiene over til 
nye plattformer og i mindre grad å åpne for publikums konstruktive samfunnsdannelse som en integrert del av dokumentaren.

\subsection{Stemme til prosess: situasjon til system}

Intervjuene viser at de uavhengige dokumentarfilmprodusentene synes det er vanskelig å sette ord på hvilken form en god transmediadokumentar skal ha. Det de setter ord på, klart og tydelig, er konflikten mellom rollen som forteller og rollen som tilrettelegger. Denne konflikten har blitt viet mye oppmerksomhet i litteraturen som omhandler de nye medienes tekster. Lev Manovich går så langt som å si at fortellingen og databasen, som metaforer for måter å lagre og dele informasjon på, er naturlige og inkompatible fiender (Manovich, 2001). Det har vært gjort mange forsøk på å løse denne konflikten, enten ved å utvikle tilpassede teorier som tar vare på retorikken eller narratologien i møte med "databasen" (Fagerjord, 2003; Ryan, 2004) eller ved å utvikle nye begreper som ikke trenger å hvile på klassisk formidlingsteori (Frasca, 1999; Aarseth, 1997). Jeg skal ikke gå dypere inn i dette her, men bare fastslå at de uavhengige dokumentarprodusentene - i møtet med transmediadokumentaren har gjenoppdaget grunnleggende problemer knyttet til nye medier og formidling.

Dette er spenninger som kommer på toppen av det allerede spente forholdet mellom de to dokumentartradisjonene produsentene forholder seg til: "den dokumentariske” og “den journalistiske" (Sørenssen, 2007). De uavhengige produsentene identifiserer seg i hovedsak med den dokumentaristiske tradisjonen, hvor det er legitimt å produsere individ-prosessfortellinger med tydelige dramaturgiske grep. Underholdningsverdien i slike dokumentarer er vel så viktig som den innsikten publikum skal sitte igjen med til slutt. I denne tradisjonen er terskelen lav for å ta i bruk iscenesettelser samt gjøre direkte inngrep i situasjonen som beskrives. I den journalistiske tradisjonen legger det journalistiske håndverket klare etiske rammer for håndtering av personer og situasjoner, og det vil ofte være legitimt å lage dokumentarer om samfunnsovergripende temaer. Jeg tror dokumentarister innenfor de to tradisjonene har ulike forutsetninger for å ta i bruk virkemidlene som faller naturlig for transmediadokumentar. De uavhengige produsentene har en lengre vei å gå når det gjelder å tenke system og ikke situasjon, til å abstrahere og ikke eksemplifisere.

På en akse fra stemme som situert perspektiv til prosess som systemisk perspektiv befinner de fleste dokumentarfilmprodusentene seg nær det som de tradisjonelt har vært dyktige på, 
som kan knyttes til individ-prosessfortellinger. En frittstående dokumentar legger mer vekt på karakterutvikling og dramaturgi enn fakta og systemkritikk. Det kan synes som filmskaperne tar med seg disse teknikkene når de forestiller seg hvordan transmediafortellinger skal formes, og flere av transmediaprosjektene som blir beskrevet i intervjuene, er tett knyttet til en sentral fortellerstemme. Samtidig kan det virke som utfordringen ved å lage dokumentar på flere plattformer, og gjerne ved hjelp av publikum, tvinger produsentene mot en mer abstrakt form. Flere av eksemplene på transmediaprosjekter som beskrives i intervjuene, er konseptuelle og mangler en klar fortellerstemme. Det er kanskje naturlig, når transmediafortelling som potensielt heterogen og uforutsigbar form tvinger fram spørsmålet om hva som binder "det hele" sammen.

\subsection{Produksjon: film til programmering}

Det er tydelig at produsentene jeg har intervjuet, vedgår at de trenger ny kompetanse i alle faser av et transmediadokumentarprosjekt: planlegging, gjennomføring og etterarbeid. Men de forholder seg til denne utfordringen på ulike måter. Matthew Powers (2012) har undersøkt hvordan journalister i USA skriver om nye tekniske arbeidsoppgaver og deler måtene de skriver om dette på, i tre - som eksempler på kontinuitet, som muligheter for journalistisk innovasjon og som en utvikling som må underordnes eksisterende praksis. Selv om dokumentarfilmprodusentene i undersøkelsen er mer enn journalister, kan man plassere det de sier om nye arbeidsoppgaver knyttet til produksjon av transmediadokumentar, ut fra disse tre kategoriene. Et viktig poeng her er at samme informant godt kan beskrive perspektiver som faller inn under flere av kategoriene.

En del av produsentene oppfatter produksjon av transmediadokumentar i kontinuitet med tradisjonell filmproduksjon. De tenker det er relativt enkelt å tilpasse produksjonsteknikkene de allerede behersker, til det nye formatet. Dette handler i hovedsak om å "shoppe" den nødvendige kompetansen fra eksterne leverandører når de trenger det, og legge dette til som nye poster i budsjettene. Transmediadokumentaren utfordrer ikke måten man produserer dokumentar på. Det er samtidig tydelig at flere av produsentene ser de nye teknikkene som en redefinering av arbeidet som tradisjonelt er knyttet til dokumentarfilmproduksjon. Flere av dem snakker positivt om muligheten for at produksjon av transmediadokumentarer kan utfordre det uavhengige dokumentarfilmmiljøet og føre til etablering av innovative dokumentarformater. Når det gjelder hvorvidt produsentene oppfatter de nye medieteknologiene 
og de nye arbeidsoppgavene som en trussel, er dette vanskelig å fastslå. Men hvis en velger å se det innsamlede materialet som et utdrag fra en diskurs, er det mulig å oppdage språklige, kanskje ubevisste, strategier som trekker linjer mellom dem som tradisjonelt har jobbet med dokumentarfilm og de nye fagfolkene som det er behov for. Flere av produsentene antyder at de helst foretrekker å kjøpe - for eksempel programmeringstjenester - gjennom mellommenn, og da gjerne som ferdige pakker. De ser på utvikling av dynamisk innhold for flere plattformer som en "sort boks” som de ytrer lite ønske om skal åpnes. Det er flere som snakker om teknologi som noe underordnet og forstyrrende og som tar oppmerksomheten vekk fra den egentlige oppgaven, som er å fortelle gode historier.

Det som jeg føler ofte skjer er jo at det er stor interesse for teknologi, eller teknologiske nyvinninger når det gjelder transmedia, men som er ekstremt dyrt, men liten fokus på å jobbe videre med det vi faktisk har som er historiefortelling som man kan utvikle i transmedia på eksisterende plattformer. (\#4)

De ser ikke for seg at det finnes programmerende dokumentarister, på samme måte som det for eksempel finnes programmerende journalister (Karlsen og Stavelin, 2013). Grunnen er nok at det i Norge enda ikke er teknisk kyndige fagfolk som har markert seg i dokumentarfeltet, og dermed har ikke produsentene noen å vise til.

På en akse fra forfatterskap ved filmproduksjon til forfatterskap ved spillproduksjon ligger dokumentarfilmprodusentene i undersøkelsen nærmest forfatterskap ved filmproduksjon. Samlet har de liten forståelse for sammenhengen mellom teknisk kompetanse og utvikling av nyskapende transmediadokumentarer. De har kommet et stykke på vei med å innse at de trenger å jobbe tettere og mer direkte med teknisk kompetente fagpersoner, men vurderer enda ikke muligheten for å gi disse en mer sentral plass i den kreative prosessen knyttet til utvikling av innhold. Produsentene ser ikke at fagpersoner med dypere teknisk forståelse i mange tilfeller kan bidra til fortellingen. Denne forståelsen er til stede med tanke på klippere og fotografer, hvor teknikken er integrert med det kunstneriske, men foreløpig ikke når det gjelder "kreative programmerere".

\section{Konklusjon}

I denne artikkelen har jeg undersøkt hvordan det uavhengige norske dokumentarfilmmiljøet har svart på utfordringen fra NFI om å lage transmediadokumentarfortellinger. Ved å sammenligne og sammenstille to kjente teorier som beskriver henholdsvis dokumentarfilm og dokumentarspill har jeg utviklet fire akser som gir en pekepinn om hvor langt de uavhengige 
dokumentarfilmprodusentene har kommet i praktisk forståelse av de nye mulighetene transmediafortellingen gir. De fire aksene er knyttet til de fire årsakene - materiale, formål, form og produksjon. Aksen knyttet til materiale går fra verden representert gjennom filmopptak til verden representert gjennom simulering. Aksen knyttet til formål går fra affekt ved identifikasjon til affekt ved abstraksjon. Aksen knyttet til form går fra stemme som situert perspektiv til prosess som systemisk perspektiv. Aksen knyttet til produksjon går fra forfatterskap ved filmproduksjon til forfatterskap ved spillproduksjon. Hovedfunnene er at dokumentarfilmprodusentene ønsker å utforske bruken av brukergenerert materiale i sine produksjoner, men at de har kommet kort når det gjelder å utvikle rammer og regler for hvordan dette skal gjennomføres. Så langt vil de fleste ha full kontroll over dette materialet til slutt, noe som jobber mot ønsket om åpenhet og reell deltagelse fra publikum. Videre ser produsentene transmediadokumentaren som en utvikling og styrking av deres muligheter for å løse samfunnsoppdraget de identifiserer seg med - avsløre for å forandre, gjennom debatt. Selv om produsentene har en intuitiv forståelse av hvordan publikumsaktivitet kan gi engasjement og forandring, har de kommet kort i arbeidet med å utvikle en forståelse for hvordan publikum skal involveres hvis dette skal ha en effekt. De uttrykker optimistiske ønsker for transmediadokumentarens rolle i samfunnet, men de har enda ikke har klart å konkretisere den. Når det gjelder form, refererer de uavhengige produsentene til NFIs definisjon av transmedia. De legger vekt på samspill mellom flere plattformer og publikums rolle med tanke på å påvirke det endelige verket. Samtidig er det tydelig at produsentene er usikre på hvordan en god og klar fortelling skal kombineres med uforutsigbarheten knyttet til publikums bidrag. Produsentene er gode på å beskrive situasjoner med tydelige karakterer i prosess, men det kan synes som transmediafortellingen tvinger dem i retning av å behandle generelle temaer i mer abstrakt form, fordi det lettere kan binde sammen et heterogent materiale. Når det gjelder produksjon, ser produsentene at de trenger nye fagkunnskaper for å håndtere transmediaprosjekter, men de regner med at de skal klare det. Samtidig har de kommet kort i arbeidet med å identifisere den rette kompetansen, og de sliter med å finne fagpersoner som de har råd til å bruke. Så langt kan det synes som om de ikke har utviklet god forståelse for sammenhengen mellom teknisk kompetanse og resultat, og de kvier seg for å åpne denne “teknologiske boksen”. Det er naturlig å følge opp denne undersøkelsen om et par år for å se hvordan produsentenes forståelse for transmediadokumentar forandrer seg med flere gjennomførte prosjekter og flere gode eksempler til etterfølgelse. 


\section{Referanser}

Almeida, A., Alvelos, H., 2010. An Interactive Documentary Manifesto, in: Aylett, R., Lim, M., Louchart, S., Petta, P., Riedl, M. (Eds.), Interactive Storytelling, Lecture Notes in Computer Science. Springer Berlin / Heidelberg, pp. 123-128.

Aston, J., Gaudenzi, sandra, 2012. Interactive documentary: setting the field. Studies in Documentary Film 6, 125-139.

Benkler, Y., 2006. The wealth of networks: how social production transforms markets and freedom. Yale University Press, New Haven.

Berntsen, T.K.N., 2008. Norsk dokumentarfilm; For knapper, glansbilder og ren idealisme? En kvalitativ undersøkelse av samhandlingen mellom uavhengige produsenter, Norsk filminstitutt og kringkasterne NRK og TV2. [WWW Document]. URL https://bora.uib.no/handle/1956/3006 (besøkt 28.1.12).

Bogost, I., 2007. Persuasive games: the expressive power of videogames. MIT Press, Cambridge, MA.

Bogost, I., Ferrari, S., Schweizer, B., 2010. Newsgames: journalism at play. MIT Press, Cambridge, Mass.

Bruns, A., 2007. Produsage, in: Proceedings of the 6th ACM SIGCHI Conference on Creativity \& Cognition, C\&C'07. ACM, New York, NY, USA, s. 99-106.

Cizek, K., 2010. Highrise: Out My WIndow [WWW Document]. URL http://interactive.nfb.ca/\#/outmywindow/ (besøkt 3.3.12).

Creswell, J.W., 2009. Research design: qualitative, quantitative, and mixed methods approaches, 3rd ed. ed. SAGE, Los Angeles.

Distrify [WWW Document], 2012. URL http://distrify.com/ (besøkt 28.1.12).

Dokumentaristene, 2009. Dokumentarfilmskapernes innspill til Kulturløftet 2.0 [WWW Document]. Løft Dokumentaren Nå. URL http://www.dokumentaristene.no/Innspillet.html

Dufresne, D., Brault, P., 2010. Prison Valley [WWW Document]. URL http://prisonvalley.arte.tv/?lang=en (besøkt 3.3.12).

Fagerholt, A., 2011. NFI støtter web-dokumentar [WWW Document]. Rushprint. URL http://rushprint.no/2011/03/ny-plattform-for-dokumentar/ (besøkt 9.5.13).

Fagerjord, A., 2003. Four axes of rhetorical convergence. Dichtung Digital 4, 30.

Frasca, G., 1999. LUDOLOGY MEETS NARRATOLOGY: Similitude and differences between (video) games and narrative. http://www.ludology.org.

Galloway, D., McAlpine, K.B., Harris, P., 2007. From Michael Moore to JFK Reloaded: Towards a working model of interactive documentary. Journal of Media Practice 8, 325-339.

Gaudenzi, S., 2013. The Living Documentary: from representing reality to co-creating reality in digital interactive documentary $(\mathrm{PhD})$.

Gifreu, A., 2011. The Interactive Documentary. Definition Proposal and Basic Features of the Emerging Genre, in: McLuhan Galaxy Conference Proceedings. s. 354-365.

Gillmor, D., 2006. We the media: grassroots journalism by the people, for the people. O'Reilly, Beijing; Sebastopol, CA.

Heidegger, M., 1954. The question concerning technology and other essays. Garland Publishing, New York \& London.

Hot Docs [WWW Document], 2013. . Canadian International Film Festival. URL http://www.hotdocs.ca/ (besøkt 4.10.13).

IDFA [WWW Document], 2013. . International Documentary Film Festival Amsterdam. URL http://www.idfa.nl/nl.aspx (besøkt 4.10.13). 
Jenkins, H., 2008. Convergence culture: where old and new media collide. New York University Press, New York.

Karlsen, J., Stavelin, E., 2013. Computational Journalism in Norwegian Newsrooms. Journalism Practice 0, 1-15.

Köhncke, A., 2006. TV \& den uavhengige nordiske dokumentarfilm (Master). Københavns Universitet.

Living Without Money - Kickstarter [WWW Document], 2011. URL http://www.kickstarter.com/projects/115591955/living-without-money-dvds-0 (sett 19.8.13).

Manovich, L., 2001. The language of new media. MIT Press, Cambridge, Mass.

Manymade - The Accidental Rockstar [WWW Document], 2013. URL http://www.manymade.org/Project/Index/53 (sett 19.8.13).

Molleindustria, 2006. McDonald's Video Game [WWW Document]. URL http://www.mcvideogame.com/index-eng.html (besøkt 31.8.12).

Munthe-Kaas, M.C., Jensen, C.L., Wiik, R.J., 2013. Project Moken [WWW Document]. URL http://www.projectmoken.com/ (besøkt 23.10.12).

Murray, J., Bogost, I., Mateas, M., Nitsche, M., 2006. Game design education: integrating computation and culture. Computer 39, 43-51.

Nash, K., 2012. Modes of Interactivity: Analysing the Webdoc. Media Culture Society 34, 195-210.

Nichols, B., 2001. Introduction to documentary. Indiana University Press, Bloomington.

O'Flynn, S., 2012. Documentary's metamorphic form: Webdoc, interactive, transmedia, participatory and beyond. Studies in Documentary Film 6, 141-157.

O'Reilly, T., 2007. What is Web 2.0: Design Patterns and Business Models for the Next Generation of Software (SSRN Scholarly Paper No. ID 1008839). Social Science Research Network, Rochester, NY.

Powers, M., 2012. "In Forms That Are Familiar and Yet-to-Be Invented" American Journalism and the Discourse of Technologically Specific Work. Journal of Communication Inquiry 36, 24-43.

Project Moken - NFI [WWW Document], 2012. URL http://www.nfi.no/bransje/tildelinger/tildelinger2012/dokumentarfilm/project-moken (sett 29.5.13).

Ryan, M.-L., 2004. Will New Media Produce New Narratives?, in: Ryan, M.-L. (Ed.), Narrative Across Media: The Languages of Storytelling. University of Nebraska Press, Lincoln; London, s. 337-360.

Shirky, C., 2009. Here comes everybody: how change happens when people come together. Penguin, London.

Stenderup, T., 1994. Har kort- og dokumentarfilmen i Norden en fremtid?: forslag til at styrke den uafhængige produktion og distribution. Nordisk Ministerråd, København.

Sørensen, I.E., 2013. Documentary in a Multiplatform Context. University of Copenhagen. Faculty of Humanities.

Sørenssen, B. 1946-, 2007. Å fange virkeligheten: dokumentarfilmens århundre. Universitetsforl., Oslo.

Tilskuddsordninger for dokumentarfilm - NFI [WWW Document], 2013. URL http://www.nfi.no/bransje/produksjon_utvikling/dokumentarfilm (sett 19.8.13).

Weinstein, M., 2006. TAMS Analyzer Anthropology as Cultural Critique in a Digital Age. Social Science Computer Review 24, 68-77.

Aarseth, E., 1997. Cybertext: perspectives on ergodic literature. Johns Hopkins University Press, Baltimore, Md. 


\title{
Article 3: Probing Privacy in Practice: Privacy regulation and instant sharing of video in social media when running
}

Joakim Karlsen

Susanne Koch Stigberg

Jo Herstad

\begin{abstract}
This paper examines privacy as something people do, seeing privacy as a constant negotiation of technical and social aspects of technology use. To be able to examine privacy aspects of live video sharing on social media, we have designed and deployed a technology probe in amateur running events. The findings suggest that audio wouldn't be shared a lot in this context, since it captures audible signs of fatigue. Further, it seems that sharing of performance indicators are problematic, so it is more likely that the probe would be used to mediate the general experience of taking part in a running event. Lastly it seems that very few would be comfortable with immediate sharing and would like to have the option of removing recordings and control its recipients. Overall, we find that when confronted with new mediating information technologies, people are quickly able to re-negotiate their privacy boundaries, using earlier experience with similar technologies.
\end{abstract}

Keywords: privacy; instant sharing, social media; video; mobile interaction.

\section{Introduction}

Privacy involves a broad range of concerns within legislative practices, social practices, cultural differences and digital and urban/domestic architecture. The activities of regulating our personal space, closing and opening doors, avoiding and seeking others, are privacy performed in practice. As our everyday life is performed with electronic networked services, this is increasingly a concern both for the HCI research community and the public at large [1]. Bellotti and Sellen [2] identified a set of challenges pertaining to privacy in digital pervasive environments as a result of separating the user's activity and the site of its effects in digital media spaces. Agre [3] has written extensively on privacy concerns and digital technologies, in particular advocating privacy as an issue not simply of individual needs, but something that arises from social roles and relationships. In this perspective, privacy is a cul- 
turally embedded and changing practice of everyday living. However, there is limited empirical research on "doing" privacy as an on-going negotiation of technical and social aspects in everyday situations, with some exceptions [4].

To get a deeper understanding of the privacy aspects of one particular context, sharing live video on social media while running, we have conducted two explorative field studies using what Hutchinson et al. [5] has coined a "technology probe". Our technology probe enabled participants in two running events to capture and share video on Facebook by opening and closing their hand. To be able to analyze and discuss the results of probing this context, we have revisited Palen and Dourish [6] work on privacy and information technology. In their perspective, the user's choice of sharing or not sharing his / her first-person feed with a larger group, can be framed as a constant negotiation of his / her privacy boundaries, a "process where people optimize their accessibility along a spectrum of "openness" and "closedness" depending on context." [6]. According to them a "genre of disclosure" is a stable and recurrent social practice where representations enabled by technology use are met with certain expectations. When these are broken privacy concerns are raised. Technology has the ability "to disrupt or destabilize the regulation of boundaries" [6].

Our technology probe, a video recording and live streaming device for use in a public setting, have challenged our users to negotiate their privacy boundaries in this context. The aim of this study has then been to investigate how users participating in running events negotiate their disclosure, identity and temporal privacy boundaries when using a technology probe for instant sharing of video on Facebook and to examine how this is a re-negotiation of previously experienced genres of disclosure.

After a brief summary of related work, we will explicate the framework of "genres of disclosure" in Section 2, before describing in Section 3, how we have probed the running and sharing context by making a fully working technological probe and deploying it in a real world setting. We will continue with a summary of our findings in Section 4, and in Section 5, we will discuss several patterns in how the privacy boundaries has been negotiated by our users. Lastly we will discuss how these patterns can be seen as re-negotiations of boundaries set up by earlier experiences with similar technologies. 


\subsection{Related work}

The technology probe developed in this study has similarities with both sports-tracking and life-logging technologies, and researchers interested in these fields have to some extent discussed privacy concerns with these technologies. The use of tracking devices for training and fitness purposes is common, but mostly for private purposes. But when these applications are networked and become more similar and/or integrated with other social media platforms people may experience expectations of joining and sharing [7][8]. Ojala and Saarela [8] categorize the motivation for joining and sharing into:

- get feedback and guidance

- get content of others

- reputation and status

- comparing results

Other studies have pointed out the importance of social support and accountability, as strong motivational factors to share exercising data [9][10]. Deborah Lupton has identified self-improvement as the main motivational factor for self-tracking [11], and has developed five "modes of tracking", that include a private mode, but also pushed, communal, imposed and exploited modes [11]. The exploited mode raises privacy concerns and "refer to the ways in which individuals' personal data (whether collected purely for their own purposes or as part of pushed, communal or imposed self-tracking) are repurposed for the (often commercial) benefit of others".

Privacy concerns have been raised by wearable computing and life-logging pioneer Steve Mann [12]. Data from logging your own life, can according to him, be misused by other people, government and media. He problematizes that history becomes a "freezer not a dustbin", something that can have negative social consequences. Two recent studies have investigated privacy aspects of life logging using wearable cameras, from the life-loggers' perspective [13] and from the bystander perspective [14]. From the life-logger perspective, people preferred to manage privacy in situ, as a result of the perceived sensitivity of the context. Most of the users in the reported study were concerned about the privacy of bystanders [13]. From the bystander perspective, people reported indifferent or negative responses to being recorded by a wearable camera. Many users expressed interest in being asked for permission and in devices for blocking the recording [14]. 
Generally, users are aware of privacy issues with sharing information on social media [8][9], and tend to prefer a friends-only social media profiles [15]. When digital media sharing crosses boundaries into public domains, both intentionally and unintentionally, users are less able to control their identity [16].

\section{Privacy}

In 1890, Warran and Brandeis [17] published their seminal article "the right to privacy" where they write:

Instantaneous photographs and newspaper enterprise have invaded the sacred precincts of private and domestic life; and numerous mechanical devices threaten to make good the prediction that 'what is whispered in the closet shall be proclaimed from the housetops' (ibid).

From these early discussions on the conditions for protecting privacy and ways of regulating privacy by law, there is an increasing focus on privacy as our everyday lives are partly performed online. The list of mechanical devices could today be extended to electronic devices that capture, store and potentially distribute dynamic information from the peoples context, such as audio, video, location and biometric data. Palen and Dourish [6] have proposed a framework for a nuanced understanding of privacy in a networked world. Their framework builds on the seminal work of Altman [18][19], and identifies three boundaries that are central to the negotiation of more or less openness and closedness.

The first and most basic boundary is the disclosure boundary, that is, what information to reveal or keep from others. For example, should I share this picture of my new bulldog on the net, or should I keep it for myself?

Secondly, the identity boundary is defined by the role taken on by the user. A user can for example represent an organization, such as the member of the dogs rights organizations, or represent herself personally.

Finally, the temporal boundary is about the effects of persisted information. Unintended recipients can interpret the information left behind in a networked system at a later time, and there is little or no way of controlling the interpretation of information, or the context in which it is interpreted. For example, the article about dogs right in your local newspaper or 
social network you shared in 2007, discussing a city plan, can be read and interpreted in 2016 in a very different discussion about the housing of dogs.

One of the most important insights from Altman's work is that privacy is not a static set of rules, but rather a dynamic process, a constant negotiation depending on the situation. In other words, privacy is something that is actively negotiated and performed. Grudin [20] puts this in the context of situated action, which is what allows the constant negotiation just described:

Why then the uneasiness, the widespread attention to privacy? It may reflect an awareness at some level of something more fundamental than privacy that is being challenged: The steady erosion of clearly situated action. We are loosing control and knowledge of the consequences of our actions, because if what we do is represented digitally, it can appear anywhere and at any time in the future. We no longer control access to anything we disclose [20].

Indeed, where are the boundaries of situated action when the information about the situation is broadcasted with networked technologies? With viewing privacy through the framework proposed by Palen and Dourish [6] as an activity, something that users "do" and negotiate instead of "have a right to", there is a possibility of gaining insights into ways that this is practiced.

\section{Probing}

Technology probes as defined by Hutchinson et al. [5] are simple, flexible, adaptable technologies deployed to find out about the unknown. Probes are not prototypes and should be used in the early stages of projects to investigate new perspectives that can constrain and open future designs [21]. Technology probes support playful interactions with new technology in new contexts and provoke participants' reactions [22].

Hutchinson et al. designed technology probes with three goals in mind: understanding the needs and desires of users in real-world setting field-testing the technology inspiring participants and researchers to think about future technology and its use. Studies have deployed technology probes, focusing on only one or several of these three research goals. In [23], simple step counters are used as ready-made technology probes to study teenagers' motivation for exercising and to find out important lessons for the design of future devices. In [24], technology probes are applied to measure and assess texting and updating functionality of 
situated displays. In [25], a mobile technology probe is designed to better understand if and when intimate couples desire to hold hands when apart.

Similar to [25], we have designed a mobile technology probe. Our research goal is to understand privacy with instant video sharing on social media while running. We have tried to create a realistic situation for users to experience instant video sharing in practice. To make sure that we were able to probe for privacy concerns in our research design, we have strived to design the probe to be simple, wearable and robust, something that is especially important for intimate, mobile context [25].

\subsection{Hardware and Software}

Our technology probe in Figure 2, consists of two parts: a mobile phone for recording and sharing videos to Facebook and a sport glove that functions as a remote control for the mobile phone. We fitted the glove with a flex-sensor and a wearable Arduino mini-processor called LilyPad. Flex-sensors are a form of resistors that change their resistance depending how hard they are bent. The LilyPad can detect these changes and transform the analogue resistance values to integer values. In the probe, these values are sent via Bluetooth to a mobile phone. The application on the phone maps the values to specific functions. Single or multiple fingers can be fitted with sensors, and this setup can support detection of many different hand gestures. In our study, we needed two functions, on and off, mapped to recording and sharing video on Facebook, so we only fitted one sensor to the middle finger on the glove. All technical components were hidden inside the glove. A red recording led was the only visible part and the glove appeared as a normal sport glove from a distance.

\subsection{Design}

"Probes are meant to collect usage data, but if users are deterred from using them because of their appearance, design should become a priority" [25]. Studies have shown that the wearability of the smart phone is not optimal for interactions on the move, for example running and walking [26][27]. To improve wearability of the phone we made careful design choices regarding placement of the phone, how the users should interact with the phone and the mapping between these interactions and the phones functions for recording and sharing video. 
Placement: The first set of design choices concerned the placement of the phone while running. Gemperle et al. [28] recommend placing larger and heavier devices on non-moving parts of the body throughout the movement. To be able to capture video in a first-person perspective, the phone needs to be positioned on the front of the body directed forward. We solved these requirements by mounting the phone in a neoprene hip belt with a see-through pocket facing forward.

Interactions: Secondly, we addressed the problems with touchscreen interactions while running. These interactions are in effect not possible in this situation, without disturbing the running experience. Users often have to stop to look at the screen and press a button [27]. We aimed to design a more unobtrusive input mode using a sports glove with movement sensors.

Mapping: The last design choices concerned the mapping of gestures to functionality. Rico and Brewster [29] recommend using gestures that are familiar in feeling or appearance. For our technology probe the start and stop recording functions need to be mapped to suitable hand gestures. They should be simple enough to perform while running and they should not have other predefined meanings. Simple hand gestures that we observed during the design process were making a fist, tapping fingers together, open hand, spread fingers, waving right/left. We ended up tying distinct hand gestures metaphorically to the mapped functions;

- hand open (record and share)

- hand closed (stop recording and sharing)

\subsection{Deployment}

We deployed the probe in two running events taking place in Strömstad, Sweden on November the 8th and Wolfen, Germany on December the 28th, 2014. The three main criteria for choosing the events were that they had good $3 \mathrm{G}$ coverage, they were accessible to the researchers and that they were semi-professional with medium distance tracks (5 and $10 \mathrm{~km})$. We recruited three participants for the first field trial and three for the second, from local sports clubs and directly at the events. We paid their registration fee and they received a $10 €$ flower present card for participating. In Table 1, we have listed the participants with age, gender and experience with sports tracking and social media. 
TABLE 1. PARTICIPANTS

\begin{tabular}{|l|l|l|l|l|l|}
\hline$\#$ & Event & Age & Gender & $\begin{array}{l}\text { Sports } \\
\text { Tracking }\end{array}$ & $\begin{array}{l}\text { Social } \\
\text { media }\end{array}$ \\
\hline$\# 1-1$ & Strömstad & $30 \mathrm{~s}$ & Male & Yes & Moderate \\
\hline$\# 1-2$ & Strömstad & $30 \mathrm{~s}$ & Female & Yes & Active \\
\hline$\# 1-3$ & Strömstad & $40 \mathrm{~s}$ & Female & Yes & Moderate \\
\hline$\# \mathbf{Z 2 - 1}$ & Wolfen & $20 \mathrm{~s}$ & Male & Yes & Moderate \\
\hline$\# \mathbf{\# - 2}$ & Wolfen & $20 \mathrm{~s}$ & Male & Yes & Moderate \\
\hline$\# \mathbf{\# - 3}$ & Wolfen & $20 \mathrm{~s}$ & Female & Yes & Moderate \\
\hline
\end{tabular}

In Strömstad, the researchers met up one hour before the start time at $12 \mathrm{pm}$. The first half hour we registered the informants for the $5 \mathrm{~km}$ track and checked the probes. Until the start at $1 \mathrm{pm}$ we fitted the technology to the individual participants and gave them brief explanations of how they could use it. They tried out the gestures, and at the same time we calibrated the on / off thresholds to their hand movements. We explained how the video they were going to record was shared on Facebook. The informants used from 24 to 34 minutes to complete the track and from 1:45 pm we conducted semi-structured interviews with each of them. We had prepared a set of guiding questions focusing on the participants' experience of instant video sharing using the probe in regard to negotiating their privacy boundaries.

In Wolfen, we followed the same procedure as in Strömstad, with some small differences. The race started earlier at $10 \mathrm{am}$, and one of the participants chose to run the $10 \mathrm{~km}$ track. We used open coding to analyze the collected data independently from each other, followed by a collaborative session, where we resolved small differences and agreed on the main findings.

\section{Findings}

All six participants, in the two separate field studies, expressed that the events were well organized and as they expected. It seemed that they felt at home in what they saw as small and friendly happenings. Figure 1 shows runners in Strömstad just before the start. The participants were more or less competitive or serious about the races, but all six said they enjoyed the experience. It didn't seem that participating in the study by using the technological probe, took away from their participation in the events themselves. In the following we denote the participants using two digits, the first for the event and the second for participant (\#)event-participant). 
When it came to placement of the probe as shown in Figure 2, the most competitive of the three in the first field study \#1-1, thought that the extra weight of the smartphone and belt on the chest was bothersome. He said the belt wasn't tight enough so it moved enough to irritate him. In the second field study one participant mentioned that it is important that the belt was positioned right. For him the belt was strapped on too low and he had to move it up while running. The other four participants in the two field studies did not report that they were bothered at all, and said they forgot about the placement of the mobile phone after a short while.

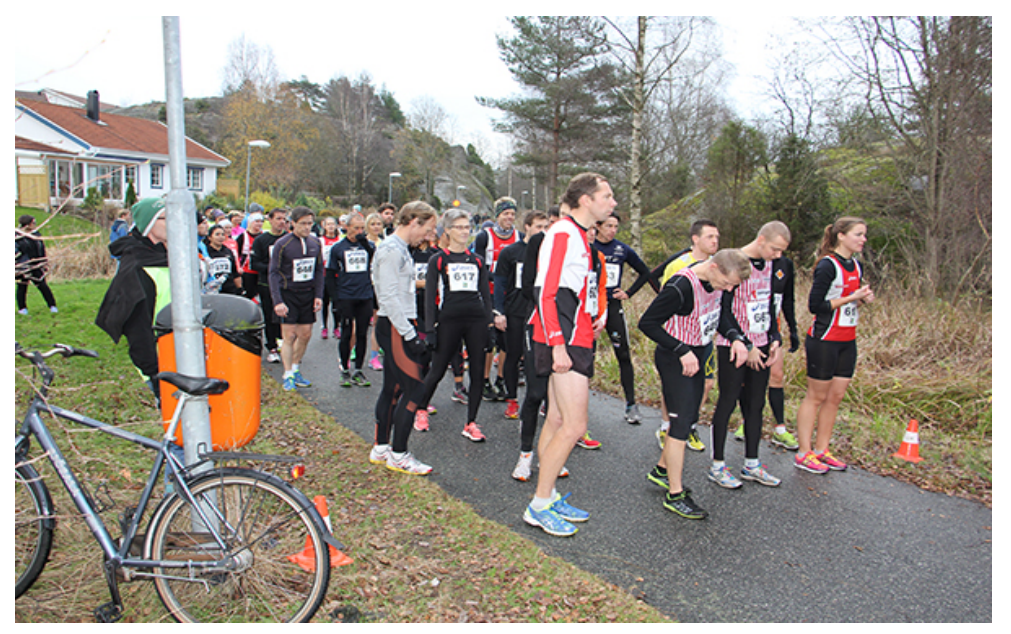

Figure 1. Starting any minute

All six participants said that the hand gestures were easy to perform and appropriate for controlling the video stream.

It is very natural to extend the hand. [...] so to turn it on with that is better than using a closed hand. \#1-1

There is no middle way. Either you open or you close your hand. This simple. \#2-1 None of the participants proposed an alternative hand gesture that could have worked better for this purpose. All of them said they "forgot" the interface after a while, but they all kept on using it and continued recording video throughout the races. 


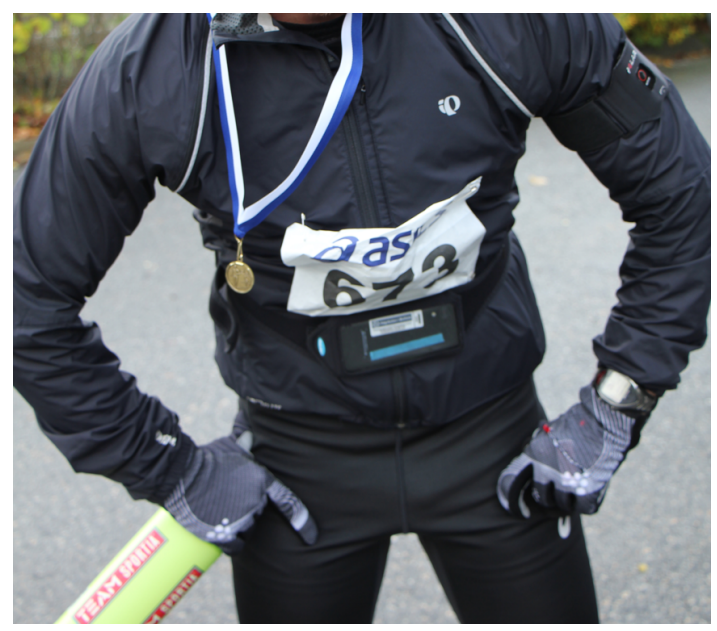

Figure 2. The equipment

\subsection{Privacy Boundaries}

The participants had few reflections on how "being a camera" in public can be problematic to others.

No I did not think about them [other people]. Do I need to think about them? \#2-3

They recorded a lot when they had people nearby, in the starting area especially, and also when they were running almost alone.

Disclosure boundary: Their attention was on when the camera should be turned on, the framing of the image and what sounds were recorded. Three of the participants had a competitive focus during the races and turned on the camera when they improved their position.

...I thought it was funny when I ran down the hill, because I am really fast at running downhill, then I usually overtake many of the other runners. So I turned on the camera on top of the hill, then let go... and thought this was really fun. \#1-1

Participants \#1-2, \#1-3 and \#2-3 were concerned about the framing of the image. The first said that she was worried because she is short, and that she filmed only the road and nothing else. The second said she tried to keep a dangling headphone-wire away from the camera. The third was worried about her hands swinging in front of the camera. Figure 3 shows two screenshots from the captured video.

Most of the participants were acutely aware of the sound captured when recording. Participant \#1-1 gave comments intended for a listener. Participant \#1-3 said she was really worried about recording heavy breathing and other audible signs of fatigue. Participant \#1-2 
turned the camera off because she needed to say something she didn't want anyone to hear. She felt that the sound was more important than the image.

...one thinks about, yes, first and foremost what one says, for what one sees can't be influenced. But what one says, I thought about that a lot. \#1-2

Participant \#2-3 hadn't been aware of the audio and was embarrassed afterwards because she talked a lot with other people while recording.

Identity boundary: All participants expressed that sharing video from participating in a sports event on social media could be positive for their image.

It wouldn't matter if some of this were published, because then people would see that I am active and... yes, I have to admit that this appeals to me, it lowered the threshold for... the social. \#1-1

Participants \#1-1, \#1-3, \#2-1, \#2-2 were skeptical though, and related that they rarely exposed themselves in this way. Participant \#1-1 and \#1-3 said that sharing from sports activities could be seen as bragging, and they would be careful of coming across as betters on social media. They both expressed irritation with other people sharing their training activities on Facebook.

...when people share training logs, I have cycled $70 \mathrm{~km}$ for example, deserving beer and taco, then I think this is bragging. \#1-1

But both these informants were more positive to sharing if the content were without tracking information.

I think, yes - sharing a film, that's nice, but sharing how far you have run, how fast and all that, that is for me, not others. Film is fun of course, that could be amusing. \#1-3

In contrast to the skeptical participants, informant \#1-2 and \#2-3 said they loved to share from activities they participate in, including sports, and that they saw no problems with using the probe to do this.

Yes, I share a lot, also from sports activities. I love running so this is nothing strange. \#1-2

It was cool. It is a new way to communicate with friends. Facebook is made to share things. \#2-3 


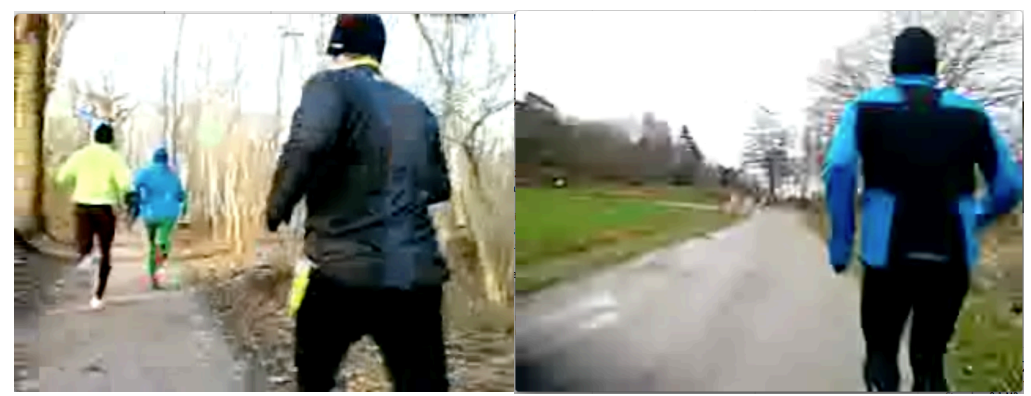

Figure 3. Screenshots from captured video

Temporality boundary: When it came to what the participants wanted to happen with the shared videos from the event, they answered differently. Participant \#1-1 said that he wanted control of the videos. He would have preferred to have them sent to his private inbox for editing before they were published. The most likely thing he would make is a "best of" edit from the competition. But when the videos were already published he was not certain what to do.

...to me it is unpleasant that the videos are out there, then I can just ask for them to be deleted. Except when I cross the goal line or something. I'll see about that. \#1-1

Both participants \#2-1 and \#2-2 wanted to keep the videos on their computers. Participant \#2-1 didn't mind having them online since he is in good shape. In contrary to this, participant \#2-2 wanted them removed or shared with selected friends only. Participant \#1-2 didn't see any problems with the videos being published. She expressed no desire to erase them and hadn't really thought of this as a problem. She said that maybe someone would look at them, maybe not. Participant \#1-3 was more skeptical, but was also comforted by the videos limited appeal. She was more worried about the audio of her huffing and puffing.

...if it is interesting to others then it can be out there, but I don't know if that is the case. I don't know that [laughs]. If it is a video, where I reveal myself, for example with breathing and puffing in the background, then I think I would have removed it. \#1-3

Participant \#2-3 said she would keep the videos that are fun and remove videos less interesting to others.

It depends, how they look. So if there is anything funny, for example when Lars passes me, if this was good, when I would keep it online and write a comment under. \#2-3

\section{Discussion}

When it came to running the events the participants had different agendas, but they participated according to what was expected of them. They followed the logic of the event, the in- 
structions from the organizers, ran the designated track and put effort into the running according to physical capabilities. They related to their time and rank in the race and happily received their prizes. None of them did anything that could be conceived as "outside" the social obligations of the events themselves. None of their actions were "out of place" [30]. The wearing of and interaction with the technological probe seemed to be unobtrusive to the participation in the event and the participants quickly understood the function of the technology and the mapping between gestures, actions and feedback.

\subsection{Negotiating openness / closedness}

When using the three privacy boundaries to understand the results of this study it is evident that the participants negotiated these boundaries differently. There are findings from the trials that point towards openness, and some that point towards closedness. It is important to note that the privacy boundaries are negotiated together. It is difficult to consider one boundary without taking the other two into account.

The first, and maybe the most interesting pattern we see, mostly concerning the disclosure boundary, is related to sensing. None of the participants thought that the first-person image was problematic, but several of them were more concerned with the audio. Both talking and audible signs of exhaustion were mentioned as problematic to share with others. It seems that the first-person view, where the participant was not visible in the image, was conceived as less private than the audio. The users understanding of the video image recorded by the probe facilitated more openness and their understanding of the nature of the audio triggered privacy concerns and more closedness. An interesting follow-up study would be to repeat the experiment with the camera mounted so that the runner could be part of the image.

The second pattern, mostly related to the disclosure and identity boundary, is about what the participants chose to record and their explanations of why they did so. We see two main stories told, with emphasis on the competition and with emphasis on the experience. Three of the participants recorded when something interesting happened in the competition, for instance overtaking other runners in the race. The other three didn't care much about this aspect, but recorded what they thought was interesting like nice scenery or social interactions. This pattern seems to point towards openness, all participants recorded a lot and with some narrative intentions. The interviews seem to indicate that the reason for this was that the 
probe didn't record and share any performance indicators, like pulse and speed. The recordings were not revealing their standing in the race or other precise measures of performance. This seemed to be important to the participants independent of how well they performed in the race. It seems that quantitative measures of their performance would have triggered more privacy concerns and lead towards more closedness.

The third pattern, mostly related to the temporality boundary, is the participants' wish to have control of the recordings. The decision they had, of turning the recording on and off, was not enough. All the participants except one wanted to be able to delete unfavorable or boring recordings before or after they were published to Facebook. Most of the participants wanted to share the recordings with a selected group of people if they could, controlling not only what they shared but also with whom. These findings seem to indicate that the participants were uneasy about the immediate and indiscriminate sharing done by the probe, pointing towards more closedness. But at the same time many of the participants were intrigued by the experience with the technological probe. It seems that they were open to experimenting with the format as long as they could have the option of removing recordings afterwards and have more control of their recipients. This is relatively easy to do on a social media platform like Facebook and this finding points in the direction of openness. Maybe the participants would be inclined to share more easily as a result of more experience with the probe.

\subsection{Re-negotiation of privacy boundaries}

The concept of "privacy genre" is mainly a descriptive term, since genres are historically situated as social practice. In our study we have developed a probe that gave our informants experience with new technology, exploring what could be called a proto-genre, but not a genre. The sharing of live video on Facebook while running is not exceptionally new or outlandish, but still not something that many people do as part of their everyday activities. So what we have been probing is mainly how people are able to negotiate privacy boundaries when using new and not commonly used information technologies. In this perspective, we have found that people rely heavily on previous experience with similar technologies when negotiating privacy boundaries "fresh". They rely on earlier and established genres of disclosure related to, in our case combinations of sports tracking, photography and social media. In this study, we were surprised by how quickly and consciously this process was undertaken by our informants, and how efficiently new boundaries where negotiated building on old. At the same 
time, we found that unfamiliar aspects of the proto-genre articulated by the probe, triggered the most intense and partly unresolved negotiations of privacy boundaries; the clearest example being the recording and live sharing of "first-person" sound.

These findings attest to the usefulness of the concept of genre of disclosure both as an analytical tool but also as a perspective useful when designing and exploring mediating technologies. People's practical everyday experience with negotiating privacy, framed and understood as a social situated dynamic, can give good guidance of what will trigger privacy concerns and what will not. This study is an initial exploration of designing and deploying technology probes to investigate privacy concerns with mediating technologies. Our results indicate that technology probes can be designed to disrupt or destabilize existing genres of disclosure, giving researchers the opportunity to study these closer, mining the interstices between them.

\section{Conclusion}

In this study, we have explored privacy concerns with instant sharing of video in social media. To understand the co-dependent technical and social aspects of instant sharing and privacy, as framed by the concept of "genres of disclosure" [6], we have developed a technological probe and conducted two field studies at running events in Sweden and Germany. In each field study three participants were fitted with a working probe sharing video instantly to Facebook by opening and closing the hand. The probe performed according to the intentions of the research design, opening up for investigating privacy in practice.

The findings suggest that audio wouldn't be shared a lot in this context, since it captures audible signs of fatigue. Further, it seems that sharing of performance indicators are problematic, so it is more likely that the probe would be used to mediate the general experience of taking part in a running event. Lastly it seems that very few would be comfortable with immediate sharing and would like to have the option of removing recordings and control its recipients. Overall, it seems that people, when using new mediating technologies, rely heavily on earlier experience with similar technologies when negotiating the privacy boundaries, emphasizing the historically situated nature of privacy in practice. We believe that probing wearable technology in the field has been important for this study, and see how our findings open up for further studies with similar mediating technologies, in other mobile contexts. 


\section{References}

[1] P. Dourish and K. Anderson, "Collective Information Practice: Emploring Privacy and Security As Social and Cultural Phenomena," Hum-Comput Interact, vol. 21, no. 3, Sep. 2006, pp. 319-342.

[2] V. Bellotti and A. Sellen, "Design for Privacy in Ubiquitous Computing Environments," in Proceedings of the Third European Conference on Computer-Supported Cooperative Work 13-17 September 1993, Milan, Italy ECSCW '93, G. de Michelis, C. Simone, and K. Schmidt, Eds. Springer Netherlands, 1993, pp. 77-92.

[3] P. E. Agre and M. Rotenberg, Technology and Privacy: The New Landscape. MIT Press, 1998.

[4] P. Kumar and S. Schoenebeck, "The Modern Day Baby Book: Enacting Good Mothering and Stewarding Privacy on Facebook," in Proceedings of the 18th ACM Conference on Computer Supported Cooperative Work \& Social Computing, New York, NY, USA, 2015, pp. 1302-1312.

[5] H. Hutchinson et al., "Technology Probes: Inspiring Design for and with Families," in Proceedings of the SIGCHI Conference on Human Factors in Computing Systems, New York, NY, USA, 2003, pp. 17-24.

[6] L. Palen and P. Dourish, "Unpacking 'Privacy' for a Networked World," in Proceedings of the SIGCHI Conference on Human Factors in Computing Systems, New York, NY, USA, 2003, pp. 129-136.

[7] R. Ling, "From ubicomp to ubiex(pectations)," Telemat. Inform., vol. 31, no. 2, May 2014, pp. 173-183.

[8] J. Ojala and J. Saarela, "Understanding Social Needs and Motivations to Share Data in Online Sports Communities," in Proceedings of the 14th International Academic MindTrek Conference: Envisioning Future Media Environments, New York, NY, USA, 2010, pp. 95-102.

[9] S. A. Munson, E. Krupka, C. Richardson, and P. Resnick, "Effects of Public Commitments and Accountability in a Technology-Supported Physical Activity Intervention," in Proceedings of the 33rd Annual ACM Conference on Human Factors in Computing Systems, New York, NY, USA, 2015, pp. 1135-1144.

[10] R. Teodoro and M. Naaman, "Fitter with Twitter: Understanding Personal Health and Fitness Activity in Social Media." in ICWSM, 2013.

[11] D. Lupton, "Self-Tracking Modes: Reflexive Self-Monitoring and Data Practices," Social Science Research Network, Rochester, NY, SSRN Scholarly Paper ID 2483549, Aug. 2014.

[12] S. Mann, "Wearable computing: a first step toward personal imaging," Computer, vol. 30, no. 2, Feb. 1997, pp. 25-32.

[13] R. Hoyle et al., "Privacy Behaviors of Lifeloggers Using Wearable Cameras," in Proceedings of the 2014 ACM International Joint Conference on Pervasive and Ubiquitous Computing, New York, NY, USA, 2014, pp. 571-582.

[14] T. Denning, Z. Dehlawi, and T. Kohno, "In Situ with Bystanders of Augmented Reality Glasses: Perspectives on Recording and Privacy-mediating Technologies," in Proceedings of the 32Nd Annual ACM Conference on Human Factors in Computing Systems, New York, NY, USA, 2014, pp. 2377-2386.

[15] F. Stutzman and J. Kramer-Duffield, "Friends Only: Examining a Privacy-enhancing Behavior in Facebook," in Proceedings of the SIGCHI Conference on Human Factors in Computing Systems, New York, NY, USA, 2010, pp. 1553-1562. 
[16] S. Lindtner, J. Chen, G. R. Hayes, and P. Dourish, "Towards a Framework of Publics: Re-encountering Media Sharing and Its User," ACM Trans Comput-Hum Interact, vol. 18, no. 2, Jul. 2011, pp. 5:1-5:23.

[17] S. D. Warren and L. D. Brandeis, "The Right to Privacy," Harv. Law Rev., vol. 4, no. 5, 1890, pp. 193-220.

[18] I. Altman, "The Environment and Social Behavior: Privacy, Personal Space, Territory, and Crowding.," Brooks / Cole Monterey, CA, 1975.

[19] I. Altman, "Privacy Regulation: Culturally Universal or Culturally Specific?" J. Soc. Issues, vol. 33, no. 3, Jul. 1977, pp. 66-84.

[20] J. Grudin, "Desituating Action: Digital Representation of Context," Hum-Comput Interact, vol. 16, no. 2, Dec. 2001, pp. 269-286.

[21] W. W. Gaver, A. Boucher, S. Pennington, and B. Walker, "Cultural Probes and the Value of Uncertainty," interactions, vol. 11, no. 5, Sep. 2004, pp. 53-56.

[22] C. Graham and M. Rouncefield, "Probes and Participation," in Proceedings of the Tenth Anniversary Conference on Participatory Design 2008, Indianapolis, IN, USA, 2008, pp. 194-197.

[23] H. M. Edwards, S. McDonald, and T. Zhao, "Exploring Teenagers' Motivation to Exercise Through Technology Probes," in Proceedings of the 25th BCS Conference on Human-Computer Interaction, Swinton, UK, 2011, pp. 104-113.

[24] D. Fitton, K. Cheverst, M. Rouncefield, and A. Dix, "Probing technology with technology probes," in In Equator Workshop on Record and Replay Technologies, 2004.

[25] S. O'Brien and F. "Floyd" Mueller, "Holding Hands over a Distance: Technology Probes in an Intimate, Mobile Context," in Proceedings of the 18th Australia Conference on Computer-Human Interaction: Design: Activities, Artefacts and Environments, New York, NY, USA, 2006, pp. 293-296.

[26] J. Bergstrom-Lehtovirta, A. Oulasvirta, and S. Brewster, "The Effects of Walking Speed on Target Acquisition on a Touchscreen Interface," in Proceedings of the 13th International Conference on Human Computer Interaction with Mobile Devices and Services, New York, NY, USA, 2011, pp. 143-146.

[27] J. Marshall and P. Tennent, "Mobile Interaction Does Not Exist," in CHI '13 Extended Abstracts on Human Factors in Computing Systems, New York, NY, USA, 2013, pp. 2069-2078.

[28] F. Gemperle, C. Kasabach, J. Stivoric, M. Bauer, and R. Martin, "Design for wearability," in Second International Symposium on Wearable Computers, 1998. Digest of Papers, 1998, pp. 116-122.

[29] J. Rico and S. Brewster, "Gestures All Around Us: User Differences in Social Acceptability Perceptions of Gesture Based Interfaces," in Proceedings of the 11th International Conference on Human-Computer Interaction with Mobile Devices and Services, New York, NY, USA, 2009, pp. 64:1-64:2.

[30] S. Harrison and P. Dourish, "Re-place-ing Space: The Roles of Place and Space in Collaborative Systems," in Proceedings of the 1996 ACM Conference on Computer Supported Cooperative Work, New York, NY, USA, 1996, pp. 67-76. 


\title{
Article 4: Aligning Participation with Authorship: Independent Transmedia Documentary Production in Norway
}

Joakim Karlsen

\begin{abstract}
Incentives to develop non-fiction transmedia projects have recently challenged the work practices of independent documentary film makers in Norway. However, research on documentary film has to a little degree captured the emerging practice of making non-fiction transmedia. Based on an interview study undertaken in 2012 / 2013 and reflections on contributing to a recent non-fiction transmedia project, I find that the emerging practice face many of the same challenges as the participative documentary practice of the 70s, mainly that facilitation of audience participation requires a break from the broadcasting logic of independent documentary film work.
\end{abstract}

Keywords: Non-fiction transmedia, independent documentary film, art worlds, practice, participative documentary

\section{Introduction}

The independent documentary film community in Norway is small and consists of a handful of companies, often set up around one or two lead creatives. There are mainly two sources of funding for these producers, the national broadcaster (NRK) and the Norwegian Film Institute (NFI), and these institutions to a large degree define the who, what and when of independent documentary production in Norway. During the winter 2011 / 2012, NFI encouraged independent documentary film producers in Norway to explore non-fiction transmedia, or "audio visual documentary projects that are not film". They arranged series of workshops and seminars, and opened their funding scheme to multi-platform documentaries. Since this initiative was taken by NFI, a couple of projects has been funded, both in 2012. The first one was Project Moken (2012) ${ }^{2}$, http://projectmoken.com, and shortly after this, the project 17 000 Islands $(2013)^{3}$ received substantial funding to develop an online tool for "sculptural editing”, http://17000islandsinteractive.com/ (Works in Chrome only). After these projects were funded, the NFI has not received any further applications for funding of any larger nonfiction transmedia projects ${ }^{4}$. 


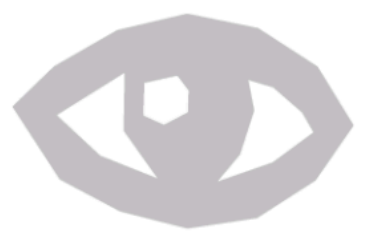

Documentaries

At the heart of Project Moken there is a feature length documentary

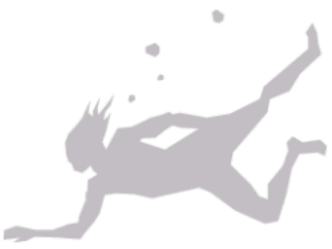

Hold your breath

Experience the underwater realm of the Moken.

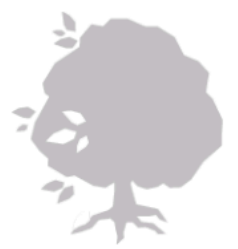

The tree campaign

One Tree can save the Moken culture! Click here to find out how and be part of it!

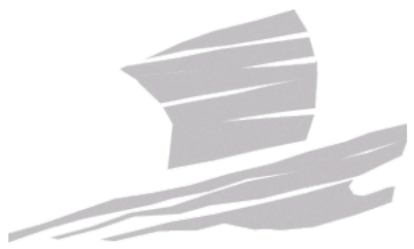

The Ocean as a place For the Moken, the ocean is a place not a barrier.

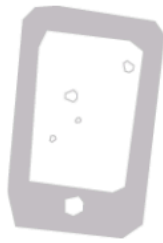

The Moken App

Be a free-diver! Hold your breath along with a Moken - renowned for their natural free-diving skills.

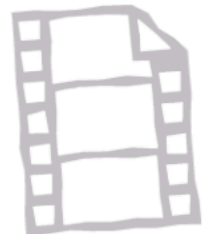

Moving Footage

Access our library of short documentary clips and edited reseach. Comments

The transmedia components of the Moken Project

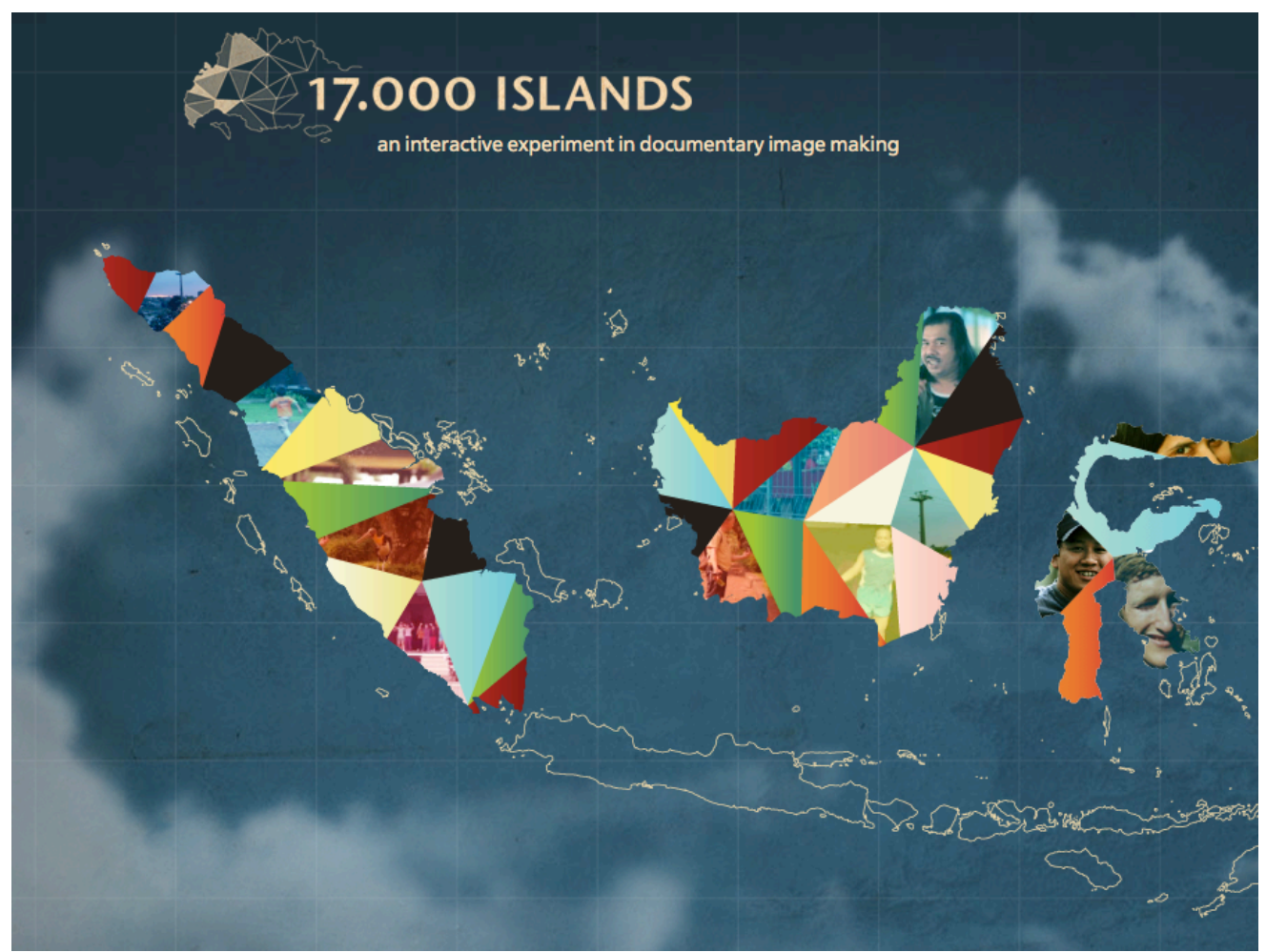

The landing page of the project 17000 Islands, Affording the possibility of "sculptural editing".

The main contribution of this article is to describe empirically some of the practices of making non-fiction transmedia in Norway in the years 2012 to 2013. How facilitating for audience participation, have challenged earlier practices of making independent documentary 
film in this context. The findings presented in this article, are most likely relevant for research on similar developments in the Nordic countries and parts of Europe, where government institutions and public service broadcasters play an important role in the funding of independent documentary film projects. The established bureaucratic practices of these institutions are set up to support traditional documentary film production, and they will need to be adapted to accommodate for new forms of documentary afforded by new media technologies.

In the following I will review relevant literature on emerging forms of documentary, and how these have the potential to reconfigure the relationship between author and audience established in the documentary film tradition. Then I will develop a perspective on documentary practice that give a framework for understanding if and how the making of making nonfiction transmedia is misaligned with earlier documentary film practices. After this, I will summarize the findings from an interview study with independent documentary producers in Norway undertaken in 2012 / 2013 and from participating in a non-fiction transmedia project, where I contributed as full member. In the discussion, I will highlight the implications of these findings for independent documentary film practitioners wanting to make non-fiction transmedia and for the institutions aiming to support them.

\subsection{Authorship, Audience Participation and Art Worlds}

Developing a taxonomy of documentary forms being developed with new media technologies, would reveal great variation. New types of non-fiction storytelling have emerged, where practitioners have experimented with new materials, tools and techniques for both making and distributing documentaries. Researchers has tried to define the emerging documentary forms, using concepts like interactive documentary ${ }^{5}$, database documentary ${ }^{6}$, webdocumentary $^{7}$ and transmedia documentary ${ }^{8}$, often focusing on interactivity and / or audience participation in their definitions. Transmedia, as defined by Henry Jenkins ${ }^{9}$, is a category of storytelling that belong to a genealogy of creating content on several platforms belonging to the same story universe. The audience engagement with the universe, across different media platforms, becomes the prime concern, and one example from fiction storytelling, is the Matrix ${ }^{10}$. However, the concept of transmedia, as used in the Norwegian context of independent documentary film production in 2011 / 2013, has taken on both a wider and narrower meaning than defined by Jenkins. It has included all types of documentary that are 
made to more than film, a more inclusive use of the term transmedia, but with an emphasis of how audience activity should influence the contents of the documentary itself, a narrower use of the concept.

The understanding of these developments, expressing a local use of the concept of transmedia, will require a developed theory of audience participation. The documentary studies field has a strong tradition of studying authors, their works of art and how the documentary film form progresses and develops historically ${ }^{11}$. However, the emerging non-fiction transmedia documentary practice, as reported on in this article, have challenged this primacy of the author ${ }^{12}$, of her work of $\operatorname{art}^{13}$ and the stable relationship between authorship and readership $^{14}$. Hart Cohen ${ }^{15}$ captures all three aspects when he claims that that what he coins the "database documentary" challenge the concept of "auteur" because of how the database opens for interactivity and unpredictable readings. Sandra Gaudenzi, when writing about interactive and participative documentaries, claim that, “...the role of the author has to move from 'narrator of a story' to 'facilitator of other people's stories"" ${ }^{16}$. She uses Bill Nichols "mode of documentary" as a starting point and proposes four "modes of interactivity ${ }^{17}$, each mode express different ways in which authors places the audience / users in relation to technology when representing reality. Further, researchers have reconceptualised the author as curator $^{18}$ and not the least as designer ${ }^{19}$. There is a move by these researchers, from an author centred understanding of documentary practice to an audience or user centred one.

When re-conceptualization the relationship between author and audience, Nico Carpentier ${ }^{20}$ is critical to deterministic simplifications of this relationship and uses the longer tradition of audience theory to resituate the debate historically with the main aim of salvaging a deep understanding of audience participation. He claims to see "enthusiastic and sometimes messianistic discourses of novelty" when it comes to " "new' media technologies and practices". Like the shift from one-to-many to many-to-many communication as articulated by Jay Rosen $^{21}$. The re-articulation of the audience into the "produser" as articulated by Axel Bruns $^{22}$, and the convergence of top-down business with bottom-up consumption and production practices as articulated by Henry Jenkins ${ }^{23}$ and Clay Shirkey ${ }^{24}$. Important for the argument in this article, Carpentier claim that deep audience participation is not necessarily a consequence of new media technologies and uses the BBC project Video Nation (1993-) to recount how this project deteriorated when moved online; $\underline{\text { htp://www.bbc.co.uk/videona- }}$

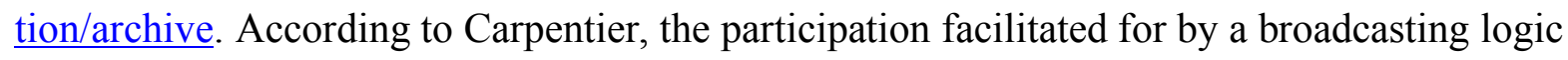


was deeper and more effective than the participation enabled when going from compiled broadcasts to online archive. He emphasizes how the development of participative media must be seen in longer historical perspective and that deep audience participation needs to be anchored in and protected by strong organizational structures.

The organizational framework of independent documentary production can be partially described by Nichols concept of mode, and his view of mode as depending on a community of practice $^{25}$, but also Howard S. Becker theory of art worlds ${ }^{26}$. Both scholars use practice theory $^{27}$ to a certain degree when explaining the phenomena they study, emphasizing that the production of film and other forms of art is historically situated both socially and materially and performed and re-performed as practice, constrained but not determined by its organizational structures. Becker describes the social embeddedness of art, how art is created in a system with high degree of participation from all involved parties. He uses two main concepts, collective (cooperative) activities and conventions, to describe an art world. The collective (cooperative) activities, according to Becker are $\left.{ }^{28} ; 1\right)$ developing an idea about the kind of work and its form, 2) executing the idea with the help of materials and equipment that has to be, 3) manufactured, which require money raised by 4) distributing the artwork to an audience, 5) all this require supporting activities, 6) for the system to work or for an artwork to exist, it needs both appreciation and response from an audience, 7) the system depends on creating and maintaining a rationale for its existence. According to Becker, there are interdependencies and cooperative links in this system that are forged by mutual knowledge of and recognition of conventions ${ }^{29}$. Conventions are what makes cooperation possible between all actors, including the audience ${ }^{30}$. An artist adapts, according to Becker, to his audience, to ensure their appreciation, by relying on an intimate knowledge of the conventions relevant for the specific art form.

To use Becker's theory of art worlds to frame and understand emerging documentary practices, as studied in this article, highlights the dilemmas and problems surfacing when developing a radically new practice within an existing art world. Transmedia non-fiction is an emerging and experimental art form, depending on new types of materials and equipment, lacking established means of distribution, with few stable sources of revenue, needing new kinds of support personnel like designers and programmers, seeking an appreciative and participating audience and with a need to align itself with the existing rationale of independent documentary film production. Further, the lack of well-established conventions for what 
transmedia non-fiction actually is, can make the process of forging new cooperative links challenging. The studies reported on in this article exemplify some of these challenges, focusing on difficulties with aligning audience participation with the current understanding of authorship, common in the independent documentary film community in Norway.

\section{Interviewing and Working with Independent Documentary Producers}

When studying practice, it is important to rely on observations and thick empirical descriptions that emphasize practice as situated, embodied and performed. Therefore, Davide Nico$\operatorname{lini}^{31}$ recommends participant observation when zooming in on the accomplishments of a practice. But when doing this, he writes, we as researchers needs to "scrutinize two practices at the same time: our epistemic practice and what concerns us." ${ }^{32}$ In this study, I have relied on interviews, but also on being a full member of several transmedia non-fiction projects. I have sought to scrutinize my own involvements and how they relate to the reported findings. This has been to take on the basic hermeneutical and iterative stance of action-research ${ }^{33}$, with constant questioning of my own role as project participant, but also by taking actively part in processes of change. My role as a co-practitioner in the project reported on here, was possible because of my background as documentary filmmaker and earlier collaboration with the director. According to Nicolini ${ }^{34}$, interviews alone are not sufficient when understanding practice, but can make sense together with field work. In this study, interviews have been a god way of uncovering practitioner's attitudes and concerns towards a not yet established practice.

\subsection{Findings from the Interviews}

To find and select the independent producers for my interviews, I used several sources. First, I used NFIs information on grants given between November 2010 to November $2012^{35}$. Second, I asked the Norwegian film and TV producers' association to name the most active independent documentary producers amongst its members. Lastly, I marked off the producers that I knew had made non-fiction transmedia or were about to do so. When this list was compiled and sorted, I contacted the producers from the top of the list and managed to get interviews with 14 informants working for 11 companies. In addition, I interviewed the production advisor for documentary at NFI at the time. The interview guide was semi structured 
and consisted of six open questions focusing on the informants understanding of and experience with transmedia. When conducting the interviews in 2012 / 2013, most of the interviewees hadn't produced any transmedia documentaries, but they had a lot of thoughts on what this new form implied when it came to their own practice, and several of them had worked on proposals for, and prototypes of transmedia projects. In the following, I will focus on findings that relate to the producer's attitudes towards renegotiating the author / audience relationship implied by their understanding of transmedia and how they saw the development of transmedia, in relation to the organizational support they had at the time.

Most the producers I interviewed, emphasized that non-fiction transmedia have the same purpose as traditional documentary film,

...I think anyone interested in telling non-fiction stories have a primary fascination with real people, real stories and real destinies, and want to convey these stories to increase understanding and expand the horizons of people. [...] and I believe this is the purpose with transmedia too. It's only a new tool to do the same (\# 12).

Even if they saw non-fiction transmedia as having the same rationale as traditional documentary film, most of the producers emphasized that a transmedia documentary must involve and represent the audience as part of the story. This opening for audience participation, was framed by several producers as a strengthening of the utilitarian aspects of documentary, by facilitating more engagement and increasing the potential for inducing real changes in society. These producers saw this as the strongest feature of transmedia documentaries, to open for a democratization of documentary film.

This is a democratization of the film format [...] When the audience is drawn into, and take part in, building an opinion, an opportunity for having a say (\# 6).

However, many of the producers were worried about how to keep editorial control when opening for audience contributions. How would they be able to steer what a documentary becomes, when much or all the material is produced by the audience itself? None of them liked the idea of letting a documentary project grow organically, based on content created by the audience.

One could imagine that the audience contributed data into a database, but if it was like this instant producing, without any quality control, then I think that it would break with what we want to do (\#2).

Many of the producers therefore emphasized the unabated need for a clearly authored narrative, even when involving the audience. The participants from the audience should be 
given clearly defined roles in line with or contributing to a story controlled by the director. One of the producers gave a reason for this,

But the important thing that is difficult for us, is to open up for user participation. We resist this, because instinctively, we know that we have become what we have become because we tell stories to an audience, not that the audience tells stories to us (\# 4).

When asked how they could facilitate for audience participation in a transmedia project, it became obvious that this was uncharted territory for most of the producers, although almost all of them would have liked to get this to work.

When it came to organizational support for making transmedia documentaries, several of the producers were not sure what NFI wanted to achieve with its initiative of supporting non-fiction transmedia. They said they would rather initiate such artistic priorities themselves, in cooperation with NFIs commissioning editors, and would have preferred a more bottom-up approach by their main funder. Further, several of the producers said they feared that transmedia projects would get too much of the relatively small amount of government money earmarked for documentary production and called for a separate funding scheme. One of the producers had the perception that transmedia production would cost a lot of money and because of this, wanted to protect what he called primary film production work,

It [transmedia] comes in the way of the primary work that we do which is storytelling for film and television. I hear about people who have done transmedia projects that are damn frustrated because they feel that money runs out... (\# 13).

Several of the producers wanted to protect the existing documentary film practitioners, and were sceptical about sharing the relatively little funds available with practitioners with other backgrounds and skills. Further, some of the producers felt insecure about how to recruit skilled people and how to negotiate a proper price for their services.

... I know how to deal in the film world, but I do not know to deal with a programmer. I do not know what it costs (\# 10).

They seemed to understand that they could alleviate this problem, by buying transmedia components from advertising agencies and game development companies, with more experience with developing content for digital platforms. However, several of the them had already realized that they couldn't afford to buy finished products from these agencies, with in their view, an unreasonable overhead. The only opportunity, mentioned by several of them, of hiring skilled people they could afford, was to find freelance workers who could help them solve clearly defined tasks. 
...often it is important to define some core issues or core challenges and find someone specific who can set aside a few hours or days or weeks to the work, instead of hiring an agency who bills a lot of hours on miscellaneous things (\# 11).

When it came to planning transmedia documentary projects, most of the producers admitted that they had little experience and that they needed to do more transmedia projects to be able to gain confidence.

I do not think I know enough about that. If I am going to plan, fund and calculate the cost of doing a larger transmedia project, I will need to get some help, indeed (\# 14).

However, several of the producers believed that the independent documentary film community would learn quickly, and that most of them had sufficient knowledge of general project management to get by. One of the informants, who had some experiences with transmedia production, said that the complexity of the projects had increased with transmedia, and that this required a new mind-set to avoid making mistakes.

You cannot launch a mobile application where the graphics is poorly linked to the code underneath and where functions are buggy. [...] I think that if you go in with a traditional television production mind-set when creating transmedia, you'll get some nasty surprises (\# 8).

\subsection{Findings from doing Project Work}

In parallel with and after conducting the interviews, I worked with the director and producer of the documentary film Our daily bread (2013), on creating transmedia content related to the film. We experienced some nasty surprises, as referred to by the last informant cited in the previous chapter, but I believe this had to do with more than a specific mind-set. We had several set-backs that exposed the challenges with creating non-fiction transmedia in this context. We chose two very different approaches in the project. The first was to work with NFI to get support for a full non-fiction transmedia project. When this failed, we devised a simpler bottom-up strategy of making a working prototype of a mobile crowdsourcing application, hoping that a tangible outcome could convince funders to support the project.

The film, that was the main component of the project, had been commissioned jointly by NRK and NFI, some time before I got involved in the transmedia development work. The film was in production when I joined the project, and the topic was Norwegian food-policies and how centralisation and monopolistic tendencies in the national food market give consumers less choice, poorer quality and higher price than would otherwise be the case. The 
first undertaking in the transmedia part of the project, was to write an application for additional funding from NFI, where the full transmedia project was defined. The work was divided between the producer, the director and me. As a starting point, I defined a project template, combining the traditional documentary film concept template with Tim Pratten's transmedia template ${ }^{36}$, a template developed for writing video game concepts ${ }^{37}$, and a general template for digital storytelling concepts ${ }^{38}$. The director and me wrote most of the application, and the producer set up a budget and plan for the project. We proposed to build a webpage on a spatial metaphor of a local grocery store. The different areas of the store, and its shelves, would to link to information about different aspects of the Norwegian food business. Further we wanted to build a mobile application using real stores as interface to a subset of the same information. We described how the audience could interact with information using their smartphones in the store, using barcodes as main reference. Lastly we proposed to arrange events where users of the webpage, the mobile application and the film could meet up for debates, lectures and other food policy related calls, before, during and after the film was broadcasted on television. The application, with a budget of $100000 \$$, that was rejected by the NFI. Little feedback was given, so it is difficult to know the real reasons behind the rejection. It could be about lack of resources, internal politics, artistic evaluation, portfolio considerations, strategic concerns, or maybe that the project template itself was unfamiliar. The positive finding from this experiment was that working out a new project template afforded the producer, director and me to reach a common understanding of what a non-fiction transmedia project was, early in the process.

Some time after this, the producer allocated some minor funds to the project, and in spring 2013, after a period of mainly conceptual work, we developed a prototype of a map-based mobile application called "My Store". With the help of one of my students, working part time on the project, and a graphic designer, we made a mobile web application with the basic functionality to find and select a store on a map and share text, images and video to it. The working prototype, with bugs and all, is available for exploration at http://itp.hiof.no. This is a copy of the project and can be freely used by the readers of this article, preferably from a mobile phone. The three screen shots below show the splash screen, the find store on the map screen and lastly the screen where you can watch what other people has uploaded, and contribute text, images or videos yourself. 


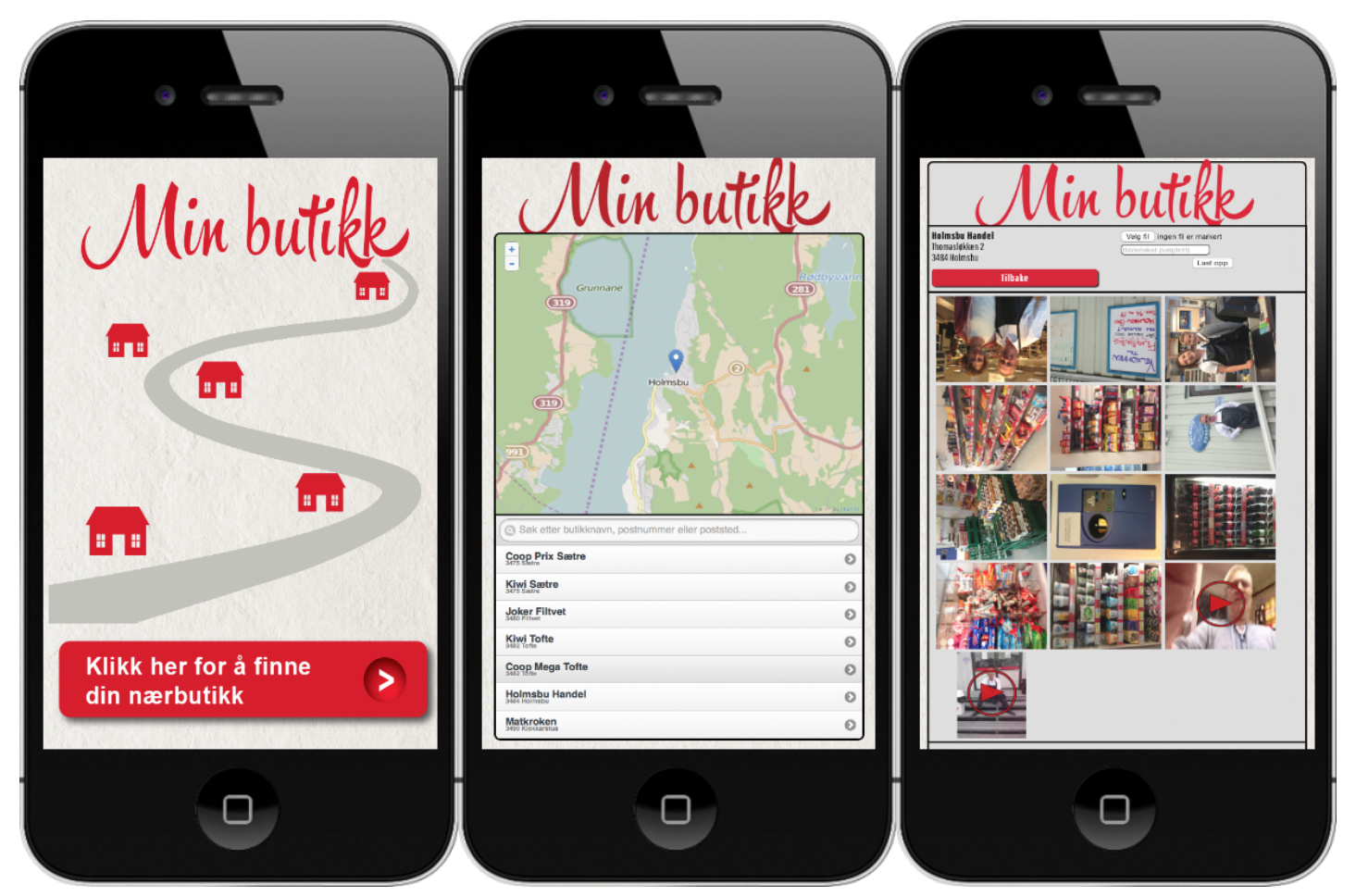

Prototype 1: Screenshots showing the main pages of the app enabling the sharing of text, images and video to a local store.

We tested the prototype as part of a local showing of the film in the little town where the main character, an owner of a small grocery store, lived. To get people to discover and use the application, we visited the community some days in advance and gave a talk about the project in a local elementary school (11-12-year olds). Here we recruited two participants and made an appointment with them to meet us at the store after school. In the meantime, we visited several stores in the area and got randomly chosen people to use the mobile application (with a little help). We thought that some genuine videos would increase the likelihood that people would contribute later. When the kids tested the mobile application at the store, a journalist from the local newspaper visited. The local screening of the film and the piece in the newspaper were on the same day, and the attendance was good. As part of the program, I introduced the app and demonstrated its use on a large screen. In our view, we had done everything we could to ensure that we were going to get a positive result from the experiment, but during the next couple of days, no contributions were made by the townspeople.

\section{Aligning audience centred with author centred practices}

Making non-fiction transmedia within the existing art world of independent documentary film production in Norway, led to breakdowns that exposed some issues with aligning the 
emerging practice with the old. Facilitating for audience participation, lead to issues concerning how to negotiate a fitting project model, how to legitimize non-fiction transmedia as a work of art and problems with adapting the scope of a non-fiction transmedia project to the broadcasting logic of independent documentary film production.

The first issue of devising a fitting project model was to adapt the traditional linear approach of traditional film making to include the necessities of iterative design. With finding user requirements, developing alternatives, prototyping and evaluation ${ }^{39}$. In the start of the project, when writing the application to NFI, we wrote transmedia content, as we would have written for film. We authored the first concept document using ideas and material that were available to us at that time, with little involvement from representatives of the audience or other stakeholders. Even if I had some experience with design work and knew that we should have devised a more user driven process to establish requirements, the focus on getting the first money got the upper hand. Basic insights from user-oriented design or interaction design, could have helped us to devise a plan, that involved real users and stakeholders from the start. This would probably have given more ideas, better ideas, and not the least ideas that would have a better chance of being supported later in the process.

In the second phase of the project we chose an approach that is much closer to what is common in a design project, making and evaluating a prototype. As most designers know, working with an iterative project model, is that a prototypes value lies in its evaluation, and a failed prototype can lead to the biggest improvements in the next iteration of the project. Taking on a design perspective, I therefore believe the prototype "my store" was partially successful. The trial uncovered some fundamental problems and possibilities with the prototype, concerning people's ability and willingness to contribute. But in this project, the result was seen as a failure. I believe this to be a consequence of how the experiment was framed, the role it was conceived to have in the larger project. Making a prototype and doing field tests is a "new" activity in a documentary project but was quickly framed as making a pilot. The main purpose of a pilot is to release funds for producing the documentary film, and the reason we made the prototype "my store" became to materialize and document how transmedia could work well, to convince NFI and NRK to support the project. When we got no contributions from people when trying it out, the prototypes value as a pilot was insignificant. 
The interviews seem to support this conflict between an iterative design logic and the more linear film production logic. The main issues when it came to project model, was how most of the producers had high confidence that they would be able to plan transmedia projects well. They simplified the problem to be about hiring the right people, to the right price, or alternatively to buy whole solutions from agencies and consultants. Understandably, they framed this more within a linear manufacturing logic than an iterative one. Most of the practitioners I interviewed have so far little experience with the many facets of attracting and engaging the audience on several platforms. They will need to get first-hand experience with making mobile applications, mini-games and multimedia, to be able to see how a user-driven iterative project model, could be a better fit for this kind of work, than an author-driven linear one.

The second issue of legitimizing an indeterminate work of art, with an uncertain moment of appreciation, is real when it comes to non-fiction transmedia. In the Norwegian context, the main event for a documentary film maker is when the film is either screened at a cinema or broadcasted on television. This is the moment of appreciation that are the main concern for all involved stakeholders in this particular art world, including its funders. Before a new "model of appreciation" is in place for non-fiction transmedia, with a more inclusive definition of what counts as an audience, it is probably going to be hard to finance these projects, as we experienced when working on funding the transmedia components of Our daily bread (2013).

The interview with the production advisor at NFI, gave an example of dilemmas surfacing when funders seek to adapt bureaucratic practice so that the innovation of new types of documentaries falls within their given mandate. According to the advisor, a good non-fiction transmedia project should have a strong audio-visual form (important in the mandate for the fund), and at the same time give the audience the ability to influence the story of the documentary itself. He used amateur sports as an example (orienteering), and claiming that an event, open to the audience, taped, edited and screened was transmedia, something that makes little sense in this context. Any filmed events, without strict control of who is participating, would become transmedia. To be able to open up for transmedia, NFI would need to reconsider its current criteria for awarding projects and make them more platform neutral and less dependent a strong narrative supported by audio-visuals. From the interviews, it seems that there is a high degree of continuity between the old and new practices when it 
comes to purpose. Documentary film practice and non-fiction transmedia practice, as understood by the interviewees, share the same concern for giving people a voice and for contributing to the creation of an engaged public around important issues in society. This insight can be a promising starting point for defining criteria that are oriented towards the value system of the independent film documentary community, but that includes indeterminate audience-driven documentary forms as legitimate works of art.

The third issue that surfaced mainly in the project work, was aligning the spatial and temporal scope inherent when making transmedia, with the broadcasting logic of independent documentary film production. The traditional understanding of authorship in documentary film implies a specific audience model. When Seymour Chatman ${ }^{40}$ describe the narrative situation, the reader is framed as the "implied reader", pointing to the fact that an author needs to establish and maintain a working model of her readership, translated to our context, of her audience. According to Elefante and Deuze ${ }^{41}$ this ability to work with "audience-in-theirheads" and use this mental model to make creative decisions is important for creative workers. For our purposes, this can be reframed as a "public service mind-set" that delineates a narrative situation that is general and non-specific, reaching out to anyone and no-one in particular. We adopted this mind-set when working with the transmedia concept and when designing and evaluating the prototype, entertaining a mental model of our audience as Norwegians in general. In combination with this, we worked with the temporal scope of a relatively big but short media event, the prime-time screening of the film on NRK. But how is it possible to design and evaluate a prototype, seen a part of this kind of media logic, when it is impossible to simulate the media event beforehand? Big media events, how they feed into the larger media output, and how audiences choose to respond, is highly unpredictable and challenging to design for.

The general audience model, with a wide scope geographically and narrow scope temporarily, is probably the opposite of what is the strength of transmedia, long term engagement with smaller communities around specific issues. This scope is comparable to what the participatory video movement in the 70 s worked with ${ }^{42}$, when the affordances of video technology as compared to film opened for new production practices emphasizing "process, not product". Stephanie Tripp ${ }^{43}$ tells how members of the Peoples Video Theatre (PVT) movement covered public events and interviewed people whom they invited, 
...to visit the group's loft in the West Village to watch the videos and discuss them. Screenings were open to the public; a flyer for one of PVT's weekend shows invited prospective attendees to "see mini documentaries," "speak back to the news," "become part of the news," and "see yourself" (qtd. in Shamberg and Raindance, "Official Manual" 18).

PVT engaged with political controversies and interviewed stakeholders "as a method of mediating (literally) disputes", with a distribution model "centered on community-based participation and decision making". Tripp uses her story of PVT and other participatory video movements to draw attention to how todays citizen journalists and Youtubers face the same challenges as the early pioneers. This study seems to indicate that the same is true for practitioners making non-fiction transmedia.

\section{Concluding Remarks}

In this article, I have given an account of how the independent documentary community in Norway received and reacted to the initiative by NFI in 2012 / 2013, to explore non-fiction transmedia. The interviews revealed that the producers were able to align the purpose of making transmedia with their current practice but didn't like the idea of losing editorial control. The producers had problems with articulating how the audience could participate, how participation could be facilitated for within their existing linear project model.

The experience of working with developing transmedia have emphasized certain issues with adapting transmedia work to fit in a documentary film project. First that the linear, productand story-oriented project model of independent documentary film production was unfitting. The iterative, experimental approach, arguably a better fit for this kind of project were sidestepped by the heavy emphasis of producing concepts and pilots that could release additional funding. Second, what counted as a work of art as codified in NFIs bureaucratic practice, failed to resolve what the nature of our project was. How a utility-oriented redefinition of funding criteria, focusing on platform neutrality and a wider definition of legitimate documentary forms, could have alleviated this problem. Lastly, that this to a large degree came down to the core concern of aligning participation with a working model of authorship. The current scope of the "public service mind-set" is geographically wide and temporarily narrow, maybe the opposite of what makes sense when building communities around societal issues. 
As noted in the introduction, there have been no major applications to NFI for funding nonfiction transmedia after the initial flurry in 2011 / 2013. This doesn't necessarily mean that there are no projects being developed, only that independent documentary producers haven't seen any reasons to add transmedia components when applying NFI for money. The reason for this could be that the initial definitional and bureaucratic problems, has created uncertainties of what counts as a legitimate non-fiction transmedia contribution. Another plausible explanation is that the independent documentary film practice in Norway has established a stable art world that will reproduce itself and change more slowly than anticipated by NFI in 2011. The practitioners rely on the well-established author-work-audience model of documentary film that is tightly coupled to an "audience-in-their-heads" approach and a the logic of public service broadcasting.

If one understands non-fiction transmedia as a continuation and strengthening of independent documentary film as a participatory practice it is possible to use the fate of the participatory video movement of the 70 s to explain the seemingly low appetite for experimentation with non-fiction transmedia in Norway recently. The participatory video movement of the 70 s has continued to be marginal ${ }^{44}$, underlining incompatibilities between a practice centred primarily on audience participation and the mainstream documentary film practice centred on authorship. This, to follow Carpentier ${ }^{45}$, indicate that facilitating for deep audience participation has less to do with new media technologies than the underlying organizational support. To use Becker's theory of art worlds, considering the importance of the conventional art works of documentary film and the rituals surrounding its distribution and appreciation, it seems more likely that the non-fiction transmedia documentary, that is no longer film, will generate an art world of its own.

1 Anders Fagerholt, 'NFI støtter web-dokumentar', Rushprint, 23 March 2011, http://rushprint.no/2011/3/ny-plattform-for-dokumentar

2 'Project Moken'NFI, 3 May 2012, http://www.nfi.no/bransje/tildelinger/tilskudd?key $=133232$

3 '17,000 Islands', 8 Desember 2016, http://17000islandsinteractive.com/

4 Interview with the production advisor at NFI, February 2016.

5 Dayna Galloway, Kenneth B McAlpine, and Paul Harris, 'From Michael Moore to JFK Reloaded: Towards a working model of interactive documentary', Journal of Media Practice, 8, 3, 2007, 325-339.

6 Hart Cohen, 'Database Documentary From Authorship to Authoring in Remediated/Remixed Documentary', Culture Unbound: Journal of Current Cultural Research, 4, 2012, 327-346. 
7 Siobhan O'Flynn, 'Documentary's metamorphic form: Webdoc, interactive, transmedia, participatory and beyond', Studies in Documentary Film, 6, 2, 2012, 141-157.

8 O'Flynn, 2012.

9 Henry Jenkins, 'Confessions of an Aca/Fan: Archives: Transmedia Storytelling 101', 8 Desember 2016, http://henryjenkins.org/2007/03/transmedia_storytelling_101.html

10 Henry Jenkins, Convergence culture: where old and new media collide, New York University Press, 2008, p. 93.

11 Hart Cohen, 'Database Documentary: From Authorship to Authoring in Remediated/Remixed Documentary', Culture Unbound: Journal of Current Cultural Research, 4, 17, 2012, 327-346.

12 Cohen, 2012.

13 Jonathan Dovey and Mandy Rose, “This great mapping of ourselves"-new documentary forms online', BFI Companion to Documentary, 2013, 366-375.

14 Nico Carpentier, 'Contextualising Author-Audience Convergences', Cultural Studies, 25, $4-5,2011,517-533$.

15 Cohen, 2012.

16 Sandra Gaudenzi, 'Strategies of Participation: The Who, What and When of Collaborative Documentaries', in New Documentary Ecologies: Emerging Platforms, Practices and Discourses, Kate Nash, Craig High and Catherine Summerhayes, eds, 2014, 129 148.

17 Sandra Gaudenzi, 'The Living Documentary: from representing reality to co-creating reality in digital interactive documentary', PhD Thesis, 2013.

18 Dovey and Rose, 2013.

19 Cohen, 2012; Sharon Daniel, 'Argument, Inquiry and Political Narrative: Navigating an Aestethics of Database Documentary', Database/Narrative/Archive, 2013; Jon Dovey, 'Documentary Ecosystems: Collaboration and Exploitation', New Documentary Ecologies: Emerging Platforms, Practices and Discourses, Kate Nash, Craig High and Catherine Summerhayes, eds, 2014.

20 Carpentier, 2011.

21 Jay Rosen, 'Afterword: the people formerly known as the audience', Participation and Media Production: Critical Reflections on Content Creation, 2008, 163-165.

22 Axel Bruns, 'Produsage', Proceedings of the 6th ACM SIGCHI conference on Creativity \& Cognition, 2007, 99-106.

23 Henry Jenkins, 2008.

24 Clay Shirky, Here comes everybody: how change happens when people come together, Penguin, 2009.

25 Bill Nichols, Representing reality: issues and concepts in documentary, Bloomington, 1991, p. 23.

26 Howard Saul Becker, Art Worlds, University of California Press, 1984; Hans van Maanen, How to Study Art Worlds : On the Societal Functioning of aesthetic Values, Amsterdam University Press, 2009.

27 Davide Nicolini, Practice Theory, Work, and Organization: An Introduction, Oxford University Press, 2012.

28 Becker, 1984, p. 2-4.

29 Becker, 1984, p. 25.

30 Becker, 1984, p. 29-30.

31 Nicolini, 2012.

32 Nicolini, 2012, p. 217.

33 Stephen. Toulmin, Beyond Theory: Changing organizations through participation, John Benjamins Publishing Company, 1996. 
34 Nicolini, 2012, p. 217.

35 'Tilskuddsordninger for dokumentarfilm', NFI, 8 Desember 2010, http://www.nfi.no/bransje/tildelinger/søkeresultat?search=\&year=2010\&type=117638

36 Robert Pratten, 'Zen Films: Transmedia Workflow', 8 Desember 2010, http://zenfilms.typepad.com/zen_films/2010/06/transmedia-workflow.html

37 Flint Dille, The Ultimate Guide to Video Game Writing and Design, Lone Eagle, 2006.

38 Carolyn Handler Miller, Digital storytelling: a creator's guide to interactive entertainment, Focal Press, 2008.

39 Helen Sharp, Yvonne Rogers, and Jenny Preece, Interaction design: beyond human-computer interaction, John Wiley, 2007, p. 15.

40 Seymour Chatman, Story and discourse: Narrative structure in fiction and film, Cornell University Press, 1980.

41 Phoebe Harris Elefante and Mark Deuze, 'Media work, career management, and professional identity: Living labour precarity', Northern Lights: Film \& Media Studies Yearbook, 10, 1, 2012, 9-24.

42 Stephanie Tripp, 'From TVTV to YouTube: A Genealogy of Participatory Practices in Video', Journal of Film and Video, 64, 1, 2012, 5-16.

43 Tripp, 2012.

44 Tripp, 2012.

45 Carpentier, 2011. 


\title{
Article 5: "You Can Dance Your Prototype If You Like": Indie Filmmakers Adapting the Hackathon
}

Joakim Karlsen

Anders Sundnes Løvlie

\begin{abstract}
Hackathon-style events are increasingly used to facilitate cross-disciplinary learning and innovation in the media industries. Based on an observational study of a hackathon organised as part of the film festival Nordic Panorama (NP) we analyze the challenges in using the hackathon format to facilitate cross-disciplinary learning and innovation for filmmakers, developers and designers. We find that many participants experienced frustrations resulting from a lack of programming skills and their expectation that the hackathon should result in "something digital". Additionally, ideals for authorship embedded in the working cultures of film and TV professionals impeded the team's ability to involve all participants on an equal footing. As implications for future hackathons we suggest organisers should consider using tools for end-user development and generative toolkits to facilitate digital making and collaborative learning. We also suggest similar events should avoid including project owners if the group work is based on existing projects.
\end{abstract}

Keywords: design; film; hackathon; hacker culture; media work

\section{Introduction}

For independent filmmakers the ongoing development of mobile and networked media has opened up new opportunities and new challenges. Many need to get familiar with methods, tools and techniques usually associated with software development and design. Research into "media work" (Deuze 2007; Hesmondhalgh 2013) has demonstrated the precarious nature of such "portfolio careers" and the pressure on media workers to acquire new skills in designing and making personalized, participatory and user-generated media (Deuze 2016). In recent years hackathons have become an increasingly popular way to facilitate practical engagement with new tools and techniques, expanding beyond the field of software development to other areas such as civic engagement and culture (Briscoe and Mulligan 2014; Irani 2015; Leckart 2012; Lodato and DiSalvo 2016). 
In this article, we report on a hackathon that took place as part of the film festival Nordic Panorama (NP) in Malmö 19-22 Sept. 2014. The purpose of the event was to facilitate multidisciplinary collaboration, innovation and learning ("Hackathon | Nordisk Panorama" 2015). The event was part of an ongoing series of hackathons taking place as part of the unconference track of the festival since 2012 in order to bring together "old disciplines" like film and television with new media and games. Around half the participants were filmmakers, while the rest came from backgrounds in art, design, game design and software development. We see the NP hackathon in the light of a broader trend of cross-disciplinary hackathons for the media, arts and culture fields (Briscoe and Mulligan 2014) such as the POV Hackathons ("POV Hackathon | POV | PBS" 2015; Filippova et al. 2017), Tribeca Hacks ("Tribeca Hacks" 2015), Popathons ("Popathon • Growing a Community of Web-Native Storytellers" 2015) and Culture Hack ("What Is Culture Hack? | Culture Hack” 2016).

Based on this case we explore the following research question: What are the main challenges in using the hackathon format to facilitate cross-disciplinary learning and innovation for filmmakers, developers and designers? We suggest that these challenges can be understood in light of the different work cultures associated with the variety of professions represented in the Nordic Panorama hackathon. The concern that professionals belonging to different domains such as science, engineering and the humanities represent different cultures with limited understanding for each other has long been a matter of scholarly debate (Snow 1959; Brockman 1995). More recently, Lewis and Usher have demonstrated the challenges in collaborations between technologists and journalists through their study of the Hacks/Hackers organisation, pointing out that journalists and hackers have "distinctive occupational norms and values" $(2014,3)$ and struggle with developing "a common language" $(2014,8)$. This article contributes to research into cross-disciplinary collaboration between filmmakers, developers and designers by exploring the challenges implied in bridging these distinct work cultures through the condensed format of a hackathon.

\subsection{Hackathons and hacker culture}

The popular image of hackathons is one of rapid, intense bursts of productivity, as captured in Wired's description of the phenomenon: "Relentless programming sessions fuelled by hope and coffee. Usually days long, hackathons bring together Silicon Valley's brightest and most sleep-deprived as they attempt to grind out software (and companies based on it)" 
(Lufkin 2012). The term hackathon is a combination of the word hack and marathon and was first used about events in the software development industry (Lodato and DiSalvo 2016). Hackathons are intensive events where participants gather to explore and experiment with a technology and/or a common theme, developing prototypes in a short timeframe, usually 2448 hours, working in teams that are either pre-formed or formed ad hoc at the start of the event. Many hackathons include a secret task or theme that is revealed at the start of the event. At the end of the event the groups present their prototypes, and prizes are often awarded by an external jury. Teams are typically free to organize themselves and their work processes as they see fit from the start to the end of the event, both when it comes to working on their project and more mundane necessities like eating and sleeping. Hackathons require thorough preparation and a particular frame of mind, geared towards aligning the complexities of software development with rapid prototyping in a way that leads to a convincing prototype (Kaitila 2012). The short timeframe favours tinkering or bricolage, often relying on ready-mades, templates, frameworks and earlier projects.

Trainer et al. (2016) describe hackathons as brief and radical collocation of work involving a trade-off between advancing technical work and forging social ties. Based on a study of hacker conferences, Coleman suggests that the apparently paradoxical need for hackers to get together physically (in spite of the apparent "virtual" nature of their activities) may be understood as a desire for ritual celebrations of the hackers' lifeworld and culture (G. Coleman 2010). Hacker culture, according to Coleman, is characterised by "an expansive pragmatic practice of instrumental yet playful experimentation and production" $(2012,99)$ as well as an ideal for productive freedom that contains tensions between independence and interdependence, "between two productive extremes - the collaborative and individual" (2012, 109). Research on game jams has emphasized social aspects of learning, in particular for handling collaboration, as well as technical skills related to new tools (Arya et al. 2013; Fowler et al. 2013).

Some studies have focused on issue-oriented and open government hackathons, discussing the relation between the entrepreneurial values inherent in the hackathon format and the possibility to use this format to explore societal issues (Johnson and Robinson 2014; Lamela et al. 2013). In an ethnographic study of an open government hackathon in India, Irani describes the hackathon as a "celebration of scientific and engineering ethos" favouring opti- 
mistic doing and making before debate; while "hackathons ostensibly produce 'demos' (software prototypes), [they] more powerfully produce entrepreneurial subjects" (Irani 2015, 800). Irani suggests that the hackathon was characterized by an "idealization of speed and vision" that conflicted with the actual ability of participants to create concrete results (2015, 816-17). Lodato and DiSalvo discuss issue-oriented hackathons which "are organized around themes considered or cast as having a 'social' quality" $(2016,540)$ and argue that such events should be judged as sites for material participation rather than production, foregrounding "how the event fosters opportunities for collaborative or collective issue articulation" $(2016,553)$. They argue that the hackathon format requires issues to be operationalized and presented as problems which can be solved technologically, rather than controversies for debate and contestation. This limits the possibility for issue articulation and formation of publics, leading instead to a focus on speculative material participation through props and “proto-publics" $(2016,554)$.

Goddard et al. (2014) have given a set of guidelines to follow when organizing a game jam, including a recommendation to use design constraints to "facilitate designed outcomes". This suggestion aligns with research on teamwork, which indicates that it is possible for groups to proceed quickly to problem-solving activities, avoiding personal and interpersonal impediments, but that this requires tasks of an impersonal and concrete nature, with clear rules "to orient the group members" (Tuckman 1965). However, for an event such as the NP Hackathon a focus on impersonal, concrete and rule based problem-solving would be at odds with the organisers' stated interest in facilitating an open process geared towards unexpected outcomes and innovation across disciplines. As research on transdisciplinary teams show, the need to "integrate knowledge and methods across subject areas to produce a synergistic result" requires openness to ideas and that the team members hold each other accountable (Collins and Fillery-Travis 2015).

\subsection{Filmmaking}

While film production is one of the archetypical examples of collaborative and industrial art, such production is also notorious for its hierarchical work structures, especially in large scale production environments like Hollywood, with clear demarcations of above and below the line film work (Caldwell 2008). This is also true, albeit on a less industrial scale, for the numerous small independent film producers in the Nordic countries (Köhncke 2006; Stenderup 
1994; Berntsen 2008). In particular the auteur tradition is strong in the Nordic countries, leading to film projects being centered around one creative leader, the director. Film production also distinguishes itself from modern software development in that it usually follows a strictly linear work flow, devoting much time and effort on the initial phases of a project, placing great emphasis on developing a profound idea worth pursuing before starting to materializing it - after which the process often follows a strict production schedule proceeding through clearly defined phases such as development, pre-production, production, post production and distribution.

Given these aspects of filmmaking one might expect that the hackathon format would not be particularly suitable for film work. However, competitions such as Reality Ends Here (Watson 2012) and The 48 Hour Film Project (48 Hour Film Project, Inc. 2017), which challenge participants to create short films in 48 hours, enjoy great popularity. The latter was originally inspired by a similar project in theatre (The 24 Hour Plays n.d.), and could more broadly be seen as an instance of the long tradition of using constraints and games to facilitate creativity in arts (Elster 2000; Mathews 1997; Mercier 2014; Boal 2002).

\subsection{Design}

While hackathons have roots in hacker culture, the phenomenon can also be framed as a collaborative, rapid prototyping event that have much in common with practices that have been developed in design, from the tradition of design charrettes (Roggema 2014) to contemporary practices in human-computer interaction (HCI) and interaction design (IxD). Work practices in HCI and IxD differ from software development in that developers are responsible for making the finished product, while the designers only make the specification for it (Wroblewski 1991). However, prototypes can be seen as bridging this gap, when understanding certain practices of prototyping as blurring the boundaries between specification and product, design and use (Ehn 2008; Fischer et al. 2004).

With the computer increasingly becoming part of all aspects of everyday life, prototyping cultures are being identified that emphasize the importance of programming and craftwork (Vallgårda 2013; Bergström and Blackwell 2016). Craftwork perspectives have also been applied to understand hacking (E. G. Coleman 2012) and programming (McCullough 1998), as 
well as independent film making (Buckland 2016). Central to theories of craftwork is working with materials, of deliberately using eyes, hands and tools to overcome material resistance to make a thing imagined (Sennett 2009). Tim Ingold discusses craft using the concept "making", which he describes as a process of inquiry, an activity which requires the designer to deal with materials to create "correspondences" in a tension between "imaginative foresight" and "material engagement" (Ingold 2013, 72).

Considering prototyping as techniques for rapidly materialising ideas into artefacts, one may view hackathons as ad-hoc design events (Lodato and DiSalvo 2015) well suited for such practices. However, many designers within the fields of HCI and IxD emphasize design as a thoughtful practice (Löwgren and Stolterman 2004) using prototyping as tools for uncovering user requirements and exploring a design space, rather than rapidly producing functional artefacts. One could argue that the format of a hackathon is at odds with utilitarian design practices focused on understanding user needs and formulating requirements and specifications.

\section{Method}

The Nordic Panorama hackathon had 26 participants, 16 male and 10 female, in 7 groups (Table 2). Many of them were selected by application and many were invited by the organizers. The first author of this article was invited by the organizers to observe the event and share insights with the organizers and participants. The cost of attending was covered by the hosting festival, both for the participants and the first author. The second author also participated in the observations, but had no costs covered by the organizers.

Our primary method when studying the hackathon was direct observation. Robson (2002) classifies observational methods along two dimensions: the degree of pre-structure and the role adopted by the observer. Regarding pre-structure, we approached this event with an open and exploratory perspective and had not formulated specific hypotheses or theoretical frameworks beforehand. Our roles were closer to being passive observers than participant observers, however we occasionally asked clarifying questions and joined in conversations in order to better understand what was going on in the groups. Before collecting data from the event, we presented our research aims and our methods to the participants and asked each participant to sign a letter of consent. To be able to get an understanding of the background 
and skills in the groups we also handed out a simple survey that the participants answered when they had some time to spare.

Robson (2002, 324-25) classify potential observational biases into; selective attention, selective encoding, selective memory and interpersonal factors. As already noted we chose an open approach to the event, but there were so much going on in the event, that some selection needed to take place. Fortunately, we were two researchers (the authors), and could cover more ground between us. We were able to visit all seven groups several times during the weekend, and we could spend significant time observing each group. For the most part we simply sat down next to a group, placed the audio recorder on the table and observed their discussions, but sometimes we also asked questions (see Figure 1). Our observations were documented through audio recordings, notes, photos and video and we recorded 20 hours and 55 minutes of audio during the event, as well as 1,5 hours of video during the concept presentations.

The analysis of the gathered material was a three-step process following abductive reasoning. First, the two authors separately used our documentation to write down a narrative vignette of each group's work in the hackathon, as observed by us. Second, we compared our vignettes, discussing similarities and differences and filling out holes and nuances in our observations. And third, these vignettes were used to draw out general themes. Regarding the validity of our findings, we made sure that they were a sound interpretation of what went on in the hackathon by doing the analysis and reviewing the narrative accounts of each of the group processes together.

\subsection{Overview of the event}

The NP hackathon conformed to many of the standard conventions for hackathons. It took place over a little more than 48 hours, from Saturday morning until Monday at noon, and was located apart from the main festival venue in a makerspace with a few large rooms and a workshop with various physical materials available for prototyping (Figure 2). However, there were two main deviations from the typical format. First of all, the starting point for the contest was not a secret theme, but two existing film and television concepts which the participants had been informed about in advance: an animated short film and a collaborative 
documentary project. Second, the teams were not formed by the participants themselves, but by the organizers ahead of the event.

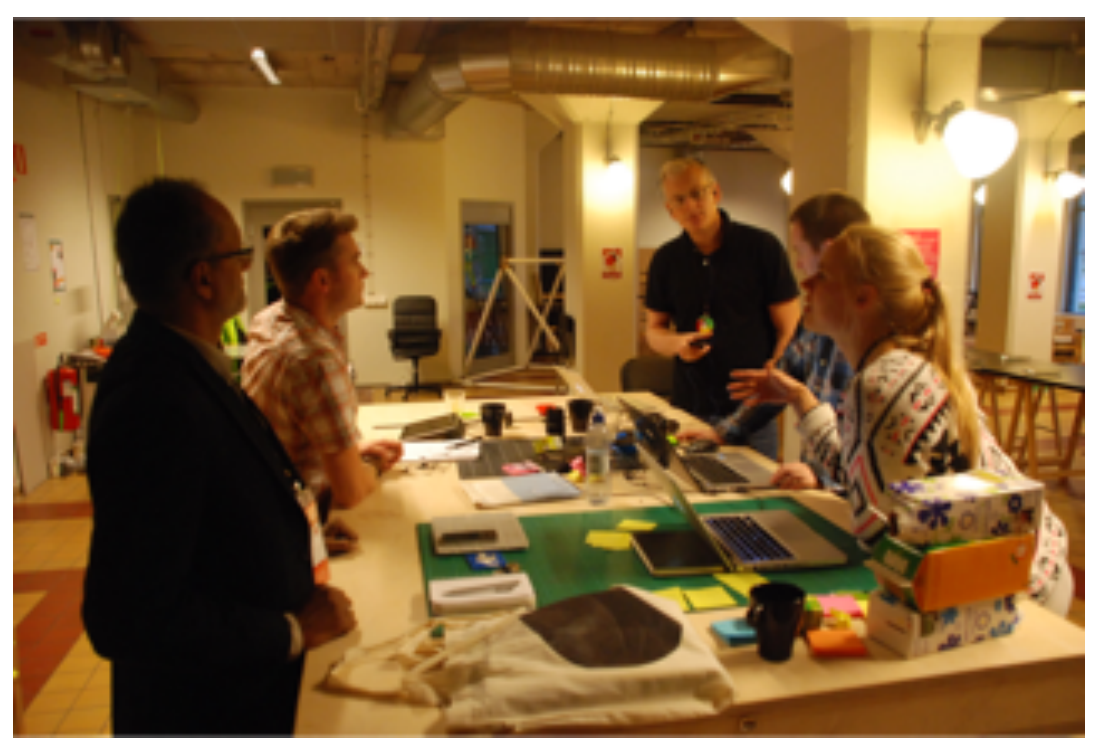

Figure 1: Observing one of the groups.

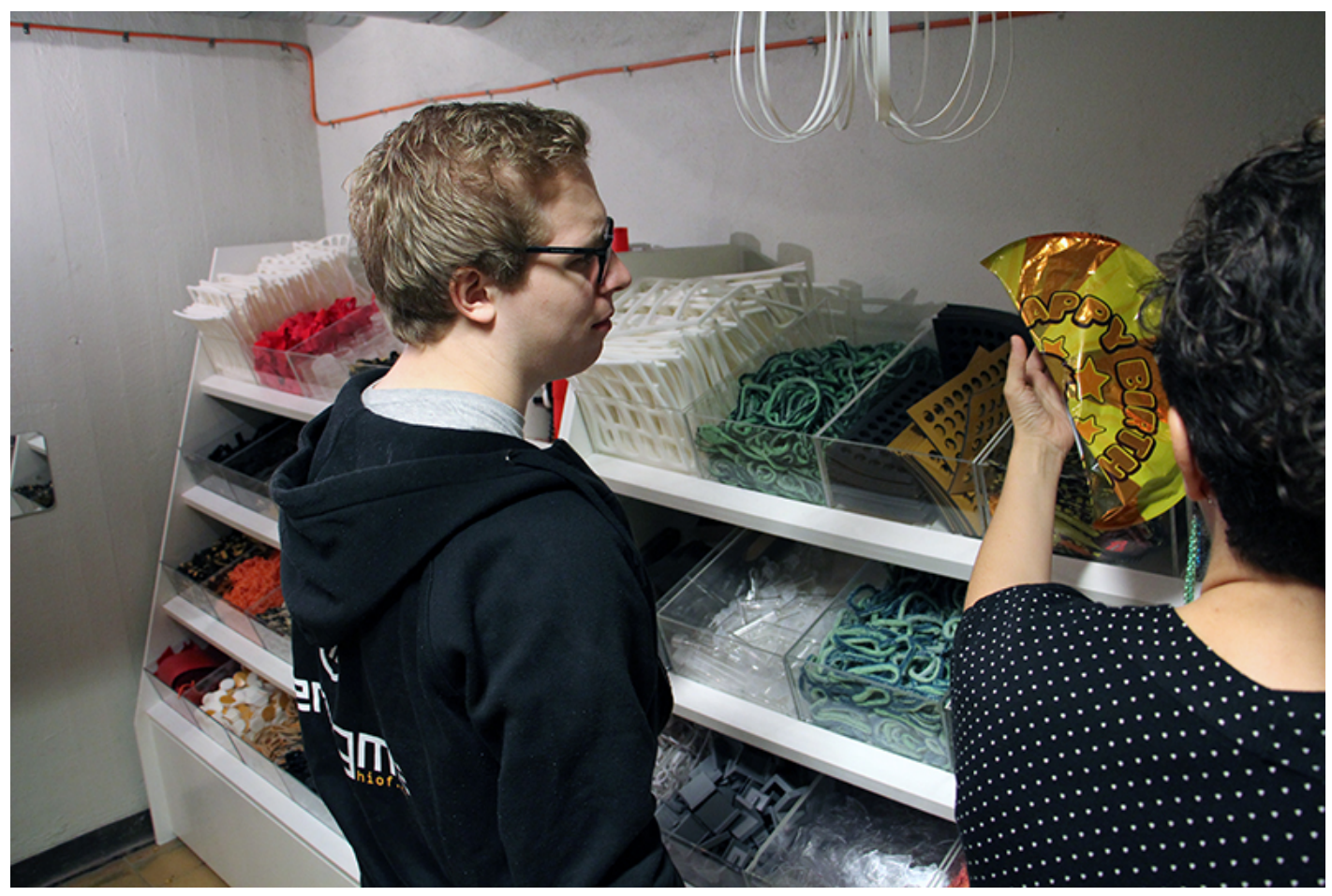

Figure 2: The hackathon took place in a well-stocked maker space.

The NPFF hackathon included a number of joint sessions with presentations for all the participants, interspersed by longer stretches of working in teams. Table 1 shows the main structure of the event. At the pre-event meet-up on Friday the plans for the event were presented, 
followed by presentations of each of the two concepts that were going to be used as basis for the hackathon. These concepts differed regarding genre, format and degree of completeness.

The animated short film project consisted of a far developed concept for an animated fiction film with much material already made: visual artwork, motion-capture data, 3D models, audio and so forth. The director showed a trailer for the film and presented the main characters, main conflict and the setting for the film (Figure 3). He explained that the team behind the film was looking for funding to produce the main movie but were also looking for ideas about how to develop the concept further, and their main motivation for participation in the hackathon appeared to be looking for fresh ideas.

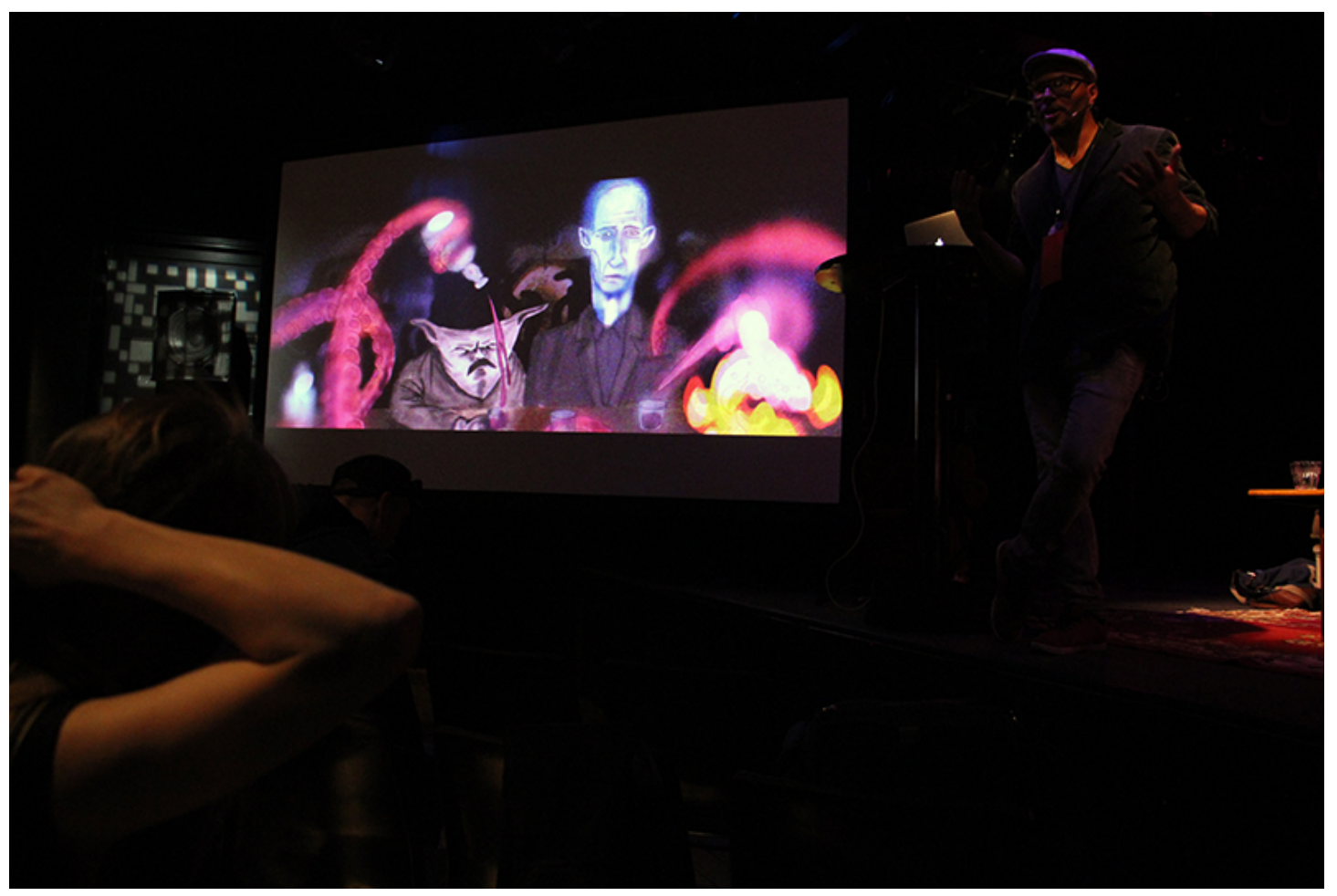

Figure 3: The project owner presenting the animated short film project.

The collaborative documentary project consisted of a concept for a reality TV show, in which a selected group of citizens control an actor as a human "avatar" conducting playful interventions in public places in order to challenge people's beliefs and prejudices. In their presentation, the directors focused on the overall ideas underlying their concept, regarding topics like democracy, participation and prejudices. They also showed a trailer for a pilot 
version of the project. The concept had originally been developed for a public broadcaster to use in their election coverage. However, the broadcaster had turned it down, and the two directors were now looking for fresh ideas about new directions for the concept. They did not have any materials to share with the participants other than the trailer.

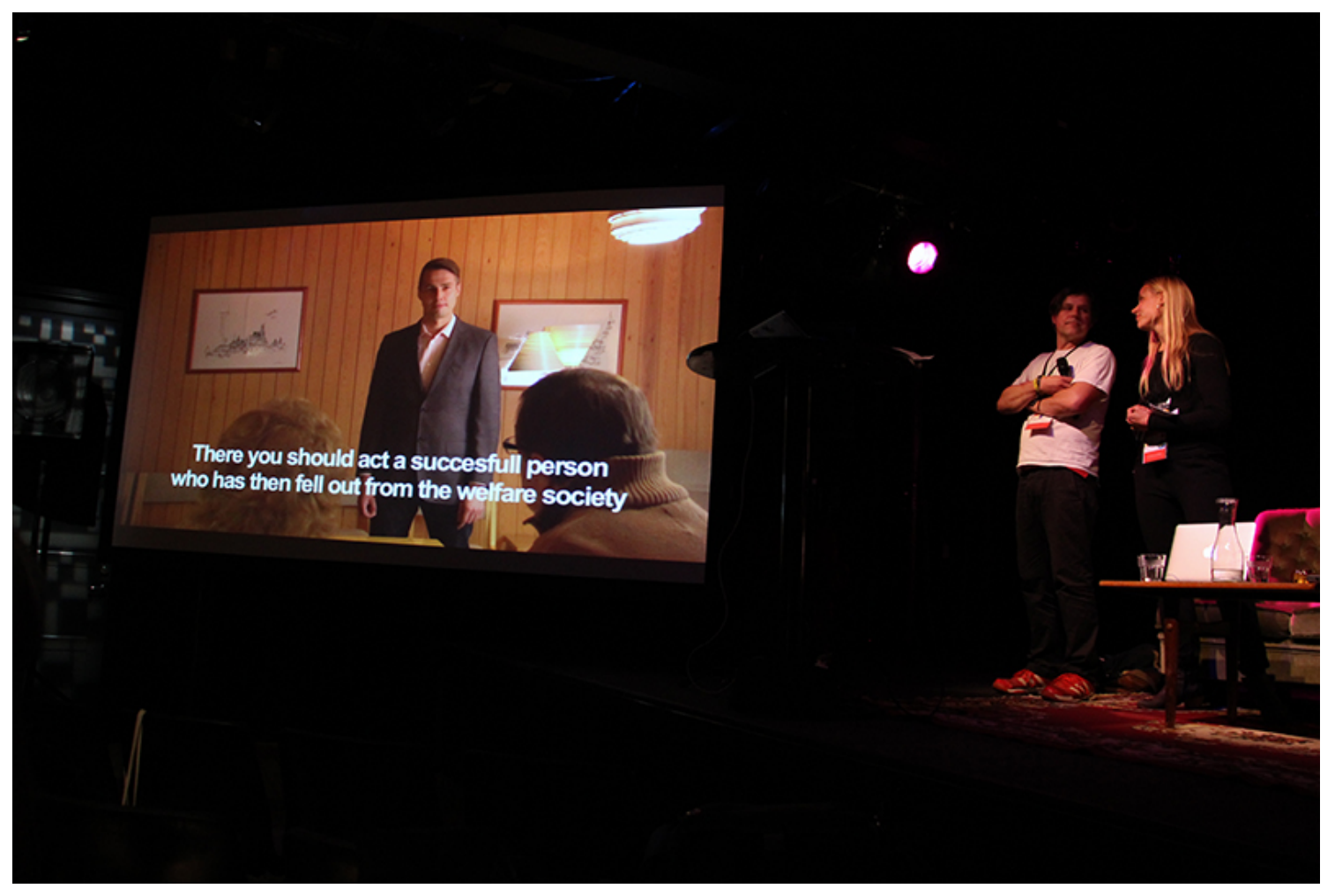

Figure 4: The project owners presenting the collaborative documentary project.

Table 1: Timetable for the event with locations.

\begin{tabular}{|l|l|l|}
\hline When & What & Where \\
\hline Friday evening & Pre-event meet up, and festival opening party & Festival venue \\
\hline Saturday morning & Breakfast and kick-off presentations of concepts & Makerspace \\
\hline Saturday, lunch & $\begin{array}{l}\text { Lunch and temporary presentations by the } \\
\text { groups }\end{array}$ & Makerspace \\
\hline Saturday evening & Dinner and drinks & Makerspace \\
\hline Sunday afternoon & "Dress rehearsal" presentations by the groups & Makerspace \\
\hline Monday at noon & Final presentations by the groups & Festival venue \\
\hline
\end{tabular}


When asked about what they hoped to get out of the hackathon, the directors of both concepts avoided giving clear directions, and chose instead to emphasize that they were open to any and all ideas that might come up. The main organizer, Eva, also gave the participants instructions that were similarly open: "For me the most exciting thing is the variation of what can come out of this process. So it doesn't have to be like a set format, you can dance your prototype if you want to."

During the hackathon the participants spent most of the time in the makerspace working in groups or separately, only interrupted by meals and a few plenary sessions. On Saturday after lunch the groups joined for what the organizer called "a peek into the process", where the groups were given one minute to explain what they were working on and whether they needed any help or resources. On Sunday at $8 \mathrm{pm}$ the groups presented their projects as a dress rehearsal. The final presentations took place on Monday at noon, in a public session at one of the festival venues open to the general festival audience.

Table 2: Groups, participants and background. The names used in this article are not the real names of the participants

\begin{tabular}{|c|c|c|}
\hline Team & Participants & Project \\
\hline 1 & $\begin{array}{l}\text { Aki, filmmaker and visual artist (project owner) } \\
\text { Betsy, composer and game tester } \\
\text { Carl, film producer } \\
\text { David, programmer }\end{array}$ & \multirow{3}{*}{ Short film } \\
\hline 2 & $\begin{array}{l}\text { Emily, web producer } \\
\text { Fatima, documentary filmmaker } \\
\text { George, programmer / IT-student }\end{array}$ & \\
\hline 3 & $\begin{array}{l}\text { Hanna, architect/programmer } \\
\text { Ivan, computer engineer and self-taught filmmaker } \\
\text { Jill, photojournalist and designer } \\
\text { Kasper, filmmaker }\end{array}$ & \\
\hline 4 & $\begin{array}{l}\text { Lars, visual artist and reality TV producer (project owner) } \\
\text { Maria, game designer and copywriter } \\
\text { Noah, computer programmer }\end{array}$ & \multirow[b]{2}{*}{ Documentary } \\
\hline 5 & $\begin{array}{l}\text { Olivia, visual artist (project owner) } \\
\text { Pat, architect / filmmaker } \\
\text { Rolf, game designer } \\
\text { Sven, documentary filmmaker with a technical background }\end{array}$ & \\
\hline
\end{tabular}




\begin{tabular}{|l|l|l|}
\hline 6 & $\begin{array}{l}\text { Thor, programmer and IT student } \\
\text { Victor, television-producer and commissioning editor } \\
\text { William, film writer } \\
\text { Ylva, artist }\end{array}$ & \\
\hline 7 & $\begin{array}{l}\text { Anna, game designer and artist } \\
\text { Ben, filmmaker } \\
\text { Camilla, university media producer } \\
\text { Dan, visual artist and designer }\end{array}$ & \\
\hline Others & $\begin{array}{l}\text { Eva, main organizer } \\
\text { Fred, engineer }\end{array}$ & \\
\hline
\end{tabular}

\section{Findings}

In the following, we will present our observations from the hackathon, focusing first on the types of productions that were made by participants in the hackathon, and thereafter on the ways in which participants organised their collaboration.

\subsection{Hacking}

All the groups except for group 7 had one participant with programming competence (the game designer in group 5 could also do programming). However, we observed little of the kind of work activity that is common in technology-oriented hackathons or game jams, where participants tend to spend much time in front of each their computer, intensely working on technical prototypes. In the NP hackathon, most of the groups spent most of their time discussing their ideas for concepts, and typically only for limited periods of time did they work on technical instantiation of their ideas, and then usually only the single participant with programming competence worked alone on the technical solution.

We consider that groups 1, 3 and 4 had a working pattern that most resemble that of a typical hackathon. All three groups included participants who had participated in hackathons before. These groups decided at the beginning of the hackathon to quickly agree on a concrete idea to implement, and then got to work on prototyping an idea which might seem conceptually half-baked, but practically realisable. These three groups were also the only groups that finished the hackathon with a software prototype (see Table 3, below). 


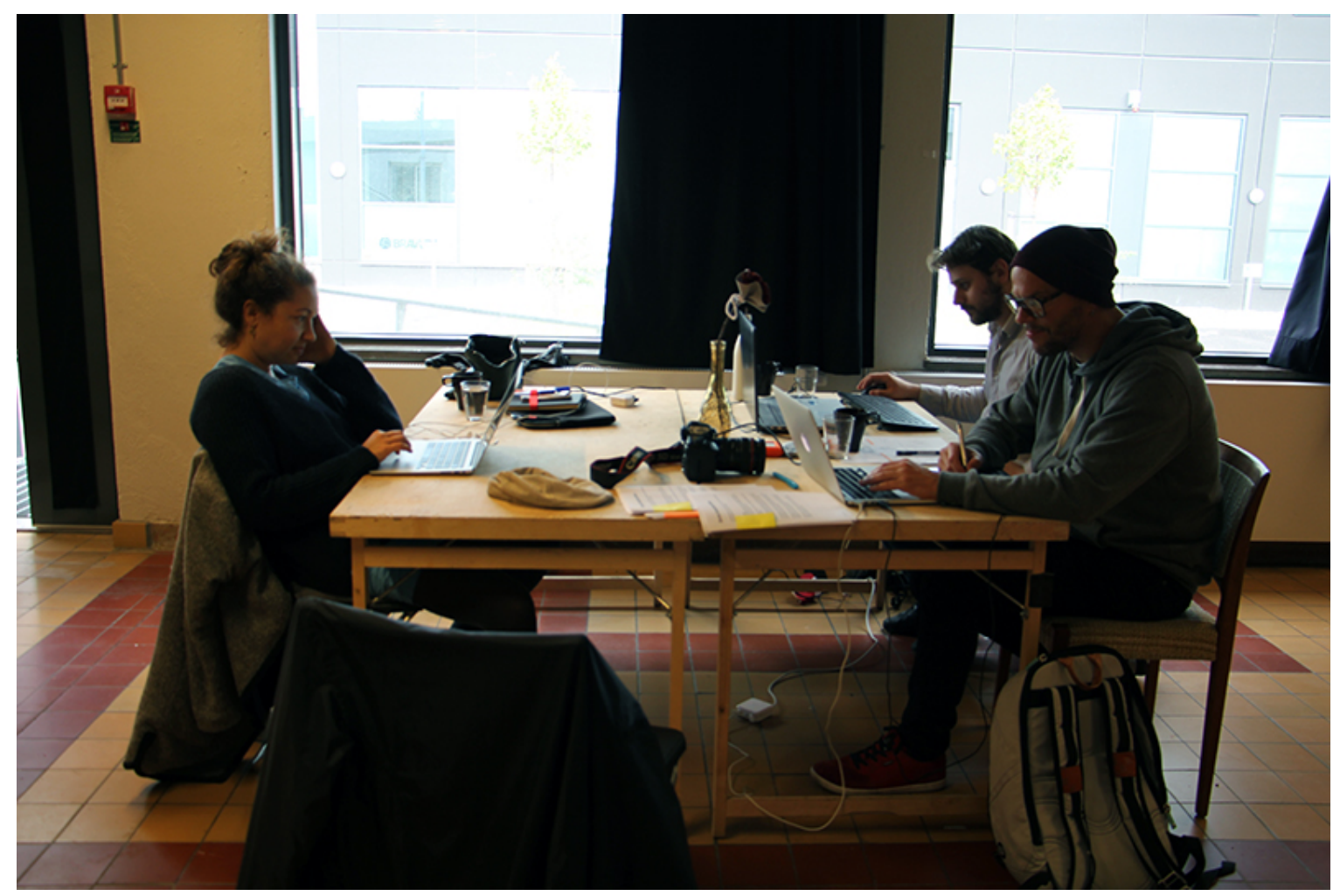

Figure 6: Participants in group 1 working on their prototype.

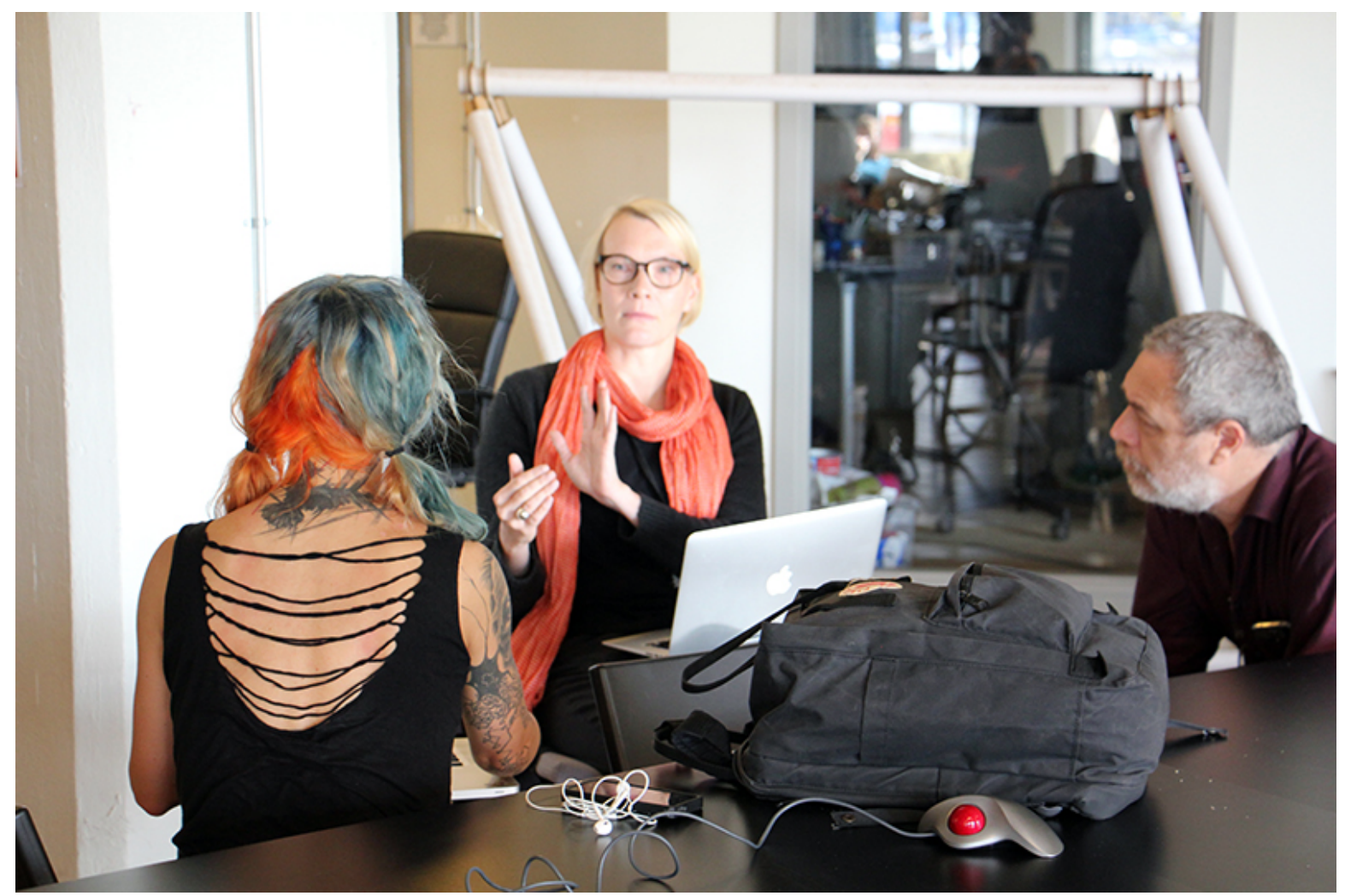

Figure 7: Participants in group 7 discussing their project. 
Groups 2, 5, 6 and 7 spent a lot of time discussing, repeatedly restarting their processes, reworking conceptual aspects of the projects they were working on. Group 6 settled on an idea for a website that would facilitate collaborative creativity and developed a proposal for a concept and an information architecture that they presented in a slideshow presentation and a short video. Group 5 developed an idea for a live game that would be played using a video connection to a player acting as "avatar", which they demonstrated using a Skype connection to a player carrying a smartphone. The final two groups, 2 and 7, made board games.

Table 3: The main and secondary making activities for the groups.

\begin{tabular}{|c|c|c|}
\hline Group & Final prototype & Presentation materials \\
\hline 1 & $\begin{array}{l}\text { A working prototype of a 3D adven- } \\
\text { ture game in Unity }\end{array}$ & $\begin{array}{l}\text { The prototype and a slideshow presenta- } \\
\text { tion }\end{array}$ \\
\hline 2 & $\begin{array}{l}\text { A physical prototype of a board } \\
\text { game }\end{array}$ & $\begin{array}{l}\text { The prototype and a slideshow presenta- } \\
\text { tion }\end{array}$ \\
\hline 3 & $\begin{array}{l}\text { A Unity simulation of an interactive } \\
\text { room installation }\end{array}$ & A video of the simulation \\
\hline 4 & $\begin{array}{l}\text { A working prototype of an "avatar" } \\
\text { system for a live event }\end{array}$ & Online text-based interface \\
\hline 5 & Concept for a live "avatar" game & $\begin{array}{l}\text { Software "card-picker" (random genera- } \\
\text { tor), slideshow presentation, Skype }\end{array}$ \\
\hline 6 & $\begin{array}{l}\text { Concept for a social media platform } \\
\text { for } \\
\text { creative activism }\end{array}$ & $\begin{array}{l}\text { Video, paper sketches, slideshow presen- } \\
\text { tation }\end{array}$ \\
\hline 7 & Concept for a board game & $\begin{array}{l}\text { Tumblr.com page with printable game } \\
\text { materials and documentation }\end{array}$ \\
\hline
\end{tabular}

\subsection{Filmmaking}

While nearly half of the participants (12 of 26) self-identified as film or TV professionals, only two of the groups ( 3 and 6 ) made videos for the final presentation. For group 3 the video was used to present a simulation made in Unity (they did not explain why they showed a video rather than demonstrating the simulation live), whereas for group 6 the video was an enquete-style collection of responses posed to other hackathon participants illustrating opinions that might be represented in the group's proposed social media platform. In other words, in neither of these cases was the video intended to be the main product. And in both cases the production of the actual video did not seem to have filled a great portion of the group's 
time, and appears to have been put together rather rapidly towards the end of the process, as a way to materialize an idea that they did not have the capacity to realize in another way.

\subsection{Design work}

As can be seen from Table 3 above, quite few of the participants ( 5 of 26) identified as designers. It is perhaps not surprising, then, that we observed little of the kinds of activities we would expect from designers, such as structured ideation processes, sketching and lo-fi prototyping, user research and/or user involvement. Group 3, which included both a designer and an architect, were the ones that most clearly adopted some designerly techniques: They started their process with an ideation session in which they wrote ideas on sticky notes and sorted them together on a board, after which they quite quickly converged on an idea that they felt they realistically could implement with the resources and competences represented in the group. After this the group divided tasks among themselves, with one person tasked with programming a virtual version in Unity, while another used the materials in the makerspace to produce a small physical prototype of their idea. Interestingly, while the makerspace had a large selection of different materials and tools available for physical prototyping only one other group, group 2, used this resource - in their case in order to produce a board game. Several other groups used sticky notes and paper materials for sketching their ideas at various points, but we did not see any clear attempts at creating more structured visualisations like storyboards, wireframes or paper prototypes. We also did not register much attention directed at identifying specific users, target groups, personas, etc. 


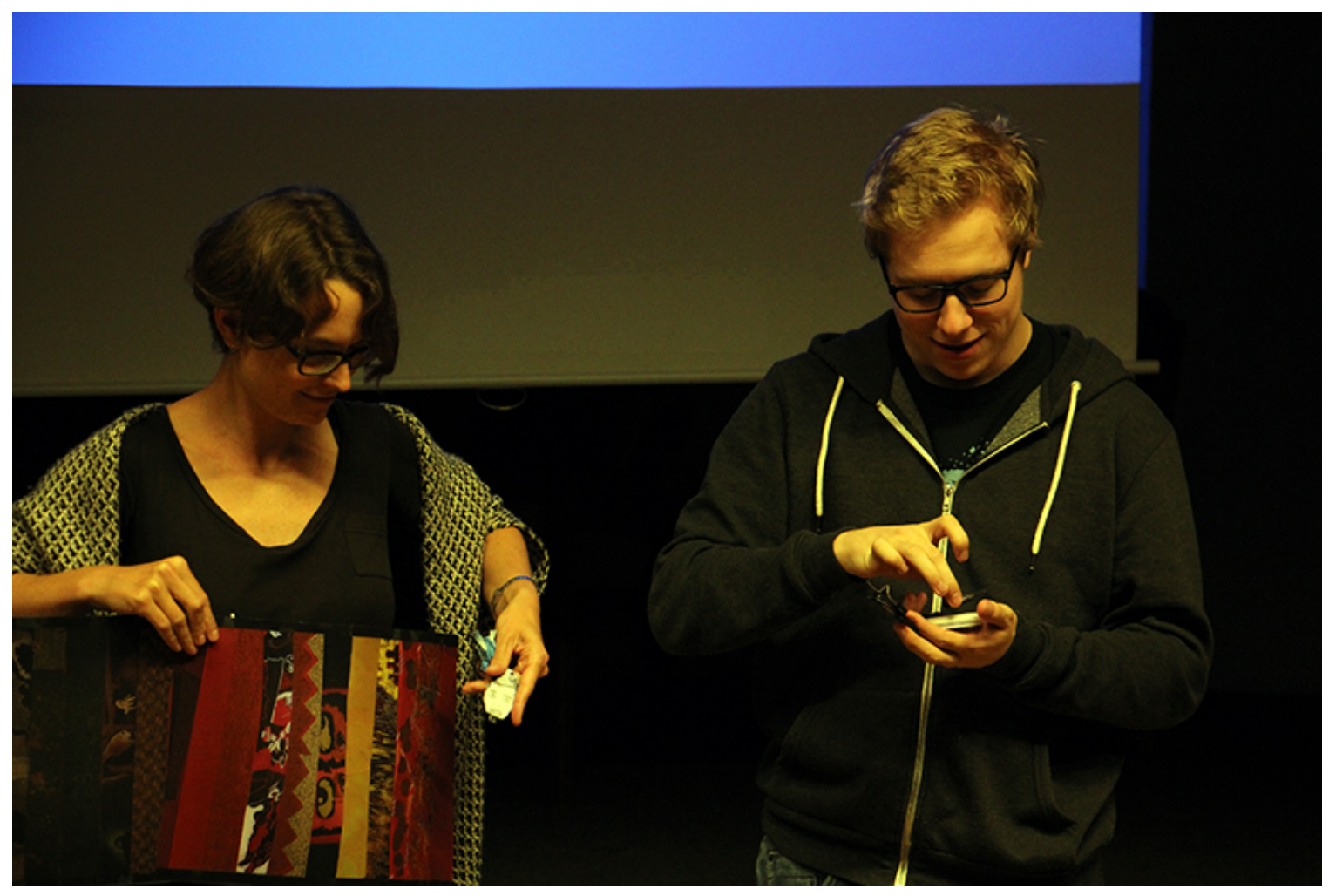

Figure 8: Members of group 2 presenting their prototype for a board game, made with materials from the maker space.

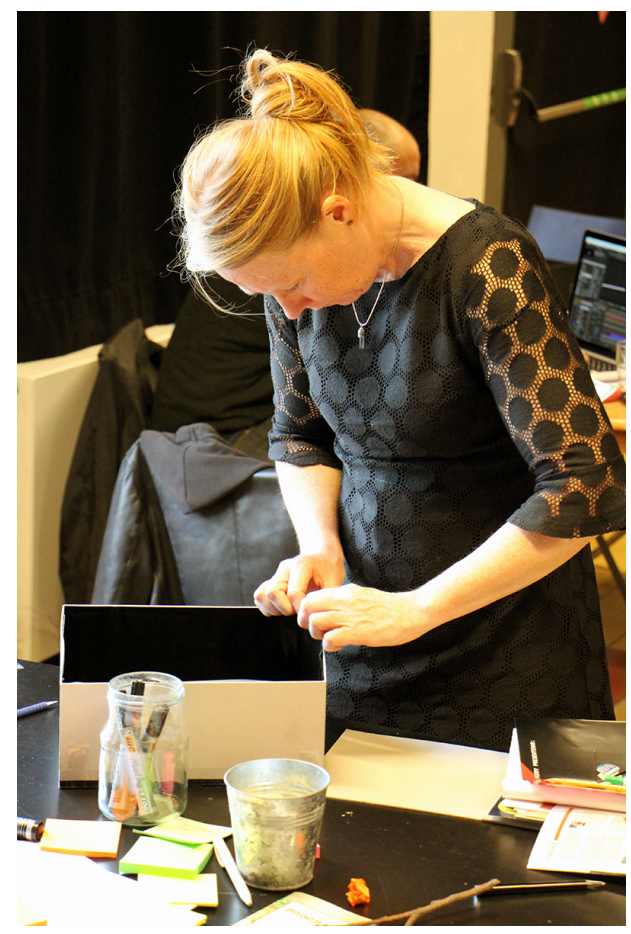

Figure 9: One of the members of group 3 working on a physical prototype. 
One of the groups - group 4 - did conduct a test which involved people outside of the hackathon. Their idea was heavily influenced by the reality TV concept, and consisted of a game in which one user agrees to act as an "avatar" carrying out instructions from remote users via a smartphone videolink, which would transmit back to the remote users the avatar's interactions with random passers-by. This group arranged a test in which one of the group members went out on the streets outside the makerspace and acted as avatar while other hackathon participants took turns giving instructions and watching the interactions on a screen in the communal space. However, while the avatar was wearing a strange hat intended to signal to passers-by that he was conducting a performance, they were not clearly informed about what was going on and should be considered unaware participants rather than users of the system (cf. Waern 2016). Group 5, who was working on a similar idea also conducted similar tests using other hackathon participants as avatars.

\subsection{Collaboration}

Two of the groups, 1 and 4, quickly established a hierarchical organisation with one person being appointed leader by the rest of the group. In the rest of the groups leadership roles were not explicitly assigned. As one could expect, we observed a variety of social dynamics in these groups: In some cases strong personalities appeared to be competing for domination in the group's discussions, while in others there were no clearly dominating individuals. All of the groups had periods where one or more members of the group went away and worked apart from the rest of the group for longer periods of time. In some of the groups $(2,5,6$ and 7) this appeared to be a result of frustration and prolonged disagreements within the group.

The groups with clear leadership, 1 and 4, coordinated very differently. In group 1 the three members worked next to each other at the same table, often engaging in small conversations about the concept and the practicalities of their prototyping. The programmer clearly assumed a subordinate role, offering his skills to the service of the director's vision. When we asked the programmer about this working arrangement he indicated that he was happy with it. He compared it to his experiences in an earlier game jam, where he had taken on the same role and had found it very rewarding:

"I was with another developer from school and we were in a team of eleven persons so it was really big, artists and game designers and us developers. And my friend told to the 
others, you can ask us, if you need anything, programming, we will make it. Just give us time and we will make it." (David)

In contrast to this, the participants in group 4 quickly split up to work separately on different parts of the concept, and at times the two non-programmers were just waiting for the programmer (who was also the group leader) to re-emerge from where he was doing his coding. The non-programmers did not seem to be bothered that the programmer worked alone much of the time. They were confident that he did what the group had agreed upon. Maria, the game designer, likened it to composing music; something she thought couldn't be done in a group. When asked where the programmer was, she answered: "He has gone into his coding world. So, he is not here." Noah, the programmer, confirmed Maria's view on what he was doing: "It just didn't help to have them. If they are looking at it while I am typing it doesn't really help."

In several of the groups we observed problems with finding agreement between participants from different professions. This was particularly clear in groups 5 and 6 , which both had film or TV professionals dominating the discussions, often prioritising conceptual work over making, in confrontations with the more technically oriented participants. In group 5 Rolf, the game designer and programmer, eventually started making a prototype on his own, loosely in line with the group's proposal, and relentlessly tried to get the others involved. However, they showed little interest in his sub-project, which consisted of making a 3D model of an hourglass to be used as a timer in the game. When Rolf tried to discuss the idea with the group on Sunday afternoon, the filmmakers Olivia and Sven had clearly given up on including Rolf's ideas in their project.

Sven: "You need one million grains of sand?"

Rolf: "Yeah and if we need that I just type in the number, one million, and there is one million."

Sven: "And they pass in a certain amount of seconds?"

Rolf: "Yes."

Sven: "Cool, yeah, do that, or a hand picking something out of a box, whatever... For me that is not important for the game."

$[\ldots]$

Rolf: "But as I said, for the program, what the question is, that is not relevant, because the questions can be anything." 
Sven: "If you hang on to that, work with that, then we can work with the questions."

Olivia: "That's what we are thinking, so I am happy to outsource this to you."

Several groups had similar difficulties in finding a workable combination of conceptual ideas and practical programming. This challenge was even more pronounced in group 7 , the only group which did not have any team member with programming skills. The group expressed frustration about this from the start of the hackathon, and in response the organiser brought in one of the helpers in the event, a computer engineer (Fred). The group tried to discuss their ideas with Fred in the hope that he could help implement them as a digital prototype of a game, but he quickly rejected the team's ideas as far too complex for the time and resources available. The group spent most of the hackathon in apparently frustrating discussions of this kind, without reaching any clear agreement on a specific idea to implement. Their final product was an idea for a board game with little detail about the game's props and mechanics.

\section{Challenges}

Our observations suggest that a primary challenge with the hackathon event is posed by the mismatch between the expectations of many of the participants and their ability to achieve concrete results. Many of the participants seemed to have a pre-understanding of the hackathon much in line with the common perception of an informal gathering focused on technological experimentation and collaborative creative activities. How these expectations were negotiated varied a lot between the groups, and between the individual participants.

The participants in groups 1, 3 and 4 seemed to act the most in line with what can be observed in ordinary hackathons, relatively quickly converging on a concrete idea for a prototype and spending most of their time working with the practical and technical challenges involved in materialising their idea. Jill, the designer in group 3 explained her experience of the process as a struggle to negotiate between different work cultures:

"When you're in, let's say in university, there is always someone, a teacher or professor who wants you to go through some sort of ideating process. So you have to do a lot of Post-Its in the beginning, or whatever. There is always a culture of how you do it. But when you come into a room like this there is no culture, because everyone come from different places. And you have to, before, people have to figure out a way to do it." 
Participants in groups 2, 5, 6 and 7 expressed frustrations and indicated that the event differed from what they expected. On the one hand, many of the programmers seemed to feel isolated in their groups and clearly indicated some discomfort with the fact that the film and TV professionals dominated the event. On the other hand, several of the non-programmers also expressed frustration with the lack of programmers who could help implement ideas into "something digital". When we asked Anna, the game designer in group 7, why the group wouldn't settle for making a non-digital prototype, she said: "I don't have time to do this just for fun. (...) I want it to be effective, I want to put this in my portfolio. (...) I have a million concepts in my head. I want them to be implemented, to be executed!"

There were some indications that the organizers of the hackathon had anticipated these problems and adapted the hackathon to accommodate for participants without skills in digital making and design. The organizers did emphasize from the start that any kind of prototyping could be undertaken, even stating that a dance would be a legitimate outcome. The choice of location in a well-stocked makerspace with a wide range of materials for physical crafts was also done in order to encourage non-digital prototyping. Furthermore, the projects that formed the basis for the work in the hackathon were clearly rooted in the film and TV genres, offering familiar ground for those professionals.

However, it is clear that the participants experienced frustrations and conflicts between the cultures of hacking, film/TV production and design that did not get resolved. The first conflict can be framed as a mismatch between the participants' general lack of programming skills and their expectation that the hackathon should result in "something digital". Even though the organizer explicitly stated that this was not a required outcome of the event, all of the groups spent most of the event searching for ways to create digital prototypes - in fact, nearly all the groups spent considerable time trying to develop concepts for some sort of computer game. The second conflict seems to be related to the ideals for authorship embedded in the working cultures of film and TV professionals. Many of the film and TV professionals insisted on extended discussions focused on conceptual issues relating to the theme and message of their project, effectively battling for authorship and making it difficult to involve all participants on an equal footing in the group's creative output. It is likely that the task of hacking already existing film and TV concepts emphasized this dynamic. 


\subsection{Conclusions and implications for future hackathons}

Many of the problems encountered by the participants in the NP hackathon seem to have come from the unclear definition of the task they were given. Since it was entirely open from the beginning what kind of material product was expected by the end of the event, many of the groups ended up spending much time and energy on overarching conceptual discussions, and only very late in the event started working on materialising their ideas. We suggest two possible strategies for meeting this challenge in future events of a similar kind.

If the purpose of the hackathon is to facilitate digital making for participants without skills in programming and design, we suggest giving them tools for end-user development such as those suggested by Fischer and Giaccardi (2006). These tools, combined with some deliberate constraints on the output from the hackathon, could enable the teams bypass some difficult negotiations and focus their creative work. However, it is important to note that some difficult negotiations may be important for cross-disciplinary learning and innovation, where articulating and resolving conflicts is central. Therefore, it is important to find a careful balance between constraints and openness.

If the purpose of the hackathon is to facilitate collaboration and mutual learning, we similarly suggest the event should offer participants some methods, tools and techniques for equalising power relations and give rise to mutual learning, taking lessons from similar work in participatory design (Kensing and Greenbaum 2013, 33-34). This could be a strategy to accommodate Lodato and DiSalvo's (2015) critique that issue-oriented hackathons tend to build on a weak notion of participation. We suggest giving participants what Sanders and Stappers (2014) label generative toolkits, which "are used to follow a [...] deliberate and steered process of facilitation, participation [and] reflection". The toolkit could be designed to address problems of working across disciplines directly, for instance by challenging role conceptions or help with creating common languages. However, such types of interventions should be used with caution in order to avoid getting in the way of the playful, free-for-all spirit associated with hackathons.

Furthermore, our observations from the NP hackathon suggest that basing the hackathon on far developed projects may be an impediment to innovation and unexpected outcomes. In particular, the decision to have the creative directors of the original projects participate in 
teams seems to have been an obstacle to experimentation, as those teams (unsurprisingly) were the ones that stuck closest to the original concept.

Finally, it seems that the term hackathon, referencing a phenomenon coming from communities mostly involved in software production, brings with it strong ideals and expectation of digital making activities. To accommodate for this, we suggest that the label "hackathon" should be used carefully, and primarily for events that align with the ideals of hacker culture. Events outside the context of software production could search for other labels that signal activities more in line with the making cultures of their participants.

\section{References}

48 Hour Film Project, Inc. 2017. “48 Hour Film Project.” http://www.48hourfilm.com/home. Arya, Ali, Jeff Chastine, Jon Preston, and Allan Fowler. 2013. "An International Study on Learning and Process Choices in the Global Game Jam:" International Journal of Game-Based Learning 3 (4): 27-46. doi:10.4018/ijgbl.2013100103.

Bergström, I., and A. F. Blackwell. 2016. "The Practices of Programming." In 2016 IEEE Symposium on Visual Languages and Human-Centric Computing (VL/HCC), 19098. doi:10.1109/VLHCC.2016.7739684.

Berntsen, Thea Karina Nesmann. 2008. "Norsk Dokumentarfilm; For Knapper, Glansbilder Og Ren Idealisme? En Kvalitativ Undersøkelse Av Samhandlingen Mellom Uavhengige Produsenter, Norsk Filminstitutt Og Kringkasterne NRK Og TV2.” https://bora.uib.no/handle/1956/3006.

Boal, Augusto. 2002. Games for Actors and Non-Actors. 2 edition. New York: Routledge.

Briscoe, Gerard, and Catherine Mulligan. 2014. "Digital Innovation: The Hackathon Phenomenon." Creativeworks London Work Paper 6. http://www.creativeworkslondon.org.uk/wp-content/uploads/2013/11/Digital-Innovation-The-Hackathon-Phenomenon1.pdf.

Brockman, John. 1995. The Third Culture: Beyond the Scientific Revolution. New York: Simon \& Schuster. https://www.edge.org/conversation/the-emerging.

Buckland, Warren. 2016. "The Craft of Independent Filmmaking." In A Companion to American Indie Film, edited by Geoff King, 407-29. John Wiley \& Sons, Inc. doi:10.1002/9781118758359.ch18.

Caldwell, John Thornton. 2008. Production Culture: Industrial Reflexivity and Critical Practice in Film and Television. Durham: Duke University Press.

Coleman, E. Gabriella. 2012. Coding Freedom: The Ethics and Aesthetics of Hacking. Princeton: Princeton University Press.

Coleman, Gabriella. 2010. "The Hacker Conference: A Ritual Condensation and Celebration of a Lifeworld." Anthropological Quarterly 83 (1): 47-72.

Collins, Ron, and Annette Fillery-Travis. 2015. "Transdisciplinary Problems: The Teams Addressing Them and Their Support Through Team Coaching," 41-52. doi:10.1007/978-3-319-11590-0 4.

Deuze, Mark. 2007. Media Work. Polity. 
2016. "Managing Media Workers.” In Managing Media Firms and Industries, edited by Gregory Ferrell Lowe and Charles Brown, 329-41. Media Business and Innovation. Springer International Publishing. doi:10.1007/978-3-319-08515-9_19.

Ehn, Pelle. 2008. "Participation in Design Things." In Proceedings of the Tenth Anniversary Conference on Participatory Design 2008, 92-101. PDC '08. Indianapolis, IN, USA: Indiana University. http://dl.acm.org/citation.cfm?id=1795234.1795248.

Elster, Jon. 2000. Ulysses Unbound: Studies in Rationality, Precommitment, and Constraints. Cambridge University Press.

Filippova, Anna, Brad Chapman, R. Stuart Geiger, James D. Herbsleb, Arun Kalyanasundaram, Erik Trainer, Aurelia Moser, and Arlin Stoltzfus. 2017. "Hacking and Making at Time-Bounded Events: Current Trends and Next Steps in Research and Event Design.” In Companion of the 2017 ACM Conference on Computer Supported Cooperative Work and Social Computing, 363-370. CSCW'17 Companion. New York, NY, USA: ACM. doi:10.1145/3022198.3022658.

Fischer, Gerhard, and Elisa Giaccardi. 2006. "Meta-Design: A Framework for the Future of End-User Development." In End User Development, edited by Henry Lieberman, Fabio Paternò, and Volker Wulf, 9:427-57. Human-Computer Interaction Series. http://link.springer.com/chapter/10.1007/1-4020-5386-X_19.

Fischer, Gerhard, Elisa Giaccardi, Yunwen Ye, Alistair G. Sutcliffe, and Nikolay Mehandjiev. 2004. "Meta-Design: A Manifesto for End-User Development." Communications of the ACM 47 (9): 33-37.

Fowler, Allan, Foaad Khosmood, Ali Arya, and Gorm Lai. 2013. "The Global Game Jam for Teaching and Learning." In Proccedings of the 4th Annual Conference on Computing and Information Technology Research and Education New Zealand, 28-34. http://www.citrenz.ac.nz/conferences/2013/pdf/2013CITRENZ_1_Fowler01GlobalGameJam_v2.pdf.

Goddard, William, Richard Byrne, and Florian "Floyd" Mueller. 2014. "Playful Game Jams: Guidelines for Designed Outcomes." In Proceedings of the 2014 Conference on Interactive Entertainment, 6:1-6:10. IE2014. New York, NY, USA: ACM. doi:10.1145/2677758.2677778.

"Hackathon | Nordisk Panorama." 2015. Accessed April 15. http://nordiskpanorama.com/sv/activity/hackathon/.

Hesmondhalgh, David. 2013. Creative Labour: Media Work in Three Cultural Industries. 1 edition. Routledge.

Ingold, Tim. 2013. Making: Anthropology, Archaeology, Art and Architecture. Routledge.

Irani, Lilly. 2015. "Hackathons and the Making of Entrepreneurial Citizenship." Science, Technology \& Human Values, April, 162243915578486. doi:10.1177/0162243915578486.

Johnson, Peter, and Pamela Robinson. 2014. "Civic Hackathons: Innovation, Procurement, or Civic Engagement?" Review of Policy Research 31 (4): 349-57. doi:10.1111/ropr.12074.

Kaitila, Christer. 2012. The Game Jam Survival Guide. Packt Publishing.

Kensing, Finn, and Joan Greenbaum. 2013. "Heritage:having a Say." In Routledge International Handbook of Participatory Design, edited by Jesper Simonsen and Toni Robertson, 21-37. London: Routledge.

Köhncke, Anne. 2006. “TV \& Den Uavhengige Nordiske Dokumentarfilm.” Master, Københavns Universitet.

Lamela, Zapico, Jorge Luis, Daniel Pargman, Hannes Ebner, and Elina Eriksson. 2013.

"Hacking Sustainability : Broadening Participation through Green Hackathons." In 
Fourth International Symposium on End-User Development. IT University of Copenhagen, Denmark. http://www.diva-portal.org/smash/record.jsf?pid=diva2:635996.

Leckart, Steven. 2012. "The Hackathon Is On: Pitching and Programming the Next Killer App." WIRED, February 17. http://www.wired.com/2012/02/ff_hackathons/.

Lewis, Seth C., and Nikki Usher. 2014. "Code, Collaboration, And The Future Of Journalism.” Digital Journalism 0 (0): 1-11. doi:10.1080/21670811.2014.895504.

Lodato, Thomas James, and Carl DiSalvo. 2015. "Issue-Oriented Hackathons as Ad-Hoc Design Events." In 4TH PARTICIPATORY INNOVATION CONFERENCE 2015, 328. http://www.researchgate.net/profile/Rianne_Valkenburg/publication/277006626_Reframing Design. Proceedings of the 4th Participatory Innovation Conference_2015_(PIN-C2015)/links/555d912608ae6f4dcc8c3b84.pdf\#page=328. . 2016. "Issue-Oriented Hackathons as Material Participation." New Media \& Society 18 (4): 539-57. doi:10.1177/1461444816629467.

Löwgren, Jonas, and Erik Stolterman. 2004. Thoughtful Interaction Design: A Design Perspective on Information Technology. Cambridge, Mass.: MIT Press.

Lufkin, Bryan. 2012. "Storyboard: Steven Leckart on Silicon Valley's Grueling Hackathons." WIRED. February 28. http://www.wired.com/2012/02/storyboard-hackathons/.

Mathews, Harry. 1997. "Translation and the Oulipo: The Case of the Persevering Maltese." Brick, A Literary Journal 57: 67-82.

McCullough, Malcolm. 1998. Abstracting Craft: The Practiced Digital Hand. MIT Press.

Mercier, Ocean Ripeka. 2014. "Film Sport: Constraint and Unrestraint in the 48-Hour Film Competition." New Cinemas: Journal of Contemporary Film 12 (3): 191-204. doi:10.1386/ncin.12.3.191_1.

"Popathon · Growing a Community of Web-Native Storytellers." 2015. Accessed November 11. http://popathon.org/.

"POV Hackathon | POV | PBS.” 2015. Accessed November 11. http://www.pbs.org/pov/hackathon/.

Robson, Colin. 2002. Real World Research. 2nd edition. Blackwell Publishing.

Roggema, Rob. 2014. “The Design Charrette.” In The Design Charrette, edited by Rob Roggema, 15-34. Springer Netherlands. doi:10.1007/978-94-007-7031-7_2.

Sanders, Elizabeth B.-N., and Pieter Jan Stappers. 2014. "Probes, Toolkits and Prototypes: Three Approaches to Making in Codesigning." CoDesign 10 (1): 5-14. doi:10.1080/15710882.2014.888183.

Sennett, Richard. 2009. The Craftsman. 1 edition. New Haven: Yale University Press.

Snow, Charles Percy. 1959. The Two Cultures and the Scientific Revolution. The Rede Lecture. London \& New York: Cambridge University Press.

Stenderup, Thomas. 1994. Har Kort- Og Dokumentarfilmen I Norden En Fremtid?: Forslag Til at Styrke Den Uafhcengige Produktion Og Distribution. Vol. 1994:602. København: Nordisk Ministerråd.

The 24 Hour Plays. n.d. "About The 24 Hour Plays." The 24 Hour Plays. http://www.24hourplays.com/about.

Trainer, Erik H., Arun Kalyanasundaram, Chalalai Chaihirunkarn, and James D. Herbsleb. 2016. "How to Hackathon: Socio-Technical Tradeoffs in Brief, Intensive Collocation." In Proceedings of the 19th ACM Conference on Computer-Supported Cooperative Work \& Social Computing, 1118-1130. CSCW '16. New York, NY, USA: ACM. doi:10.1145/2818048.2819946.

“Tribeca Hacks.” 2015. Tribeca Film Institute. Accessed November 11. https://tribecafilminstitute.org/programs/detail/tribeca_hacks. 
Tuckman, Bruce W. 1965. "Developmental Sequence in Small Groups." Psychological Bulletin 63 (6): 384-99. doi:10.1037/h0022100.

Vallgårda, Anna. 2013. "Giving Form to Computational Things: Developing a Practice of Interaction Design.” Personal and Ubiquitous Computing 18 (3): 577-92. doi:10.1007/s00779-013-0685-8.

Waern, Annika. 2016. "The Ethics of Unaware Participation in Public Interventions." In Proceedings of the 2016 CHI Conference on Human Factors in Computing Systems, 803-814. CHI '16. New York, NY, USA: ACM. doi:10.1145/2858036.2858188.

Watson, Jeff. 2012. "Reality Ends Here: Environmental Game Design and Participatory Spectacle.” Ph.D. dissertation, Los Angeles: University of Southern California. http://digitallibrary.usc.edu/cdm/ref/collection/p15799coll3/id/87218.

"What Is Culture Hack? | Culture Hack." 2016. Accessed April 14. http://culturehack.org.uk/about/.

Wroblewski, David A. 1991. "The Construction of Human-Computer Interfaces Considered as a Craft.” In Taking Software Design Seriously, edited by John Karat, 1-19. San Diego, CA, USA: Academic Press Professional, Inc. http://dl.acm.org/citation.cfm?id=110707.110708. 